\title{
Strategies for improving hemodynamic stability during hemodialysis : clinical and pathophysiological studies
}

Citation for published version (APA):

van der Sande, F. M. (1999). Strategies for improving hemodynamic stability during hemodialysis : clinical and pathophysiological studies. [Doctoral Thesis, Maastricht University]. Universiteit Maastricht. https://doi.org/10.26481/dis.19991119fs

Document status and date:

Published: 01/01/1999

DOI:

10.26481/dis.19991119fs

Document Version:

Publisher's PDF, also known as Version of record

\section{Please check the document version of this publication:}

- A submitted manuscript is the version of the article upon submission and before peer-review. There can be important differences between the submitted version and the official published version of record.

People interested in the research are advised to contact the author for the final version of the publication, or visit the DOI to the publisher's website.

- The final author version and the galley proof are versions of the publication after peer review.

- The final published version features the final layout of the paper including the volume, issue and page numbers.

Link to publication

\footnotetext{
General rights rights.

- You may freely distribute the URL identifying the publication in the public portal. please follow below link for the End User Agreement:

www.umlib.nl/taverne-license

Take down policy

If you believe that this document breaches copyright please contact us at:

repository@maastrichtuniversity.nl

providing details and we will investigate your claim.
}

Copyright and moral rights for the publications made accessible in the public portal are retained by the authors and/or other copyright owners and it is a condition of accessing publications that users recognise and abide by the legal requirements associated with these

- Users may download and print one copy of any publication from the public portal for the purpose of private study or research.

- You may not further distribute the material or use it for any profit-making activity or commercial gain

If the publication is distributed under the terms of Article $25 \mathrm{fa}$ of the Dutch Copyright Act, indicated by the "Taverne" license above, 


\section{Strategies for Improving Hemodynamic Stability during Hemodialysis}

Clinical and Pathophysiological Studies 
- FM van der Sande, Heeze 1999 ISBN 90-9013193-0

Cover illustration: Harry Kranen

Printing of this thesis was made possible by Fresenius Medical Care BV, Baxter BV, Merck Sharp \& Dohme BV, Byk BV, AstraZeneca BV, Janssen-Cilag BV, Gambro BV, Fresenius Kabi BV, Sanofi Winthrop. 


\section{Strategies for Improving Hemodynamic Stability during Hemodialysis}

\section{Clinical and Pathophysiological Studies}

\section{PROEFSCHRIFT}

ter verkrijging van de graad van doctor aan de Universiteit Maastricht, op gezag van de Rector Magnificus, Prof. dr. A.C. Nieuwenhuijzen Kruseman, volgens het besluit van het College van Decanen, in het openbaar te verdedigen op vrijdag 19 november 1999 om 16.00 uur

$$
\text { door }
$$

Franciscus Martinus van der Sande geboren op 5 november 1957 te Amsterdam 


\section{Promotor}

Prof. dr. KML Leunissen

\section{Co-promotor}

Dr. JP Kooman

\section{Beoordelingscommissie}

Prof. dr. RAMG Donckerwolcke (voorzitter)

Prof. dr. NW Levin (Albert Einstein College of Medicine, New York, USA)

Prof. dr. F Locatelli (Ospedale di Lecco, Lecco, Italy)

Prof. dr. HAJ Struijker Boudier

Dr. JHM Tordoir 
Aan: Edith en Gerben 



\section{Contents}

\section{Chapter 1 Introduction 9}

Chapter 2 The hemodynamic effect of different ultrafiltration rates in patients with cardiac failure and patients without cardiac failure: comparison between isolated ultrafiltration and ultrafiltration + hemodialysis $\mathbf{3 3}$

Chapter 3 Effect of intravenous saline, albumin or hydroxyethylstarch on blood volume during combined ultrafiltration and hemodialysis 51

Chapter 4 Effect of intravenous fluids on blood pressure course during hemodialysis in hypotensive prone patients 67

Chapter 5 Effect of dialysate calcium concentrations on intradialytic blood pressure course in cardiac-compromised patients $\mathbf{8 1}$

Chapter 6 Effects of dialysate temperature on energy balance during hemodialysis: quantification of extracorporeal energy transfer 95

Chapter 7 Thermal energy balance and body temperature: comparison between isolated ultrafiltration and hemodialysis at different dialysate temperatures 109

Chapter 8 Energy transfer is the single most important factor for the difference in vascular response between isolated ultrafiltration and hemodialysis 119

Chapter 9 General Discussion 133

Chapter 10 Summary and concluding remarks 149

Chapter 11 Samenvatting 157

Dankwoord 165

Curriculum vitae 169 



\section{Chapter 1}

\section{Introduction}

FM van der Sande

In part published: Hemodynamic instability, arrhythmia's, and dialysis reactions. KML Leunissen, JP Kooman, FM van der Sande. In: Complications during dialysis. Editors: $N$ Lameire and $R$ Mehta. Marcel Dekker, Inc New York, Basel, Hong Kong (in press) 


\section{General introduction}

Intermittent hemodialysis induces rapid changes in the fluid and solute status of the patient. This may lead to clinical symptoms which can vary from slight discomfort to life threatening complications. Despite the growing understanding of the pathophysiological mechanisms that contribute to hemodynamic instability during hemodialysis, hypotension still remains one of the most cumbersome complications in dialysis therapy.

In hemodialysis patients, structural abnormalities at all the levels of the cardiovascular system are common ${ }^{1-4}$. These have important clinical complications, which are reflected by the fact that the majority of the patients die from cardiovascular diseases. Also, the presence of cardiovascular abnormalities is a risk factor for the development of intradialytic hypotension ${ }^{6.7}$. This explains the clinical observation that the incidence of symptomatic hypotension is especially high in elderly patients ${ }^{8-10}$, who often have a history of long-standing hypertension and atherosclerosis.

\section{Hemodialysis associated hypotension}

Hypotension during dialysis may induce ninor but troublesome side-effects to the patient, such as nausea. vomiting, and dizziness, but may also lead to severer complications, such as cardiac or cerebral ischemia. Hypotension can also reduce the efficacy of the treatment, both because dialysis sometimes has to be (temporarily) terminated and because of the reduced urea removal from the tissues related to vasoconstriction ("internal dialyzer"). Whereas there are dialysis patients who hardly suffer from hypotensive episodes, hemodialysis hypotension is especially frequent in elderly people and in those patients with a compromised cardiovascular system. Primarily in the latter group, hypotension may have serious consequences.

The pathogenesis of hemodialysis hypotension is multifarious. Under normal circumstances, there are three factors of major importance in the maintenance of hemodynamic stability during hypovolemia: first: the refill of blood volume from the interstitial compartment (blood volume preservation), secondly; the constriction of the resistance vessels (small arteries and arterioles), leading to an increase in systemic vascular resistance, and thirdly; the maintenance of cardiac output, which occurs through an increase in myocardial contractility, heart rate, and constriction of the capacitance vessels (venules and veins), leading to centralisation of blood volume. In this respect an intact cardiovascular system is of major importance ${ }^{11}$. In addition to a decline in blood volume, also a disturbance in the latter two factors may contribute to intradialytic hypotension. This explains the fact that in healthy 
subjects, a decrease in blood volume of $25 \%$ is generally well tolerated ${ }^{12}$, whereas in dialysis patients during dialysis, hypotension often occurs at a much lesser reduction in blood volume ${ }^{13}$. The importance of each of these factors may differ from patient to patient and from treatment to treatment.

\section{Intravascular volume preservation}

During ultrafiltration, fluid is removed from the intravascular space by convection owing to differences in hydrostatic pressure between the blood and dialysate compartments. Ultrafiltration can be performed with (combined ultrafiltration / hemodialysis) or without concomitant hemodialysis treatment (isolated ultrafiltration).

In accordance with the Starling formula, the decrease in intravascular pressure and the increase in intravascular colloid osmotic pressure will induce a fluid shift between the intravascular and interstitial compartments, which partly compensates for the fluid removed through the dialyzer. However, in most cases, the refill from the interstitial compartment to the intravascular compartment will not be complete and blood volume will decrease ${ }^{14,15}$. Intravascular hypovolemia may, therefore, even occur when the interstitial compartment is still fluid-overloaded.

Several mechanisms, mainly related to the dialysis treatment but also patientassociated factors, will influence blond volume preservation and therefore hemodynamic stability during dialysis.

\section{Ultrafiltration rate}

A determinant of blood volume preservation is the ultrafiltration rate. Despite a rapid decrease in vascular hydrostatic pressure, the fluid which is removed from the intravascular compartment cannot be compensated completely by refill from the interstitial compartment. especially at higher ultrafiltration rates ${ }^{13,16.17}$. Therefore great care should be applied to avoid considerable changes in blood volume. A higher ultrafiltration rate may be associated with a larger decrease in intravascular volume which may lead to a decrease in blood pressure. Several studies have shown a clear relation between symptomatic hypotension, the total amount of ultrafiltration and the rate at which this removal occurs ${ }^{8,16,18,19}$. At an ultrafiltration rate exceeding the rate of blood volume preservation, the blood volume declines progressively ${ }^{20.21}$. The degree to which blood volume declines during a constant ultrafiltration rate differs between patients and is depending on several factors, as will be discussed. 


\section{Fluid status of the patient}

The fluid status of the patient has a major influence on changes in blood volume during dialysis, which can be explained by the hydration state of the interstitial space. When the patient is underhydrated, refill of blood volume from the extravascular compartment is hampered because the interstitium is also fluid depleted and interstitial hydrostatic pressure is low. In contrast, interstitial pressure is high in hypervolemic patients, which will induce a volume shift into the intravascular compartment when fluid is removed during dialysis ${ }^{22-25}$. Therefore, an optimal fluid status of the patient is of utmost importance in blood volume preservation during dialysis. In clinical practice, this is attempted by prescribing a "dry weight" for the patient.

Dry weight has been defined as the weight below which the patient is free of edema and normotensive without symptomatic complaints during dialysis ${ }^{26}$. However, this strategy may fail to assess the optimal fluid status of the patient, as clinical symptoms may be a late symptom of underhydration on one hand, whereas especially in case of aggressive ultrafiltration, the patient may still be fluid overloaded despite the occurrence of symptomatic hypotension. Therefore, more objective methods are needed. Physical examination, though of great importance, will often fail to detect subtle variations in fluid status. Radiography of the chest will only show severe overhydration. Biochemical markers, like atrial natriuretic peptide (ANP) and cyclic guanosine monophosphate (cGMP), which are released in response to left atrial stretch ${ }^{27.28}$, are difficult to apply in an acute clinical setting, whereas their reliability in the assessment of underhydration is questionable ${ }^{26}$. Bioimpedance spectroscopy (BIS) is reproducible and quick and correlates generally well with isotope dilution techniques ${ }^{29.30}$. However, a problem with the use of BIS in the assessment of dry weight is the absence of reference data for the dialysis population and the fact that in individual patients the difference between BIS and isotope dilution techniques may be clinically significant ${ }^{29.31}$. Moreover, some authors did not find BIS to be reliable in the assessment of acute changes in fluid state during dialysis ${ }^{32.33}$. Regional impedance (conductivity) measurements on the other hand were found to be fairly sensitive in the detection of fluid state during dialysis ${ }^{28,29}$. Echography of the inferior caval vein correlates well with blood volume and right atrial pressure in dialysis patients and was found to be of clinical value in the assessment of dry weight in dialysis patients. Ideally, inferior caval vein diameter (ICVD) should be measured 1-2 hrs after dialysis because of ungoing refill from the interstitium ${ }^{17}$. As ICVD is a deviation of right atrial pressure, one should be careful with the interpretation of ICVD as a marker of dry weight in patients with severe left ventricular and/or valvular dysfunction ${ }^{34}$. 


\section{Dialysate sodium}

During dialysis, sodium that has accumulated during the interdialytic period needs to be removed. Usually a small gradient between blood and dialysate sodium is present. In the earlier days of dialysis, lower sodium concentrations of the dialysate were frequently used. However, this approach was associated with an increased incidence of hypotensive periods compared with the use of higher sodium concentrations in the dialysate, which appeared to be related to impaired blood volume preservation ${ }^{25.35}$. One view attributes this phenomenon to a disequilibrium between the intracellular and extracellular spaces. During dialysis, urea diffuses into the dialysate. Urea rapidly equilibrates between the intravascular and interstitial compartments, whereas ion transport across the cellular membrane is delayed. Especially with a low dialysate sodium concentration, the extracellular space becomes hypotonic relative to the intracellular space, which will promote the movement of fluid into the cell ${ }^{35}$. A sodium influx from the dialysate into the patient would prevent the rapid fall in extracellular osmolality and, in consequence the intracellular fluid shift. Still, the effect of a higher dialysate sodium concentration on blood volume preservation ${ }^{20.36}$ could also be explained by a fluid shift from the interstitial to the intravascular compartment caused by a delay in sodium diffusion from the intravascular compartment to the interstitial space $^{20}$. However, in regard to clinical practice a higher dialysate sodium may result in an increase of exchangeable sodium, stimulating the fluid intake, and in consequence increasing interdialytic weight gain leading to hypertension ${ }^{37}$.

\section{Buffer substrate}

The choice of dialysate buffer also influences blood volume preservation. Acetate induces arteriolar vasodilatation, which increases pre-capillary hydrostatic pressure and provokes a shift from the intra-vascular to the interstitial space. Bicarbonate has less vasodilatation qualities and, therefore, exerts a more favourable effect on blood volume preservation ${ }^{25,38}$. Moreover, in patients with a compromised cardiac function, acetate may further impair refill of blood volume because of increased pressure in the post-capillary venules secondary to left ventricular dysfunction by the cardiodepressant effects of acetate ${ }^{\text {;y }}$.

\section{Venous compliance}

In dialysis patients with pre-existing hypertension, not only structural cardiac and arterial changes are present, but also the compliance of the venous system (volume/pressure ratio) is reduced which appears to be caused by structural abnormalities of the venous wall ${ }^{3.40}$. In patients with a reduced compliance of the venous system, refill of blood volume from the interstitial compartment is hampered because of a disturbance in the capillary Starling equilibrium. 
The effect of venous compliance on blood wolume preservation can be explained by the fact that in patients with a reduced venous compliance (i.e. increased stiffness of the venous wall), the pressure in the post-capillary venules is higher for a given level of blood volume, which reduces the fluid shift from the interstitial to the intra-vascular compartment ${ }^{41}$. During isolated ultrafiltration a steeper decline in blood volume was observed in patients with reduced venous compliance compared with patients with normal venous compliance ${ }^{42}$. This phenomenon is likely to be of importance mainly in the first part of a dialysis sussion, because refill from the interstitial compartment is initially dependent upon the Starling equilibrium before dialysis ${ }^{15}$. After 60 to 120 minutes (min) the fall in venous pressure and the rise in colloid osmotic pressure will result in the establishment of a new equilibrium ${ }^{15}$.

\section{Systemic vascular resistance}

During hypovolemia, constriction of the pre-capillary vessels, leading to an increase in systemic vascular resistance, is of vital importance for the maintenance of hemodynamic stability. This response appears to be disturbed during hemodialysis. In a minority of patients, autonomic neuropathy will certainly contributc to this phenomenon. However, the major cause of the impaired response appears to be a consequence of the treatment itself.

\section{Autonomic neuropathy}

Diabetes mellitus, which has a high incidence in hemodialysis patients, may lead to reduced arteriolar constriction because of autonomic neuropathy affecting the efferent sympathetic pathways ${ }^{42}$. However, the efferent sympathetic pathways seem to be generally intact in non-diabetic dialysis patients, as the vascular response is normal in response to a sympathetic stimulus like the cold pressor test. Moreover, the vasoconstrictor responses to hypovolemia are also preserved during isolated ultrafiltration ${ }^{3.743}$. As will be discussed later, the autonomic defect will primarily affect the heart rate response during hypovolemia. In non-diabetic dialysis patients, the hemodialysis treatment itself appears to be primarily responsible for the impaired vascular response.

\section{Hemodialysis treatment}

In contrast to isolated ultrafiltration and hemofiltration, vasoreactivity is impaired during hemodialysis. In addition, the increase in plasma levels of vasoactive peptides, like catecholamines, vasopressin, and renin, was found to be less distinct during hemodialysis compared with isolated ultrafiltration and hemofiltration ${ }^{43-46}$. This impaired vascular reactivity appears to be the major determinant that explains 
the improved blood pressure response during isolated ultrafiltration compared with hemodialysis ${ }^{43}$. Acetate, which is less frequently used currently, has a profound direct vasodilatating effect $\mathrm{t}^{43,44,47}$, possibly caused by the effect of acetate itself or through the formation of adenosine ${ }^{48}$. However, the constriction of the capacitance and resistance vessels is also reduced during bicarbonate dialysis. Factors like changes in osmolality and ionized calcium do not appear to be responsible for this phenomenon ${ }^{4 y .50}$. It has been suggested that the production of cytokines, such as interleukin-1 (IL-1) and tumour necrosis factor- $\alpha$ (TNF- $\alpha$ ) during dialysis, leads to an increased production of inducible nitric oxide synthetase in smooth muscle, which attenuates the vasoconstrictor response during hemodialysis ${ }^{51}$. Cytokine production is especially stimulated by the use of bio-incompatible membranes in combination with contaminated dialysate ${ }^{52}$. As a matter of fact, nitric oxide was found to be increased in hemodialysis patients with symptomatic hypotension compared with patients without hemodynamic instability ${ }^{53}$. In contrast, recent studies have failed to show any difference in hemodynamic stability between dialysis with bio-incompatible versus bio-compatible membranes ${ }^{54-56}$. Moreover, vascular reactivity was not improved by the use of ultrapure dialysate ${ }^{57}$ or biocompatible membranes ${ }^{58}$. In addition, the time required for nitric oxide production is in disagreement with the fact that differences in vascular reactivity between isolated ultrafiltration and hemodialysis are present as early as 15 to $30 \mathrm{~min}$ into the dialysis $\operatorname{run}^{7,43,59,60}$. An increased concentration of the vasodilator peptide adenosine was found after episodes with severe symptomatic hypotension ${ }^{6 !}$. However, it is not known whether the increase in adenosine is of primary pathogenic importance or a consequence of increased release from ischemic tissue.

\section{Temperature of the dialysate}

It is likely that the energy balance between the patient and the extracorporeal circuit plays an important role in the pathogenesis of the impaired vascular response during dialysis, as the hemodynamic reaction differs between dialysis with standard $\left(37^{\circ} \mathrm{C}\right.$ to $\left.38^{\circ} \mathrm{C}\right)$ versus $\mathrm{cool}\left(35^{\circ} \mathrm{C}\right.$ to $\left.36^{\circ} \mathrm{C}\right)$ temperature of the dialysate. Both blood pressure response and vascular reactivity are improved with the use of cool dialysate, whereas the blood returning from the extracorporeal circuit to the patient is also much cooler during isolated ultrafiltration and hemofiltration compared with 'standard' dialysis ${ }^{62-64}$. It is interesting to see that the differences in vascular reactivity between hemodialysis and hemofiltration disappear for the greater part when both treatment modalities are matched for blood temperature in the venous blood lines ${ }^{63}$.

Dialysis treatment affects core temperature control of the patient. However, the mechanisms behind the thermal effects of dialysis have not yet been clarified. Nevertheless, the increase in core temperature during dialysis likely has a ver̃y important effect on the vascular response during dialysis, as at least part of the 
vasodilatation during dialysis can be explained by dilatation of the (thermoregulatory) cutaneous blood vessels in order to get rid of the excess heat, counteracting the normal vascular response to hypovolemia.

\section{Cardiac output}

In addition to an increase in systemic vascular resistance, compensatory mechanisms will attempt to maintain cardiac output during hypovolemia in order to prevent hypotension. Major determinants of cardiac output are heart rate, myocardial contractility and venous return, in combination with the compliance characteristics of the heart.

\section{Responses of the heart and capacitance vessels to hypovolemia during dialysis}

\section{Heart rate}

In healthy subjects, heart rate will increase during hypovolemia in an attempt to compensate for the reduction in preload. This is mediated by an increase in sympathetic tone caused by a reduction in inhibitory impulses from the volume receptors in the atria and pulmonary veins and the high pressure receptors in the aorta and carotid sinus. In hemodialysis patients the heart rate response may be impaired by autonomic neuropathy and sympathetic dysfunction.

\section{Autonomic neuropathy}

Many hemodialysis patients have signs of autonomic neuropathy, characterized by dysfunction of the baroreceptor reflex arc. The autonomic defect is primarily located in the afferent part of the baroreceptor reflex arc and in the efferent parasympathetic response, which may impair the heart rate response during hypovolemia $^{65.66}$.

Studies regarding the impact of autonomic neuropathy on hemodialysis hypotension have shown conflicting results. Although in some studies a relationship was observed between disturbances in the baroreceptor reflex arc and hemodialysis hypotension $^{67-69}$, other authors did not find such a relationship ${ }^{70.71}$. Probably, autonomic neuropathy does not play a major role in the pathogenesis of hemodialysis associated hypotension. 


\section{Acute sympathetic dysfunction}

Some episodes of acute hypotension during dialysis appear to be related to an acute decrease in sympathetic activity, which is preceded by a large burst in sympathetic activity $^{72}$. This reduction in sympathetic activity leads to an acute decrease in peripheral vascular resistance and a reduction in heart rate. The acute reduction in sympathetic activity is probably caused by the Bezold-Jarisch reflex, which is evoked by stimulation of left ventricular baroreceptors in response to severe left ventricular underfilling.

This reflex is probably only elicited during severe hypovolemia, as many episodes of symptomatic hypotension are accompanied by an increased or unchanged heart rate r3.74 $^{73}$. However, this reflex might be responsible for the acute collapse sometimes observed in dialysis patients during fluid removal.

\section{Myocardial contractility}

An increase in sympathetic activity during hypovolemia will also stimulate myocardial contractility, which leads to a more efficient emptying of the heart. For the increase in myocardial contractility, adequate systolic and diastolic function of the heart is a prerequisite.

\section{Systolic dysfunction of the heart}

Reduced myocardial contractility, leading to systolic dysfunction of the heart, is present in a significant minority of dialysis patients. In patients with systolic dysfunction, dilated cardiomyopathy is often present.

Defined as a fractional shortening of Iess than $25 \%$ on echocardiography, systolic dysfunction is found in approximately $15 \%$ of dialysis patients. Systolic dysfunction has an adverse prognosis in dialysis patients ${ }^{75,70}$ and predispuses the patient to symptomatic hypotension because the heart cannot respond well to changes in filling volume and the heart requires higher filling pressures to maintain an adequate cardiac output.

Risk factors for dilated cardiomyopathy in dialysis patients include chronic volume overload, hypertension, anaemia, ischemic heart disease, the arteriovenous fistula, carnitine deficiency, and older age. Systolic dysfunction is primarily associated with ischemic heart disease, anaemia, and older age ${ }^{75.76}$.

Also acute cardiac problems, such as coronary ischemia and cardiac arrhythmia's can cause reduced cardiac contractility. 


\section{Diastolic dysfunction of the heart}

In addition to the systolic function of the heart, also its diastolic function is of great importance in the hemodynamic response to hypovolemia. Diastolic dysfunction can be defined as an impaired capacity of the ventricle to accept blood without a disproportionate change in ventricular pressure. In other words, the compliance (volume/pressure ratio) of the ventricle is reduced.

Because of the increased sensitivity to changes in volume, a small increase in ventricular volume leads to a steep increase in ventricular pressure and a small decrease in ventricular volume induces a steep decline in left ventricular pressure ${ }^{6.65 .77}$. When the compliance of the heart is reduced, the sensitivity of the heart to changes in filling volume increases. Therefore, patients with a reduced left ventricular compliance have a very small margin between clinical overhydration and underhydration and are prone both to symptomatic hypotension and congestive heart failure ${ }^{6.77}$. A reduction in ventricular compliance also increases the importance of atrial contraction for cardiac filling. Therefore, patients with diastolic dysfunction are especially sensitive to supraventricular arrhythmia's, such as atrial fibrillation ${ }^{77}$. Reduction of the compliance of the left ventricle (diastolic dysfunction) may be caused by structural abnormalities of the cardiac wall, such as left ventricular hypertrophy, or to functional abnormalities resulting in impaired cardiac relaxation, such as coronary ischemia.

Diastolic dysfunction of the left ventricle is frequent in dialysis patients, primarily caused by the high prevalence of left ventricular hypertrophy. Also abnormalities in cardiac ultrastructure and the frequent occurrence of cardiac ischemia will undoubtedly contribute to the high incidence of diastolic dysfunction in this group of patients ${ }^{75,76,78}$. In clinical studies, it has been shown that dialysis patients with reduced left ventricular compliance are particularly sensitive to hemodialysis hypotension ${ }^{76,77}$.

\section{Influence of dialysis on cardiac function}

During hemodialysis, an increase in myocardial contractility has been observed. This has been attributed to fluid removal, an increase in ionized calcium, the removal of cardiodepressor uremic toxins, or a reduction in afterload (myocardial wall tension during systolic ejection) caused by dilatation of the resistance vessels ${ }^{7.25}$. Whereas the use of acetate does not appear to have a major impact on cardiac contractility in patients with normal cardiac function, it may have cardiodepressor effects in patients with systolic dysfunction of the heart ${ }^{39.81}$.

Calcium ions have a pivotal role in the contractile process of both vascular smooth muscle cells and cardiac myocytes. The concentration of calcium in the dialysate can be varied over a wide range. Several studies have shown that changes in ionized calcium may have significant hemodynamic effects ${ }^{22,83}$. This effect on blood 
pressure seems to be mediated predominantly through changes in myocardial contractility although several investigators found a change in vascular reactivity ${ }^{79.82-86}$. As ionized calcium has a direct effect on the contractility of the cardiac smooth muscle cells ${ }^{79,84.85}$, the use of lower calcium concentrations in the dialysate $(1.25 \mathrm{mmol} / \mathrm{L})$ may influence cardiac contractility.

Cardiac contractility is also increased with the use of cool dialysis, which contributes to the improved hemodynamic stability with the use of this method ${ }^{87}$.

\section{Venous return}

Sixty to eighty percent of the total blood volume is located within the capacitance vessels. Therefore, the structure and the function of the venous system can have a major effect on the maintenance of cardiac output during hypovolemia. The venous system can be regarded both as a blood reservoir and as a conduction system for the return of blood from the tissues to the heart. Regarding its function as a blood reservoir, it is of importance to note that under basal circumstances, a large amount of blood is hemodynamically inactive (unstressed). During hypovolemia, passive and active venoconstriction will result in centralization of blood volume. As the venous wall is very flexible, a reduction in blood volume will result in collapse of the venous wall, leading to passive venoconstriction (de Jager-Kroch phenomenon). Active venoconstriction occurs by contraction of smooth muscle in the venous wall ${ }^{88.89}$.

Regarding the function of the venous compartments as a conduction system for the hemodynamically active (stressed) blood volume, the concept of venous compliance is of importance. Venous compliance is defined as the volume/pressure relationship of the venous system. It is mainly determined by the structure of the venous wail. A reduction in venous compliance increases the sensitivity of the system to changes in blood volume: thus, an increase in blood volume results in a greater increase in central venous pressure and a decrease in blood volume will lead to a more pronounced decline in central venous pressure $e^{7,90,9 !}$

\section{Impaired venoconstriction}

During hypovolemia, passive and active venoconstriction contribute to the maintenance of adequate cardiac filling pressures (preload) by centralization of blood volume. By analogy with its effect on to the resistance vessels, hemodialysis appears to impair the vasomotor response of the capacitance vessels. This effect is present both during acetate and bicarbonate dialysis ${ }^{7,47,92}$. However, the effect of acetate dialysis is probably more distinct, as preload was found to decrease more during acetate compared with bicarbonate dialysis despite equivalent ultrafiltration, 
suggesting a more pronounced reduction in venous return during hemodialysis ${ }^{93}$. By contrast, significant venoconstriction occurs during isolated ultrafiltration and hemofiltration. In analogy to the resistance vessels, at least part of this effect is related to the energy balance during dialysis as venoconstriction is also increased during cool dialysis in comparison to standard temperature dialysis ${ }^{63}$. Moreover, the clear difference in reactivity of the forearm veins between hemodialysis and hemofiltration disappears when both treatments are matched to extracorporeal blood temperature in the venous blood line ${ }^{64}$.

\section{Reduced venous compliance}

Independent of the effect on blood volume preservation, the fall in central venous pressure is greater in patients with reduced venous compliance ${ }^{42}$. As mentioned previously, venous compliance is especially reduced in dialysis patients with preexisting hypertension probably caused by structural abnormalities of the venous wall $^{3.41}$. The larger decrease in central venous pressure in patients with reduced venous compliance is caused by an increased sensitivity of the venous system to changes in volume status, owing to the steeper volume/pressure relationship ${ }^{7.89}$. This is in accordance with the more pronounced increase and decrease in central venous pressure during volume loading and unloading in non-uremic hypertensive patients with reduced venous compliance ${ }^{91}$.

\section{Conclusion}

In hemodialysis patients, structural changes at all levels of the cardiovascular system are common ${ }^{14}$. The presence of these cardiovascular changes is a risk factor for the development of intradialytic hypotension. This explains the clinical observation that the incidence of symptomatic hypotension is especially high in elderly hemodialysis patients who often have a history of long-standing hypertension and atherosclerosis, and in hemodialysis patients with cardiovascular disease. In the pathogenesis of intradialytic hypotension two other factors play a major role, which may be augmented by the presence of structural cardiovascular changes: the decrease in blood volume and an impairment in cardiovascular reflexes during dialysis. Most studies on hemodynamic stability during hemodialysis are done on patients with a normal cardiac function. However, with an increasing number of cardiovascular compromised dialysis patients, special attention should be given to this group. As the age of patients on hemodialysis increases steadily, it is a challenge to provide a comfortable treatment for these patients by reducing the incidence of symptomatic hypotensive periods. This can often be accomplished by the use of relatively simple clinical manoeuvres. 


\section{Introduction to the study}

Symptomatic hypotension is a frequently occurring phenomenon in the dialysis population, and might even be of more clinical importance in cardiovascular compromised patients. Symptomatic hypotension may occur as a result of a fall in blood volume and reduced vascular reactivity during dialysis in combination with structural abnormalities of the cardiovascular system.

There are several studies showing a more stable hemodynamic state during isolated ultrafiltration compared with hemodialysis combined with ultrafiltration ${ }^{4.99}$. Under normal conditions, the cardiovascular response to a decline in blood volume mainly includes, apart from an increase in heart rate, an increase in both total peripheral resistance and venous tone. The latter results in a centralization of blood volume, thus maintaining adequate cardiac filling pressure and cardiac output. It has been shown that these cardiovascular regulating mechanisms are inhibited during hemodialysis combined with ultrafiltration, but are normal during isolated ultrafiltration. Especially in patients with a reduced left ventricular compliance or an otherwise compromised left ventricular function who are highly dependent on adequate venous return for the maintenance of cardiac output i.e. blood pressure, abnormalities of the cardiovascular system, and especially of the venous system can play an important role in the induction of hypotensive periods during hemodialysis. Therefore it is of importance to study the blood pressure response in relation to changes in blood volume in patients with cardiac failure compared with patients without cardiac failure during isolated ultrafiltration and hemodialysis combined with ultrafiltration at different ultrafiltration rates in order to find the optimal strategy for fluid removal (chapter 2).

Volume expansion is frequently performed by infusions of saline, a practice that frustrates attempts to attain dry weight by increasing the fluid burden, thus necessitating greater ultrafiltration and further hypotension. The most commonly used volume expanders are hypertonic saline, albumin, dextran and mannitol. However, because of the attending side-effects of hypertonic saline (thirst, interdialytic weight gain, hypertension) this fluid is not without drawbacks and therefore of limited clinical importance ${ }^{40.100-105}$. The effect of albumin infusion in the management of hypovolemia is well known. Compared with other solutions, albumin is expensive, and can cause side-effects (allergic reactions). Therefore, the ideal fluid would be inexpensive, rapid in onset, prolonged in duration, and associated with no side-effects. In intensive care wards hydroxyethylstarch (HES), a relatively inexpensive synthetic colloid is used in the management of hypovolemic disturbances ${ }^{106,107}$. Because of its physicochemical properties HES, has a longstanding volume effect up to $4 \mathrm{hrs}^{108}$. It can be expected, therefore, that hyperoncotic HES $10 \%$ might be of clinical importance in dialysis patients. First the effectiveness of saline $(0.9 \%)$, albumin $(20 \%)$ and HES $(10 \%)$ on blood 
volume, hemodynamic parameters and vascular reactivity was compared during hemodialysis combined with ultrafitration in patients without cardiac failure (chapter 3) and secondly the clinical effect of hypertonic saline (3\%), albumin $(20 \%)$ and HES (10\%) on blood pressure course was studied in cardiac compromised patients (chapter 4).

The concentration of calcium in the dialysate can vary over a wide range. It is known that calcium ions can have a pivotal role in the contractile process of both vascular smooth muscle cells and cardiac myocytes. Previous studies showed that changes in ionized calcium levels have significant hemodynamic effects, which seems to be mediated predominantly through changes in myocardial contractility ${ }^{79,82-86}$. Since it is known that hypotensive periods during hemodialysis are also caused by the inability of the cardiovascular regulatory mechanisms to compensate for the decrease in blood pressure, it could be of clinical importance to study the effect of changes in ionized calcium on the intradialytic blood pressure course especially in cardiac compromised patients who are prone to hypotensive episodes during hemodialysis combined with ultrafiltration (chapter 5).

In addition to a decline in blood volume, an impaired cardiovascular response is implicated in the pathogenesis of intradialytic hypotension. The latter phenomenon appears to be at least partly related to changes in extracorporeal blood temperature $^{\text {Il }}$. Since the early $1980^{\circ}$ s various studies have shown a decrease in symptomatic hypotensive periods with the use of low temperature dialysate $\left(35^{\circ} \mathrm{C}\right.$ to $36^{\circ} \mathrm{C}$ ) compared with standard temperature $\left(37^{\circ} \mathrm{C}\right.$ to $\left.38^{\circ} \mathrm{C}\right)$ dialysate ${ }^{109,110}$. This was associated with an improved reactivity of the capacitance and resistance vessels and an increase in cardiac contractility ${ }^{63.94}$, possibly mediated by an increased activity of the sympathetic nervous system ${ }^{63,94,111}$. Although the effect of dialysate temperature on hemodynamics is well recognized, information on the energy transfer between the patient and the extracorporeal system is scarce. It has been observed that core temperature increases with the use of a dialysate temperature between $37^{\circ} \mathrm{C}$ and $38^{\circ} \mathrm{C}^{110.112}$. However, whether this is caused by heat load from the extracorporeal system, or by an effect of the dialysis procedure on body temperature regulation is not known. Moreover, there is few detailed information on the difference in energy balance between standard and low temperature dialysate. In order to gain more insight into this phenomenon, the energy transfer between extracorporeal circuit and the patient as well as the blood pressure response during hemodialysis with the use of low $\left(35.5^{\circ} \mathrm{C}\right)$ and standard $\left(37.5^{\circ} \mathrm{C}\right)$ temperature dialysate was studied (chapter 6). Isolated ultrafiltration (i-UF) has been shown to improve vascular reactivity even more in comparison with cool hemodialysis $\left(35.5^{\circ} \mathrm{C}\right)^{63}$. This might, among other things, be caused by differences in energy transfer between the two treatment modalities. Therefore it might be of clinical importance to study the effect of changes in the extracorporeal energy transfer rather than studying dialysate temperature, and thereby give us the 
opportunity to compare the thermal energy effects of isolated ultrafiltration with hemodialysis combined with ultrafiltration using different dialysate temperatures (chapter 7). In the final study the relative importance of thermal parameters on the vascular response during hemodialysis was studied. The main goal of this study was to elucidate whether differences in vascular response between isolated ultrafiltration and hemodialysis combined with ultrafiltration are only related to differences in thermal balance. Therefore, in this study we compared the effect of various thermal energy balances and dialysate temperatures on vascular reactivity (chapter 8).

Finally, the optimal approach for treating cardiovascular compromised dialysis patients will be discussed (chapter 9). 


\section{Aims of the Study}

The aims of the present study are to identify clinically important factors that could be of importance in optimising blood volume preservation and hemodynamic stability in cardiac compromised dialysis patients. In the final study the relative importance of thermal energy balance on vascular reactivity will be studied. Primarily, this will be done in order to elucidate whether the divergent vascular reactivity between isolated ultrafiltration and hemodialysis combined with ultrafiltration is only due to thermal differences.

The role of the following factors on blood volume preservation and hemodynamic stability during dialysis therapy is studied:

- ultrafiltration-rate

- intravenous fluids

- dialysate calcium concentration

- extracorporeal blood temperature and thermal energy balance

The first study compares isolated ultrafiltration and hemodialysis combined with ultrafiltration in relation to differences in ultrafiltration-rate.

1. Effect of different ultrafiltration-rates on blood volume preservation and blood pressure course during isolated ultrafiltration and hemodialysis combined with ultrafiltration (bicarbonate) in patients with and without cardiac failure. (chapter 2)

The following studies address the efficacy of various infusion fluids regarding blood volume preservation and the blood pressure response during hemodialysis combined with ultrafiltration which is of importance in the acute treatment of hypotensive episodes during hemodialysis.

2. Effect of different intravenous fluids in patients without and with cardiac failure (chapter 3 and 4).

3. In order to assess the importance of the effect of dialysate calcium on the hemodynamic response during dialysis, the following chapter deals with the effect of different dialysate calcium concentrations in patients with cardiac failure (chapter 5) on blood volume preservation, blood pressure course and (cardio)vascular reactivity during hemodialysis combined * with ultrafiltration (bicarbonate)

Although the effect of dialysate temperature on hemodynamic parameters is well recognized, information on the energy transfer between the patient and the 
extracorporeal system is scarce. It has been observed that core temperature increases with the use of a higher dialysate temperature. However, whether this is caused by heat load from the extracorporeal system, or by an effect of the dialysis procedure on body temperature regulation, is not known. Moreover, there is little detailed information on the difference in energy balance between what is called the standard dialysis, low temperature dialysis and isolated ultrafiltration. In order to gain more insight into this phenomenon, in the final three different studies in patients without cardiac failure, the thermal energy balance between the extracorporeal circuit and the patient is assessed.

4. Effect of dialysate temperature on energy balance during hemodialysis (chapter 6).

5. Effect of isolated ultrafiltration and hemodialysis combined with ultrafiltration on thermal energy balance and core temperature (chapter 7).

6. Effect of thermal energy balance and dialysate temperatures during isolated ultrafiltration and hemodialysis combined with ultrafiltration on changes in vascular reactivity (chapter 8 ).

Finally, the optimal approach for treating cardiovascular compromised dialysis patients will be discussed.

7. General discussion: Strategies for optimal treatment of cardiovascular compromised dialysis patients (chapter 9). 


\section{References}

1. Foley RN, Parfrey PS, Harnett JD. Left ventricular hypertrophy in dialysis patients. Semin Dial 1992;5:34-41.

2. Rostand SG, Kirk KA, Rutskey EA. The epidemiology of coronary artery disease in patients on maintenance hemodialysis: implications for management. Contrib Nephrol 1986;52:34-41.

3. Kooman JP, Wijnen JAG, Draayer P, van Bortel L, Gladziwa U, Struyker Boudier HAJ, Peltenburg HG, van Hooff JP, Leunissen KML. Compliance and reactivity of the peripheral venous sytem in patients treated with chronic intermittent hemodialysis. Kidney Int 1992;41:1041-8.

4. London G, Marchais SJ, Safar ME, Genest AF, Guerin AP, Metivir F, Chedid K, London AM. Aortic and large artery compliance in end-stage renal failure. Kidney Int 1990;37:137-42.

5. Geerlings W, Tufveson G, Brunner FP, Ehrich JHH, Fassbinder W, Landais P, Mallick N, Margreiter R, Raine AEG, Rizzoni G, Selwood N. Combined report on regular dialysis and transplantation in Europe, XXI, 1990. Nephrol Dial Transplant 199;69:S5-S29.

6. Ritz E, Rambausek M, Mall G, Ruffman K, Mandelbaum A. Cardiac changes to uremia and their possible relation to cardiovascular instability on dialysis. Contrib Nephrol 1990:78:221-9.

7. Kooman JP, Gladziwa U, Bocker G, van Bortel LMAB, van Hooff JP, Leunissen KML. Role of the venous system in hemodynamics during ultrafiltration and bicarbonate dialysis. Kidney Int 1992;42;718-26.

8. Henderson LW. Symptomatic hypotension during dialysis. Kidney Int 1980;17:51-6.

9. Henrich WL. Hemodynamic instability during hemodialysis. Kidney Int 1986;30:605-12.

10. Zucchelli P, Santoro A. Dialysis-induced hypotension: a fresh look at pathophysiology. Blood Purif 1993:11:85 98.

11. Leunissen KML, Kooman JP, van Kuijk W, Luik AJ, van der Sande F, van Hooff JP Preventing haemodynamic instability in patients at risk for intra-dialytic hypotension. Nephrol Dial Transplant 1996; 11:S11-S5.

12. Hinds CJ, Watson D. Intensive care. WB Saunders Co 1996;72.

13. Mann H, Ernst E, Gladziwa U, Schallenberg U, Stiller S. Changes in blood volume during dialysis are dependent upon the rate and amount of ultrafiltrate. Trans Am Soc Art Org 1989;35:250-2.

14. Rodriguez M, Pederson JA, Llach F. Effect of dialysis and ultrafiltration on osmolality, colloid osmotic pressure, and vascular refilling rate. Kidney Int $1985 ; 28: 808-13$.

15. Fauchald P. Effect of ultrafiltration on body fluid volumes and transcapillary colloid osmotic gradient in hemodialysis patients. Contrib Nephrol 1989;74:170-5.

16. Ronco C. Fabris A, Chiaramonte S, De Dominicis E, Feriani M, Brendolan A, Bragantini L, Milan M, Dell'Aquila R, La Greca G. Comparison of four different short dialysis techniques. Int J Art Org 1988;11:169-74. 
17. Katzarski KS, Nisell J, Randmaa I, Danielsson A, Freyschuss U, Bergström J. A critical evaluation of ultrasound measurement of inferior vena cava diameter in assessing dry weight in normotensive and hypertensive dialysis patients. Am J Kidney Dis 1997;30:459-65.

18. Keshaviah P, Shapiro FL. A critical examination of dialysis-induced hypotension. Am J Kidney Dis $1982 ; 2: 290-301$.

19. Van Stone JC, Bauer JH, Carey J. The effect of dialysate sodium concentration on body fluid distribution during hemodialysis. Trans Am Soc Artif Organs 1980;26:383-6.

20. Leunissen KML, Kouw P, Kooman JP, Cheriex EC, de Vries PMJM, Donker AJM, van Hooff JP. New techniques to determine fluid status in hemodialyzed patients. Kidney Int 1993;43:S50-S56.

21. Flemming SJ, Wilkinson JS, Aldridge C, Greenwood RN, Baker LRI, Cattell WR. Blood volume changes during isolated ultrafiltration and combined ultrafiltrationdialysis. Nephrol Dial Transplant 1988;3:272-6.

22. Koomans HA, Geers AB, Dorhout Mees EJ. Plasma volume recovery after ultrafiltration in patients with chronic renal failure. Kidney Int 1984;26:848-54.

23. Lopot F, Kotyk P, Blaha J, Forejt J. Use of continuous blood volume monitoring for detecting inadequately high dry weight. Int J Art Org 1996;19:411-4.

24. Bogaard H, de Vries JP, de Vries PM. Assessment of refill and hypovolemia by continuous surveillance of blood volume and extracellular blood volume. Nephrol Dial Transplant 1994;9:1283-7.

25. Leunissen KML, Noordzij TC, van Hooff JP. Pathophysiologic aspects of plasma volume preservation during dialysis and ultrafiltration. Contrib Nephrol 1990;78:201-11.

26. Lauster F, Gerzer R, Weil J, Fulle HJ, Schiff H. Assessment of dry body weight in hemodialysis patients by the biochemical marker cGMP. Nephrol Dial Transplant 1990;5:356-61.

27. Kouw PM, Kooman JP, Cheriex EC, Olthof CG, de Vries PM, Leunissen KML. Assessment of postdialysis dry weight: a comparison of techniques. J Am Soc Nephrol 1993;4:98-104.

28. Leunissen KML, Menheere PPCA, Cheriex EC, van den Berg BW, Noordzij TC, van Hooff JP. Plasma alpha-human atrial natriuretic peptide and volume status in chronic hemodialysis patients. Nephrol Dial Transplant 1989;4:382-6.

29. Kong $\mathrm{CH}$, Thompson CM, Lewis CA, Hill PD, Thompson FD. Determination of total body water in uraemic patients by bioelectrical impedance. Nephrol Dial Transplant 1993;8:716-9.

30. Segal KR, Burastero S, Chun A, Coronel P, Pierson RN, Wang J. Estimation of extracellular and total body water by multiple-frequency bioelectrical-impedance measurement. Am J Clin Nutr 1991;54:26-9.

31. Chertow GM, Lowrie EG, Wilmore DW, Gonzalez J, Lew NL, Ling J, Leboff MS, Gottlieb MN, Huang W, Zebrowski B, College J, Lazarus JM. Nutritional assessment with bioelectrical impedance analysis in maintenance hemodialysis. J Am Soc Nephrol 1995;6:75-81. 
32. Formica C, Atkinson MG, Nyulasi I, McKay J, Heale W, Seeman E. Body composition following hemodialysis: studies using dual-energy $\mathrm{x}$-ray absorptiometry and bioelectrical impedance analysis. Osteoporosis International 1993;3:192-7.

33. Mandolfo S, Farina M, Imbasciati E. Bioelectrical impedance and hemodialysis. Int J Artif Org 1995;18:700-4.

34. Mandelbaum A, Ritz E. Vena cava diameter measurement for estimation of dry weight in hemodialysis patients. Nephrol Dial Transplant 1996; 11:S24-S27.

35. Flemming SJ, Wilkinson JS, Greenwood RN, Aldridge C, Baker LR, Cattel WR. Effect of dialysate composition on intercompartimental fluid shift. Kidney Int $1984 ; 26: 848-54$.

36. Kouw PM, Olthof CG, Gruteke P. Influence of high and low sodium dialysis on blood volume preservation. Nephrol Dial Transplant 1991;6:876-80.

37. Robson M, Oren A, Ravid M. Dialysate sodium concentration, hypertension, and pulmonary edema in hemodialysis patients. Dial Transplant 1978;7:678-9.

38. Hsu CH, Swartz RD, Somermeyer MG. Bicarbonate hemodialysis: influence on plasma refilling and hemodynamic stability. Nephron 1984;38:202-8.

39. Leunissen KML, Cheriex EC, Janssen JH, Teule GJ, Mooy JM, Ramentol M, van Hooff JP. Influence of left ventricular function on changes in plasma volume during acetate and bicarbonate dialysis. Nephrol Dial Transplant 1987;2:99-103.

40. Kooman JP, Daemen MJ, Wijnen R, Verluyten-Goessens MJ, van Hooff JP, Leunissen KML. Morphological changes of the venous system in uremic patients. Nephron 1995;69:454-8.

41. London GM, Safar ME, Levenson JA, Simon AC, Temmar MA. Renal filtration fraction, effective vascular compliance, and partition of fluid volumes in sustained essential hypertension. Kidney Int 1981;20:97-103.

42. Henrich WL. Autonomous insufficiency. Arch Int Med 1982;142:339-44.

43. Baldamus CA, Ernst W, Frei UW, Koch KM. Sympathetic and hemodynamic response to volume removal during different forms of renal replacement therapy. Nephron 1982;31:324-32.

44. Hegbrant J, Thysell H, Martensson L, Ekman R, Boberg U. Changes in plasma levels of vasoactive peptides during sequential bicarbonate dialysate. Nephron 1993;63:309-13.

45. Bergström J. Catecholamines and control of blood pressure during hemodialysis and hemofiltration. Kidney Int 1988;34:S110-S4.

46. Odar-Cederlof I, Theodorsson E, Eriksson CG, Hamberger B, Tidgren B, Kjellstrand CM. Vasoactive agents and blood pressure regulation in sequential ultrafiltration and hemodialysis. Int J Art Org 1993;16:662-9.

47. Nakamura $Y$, Ikeda $T$, Takata $S$, Yokoi $H$, Hirono $M$, Abe $T$, Takazakura $F$, Kobayashi $K$. The role of peripheral capacitance and resistance vessels in hypotension following hemodialysis. Am Heart J 1991;121:1170-7.

48. Carmichael FJ, Salvidia V, Varghese GA, Israel Y, Orrego H. Ethanol-induced increase in portal blood flow: role of acetate and $\mathrm{Al}$ and $\mathrm{A} 2$-adenosine receptors. Am J Phys 1988:255:G417-G23. 
49. van Kuijk WH, Wirtz JJ, Grave W, de Heer F, Menheere PP, van Hooff JP, Leunissen KML. Vascular reactivity during combined ultrafiltration-hemodialysis. Influence of dialysate sodium. Nephrol Dial Transplant 1996;11:323-8.

50. van Kuijk WH, Mulder WA, Hanff GA, Leunissen KML. The effect of changes in plasma ionized calcium on blood pressure and vascular reactivity during ultrafiltration and hemodialysis. Clin Nephrol 1997;47:190-6.

51. Henderson LW, Koch KM, Dinarello CA, Shaldon S. Hemodialysis hypotension: The interleukin-1 hypothesis. Blood Purif 1993;1:3-8.

52. Dinarello CA. Interleukin-1 and tumor necrosis factor and their naturally occurring antagonists during hemodialysis. Kidney Int 1992;42:S68-S72.

53. Yokokawa $\mathrm{K}$, Mankus R, Saklayen MG, Kohno M, Yasunari K, Minami M, Kano $\mathrm{H}$, Horio $\mathrm{T}$, Takeda $\mathrm{T}$, Mandel AK. Increased nitric oxide production in patients with hypotension during hemodialysis. An Int Med 1995;123:35-7.

54. Bergamo Collaborative Dialysis Study Group. Acute intradialytic well-being; results of a clinical trial comparing polysulfone with cuprophane. Kidney Int 1991;40:714-9.

55. Collins DM, Lambert MB, Tannenbaum JS, Oliverio M, Schwab SJ. Tolerance of hemodialysis: a randomized prospective trial of high-flux versus conventional highefficiency hemodialysis. J Am Soc Nephrol 1993;4:148-54.

56. Skroeder NR, Jacobson SH, Lins LE, Kjellstrand CM. Acute symptoms during and between hemodialysis: the relative role of speed, duration, and biocompatibility of dialysis. Artif Org 1994;18:880-7.

57. van Kuijk WH, Buurman WA, Gerlag PG, Leunissen KML. Vascular reactivity during combined ultrafiltration-hemodialysis: influence of dialysis derived contaminants. J Am Soc Nephrol 1996;7:2664-9.

58. Aakhus S, Bjoernstad $\mathrm{K}$, Jorstad $\mathrm{S}$. Systemic cardiovascular response in hemodialysis without and with ultrafiltration with membranes of high and low biocompatibility. Blood Purif 1995;13:229-40.

59. McGrath BP, Ledingham JG, Benedict CR. Catecholamines in peripheral venous plasma in patients on chronic hemodialysis. Clinical Science in Molecular Medicine 1978;55:89-96.

60. Converse RL, Jacobson TN, Jost CM, Toto RD, Jost CM, Cosentino F, FouadTarazi F, Victor RG. Sympathetic overactivity in patients with chronic renal failure. N Eng J Med 1992;327:1912-8.

61. Shinzato T, Milwa M, Nakai S, Morita H, Odani H, Inove I, Maeda K. Role of adenosine in dialysis-induced hypotension. J Am Soc Nephrol 1994;4:1987-94.

62. Coli U, Landini S, Lucatello S, Fracasso A, Morachiello P, Righetto F, Scanterla F, Onesti G, Bazzato G. Cold as cardiovascular stabilizing function in hemodialysis: hemodynamic evaluation. Trans Am Soc Artif Int Org 1983;29:71-5.

63. van Kuijk WH, Luik AJ, de Leeuw PW, van Hooff JP, Nieman FH, Habets HM, Leunissen KML. Vascular reactivity during hemodialysis and isolated ultrafiltration: thermal influences. Nephrol Dial Transplant 1995;16:1852-8. 
64. van Kuijk WH, Hillion D, Savoiu C, Leunissen KML. Critical role of the extracorporeal blood temperature in the hemodynamic response during hemofiltration. J Am Soc Nephrol 1997;8:949-55.

65. Bondia A, Tabernero JM, Macias JF, Martin-Luengo C. Autonomic nervous system in hemodialysis. Nephrol Dial Transplant 1988;2:174-80.

66. Nakashima Y, Fouad FM, Nakamoto S, Textor SC, Bravo EL, Tarazi RC. Localisation of autonomic nervous system dysfunction in dialysis patients. Am J Nephrol 1987;7:375-81.

67. Heber ME, Lahiri A, Thompson D, Raftery EB. Baroreceptor, not left ventricular, dysfunction is the cause of hemodialysis hypotension. Clin Nephrol 1989;32:79-86.

68. Lin YF, Wang JY, Shum AY, Jiang HK, Lai WY, Lu KC, Diang LK, Shieh SD. Role of plasma catecholamines, autonomic, and left ventricular function in normotensive and hypotension prone dialysis patients. Trans Am Soc Artif Int Org 1993;39:946-53.

69. Stojceva-Taneva O, Masin G, Polenakovic M, Stojcev S, Stojkovski L. Autonomic nervous system dysfunction and volume nonresponsive hypotension in hemodialysis patients. Am J Nephrol 1991;11:123-6.

70. Nies AS, Robertson D, Stone WJ. Hemodialysis hypotension is not the result of uremic peripheral autonomous neuropathy. J Lab Clin Med 1979;94:395-402.

71. Ligtenberg G, Blankestijn PJ, Boomsma F, Koomans HA. No change in automatic function tests during uncomplicated hemodialysis. Nephrol Dial Transplant 1996; 11:651-6.

72. Converse RL, Jacobsen TN, Jost CMT, Toto RD, Grayburn PA, Obregon TM, Fouad-Tarazi F, Victor RG. Paradoxical withdrawal of reflex vasoconstriction as a cause of hemodialysis-induced hypotension. J Clin Invest 1992;90:1657-65.

73. Santoro A, Mancini E, Spongano M, Rnssi M, Paolini F, Zucchelli P. A haemodynamic study of hypotension during hemodialysis using electrical bioimpedance cardiography. Nephrol Dial Transplant 1990;5:S147-S53.

74. Zoccali C, Tripepi G, Mallamaci F, Pannuccio. The heart rate response to dialysis hypotension in hemodialysis patients. Nephrol Dial Transplant 1997;12:519-23.

75. Parfrey PS, Harnett Foley RN, Parfrey PS, Harnett JD. Left ventricular hypertrophy in dialysis patients. Sem Dial 1992;5:34-41.

76. Kooman JP, Leunissen KML. Cardiovascular aspects in renal disease. Curr Op Nephrol Hypert 1993;2:791-7.

77. Cohen-Solal A. Left ventricular diastolic dysfunction: pathophysiology, diagnosis and treatment. Nephrol Dial Transplant 1998;13:S3-S5.

78. Wizemann V, Blank S, Kramer W. Diastolic dysfunction of the left ventricle in dialysis patients. Contrib Nephrol 1994;106:106-9.

79. Henrich WL, Hunt JM, Nixon JV. Increased ionized calcium and left ventricular contractility during hemodialysis. N Eng J Med 1984;310:19-23.

80. Drüeke T, I e Pailleur C. Cardiomyopathy in patients on maintenance hemodialysis. Contrib Nephrol 1986;52:27-33.

81. Leunissen KML, Hoorntje SJ, Fiers HA. Acetate versus bicarbonate dialysis in critically ill patients. Nephron 1986;42:146-51. 
82. Maynard JC, Cruz C, Kleerekoper M, Levin NW. Blood pressure response to changes in serum ionized calcium during hemodialysis. Ann Intern Med 1986; 104:358-61.

83. Fellner SK, Lang RM, Neumann A, Spencer KT, Bushinsky DA, Borow KM. Physiological mechanism for calcium-induced changes in systemic arterial pressure in stable dialysis patients. Hypert 1989;13:213-8.

84. Leunissen KML, van den Berg BW, van Hooff JP. Ionized calcium plays a pivotal role in controlling blood pressure during hemodialysis. Blood Purif 1989;7:233-9.

85. Lang RM, Fellner SK, Neumann A, Budshinsky DA, Borow KM. Left ventricular contractility varies directly with blood ionized calcium. Ann Intern Med 1988; 108:524-9.

86. van Kuijk WHM, Mulder AW, Peels CH, Harff GH, Leunissen KML. Influence of changes in ionized calcium on cardiovascular reactivity during hemodialysis. Clin Nephrol 1997;47:190-6.

87. Levy FL, Grayburn PA, Foulks CJ, Brickner ME, Henrich WL. Improved left ventricular contractility with cool temperature hemodialysis. Kidney Int 1992;41:961-5.

88. Daugirdas JT. Dialysis hypotension; a hemodynamic analysis. Kidney Int 1991;39:233-46.

89. Greenway CV, Wayne Lautt W. Blood volume, the venous system, preload, and cardiac output. Canadian J Phys Phar 1986;64:383-7.

90. Hintze TH, Vatner SF. Cardiac dynamics during haemorrhage: relative unimportance of adrenergic inotropic responses. Circ Res 1992;50:705-13.

91. Safar ME, London GM, Levenson JA, Simon AC, Chau NP. Rapid dextran infusion in essential hypertension. Hypertension 1979;1:615-23.

92. Bradley JR, Evans DB, Gore SM, Cowley AJ. Is dialysis hypotension caused by an abnormality of venous tone? B Med J 1988;296:1634-7.

93. Jahn H, Schohn D,Schmitt R. Hemodynamic modifications induced by fluid removal and treatment modalities in chronic hemodialysis patients. Blood Purif 1983;1:80-9.

94. Bergström J, Asaba H, Furst $P$, Oules R. Dialysis, ultrafiltration and blood pressure. Proc Eur Dial Transplant Assoc 1976;13:293-305.

95. Hampl H, Paeprer H, Unger V, Fischer C. Resa I, Kessel M. Hemodynamic changes during hemodialysis, sequential ultrafiltration, and hemofiltration. Kidney Int 1980; 18:S83-S8.

96. Jones EO, Ward MK, Hoenich NA, Keer DNS. Separation of dialysis and ultrafiltration-does it really help ? Proc Eur Dial Transplant Assoc 1977;14:160-6.

97. Rouby JJ, Rottembourg J, Durande JP, Basset JY, Legrain M. Plasma volume changes induced by regular hemodialysis and controlled sequential ultrafiltration hemodialysis. Dial Transplant 1979;8:237-40.

98. Rouby JJ, Rottembourg J, Durande JP, Basset JY, Degoulet P, Glaser P, Legrain $M$. Hemodynamic changes induced by regular hemodialysis and sequential ultrafiltration hemodialysis: A comparative study. Kidney Int 1980;17:801-10. 
99. Wehle B, Asaba H, Castenfors J, Furst P, Gunnarsson B, Shaldon S, Bergström J. Hemodynamic changes during sequential ultrafiltration and dialysis. Kidney Int 1979; 15:411-8.

100. Bergonzi G, Paties C, Vassallo G, Zangrandi A, Poisetti PG, Ballochi S, Fontana F, Scarpioni L. Dextran deposits in tissues of patients undergoing hemodialysis. Nephrol Dial Transplant 1990;5:54-8.

101. Richter AW, Hedin H. Dextran hypersensitivity. Immunology Today 1982;3:132-8.

102. Better OS, Rubinstein I, Winaver JM, Knochel P. Mannitol therapy revisited (19401997) Kidney Int 1997;51:886-94.

103. Aviram A, Pfau A, Czackes JW, Ullman TD. Hyperosmolality with hyponatremia caused by inappropriate administration of mannitol. Am J Med 1967;42:648-50

104. Dorman HR, Sondheimer JH, Cadnapaphornchai P. Mannitol-induced acute renal failure. Medicine (Baltimore) 1990;69:153-9.

105. Conte G, Dal Canton A, Imperatore P, De Nicola L, Gigliotti G, Pisanti A, Memoli B, Fuiano G, Esposito C, Andreucci VE. Acute increase in plasma osmolality as a cause of hyperkalemia in patients with renal failure. Kidney Int 1990;38:301-7.

106. Hankeln K, Radel C, Beez M, Laniewsky P, Bohmert F. Comparison of hydroxyethylstarch and lactated Ringer's solution on hemodynamics and oxygen transport of critically ill patients in prospective crossover studies. Crit Care Med 1989; 17:133-5.

107. Boldt J, Heesen M, Muller M, Pabsdorf M, Hempelmann G. The effects of albumin versus hydroyethyl starch on cardiorespiratory and circulatory variables in critically ill patients. Anest Analg 1996;83:254-61.

108. Weidler B, von Bormann B, Sommermeyer K, Lohmann E, Peil J, Hempelmann G. Pharmakokinetische Merkmal als Kriterien für den klinische Einsatz von Hydroxyethylstarke. Arnzheim.-Forsch Drug Res 1991;41:494-8.

109. Jost CMT, Agrawal R, Khair-El-Din T, Grayburn PA, Victor RG, Henrich WL. Effects of cooler temperature dialysate on hemodynamic stability in problem dialysis patients. Kidney Int 1993;44:606-12.

110. Maggiore Q, Pizzarelli F, Sisca S, Zoccalli C, Parlongo S, Nicolo F, Creazzo G. Blood temperature and vascular stability during hemodialysis and hemofiltration. Trans Am Soc Artif Intern Organs 1982;28:523-7.

111. Mahida BH, Dumler F, Zasuwa G, Fleig G, Levin NW. effect of cooler dialysate on serum catecholamines and blood pressure stability. Trans Am Soc Artif Intern Organs 1983;24:383-9.

112. Provenzano R, Sawaya B, Frinak S, Polashegg HD, Roy T, Zasuwa G, Dumler F, Levin NW. The effect of cooled dialysate on thermal energy balance in hemodialysis patients. ASAIO Trans 1988;34:515-8. 


\section{Chapter 2}

The hemodynamic effect of different ultrafiltration rates in patients with cardiac failure and patients without cardiac failure: comparison between isolated ultrafiltration and ultrafiltration + hemodialysis

FM van der Sande, AW Mulder, SJ Hoorntje, KH Peels, WHM van Kuijk, JP Kooman, KML Leunissen

Clin Nephrol 1998;50:301-308 


\section{Abstract}

The increasing number of dialysis patients with cardiovascular diseases will lead to an increase in the incidence of intradialytic hypotension. Intradialytic hypotension is determined by changes in plasma volume, changes in vascular reactivity and structural cardiovascular changes. In this study the effect of two different ultrafiltration-rates (UF-rate), i.e. 500 and $1000 \mathrm{~mL} / \mathrm{hr}$, on plasma volume, extracellular volume and arterial blood pressure was studied during 4 different treatments of $2 \mathrm{hrs}$ combined ultrafiltration + hemodialysis (UF+HD) and 2 hrs isolated ultrafiltration (i-UF). Fifteen patients, 8 patients with cardiac failure, CFpts (NYHA classification III and IV) and 7 patients without cardiac failure (NCFpts) were investigated during a standardized dialysis treatment. The decrease in plasma volume and decrease in extracellular volume was comparable both between i-UF and UF + HD and comparable between CFpts and NCFpts and was only dependent on the UF-rate. i-UF resulted in minor blood pressure changes in both CFpts and NCFpts. In CFpts, UF +HD resulted in a significant decrease in systolic blood pressure (SBP) at both UF-rates while in NCFpts SBP decreased significantly only at the higher UF-rate during UF+HD. Although there were no significant differences in hemodynamic stability during the different treatment modalities between CFpts and NCFpts, the decrease in SBP in CFpts at the higher UF-rate during UF+HD was much more distinct.

From this clinical study we conclude that differences in hemodynamic stability between i-UF and UF +HD and between (Fpts and NCFpts are not related to differences in plasma volume preservation. Other tiuctors like different changes in vascular reactivity and in CFpts structural cardiovascular changes might be responsible for the differences observed. 


\section{Introduction}

Despite the growing understanding of the pathophysiological mechanisms that contribute to hemodynamic instability during hemodialysis, hemodialysis associated hypotension still remains a significant cause of patient morbidity'. The incidence of intradialytic hypotension is estimated at $25 \%$ and is even expected to increase because of an increasing number of elderly dialysis patients and an increasing number of cardiovascular compromised dialysis patients ${ }^{2}$. In these hemodialysis patients, structural cardiovascular abnormalities such as a decreased left ventricular compliance and a decreased venous compliance in combination with autonomic nervous system (ANS) dysfunction are common ${ }^{3-6}$. These structural cardiovascular changes have important clinical implications, making dialysis patients more susceptible to the development of intradialytic hypotension ${ }^{7,8}$.

With regard to the pathogenesis of intradialytic hypotension there are three important factors; first changes in plasma volume preservation (PVP), second changes in vascular reactivity, and third the above mentioned structural cardiovascular changes. There are several studies showing a more stable hemodynamic state during isolated ultrafiltration (i-UF) compared with ultrafiltration combined with hemodialysis $(\mathrm{UF}+\mathrm{HD})^{9 \cdot 14}$. It some studies it was suggested that this was caused by differences in $\mathrm{PVP}^{9.14}$, but this could not be confirmed in other studies $^{15.16}$. Under normal conditions, the cardiovascular response to a decline in plasma volume (PV) mainly includes, apart from an increase in heart rate, an increase in both total peripheral resistance and venous tone. The latter results in a centralisation of blood volume, thus maintaining adequate cardiac filling pressure and cardiac output? ${ }^{7}$. It has been shown that these regulating mechanisms are inhibited during UF+HD, but are normal during $\mathrm{i}-\mathrm{UF}^{10,14,17,18}$. Especially in patients with severe cardiac impairment or in those with a decreased left ventricular compliance, who are highly dependent upon the maintenance of cardiac filling pressures, a diminished vascular reaction during hemodialysis is very likely an important factor in the pathogenesis of hypotensive periods during hemodialysis 3.7. $^{39-23}$. Nevertheless in many hemodialysis patients, fluid removal even with a decline in PV of $20 \%$ is well tolerated ${ }^{24}$.

Since most studies on hemodynamic stability during i-UF and UF + HD were done on patients without cardiac failure (NCFpts), it is of importance to investigate in patients with cardiac failure (CFpts) the blood pressure response, in order to find the optimal strategy for fluid removal. Therefore, we studied the clinical effects of different ultrafiltration rates (UF-rates) both during i-UF and UF +HD on intravascular and extracellular volume changes and on hemodynamics in CFpts compared with NCFpts. 


\section{Patients and methods}

After obtaining informed consent for participation in the study, 15 patients on intermittent hemodialysis were included. The patients were selected on the basis of symptoms and echocardiographic information, the first group of 8 patients (3 women, 5 men) were patients with cardiac failure (C.Fpts) defined as complaining of symptoms with less than normal activity and symptoms at rest (NYHA classifications III and IV), moreover these patients had a severe left ventricular dysfunction (i.e. left ventricular systolic dysfunction) defined as an ejection fraction of less than 35\%, in the second group of 7 patients (NCFpts. 3 women, 4 men) there were no cardiac complaints and patients had no left ventricular dysfunction ${ }^{25}$.

The aetiology of the cardiac failure in CFpts was due to anterior myocardial infarction (4 patients), posterior myocardial infarction ( 1 patient), and hypertension (3 patients), in NCFpts 1 patient had an anterior myocardial infarction and 1 patient hypertension.

In CFpts the aetiology of the renal failure included reflux nephropathy ( 1 patient), glomerulosclerosis ( 3 patients), chronic glomerulonephritis (3 patients), and secondary amyloidosis (1 patient), and in NCFpts reflux nephropathy (2 patients), glomeruloscierosis ( 2 patients), IgA nephropathy ( 2 patients), and shunt nephritis (1 patient). All vasoactive medication was continued to study daily clinical practice in the treatment of severely CFpts who are dependent on cardiovascular medication. The CFpts used the following medication, angiotensin converting enzyme inhibitors ( 2 patients), $\beta$-blocking agents ( 2 patients), and nitrates (2 patients), and NCFpts used angiotensin converting enzyme inhibitors ( 2 patients), $\beta$-blocking agents ( 2 patients), and calcium channel blocking agents (2 patients).

\section{Methods}

The patients were studied on their regular day of dialysis with a weekly interval. In this clinical study 4 different types of therapy were performed in each patient; i-UF with UF-rate of $500 \mathrm{~mL} / \mathrm{hr}$ (i-UF S00), i-UF with UF-rate of $1000 \mathrm{~mL} / \mathrm{hr}$ (i-UF 1000), UF + HD with UF rate of $500 \mathrm{~mL} / \mathrm{hr}(U \mathrm{~F}+\mathrm{HD} 500)$, and UF+HD with UF-rate of $1000 \mathrm{~mL} / \mathrm{hr}$ (UF+HD 1000). Interdialytic weight gain was $3.0 \mathrm{~kg}$ above their dry weight that was estimated by echography of the inferior caval vein $^{26}$. The patients were ultrafiltrated to $1.0 \mathrm{~kg}$ above their dry weight and furthermore meticulous attention was given to prevent underhydration ${ }^{27.28}$. This was done in order to prevent dangerous symptomatic hypotensive periods during the study period in these vulnerable patients. 
The study started with the insertion of the needles after which patients were at supine rest for $10 \mathrm{~min}$. Dialysis was performed with a Monitral-S dialysis monitor (Hospal, France) using AN69 membranes (AN69, Hospal, France) in all treatments.

The composition of the dialysate was: sodium $141 \mathrm{mmol} / \mathrm{L}$, potassium $2.0 \mathrm{mmol} / \mathrm{L}$, bicarbonate was individualized (between 30 and $36 \mathrm{mmol} / \mathrm{L}$ ), acetate $3 \mathrm{mmol} / \mathrm{L}$, magnesium $0.5 \mathrm{mmol} / \mathrm{L}$ and chloride $108 \mathrm{mmol} / \mathrm{L}$. The dialysate calcium concentration was $1.75 \mathrm{mmol} / \mathrm{L}$, thereby excluding the possibility of a decrease in myocardial contractility caused by a decrease in ionized calcium ${ }^{29.30}$. In all studies the dialysate temperature was $37.5^{\circ} \mathrm{C}$. Blood flow was $250 \mathrm{~mL} / \mathrm{min}$ and dialysate flow was $500 \mathrm{~mL} / \mathrm{min}$.

The hematocrit value gives an indication of changes in relative blood volume since the number of red cells in whole blood is not significantly affected by dialysis and the mean corpuscular volume of the red cells remains essentially constant as has been confirmed by several studies ${ }^{31-33}$. Therefore, the decline in PV was assessed by the serial hematocrit (Hct) method and calculated according to the following formula ${ }^{34}$ :

$$
\Delta \text { plasma volume }=\frac{(100)}{\left(100-\mathrm{Hct}_{\text {before }}\right)} \times \frac{100\left(\mathrm{Hct}_{\text {before }}-\mathrm{Hct}_{\text {after }}\right)}{\mathrm{Hct}_{\text {after }}}
$$

Before, as well as after 1 and 2 hrs of i-UF, and after 1 and 2 hrs of UF + HD at the two different UF-rates, blood was withdrawn from the arterial line for the determination of: hematocrit (derived from mean corpuscular volume and red cell count, Coulter Gen-S, USA), plasma sodium (after dilution ion-selective method, Beckman CX-7, Brea, California, USA), osmolality (Osmomat 30, Gonotec, Berlin, Germany) and colloid osmotic pressure (COP). The coefficient of variation for determination of plasma sodium was $0.8 \%$ and for hematocrit $0.9 \%$ as reported by the manufacturers.

Arterial blood pressure and heart rate were measured every $10 \mathrm{~min}$ with an automatic blood pressure monitor (Dinamap $1486 \mathrm{SX}$, Critikon Inc., USA). The mean value of three consecutive measurements was calculated.

Changes in extracellular volume (resistivity) were assessed by multifrequency bioimpedance measurements, for which a tetrapolar integrated system was used (BIA 109 RJL Akern). Four tape electrodes were applied, two at the dorsal surface of one hand and two at the dorsal surface of the ipsilateral foot. This non-invasive method was validated to measure intracellular and extracellular conductivity and consequently transcellular fluid shifts, the reproducibility was in healthy subjects $r=0.975$ and in dialysis patients $r>0.987^{35}$.

After dialysis a two-dimensional echocardiogram was obtained with the patient in the left lateral decubitus position for measurement of left ventricular ejection 
fraction according to the method of Dodge ${ }^{36}$.

\section{Statistical analysis}

Changes in hemodynamic parameters within each treatment as well as differences between treatments were analyzed by repeated measurements MANOVA (SPSS-PC version). The relation between changes in PV and arterial blood pressure and changes in extracellular volume and arterial blood pressure were analyzed using linear regression (Pearson's r). All laboratory parameters were analyzed by Friedmans ANOVA and if appropriate, by the Wilcoxon's signed-rank test. Changes in laboratory parameters within each treatment between groups were analyzed by Mann-Whitney signed ranksum test. All values are expressed as mean $\pm S D$.

\section{Results}

\section{Patient characteristics}

Table 2.1 shows number of patients, gender, age, known duration on hemodialysis, ejection fraction and E/A ratio. Only the ejection fraction was significantly lower in CFpts as compared with NCFpts $(27.63 \pm 5.04 \%$ versus $52.14 \pm 3.19 \%$, $\mathrm{p}<0.05$ ).

In CFpts the interdialytic weight gain in i-UF 500, i-UF 1000, UF+HD 500 and UF+HD 1000 were, respectively, $2.53 \pm 0.48 \mathrm{~kg}, 2.69 \pm 0.22 \mathrm{~kg}, 2.56 \pm 0.70 \mathrm{~kg}$ and $2.86 \pm 0.39 \mathrm{~kg}$, and in NCFpts, respectively, $2.31 \pm 0.70 \mathrm{~kg}, 2.41 \pm 0.49 \mathrm{~kg}$, $2.16 \pm 0.35 \mathrm{~kg}$ and $2.37 \pm 0.20 \mathrm{~kg}$. Within each group and between the two groups there were no significant differences in interdialytic weight gain during the four different treatments. In CFpts the mean ultrafiltration volume at 2 hrs during i-UF: 500, i-UF 1000, UF +HD 500 and UF+HD 1000 was respectively $1030 \pm 24 \mathrm{~mL}, 2090 \pm 73 \mathrm{~mL}, 998 \pm 20 \mathrm{~mL}$ and $1970 \pm 100 \mathrm{~mL}$, and in NCFpts respectively $1020 \pm 48 \mathrm{~mL}, 2082 \pm 34 \mathrm{~mL}, 1029 \pm 20 \mathrm{~mL}$ and $2028 \pm 69 \mathrm{~mL}$. The ultrafiltration volume was comparable within and between the two groups and was only dependent on the UF-rate.

\section{Changes in intravascular volume}

Table 2.2 shows changes in intravascular volume (plasma volume) versus baseline in the two groups CFpts and NCFpts. PV decreased in CFpts with $12 \pm 3 \%$, $20 \pm 7 \%, 9 \pm 3 \%$ and $17 \pm 4 \%$ during, respectively, i-UF 500 , i-UF 1000 , $\mathrm{UF}+\mathrm{HD} 500$ and $\mathrm{UF}+\mathrm{HD} 1000$ versus $8 \pm 5 \%, 20 \pm 8 \%, 5 \pm 6 \%$ and $19 \pm 8 \%$ in NCFpts. The decrease in PV was comparable between CFpts and NCFpts both 
during $\mathrm{i}-\mathrm{UF}$ and UF+HD and was only dependent on the UF-rate.

\section{Changes in extracellular volume}

Relative changes in extracellular volume (resistivity) versus baseline in the two groups are shown in table 2.2. In each group there was a significant decrease in extracellular volume (increase in resistivity) in the four different treatments. The decrease in extracellular volume was comparable between the two groups and was only dependent on the UF-rate.

Table 2.1 Patient characteristics.

\begin{tabular}{lrrrr}
\hline & Patients with cardiac failure & Patients without cardiac failure \\
\hline Number & 8 & 7 & \\
Man/woman & $5 / 3$ & $4 / 3$ & \\
Age, year & 67.50 & $(14.99)$ & 67.43 & $(15.22)$ \\
Time on dialysis, months & 38.00 & $(37.56)$ & 68.00 & $(57.63)$ \\
E/A ratio & 0.68 & $(0.23)$ & 0.88 & $(0.30)$ \\
Ejection fraction, \% & 27.63 & $(5.04)^{2}$ & 52.14 & $(3.19)$ \\
\hline
\end{tabular}

Mean (SD). Patients with cardiac failure vs. patients without cardiac failure, ${ }^{1} p<0.05$.

Table 2.2 Changes in intravascular (plasma volume) and extracellular (resistivity) volume.

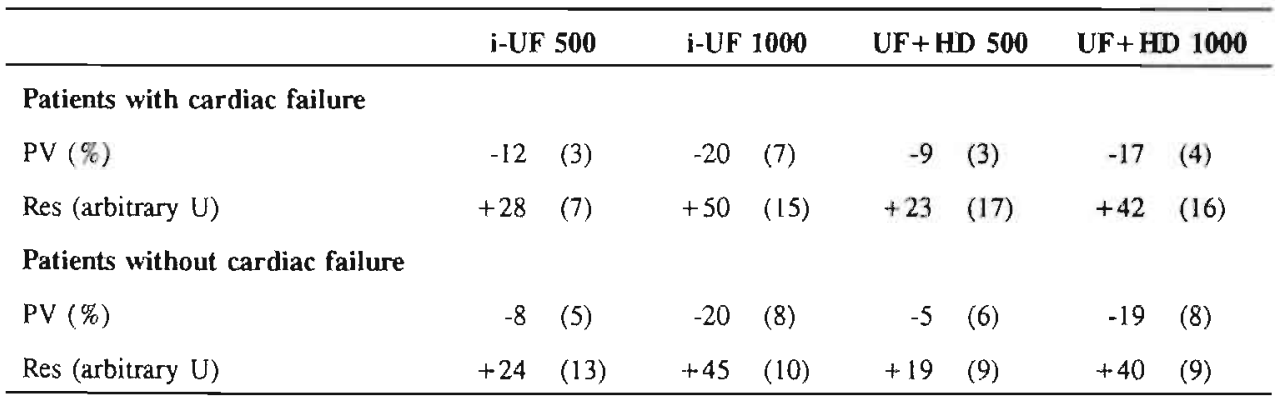

$\mathrm{PV}=$ plasma volume; Res = resistivity, arbitrary units. Mean (SD).

All data: changes versus baseline, $\mathrm{p}<0.05$.

\section{Changes in hemodynamic parameters}

Table 2.3 shows the results of changes in hemodynamic parameters (systolic blood pressure, diastolic blood pressure, mean arterial pressure and heart rate). In CFpts, $\mathrm{UF}+\mathrm{HD}$ as compared with i-UF resulted in a significant decrease in SBP at both UF-rates, while in contrast in NCFpts SBP decreased significantly only at the 
higher UF-rate during UF+HD. Between CFpts and NCFpts there were no significant differences in hemodynamic parameters. $\mathrm{i}$-UF resulted in minor hemodynamic changes in both groups. We found neither a relation between changes in PV and arterial blood pressure, nor a relation between changes in extracellular volume and arterial blood pressure in both groups.

During the four different treatments none of the patients had a hypotensive period that triggered a therapeutic response, wich was our intention.

Table 2.3 Changes in hemodynamic parameters.

\begin{tabular}{lcccccccc}
\hline & i-UF 500 & i-UF $\mathbf{1 0 0 0}$ & UF + HD 500 & UF + HD 1000 \\
\hline Patients with cardiac failure & & & & & & & & \\
SBP (mmHg) & +4 & $(19)$ & -4 & $(22)$ & -11 & $(1.3)^{1}$ & -27 & $(26)^{2.3}$ \\
DBP (mmHg) & +4 & $(9)$ & -1 & $(11)$ & -4 & $(9)$ & -5 & $(22)$ \\
MAP (mmHg) & +5 & $(12)$ & +3 & $(16)$ & -2 & $(12)$ & -10 & $(24)^{1}$ \\
Heart rate (beats/min) & -3 & $(8)$ & +4 & $(7)$ & +2 & $(6)$ & +3 & $(9)$ \\
Patients without cardiac failure & & & & & & & & \\
SBP (mmHg) & +12 & $(7)^{2}$ & -5 & $(16)$ & +4 & $(21)$ & -16 & $(10)^{2.4}$ \\
DBP (mmHg) & +8 & $(9)^{\prime}$ & +2 & $(7)$ & +3 & $(7)$ & -2 & $(10)$ \\
MAP (mmHg) & +7 & $(9)^{1}$ & -1 & $(11)$ & +3 & $(13)$ & -7 & $(8)^{4}$ \\
Heart rate (beats/min) & -2 & $(5)$ & -3 & $(6)$ & +1 & $(10)$ & +7 & $(6)^{2.3}$ \\
\hline
\end{tabular}

$\mathrm{SBP}=$ systolic blood pressure; $\mathrm{DBP}=$ diastolic blood pressure; $\mathrm{MAP}=$ mean arterial blood pressure.

Data are given in mean (SD). Changes versus baseline, ${ }^{I}=p<0.05,{ }^{2}=p<0.001$. Changes between treatments within groups i-UF 1000 vs. UF + HD $1000 .^{3}=\mathrm{p}<0.001,{ }^{4}=\mathrm{p}<0.05$.

\section{Changes in laboratory parameters}

The laboratory data are presented in table 2.4. Plasma sodium before the four treatments, i-UF 500, i-UF 1000, UF+HD 500 and UF+HD 1000 was respectively $135.4 \pm 3.5 \mathrm{mmol} / \mathrm{L}, 135.4 \pm 2.7 \mathrm{mmol} / \mathrm{L}, 135.5 \pm 2.6 \mathrm{mmol} / \mathrm{L}$ and $134.5 \pm 2.9 \mathrm{mmol} / \mathrm{L}$ in CFpts, and in NCFpts. respectively, $135.7 \pm 3.1 \mathrm{mmol} / \mathrm{L}$, $135.1 \pm 3.3 \mathrm{mmol} / \mathrm{L}, \quad 135.4 \pm 3.0 \mathrm{mmol} / \mathrm{L}$ and $134.7 \pm 4.4 \mathrm{mmol} / \mathrm{L}$, and was comparable between CFpts and NCFpts. The changes in plasma sodium were also comparable between CFpts and NCFpts as well as after i-UF and UF+HD at both UF-rates within CFpts and NCFpts and there were no significant differences between the two groups (table 2.4). At all treatments there was a significant increase in COP, both in CFpts and NCFpts. COP was significantly higher during i-UF and UF + HD at the higher UF-rates within each group. Osmolality decreased significantly during UF + HD at both UF-rates in CFpts and NCFpts.

There were no significant differences in sodium and osmolality between CFpts and NCFpts within each treatment. The percentage increase in COP during i-UF and 
UF + HD was comparable between CFpts and NCFpts.

Table 2.4 Changes in laboratury parameters versus baseline.

\begin{tabular}{|c|c|c|c|c|c|}
\hline & i-UF & 500 & i-UF 1000 & UF + HD 500 & $\mathrm{UF}+\mathrm{HD} 1000$ \\
\hline \multicolumn{6}{|l|}{$\begin{array}{l}\text { Patients with cardiac } \\
\text { failure }\end{array}$} \\
\hline Sodium (meg/L) & -0.13 & $(1,73)$ & $+0.63(2.13)$ & $+1.00(2.98)$ & $+1.38(2.39)$ \\
\hline COP $(\because)$ & +14.40 & $(5.76)^{3}$ & $+32.93(11.48)^{1}$ & $+9.95(8.13)^{\prime}$ & $+27.10(8.55)$ \\
\hline Osmol (mosmol $/ \mathrm{kg}$ ) & +63 & $(4.07)$ & $-2.63(2.88)$ & $-13.75(6.23)^{!}$ & $-9.13(5.38)$ \\
\hline \multicolumn{6}{|c|}{ Patients without cardiac failure } \\
\hline Sodium (meq/L) & -14 & $(1.35)$ & $-1.29(1.98)$ & $+0.71(1.98)$ & $+1.57(2.70)$ \\
\hline $\operatorname{COP}(\%)$ & +11.62 & $(5.83)^{i}$ & $+44.17(11.18)^{i}$ & $+12.58(10.57)^{t}$ & $+29.06(8.54)^{1}$ \\
\hline Osmol (mosmol/kg) & -4.00 & $(5.23)$ & $+0.14(4.30)$ & $-16.29(5.59)^{1}$ & $-11.86(6.62)^{1}$ \\
\hline
\end{tabular}

$\mathrm{COP}=$ colloid osmotic pressure, percentage increase; Osmol = osmolality.

Data are given in mean (SD). Changes versus baseline, $=p<0.05$.

\section{Discussion}

In this clinical study changes in plasma volume preservation (PVP) and hemodynamic stability in patients with cardiac failure (CFpts) and patients without cardiac failure (NCFpts) were investigated during i-UF and UF+HD at two different UFrates, $500 \mathrm{~mL} / \mathrm{hr}$ and $1000 \mathrm{~mL} / \mathrm{hr}$. Our results show distinct differences in intradialytic hemodynamic stability between i-UF and UF + HD which were not related to differences in PVP.

Changes in plasma volume were measured by the serial hematocrit technique whereas changes in extracellular volume (resistivity) were measured by multifrequency BIA. It should be noted that absolute changes in extracellular volume measured by BIA should be interpreted with caution but that this technique is fairly reliable in the assessment of relative changes ${ }^{37}$. It is known from previous studies that relative changes in blood volume can be determined during hemodialysis by the serial monitoring hematocrit ${ }^{38-40}$. All methods measure a physical phenomenon which is a function of blood volume relative to its initial volume. Most of the automatic devices of continuously measuring blood volume are derived from the serial hematocrit method. Moreover, measurements of hematocrit by optical devices correlate well with those determined by centrifugation $(r=0.89-0.996)^{38.40}$. Recently, Rasmussen validated van Beaumont's formula, by measuring circulating hemoglobin, blood volume and plasma volume by carbon monoxide technique during isovolemic hemodialysis ${ }^{41}$. They concluded that van 
Beaumont's formula is valid during hemodialysis.

In our study, within each group PV and extracellular volume decreased significantly during i-UF and UF+HD at both UF-rates. The height of reduction in PV and extracellular volume was dependent on the UF-rate. During the higher UF-rate $(1000 \mathrm{~mL} / \mathrm{hr}) \mathrm{PV}$ and extracellular volume decreased more than during the lower UF-rate $(500 \mathrm{~mL} / \mathrm{hr})$. Between the two groups the decrease in PV and extracellular volume was comparable during $\mathrm{i}-\mathrm{LIF}$ and UF + HD at the UF-rate of $500 \mathrm{~mL} / \mathrm{hr}$ as well as at the UF-rate of $1000 \mathrm{~mL} / \mathrm{hr}$. In earlier publications on hemodynamic stability comparing i-UF and UF + HD in NCFpts, some studies found a better preservation of PV during i-UF compared with UF $+\mathrm{HD}^{11,12,42,43}$. These differences could be explained by differences in transcellular fluid shifts related to the decrease of osmolality during UF $+\mathrm{HD}^{33.44-46}$. The decrease in plasma osmolality during $\mathrm{UF}+\mathrm{HD}$ is the result of a decrease in plasma urea (BUN), which is not an active osmol, together with changes in the concentration of different electrolytes, especially sodium which is a tonicly active substance ${ }^{47}$. It has been shown that increasing the dialysate sodium concentration has an important effect on PVP via an increase in plasma tonicity ${ }^{48-51}$. The different results in PVP between i-UF and $\mathrm{UF}+\mathrm{HD}$ reported in the literature could be related either to the use of acetate as a buffer, which has a negative effect on PVP ${ }^{52.53}$, or to differences in the sodium concentration of the dialysate ${ }^{5.55}$. In our study we also did not observe any difference in PVP between i-UF and UF+HD, neither in CFpts, nor in NCFpts despite a significant decrease in plasma osmolality during UF+HD, which was related to BUN clearance. This can be explained by the avoidance of a low sodium concentration of the dialysate and the use of bicarbonate dialysis. Also changes in COP could effect fluid shifts and thereby influence PVP ${ }^{36,57}$. In our study there were no significant differences in percentage increase in COP between CFpts and NCFpts during i-UF and UF+HD at the higher UF-rate.

In CFpts, SBP decreased significantly during UF +HD at both UF-rates and in NCFpts only at the higher UF-rate. During i-UF, SBP was stable both in CFpts and in NCFpts at both UF-rates. Therefore, the blood pressure response to fluid removal was different between $\mathrm{i}-\mathrm{UF}$ and $\mathrm{UF}+\mathrm{HD}$, which was most distinct in CFpts. These differences were not explained by differences in PVP. From previous data in the literature, it can be concluded that the more adequate vascular reactivity i.e. increase in venous tone, and peripheral vascular resistance during i-UF as compared with bicarbonate UF+HD is the key factor in the observed better hemodynamic stability during i-UF $F^{7.9 .14 .17 .58 .59}$. In our study this difference is not related to the use of vascular active medication because the patients were using the same medication during i-UF, during which cardiovascular reactivity was adequate. Under normal circumstances, the cardiac response to a decline in blood volume consists of an enhanced contractility and an increased heart rate. In our study there were no changes in heart rate within each group and between the two groups. ANS 
dysfunction is common in patients on hemodialysis, and mainly characterized by a dysfunction of the baroreceptor reflex $\operatorname{arc}^{6}$. The ANS defect is primarily located in the afferent part of the baroreceptor reflex arc and in the efferent parasympathetic response during hypovolemia ${ }^{61.62}$. Studies regarding the impact of ANS dysfunction on intradialytic hemodynamics have shown conflicting results. Although in some studies a relationship was observed between disturbances in the baroreceptor reflex arc and intradialytic hypotension ${ }^{63-65}$, the results are not confirmed by others ${ }^{66-68}$. In addition to pre-existent ANS dysfunction, the hemodialysis treatment itself may interfere with the normal heart rate response. Bergström extensively reviewed the relation between the ANS and blood pressure control in dialysis therapy. It might be concluded on the basis of cathecholamine levels that UF+HD is indeed associated with an impairment of the ANS function. UF $+H D$ induces a variable response of plasma noradrenaline whereas in contrast, both i-UF and hemofiltration are associated with a marked increase. However, the noradrenaline response to different autonomic stimuli is probably not impaired by $U F+H^{69}$. Zucchelli observed an acute dysfunction of the baroreceptor, assessed by Valsalva manoeuvre, induced by the dialysis treatment itself $f^{70}$. In contrast, an improvement in baroreceptor function was observed after hemofiltration". More important however is the fact that during the use of microneurography some episodes of acute hypotension are related to an acute decrease in sympathetic activity, which is preceded by a large burst in sympathetic activity ${ }^{72}$. The reduction in sympathetic activity was related to an acute decrease in peripheral vascular resistance and a reduction in heart rate. The acute reduction in sympathetic activity appears to be related to the Bezold-Jarish reflex, which is evoked by a stimulation of left ventricular baroreceptors in response to severe left ventricular underfill. However, this reflex probably is only elicited during severe hypovolaemia, as many episodes of symptomatic hypotension are accompanied by an increased or unchanged heart rate $^{73,74}$.

Apart from left ventricular systolic dysfunction it has also been shown in patients with left ventricular diastolic dysfunction that left ventricular pressure can rapidly decrease by rapid ultrafiltration, thereby causing hypotensive episodes during dialysis $^{21.75}$. Left ventricular diastolic dysfunction is characterized by a decrease in E/A ratio. It has been shown by invasive measurements that left ventricular underfilling preceded hypotensive periods during dialysis ${ }^{75}$. It could be expected that in CFpts with a left ventricular diastolic dysfunction, who are highly dependent on an adequate preload, the decrease in PV during dialysis in combination with an inadequate vascular reactivity and ANS dysfunction will impair cardiac output and thus hemodynamic stability. In our study it could be hypothesized that the clinical significant decrease of SBP in CFpts at the higher UF-rate during UF + HD might be caused by an inadequate vascular reactivity, as a reaction on the decline of PV in combination with the decreased left ventricular compliance. 
In conclusion, differences in intradialytic hemodynamic stability between patients with cardiac failure and patients without cardiac failure are not related to changes in plasma volume preservation. In patients with cardiac failure who need high ultrafiltration rates to reach normovolaemia, isolated ultrafiltration might be a good option. Further studies in patients with cardiac failure are needed to look at the effects of vascular reactivity and left ventricular compliance on plasma volume preservation and hemodynamics. 


\section{References}

1. Laupacis A, Muirhead N, Keown P, Wong C. A disease-specific questionnaire for assessing quality of life in patients on hemodialysis. Nephron 1992;60:302-6.

2. Zucchelli $P$, Santoro A. Dialysis-induced hypotension: $a$ fresh look at pathophysiology. Blood Purif 1993; 11:85-98.

3. Kooman JP, Wijnen JAG, Draaijer P, van Bortel L, Gladziwa U, Struyker Boudier HAJ, Peltenburg HG, van Hooff JP, Leunissen KML. Compliance and reactivity of the peripheral venous system in patients treated with chronic intermittent hemodialysis. Kidney Int 1992:41:1041-8.

4. London GM, Marchais SJ, Safar ME, Genest AF, Guerin AP, Metivier F, Chedid $\mathrm{K}$, London AM. Aortic and large artery compliance in end-stage renal failure. Kidney Int 1990;37:137-42.

5. Parfrey PS, Harnett JD, Foley RN. Left ventricular hypertrophy in dialysis patients. Semin Dial 1992;5:34-41.

6. Rostand SG, Kirk KA, Rutskey EA. The epidemiology of coronary artery disease in patients on maintenance hemodialysis: implications for management. Contrib Nephrol 1986;52:34-41.

7. Kooman JP, Gladziwa U, Bocker G, van Bortel LMAB, van Hooff JP, Leunissen KML. Role of the venous system in hemodynamics during ultrafiltration and bicarbonate dialysis. Kidney Int 1992:42:718-26.

8. Ritz E, Rambausek M, Mall G, Rufiman K, Mandelbaum A. Cardiac changes to uremia and their possible relation to cardiovascular instability on dialysis. Contrib Nephrol 1990:78:221-9.

9. Bergström J, Asaba H, Furst P, Oules R. Dialysis, ultrafiltration and blood pressure. Proc Eur Dial Transplant Assoc 1976;13:293-305.

10. Hampl H, Paeprer H, Unger V, Fischer C, Resa I, Kessel M. Hemodynamic changes during hemodialysis, sequential ultrafiltration, and hemofiltration. Kidney Int 1980;18:S83-S8.

11. Jones EO. Ward MK, Hoenich NA, Keer DNS. Separation of dialysis and ultrafiltration-does it really help ? Proc Eur Dial Transplant Assoc 1977; 14: 160-6.

12. Rouby JJ, Rottembourg J, Durande IP, Basset JY, Legrain M. Plasma volume changes induced by regular hemodialysis and controlled sequential ultrafiltration hemodialysis. Dial Transplant 1979;8:237-40.

13. Rouby JJ, Rottembourg J, Durande JP, Basset JY. Degoulet P, Glaser P, Legrain M. Hemodynamic changes induced by regular hemodialysis and sequential ultrafiltration hemodialysis: A comparative study. Kidney Int 1980;17:801-10.

14. Wehle B, Asaba H, Castenfors J, Furst P, Gunnarsson B, Shaldon S. Bergström J. Hemodynamic changes during sequential ultrafiltration and dialysis. Kidney Int 1979;15:411-8.

15. Flemming SJ, Wilkinson JS, Aldridge C, Greenwood RN, Baker LRI, Cattell WR. Blood volume changes during isolated ultrafiltration and combined ultrafiltrationdialysis. Nephrol Dial Transplant 1988;3:272-6. 
16. Rodriguez M, Pederson JA, Llach F. Effect of dialysis and ultrafiltration on osmolality, colloid osmotic pressure, and vascular refilling rate. Kidney Int $1985 ; 28: 808-13$.

17. Baldamus CA, Ernst W, Frei UW, Koch KM. Sympathetic and hemodynamic response to volume removal during different forms of renal replacement therapy. Nephron 1982;31:324-32.

18. Chaignon $\mathrm{M}$, Tzuoh Chen W, Tarazi RC, Bravo EL, Nakamoto S. Effect of hemodialysis on blood volume distribution and cardiac output. Hypert 1981;3:327-32.

19. Harnett JD, Kent GM, Barre JM, Taylor R, Parfrey PS. Risk factors for the development of left ventricular hypertrophy in a prospectively followed cohort of dialysis patients. J Am Soc Nephrol 1994:4:1486-90.

20. Kooman JP, Leunissen KML. Cardiovascular aspects in renal disease. Curr Opin Nephrol Hypertens 1993;2:791-7.

21. Kramer W, Wizemann V, Lammlein G, Thormann J, Kindler M, Schlepper M, Schutterle G. Cardiac dysfunction in patients on maintenance hemodialysis Contrib Nephrol 1986;52:110-24.

22. London GM, Safar ME, Levenson JA, Simon AC, Temmar MA. Renal filtration fraction, effective vascular compliance, and partition of fluid volume in sustained essential hypertension. Kidney Int 1981;20:97-103.

23. Parfrey PS, Harnett JD, Griffiths SM, Gault MH, Barre PE. Congestive heart failure in dialysis patients. Arch Int Med 1988;148:1519-25.

24. Mann H, Ernst E, Gladziwa U, Schallenberg U, Stiller S. Changes in blood volume during dialysis are dependent upon the rate and the amount of ultrafiltrate. Trans Am Soc Artif Organs 1989;35:250-2.

25. The Criteria Committee of the New York Heart Association. Diseases of the Heart and Blood Vessels; Nomenclature and Criteria for Diagnosis. 1964 6th Ed. Little, Brown, Boston.

26. Cheriex EC, Leunissen KML, Janssen JHA, Mooy JMV, van Hooff JP. Echography of the vena cava inferior is a simple and reliable tool for the estimation of dry weight in hemodialysis patients. Nephrol Dial Transplant 1989:4:563-8.

27. Bonnie E, Lee WG, Stiller S, Mann H. Influence of fuid overload on vascular refilling in hemodialysis: continuous measurements with the conductivity method. Progress in Artif Organs 1985;1:135-7.

28. Leunissen KML, Noordzij TC, van Hooff JP. Pathophysiologic aspects of plasma volume preservation during dialysis and ultrafiltration. Contrib Nephrol 1990;78:201-11.

29. Henrich WL, Hunt JM, Nixon JV. Increased ionized calcium and left ventricular contractility during hemodialysis. N Engl J Med 1984;310:19-23.

30. Leunissen KML, van den Berg BW, van Hooff JP. Ionized calcium plays a pivotal role in controlling blood pressure during hemodialysis. Blood Purif 1989;7:233-9.

31. Flemming SJ, Wilkinson JS, Aldridge C. Dialysis-induced change in erythrocyte volume: Effect on change in blood volume calculated from packed cell volume. Clin Nephrol 1988;29:63-8. 
32. Hsu CH, Swartz RD, Sommermeyer MG, Raj A. Bicarbonate hemodialyis. Influence on plasma refilling and hemodynamic stability. Nephron 1984;38;202-8.

33. Swartz RC, Somermeyer MH, Hsu CH. Preservation of plasina volume during hemodialysis depends upon dialysate osmolality. Am J Nephrol 1982;2:189-94.

34. van Beaumont W. Evaluation of hemoconcentration from haematocrit measurements. J Appl Physiol 1972;32:712-3.

35. de Vries PMJM, Meijer JH, Vlaanderen K, Visser V, Oe PL, Donker AJM, Schneider H. Measurement off transcellular fluid shift during hemodialysis. Part 2. in vitro and clinical evaluation. Med Biol Eng Comput 1989;27:152-8.

36. Dodge HT, Sheehan H. Quantitative contrast angiography for assessment of ventricular performance in heart disease. J Am Coll Cardiol 1983;1:73-81.

37. Kurtin PS, Shapiro AC, Tomita H, Raizman D. Volume status and body composition of chronic dialysis patients: Utility of bioelectric impedance plethysmography. Am J Nephrol 1990:10:363-7.

38. Leypoldt JK, Cheung AK, Steuer RR, haris DH, Conis JM. Determination of circulating blood volume by continuously monitoring hematocrit during hemodialysis. J Am Soc Nephrol 1995;6;214-9.

39. Maeda K, Morita H, Shizato T, Vega BV, Kobayakawa H, Ishihara T, Inagaki $H$, Igarashi I, Kitano T. Role of hypovolemia in dialysis-induced hypotension. Artif Organs 1988:12:116-21.

40. Steuer RR, Haris DH, Conis JM. A new optical technique for monitoring hematocrit and circulating blood volume: Its application in renal disease. Dial Transplant 1992;22:260-5.

41. Rasmussen KC, Hansen R, Fugleberg S, Fogh-Andersen N. Van Beaumont's formula is valid during hemodialysis. Spectrophotometric determination of body circulating hemoglobin. Scan J Clin Lab Invest 1993;53:211-4.

42. Iseki K, Onoyama K, Maeda $T$, Shimamatsu K, Harada A, Fujimi S, Omae T. Comparison of hemodynamics induced by conventional acetate hemodialysis, bicarbonate hemodialysis and ultrafiltration. Clin Nephrol 1980; 14:294-8.

43. Leunissen KML, Cheriex EC, Janssen J, Teule GJJ, Mooy JMV, Ramentol M, van Hooff JP. Influence of left ventricular function on changes in plasma volume during acetate and bicarbonate dialysis. Nephrol Dial Transplant 1987;2:99-103.

44. Basile C, Coates JE, Ulan RA. Plasma volume changes induced by hypertonic hemodiafiltration and standard hemodialysis. Am J Nephrol 1987;7:264-9.

45. Keshaviah P, Shapiro FL. A critical examination of dialysis induced hypotension. Am J Kidney Dis 1982;11:290-301.

46. Palmer BF. The effect of dialysate composition on systemic hemodynamics. Sem Dial 1992;5:54-60.

47. Gennari FJ. Serum osmolality uses and limitations. N Eng J Med 1984;310:102-5.

48. Aguilera D, Diab N, Faivre J-M. Influence of sodium dialysate variation on hemodynamic stability. Kidney Int 1988;34:S187-S9.

49. Cybulsky AVE, Matni A, Hollomby DJ. Effects of high sodium dialysate during maintenance hemodialysis. Nephron 1985;41:57-61. 
50. Henrich WL, Woodard TD, Blachley JD, Gomez-Sanchez C, Pettinger W, Cronin RE. Role of osmolality in blood pressure after dialysis and ultrafiltration. Kidney Int 1980;18:480-8.

51. Henrich WL, Woodard TD, McPaull JJ. The chronic efficacy and safety of high sodium dialysate: double-blind, crossover study. Am J Kidney Dis 1982;2:349-53.

52. Leunissen KML, Kooman JP, van Kuijk WHM, van Hooff JP. Bicarbonate dialysis: a review and future perspectives. Sem Dial. 1994;7:186-91.

53. Liang CS, Lowenstein JM. Metabolic control of the circulation. Effects of acetate and pyruvate. J Clin Invest 1978;62:1029-38.

54. Schultze G, Maiga M, Neumayer H-H, Wagner K, Keller F, Molzahn M, Nigam S. Prostaglandin $E_{2}$ promotes hypotension on low-sodium hemodialysis. Nephron 1984:37:250-6.

55. Van Kuijk WHM, Wirtz JJJM, Grave W, de Heer F, Menheere PPCA, van Hooff $J P$, Leunissen KML. Vascular reactivity during combined ultrafiltrationhemodialysis: influence of dialysate sodium. Nephrol Dial Transplant 1995;11:323-8.

56. Bergström J. Changes in blood pressure and hemodynamics during ultrafiltration and dialysis. Dial Transplant 1978;7:1087-91.

57. Rodriquez M, Llach F. Pederson JA, Palma A. Changes in plasma oncotic pressure during isolated ultrafiltration. Kidney Int 1982;21:519-23.

58. Bradley JR, Evans DB, Gore SM, Cowley AJ. Is dialysis hypotension caused by an abnormality of venous tone ? Br Med J 1988;296:1634-7.

59. Leunissen KML, van den Berg BW, Cheriex EC, Slaaf DW, Reneman RS, van Hooff JP. Influence of fluid removal during hemodialysis on macro- and skin microcirculation. Nephron 1990;54:162-8.

60. Campese VM, Romoff MS, Levitan D, Lane K, Massry SG. Mechanismus of autonomic nervous system dysfunction in uremia. Kidney Int 1981;20:246-53.

61. Bondia A, Tabernero JM, Macias JF, Martin-Luengo C. Autonomic nervous system in hemodialysis. Nephrol Dial Transplant 1988;2:174-80.

62. Nakashima Y, Fouad FM, Nakamoto S, Textor SC, Bravo EL, Tarazi RC. Localisation of autonomic nervous system dysfuction in dialysis patients. Am $\mathbf{J}$ Nephrol 1987;7:375-81.

63. Heber ME. Lahiri A, Thompson D, Raftery EB. Baroreceptor, not left ventricular dysfunction is the cause of hemodialysis hypotension. Clin Nephrol 1989;32:79-86.

64. Lin YF, Wang JY, Shum AY, Jiang HK, LAi WY, Diang LK, Shieh SD. Role of plasma cathecholamins, autonomic, and left ventricular function in normotensive and hypotensive prone dialysis patients. ASAIO $f$ 1993;39:946-53.

65. Stojceva-Taneva O, Masin G, Polenakovic M, Stojcev S, Stojkovski L. Autonomic nervous system dysfunction and volume nonresponsive hypotension in hemodialysis patients. Am J Nephrol 1991;11:123-6.

66. Ligtenberg G, Blankenstijn PJ, Boomsma F, Koomans HA. No change in autonomic function tests during uncomplicated hemodialysis. Nephrol Dial Transplant 1996; 11:651-6. 
67. Naik MB, Mathis CJ, Wilson CA, Reid JL, Warren DJ. Cardiovascular and autonomous reflexes in hemodialysis patients. Clin Sci 1981;60:165-70.

68. Nies AS, Robertson D, Stone WJ. Hemodialysis hypotension is not the result of uremic peripheral autonomous neuropathy. J Lab Clin Med 1979;94:395-402.

69. Bergström J. Cathecholamines and control of blood pressure during hemodialysis and hemofiltration. Kidney Int 1988;34:S110-S4.

70. Zuchelli P, Santoro A, Sturani A, Degli Esposti E, Chiarini C, Zuccala A. Effects of hemodialysis and hemofiltration on the autonomic control of cicrculation. Trans Am Soc Artif Intern Organs 1984;30:163-7.

71. Baldamus CA, Mantz P, Kachel HG, Koch KM, Schoeppe W. Baroreflex in patients undergoing hemodialysis and hemofiltration. Contrib Nephrol 1984;41:409-14.

72. Converse RL, Jacobsen TN, Jost CMT, Toto RD, Obregon TM, Fouad-Tarazi F, Victor RG. Paradoxical withdrawal of reflex vasoconstriction as a cause of hemodialysis-induced hypotension. J Clin Invest 1992;90:1657-65.

73. Santoro A, Mancini E, Spongano M, Rossi M, Paolini F, Zucchelli P. A hemodynamic study of hypotension during hemodialysis using electrical bioimpedance cardiography. Nephrol Dial Transplant 1990;5:S147-S53.

74. Zoccali C, Tripepi G, Mallamaci F, Pannucio F. The heart rate response to dialysis hypotension in hemodialysis patients. Nephrol Dial Transplant 1997;12:519-23.

75. Ruffmann K, Mandelbaum A, Bommer J, Schmidli M, Ritz E. Doppler echocardiographic findings in dialysis patients. Nephrol Dial Transplant 1990;5:426-31. 


\section{Chapter 3}

\section{Effect of intravenous saline, albumin or hydroxyethylstarch on blood volume during combined ultrafiltration and hemodialysis}

FM van der Sande, JP Kooman, JNM Barendregt, FHM Nieman, KML Leunissen

J Am Soc Nephrol 1999; 10: 1303-8 


\section{Abstract}

It is generally advocated to use saline or albumin infusions during symptomatic hypotension during dialysis. However, because of their side-effects and/or costs they are of limited use. Hydroxyethylstarch (HES), a synthetic colloid with a long-standing volume effect, is used in the management of hypovolemia. In this study the efficacy of three fluids (isotonic saline $(0.9 \%)$, albumin $(20 \%)$ and HES $(10 \%)$ ) was assessed, during three treatment sessions with combined ultrafiltration and hemodialysis, which differed in the type of fluid given intravenously. Changes in relative blood volume (BV), systolic blood pressure (SBP) and vascular reactivity (venous tone (VT)) were compared. An intravenous infusion of $100 \mathrm{~mL}$ of fluid was given when the decrease in BV versus baseline was more than $10 \%$ as measured by a continuous optical reflection method. The ultrafiltration was continued. BV decreased significantly versus baseline independent of the intravenous fluid administration in all the three treatment sessions. However, when we compared BV at the end of the dialysis session with those at the time of infusion, BV continued to decrease significantly with saline (change in BV $-4.56 \pm 2.75 \% ; p<0.05$ ) and albumin (change in BV $-2.13 \pm 2.51 \% ; \mathrm{p}<0.05$ ), but not with HES (change in BV $-0.15 \pm 2.17 \%$;ns). Between albumin and HES there were no significant differences in changes in BV (ns), whereas between HES and saline $(p<0.05)$ and between albumin and saline $(p<0.05)$ the differences in BV changes were significant. SBP remained unchanged within all sessions. Although SBP tended to decrease more with saline than with albumin and HES, the difference was not significant. The higher decrease in BV and SBP with saline was counterbalanced by a significantly higher increase in VT, while VT remained unchanged in the other two sessions.

The conclusion is that HES is a promising fluid in preserving blood volume, comparable to albumin, but superior to saline. 


\section{Introduction}

Symptomatic hypotension is a common complication of hemodialysis occurring in 20 to $30 \%$ of patients ${ }^{1}$. It will not only endanger the patient but will also reduce the effectiveness of the dialysis therapy. Particularly in patients with a compromised cardiovascular system the risk of hypotension is high ${ }^{2}$. The immediate cause is intravascular hypovolemia related to the dialysis procedure, although other factors such as autonomic neuropathy, left ventricular dysfunction, inappropriate activation of cardiovascular reflexes, and abnormal vascular compliance can also be of importance $e^{3.8}$.

Nevertheless, the acute management of intradialytic hypotension is dependent on volume expansion regardless of the underlying mechanism. Volume expansion is frequently performed by infusions of saline, a practice that frustrates attempts to attain dry weight by increasing the fluid burden, thus necessitating greater ultrafiltration and further hypotension. The use of hypertonic or hyperoncotic solutions during symptomatic hypotension has also been proposed, although none of the studies investigated the effect on blood volume. The most commonly used fluids are saline, albumin, dextran and mannitol. However, because of the sideeffects of hypertonic saline (thirst, interdialytic weight gain, hypertension), dextran (acute anaphylactic reactions, prolonged bleeding time, intracellular deposition, especially in macrophages, and interstitial deposition of dextran in various tissues), and mannitol (hyponatremia, hyperkalemia, metabolic acidosis, and deposition in tissues may occur) these are of limited clinical use $\mathrm{e}^{10-15}$. The effect of albumin infusion in the management of hypovolemia is well known. Compared with other solutions, albumin is expensive and can cause side-effects (allergic reactions). Also, it was recently reported that there was an increased risk of death in patients treated wit albumin because of hypovolemia ${ }^{16}$. So, the ideal fluid would be inexpensive, rapid in onset, prolonged in duration, and associated with no side-effects. In intensive care wards hydroxyethylstarch (HES), a relatively inexpensive synthetic colloid is used in the management of hypovolemic disturbances ${ }^{17.18}$. Compared with albumin HES is much cheaper: $\$ 3$ (US\$) for $100 \mathrm{~mL}$ of HES $10 \%$ versus $\$ 52$ for $100 \mathrm{~mL}$ of albumin $20 \%$. Because of its physicochemical properties HES has a long-standing volume effect up to $4 \mathrm{hrs}^{19}$. It can therefore be expected that hyperoncotic HES $10 \%$ might also be of clinical importance in dialysis patients. In this study therefore, the effectiveness of saline $(0.9 \%)$, albumin $(20 \%)$ and HES (10\%) on blood volume (BV), hemodynamic parameters, and vascular reactivity during combined ultrafitration and hemodialysis (UF+HD) was compared. 


\section{Patients and methods}

\section{Patients and dialysis}

After giving informed consent for participation in the study, 10 patients ( 4 women, 6 men) on chronic intermittent hemodialysis were included. The patient group had a mean age of $61.4 \mathrm{yr}$ (range, 40 to 75 ) and the mean time on hemodialysis was 13.7 mo (range, 5 to 60 ). All were stable dialysis patients who rarely suffered from intradialytic hypotension. Exclusion criteria were severe coronary (NYHA II or more) heart disease and compromised left ventricular function (ejection fraction $\leq 30 \%$ ). The aetiology of the renal failure was nephrosclerosis (4 patients), diabetic nephropathy ( 1 patient), IgA nephropathy ( 1 patient), chronic transplant dysfunction (1 patient), oxalosis nephropathy ( 1 patient), adult polycystic disease (1 patient) and antiglomerular basement membrane nephritis ( 1 patient). By adjusting fluid intake, patients were able to achieve a pre-dialysis weight that was similar in the three sessions. The optimal dry-weight was estimated by echography of the inferior caval vein ${ }^{20}$.

Each patient was studied on the regular day of his or her dialysis schedule with a weekly interval during UF + HD. Each patient served as his or her own control and was studied during three hemodialysis sessions that differed only in the type of intravenous fluid given. Dialysis was performed with a Gambro AK-100 module (Gambro, Lund, Sweden) using hemophane membranes (GFS-16; Gambro, Lund, Sweden). To prevent the effect of a sait load on changes in blood volume ${ }^{21}$ and the effect of dialysate temperature on hemodynamic parameters and vascular reactivity ${ }^{22}$ the composition of the dialysate was individualized. Dialysate sodium is serum sodium, chloride depending on dialysate sodium, bicarbonate individualized (between 32 and $36 \mathrm{mmol} / \mathrm{L}$ ), potassium $2.0 \mathrm{mmol} / \mathrm{L}$, acetate $3.0 \mathrm{mmol} / \mathrm{L}$, magnesium $0.5 \mathrm{mmol} / \mathrm{L}$, calcium $1.5 \mathrm{mmol} / \mathrm{L}$, and glucose $2.0 \mathrm{mmol} / \mathrm{L}$. The dialysate temperature was adjusted according to core temperature of the patient, measured with an ear thermometer (Genius First Temp Model 3000A, Sherwood Medical, Sussex, United Kingdom) which correlates well with intra-arterial measured temperature $(r=0.999, p=0.0001)^{23}$. The blood flow was $250 \mathrm{~mL} / \mathrm{min}$ and dialysate flow $500 \mathrm{~mL} / \mathrm{min}$.

\section{Study protocol}

The study started with the insertion of the needles, after which patients were allowed supine rest for $30 \mathrm{~min}$.

An intravenous infusion of $100 \mathrm{~mL}$ of saline $(\mathrm{NaCl} 0.9 \%$; Baxter, Utrecht, The Netherlands), albumin (Cealb-20\%; Centraal Laboratorium Bloedtransfusie, Amsterdam, The Netherlands), or HES (Haes-steril 10\%; Fresenius, Den Bosch, 
The Netherlands) was given at room temperature $\left(22^{\circ} \mathrm{C}\right)$ when the decrease in relative blood volume (BV) was more than $10 \%$ measured with an optical reflection method. The ultrafiltration was continued at the same rate. The order of the intravenous infusions was randomized. Measurements were performed just before the start of UF +HD $(t=0)$, when the decrease in BV was more than $10 \%(t=i v)$, and after $1(t=1), 5(t=5), 15(t=15)$ and $30 \mathrm{~min}(t=30)$ after $t=i v$, and at the end of $\mathrm{UF}+\mathrm{HD}(\mathrm{t}=\mathrm{end})$.

\section{Methods}

Changes in relative BV were measured continuously and noninvasively by an optical reflection method that measures the absorption and scattering properties of red blood cells as they pass trough the hemodialysis circuit (Crit-line, In-Line Diagnostics, Riverdale, UT). The optical sensor was clipped to the in-line blood chamber on the arterial line and trends of hematocrit and \%BV (versus time) were logged over the entire treatment period. It is known from previous studies that relative changes in BV can reliably be determined during hemodialysis by the serial monitoring of hematocrit ${ }^{24-26}$. Most of the automatic devices to measure continuous BV are derived from the serial hematocrit method. All methods measure a physical phenomenon that is a function of BV relative to its initial volume. Measurements of hematocrit by optical devices correlate well with those determined by centrifugation $(\mathrm{r}=0.89-0.996, \mathrm{p}<0.05)^{24-26}$. The baseline value was obtained after $2 \mathrm{~min}$ of extracorporeal circulation at a blood flow of $250 \mathrm{~mL} / \mathrm{min}$ without ultrafiltration to exclude the influence of saline (recirculation) present in the extracorporeal circuit at the start of dialysis.

Bioimpedance (BIA) measurements were performed using a Xitron $^{\mathrm{R}} 4000 \mathrm{~B}$ bioimpedance analyzer (Xitron Technologies, Inc, San Diego, CA). The electrodes were placed contralateral to the site of vascular access. A range of frequencies between 5 and $500 \mathrm{kHz}$ was used. Estimations of extracellular and intracellular volume and fat-free and fat mass were calculated by equations provided by the manufacturer. Bioimpedance measurements were validated to measure intracellular and extracellular conductivity and consequently transcellular fluid shifts, and the reproducibility was in healthy subjects $r=0.975$ and in dialysis patients $r>0.987$, although it must be cautiously applied to the measurement of absolute volume changes in dialysis patients ${ }^{27,28}$.

Before as well as at the end of dialysis, a blood sample was taken for the determination of sodium (Beckman CX-7; Brea, CA), ionized calcium (ABL 505 radiometer; Copenhagen, Denmark), total $\mathrm{CO}_{2}$, colloid osmotic pressure (COP), and osmolality (Fiske 2400, Copenhagen, Denmark).

Arterial blood pressure (BP) and heart rate (HR) were measured with the Finapres method (Finapres, Ohmeda 2300; Lameris, The Netherlands). The mean value of 3 min was calculated. With the Finapres device, arterial BP and HR are measured 
beat to beat at zero transmural pressure by the use of a small finger cuff that is equipped with an infrared photoplethysmograph ${ }^{29}$. The Finapres cuff was applied to the third finger.

Vascular reactivity was studied at the nonfistula arm that was positioned just above heart level using strain-gauge plethysmography as described by Whitney (Periflow; Janssen Scientific Instruments, Beerse, Belgium) ${ }^{30}$. An inflatable cuff was applied to the upper arm while the mercury-filled strain gauge was positioned at the thickest part of the forearm. In addition, an antecubital vein was cannulated (Venflon, $1 \mathrm{~mm}$ diameter) for the recording of direct intravenous pressure (Hewlett-Packard 78205C pressure monitor). Venous tone (VT) (active venous constriction) and forearm vascular resistance (FVR) were measured as described previously by van Kuijk et $\mathrm{al}^{22}$. The coefficient of variation of consecutive measurements is $11.9 \%^{8}$.

\section{Statistical analysis}

Changes in hemodynamic parameters within each session as well as within patients differences between sessions were analyzed by repeated measurements MANOVA (SPSS-PC version 6.1) $)^{31}$. If the sphericity of the variance-covariance matrix of repeated measurements appeared to be violated, degrees of freedom in the univariate MANOVA tests were corrected by the Greenhouse-Geisser epsilon to avoid Type I error in testing the F-ratio. Reversed Helmert contrasts were used to test between sessions and in addition orthogonal polynomial contrasts within time were made taking $\mathrm{t}=0$ as well as $\mathrm{t}=\mathrm{iv}$ as baselines. Predialysis weights, UF-rate and dialysate temperature were analyzed by the t-test. All laboratory parameters were analyzed by Friedman ANOVA and if appropriate, by the Wilcoxon signedrank test. A $\mathrm{p}<0.05$ was considered significant. All values are expressed as mean \pm SD.

\section{Results}

\section{Patient characteristics}

The predialysis weights in the three treatment sessions, saline $(0.9 \%)$, albumin $(20 \%)$ and HES $(10 \%)$ were $79.22 \pm 10.50,78.87 \pm 10.60$, and $79.08 \pm 10.80 \mathrm{~kg}$ (ns). The mean ultrafiltration-rate (UF rate) was $0.94 \pm 0.11,0.94 \pm 0.10$, and $0.94 \pm 0.10 \mathrm{~L} / \mathrm{hr}$, respectively, in the three treatment sessions (ns). Dialysate temperatures were, respectively, $36.56 \pm 0.56^{\circ} \mathrm{C}, \quad 36.41 \pm 0.69^{\circ} \mathrm{C}$, and $36.56 \pm 0.56^{\circ} \mathrm{C}$ in the three treatment sessions (ns). 


\section{Changes in relative blood volume}

Data are given in Figure 3.1. Time of intravenous infusion of saline $(0.9 \%)$, albumin (20\%) and HES (10\%) was, respectively, $2.20 \pm 0.55,2.35 \pm 0.49$, and $2.31 \pm 0.49 \mathrm{hr}(\mathrm{ns})$.

BV decreased significantly versus baseline during UF $+\mathrm{HD}$ in all three treatment sessions $(\mathrm{p}<0.05)$. The decrease was significantly higher when using saline compared with albumin $(\mathrm{p}<0.05)$ and saline compared with HES $(\mathrm{p}<0.05)$. Between albumin and HES, there were no significant differences, although BV tended to decrease less versus baseline with HES compared with albumin.

When we compared the values at $\mathrm{t}=$ end with those at $\mathrm{t}=\mathrm{iv}, \mathrm{BV}$ decreased significantly with saline (change in BV $-4.56 \pm 2.75 \% ; \mathrm{p}<0.05$ ) and albumin (change in BV $-2.13 \pm 2.51 \% ; \mathrm{p}<0.05$ ), but not with HES (change in BV $-0.15 \pm 2.17 \%$; ns). The decrease in $B V$ in $t=e n d$ versus $t=i v$ was again significantly higher when using saline compared with albumin $(p<0.05)$ and using saline compared with HES $(p<0.05)$; between albumin and HES there were no significant differences. After the intravenous infusion of albumin and HES there was an immediate and sustained effect on BV.

\section{$\Delta \mathrm{BV}(\%)$}

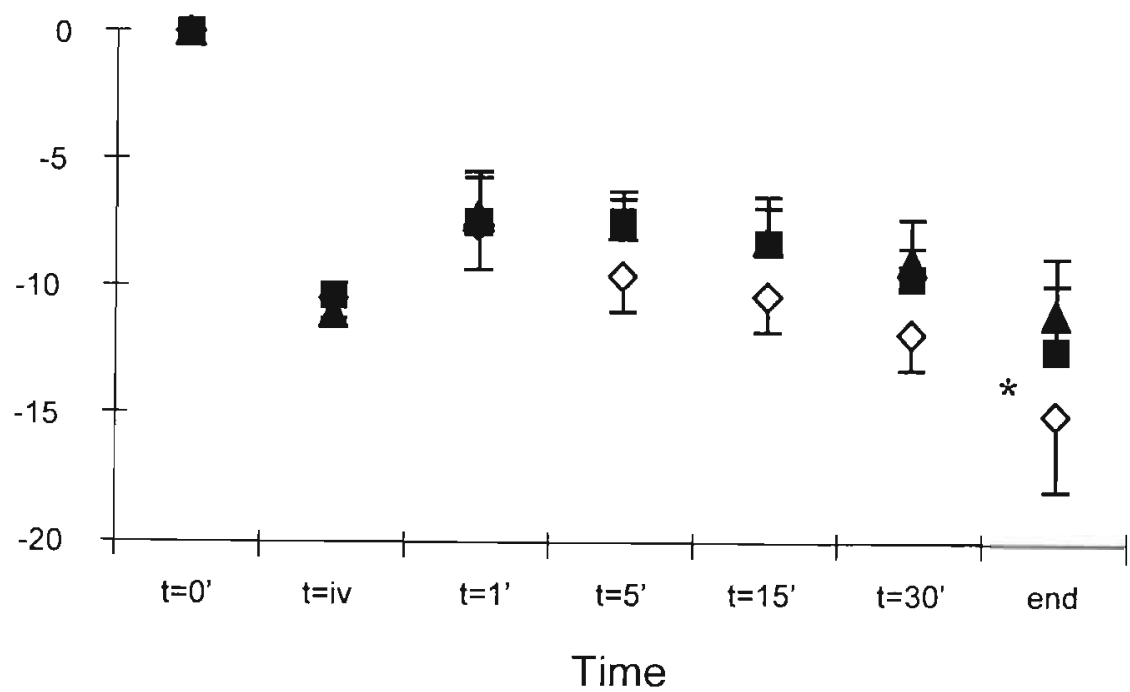

Figure 3.1 Blood volume course: Percentage changes in blood volume versus baseline. Closed square is study with intravenous albumin, open diamant is study with intravenous saline, and closed triangle is study with intravenous hydroxyethylstarch. "p $<0.05$, albumin and hydroxyethylstarch versus saline. 


\section{Extracellular and intracellular volume}

Changes in extracellular (VECF) and intracellular volume (VICF) are shown in Table 3.1. VECF decreased and VICF increased significantly in all sessions. Among the three sessions there were no significant differences.

Table 3.1 Intracellular and extracellular volume ${ }^{1}$

\begin{tabular}{lcccccccc}
\hline Treatment & \multicolumn{3}{c}{ Intracellular volume } & \multicolumn{3}{c}{ Extracellular volume } \\
\hline & \multicolumn{1}{c}{$\mathrm{t}=0$} & $\mathrm{t}=\mathrm{iv}$ & $\mathrm{t}=\mathrm{end}$ & $\mathrm{t}=0$ & $\mathrm{t}=\mathrm{iv}$ & $\mathrm{t}=\mathrm{end}$ \\
Saline $(0.9 \%)$ & $15.16(1.93)$ & $16.33(2.08)$ & $16.56(1.79)^{2}$ & 21.35 & $(2.05)$ & $19.24(1.85)$ & $18.46(1.89)^{2}$ \\
Albumin (20\%) & $15.74(2.58)$ & 16.19 & $(2.00)$ & 16.56 & $(2.34)^{2}$ & $20.75(1.82)$ & $18.91(1.66)$ & $17.84(1.92)^{2}$ \\
HES (10\%) & $15.88(2.29)$ & $16.56(2.01)$ & $16.49(1.73)^{2}$ & $20.78(2.18)$ & $18.83(2.18)$ & $18.05(2.15)^{2}$ \\
\hline
\end{tabular}

'Data are given in mean (SD). Intracellular and extracellular volume are given in litres. HES = hydroxyethylstarch. ${ }^{2} p<0.05$, $t=$ end vs. $t=0$.

\section{Systolic BP}

Figure 3.2 shows the results of the systolic BP (SBP) in the three sessions. There were no significant differences in SBP course within each session. With saline, SBP tended to decrease more compared with albumin and HES, although the difference was not significant.

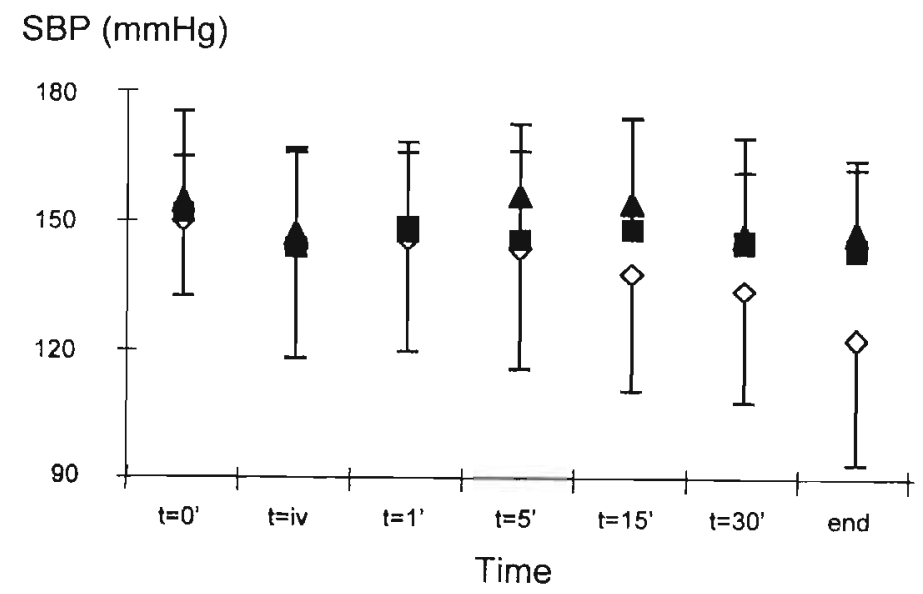

Figure 3.2 Systolic BP course. Closed square is study with intravenous albumin, open diamant is study with intravenous saline, and closed triangle is study with intravenous hydroxyethylstarch. 


\section{Venous tone and forearm vascular resistance}

In Table 3.2 the results of changes in VT and FVR in the three sessions are shown. VT increased significantly with isotonic saline and remained unchanged with albumin and HES, and was significantly higher with isotonic saline compared with albumin but not with HES. FVR increased significantly in the three sessions and there were no significant differences between saline, albumin and HES.

Table 3.2

Forearm vascular resistance and venous tonel

\begin{tabular}{|c|c|c|c|c|c|c|}
\hline \multirow[t]{2}{*}{ Treatment } & \multicolumn{3}{|c|}{ Forearm vascular resistance } & \multicolumn{3}{|c|}{ Venous tone } \\
\hline & {$[-0$} & $1-i v$ & $t=\mathrm{end}$ & $t=0$ & $\mathrm{l}=\mathrm{iv}$ & $t=$ end \\
\hline Saline $(0.9 \%)$ & $29.66(15.68)$ & $48.94(30.85)$ & $45.30(44.12)^{2}$ & $28.31 \quad(6.91)$ & $28.46(4.84)$ & $35.85(9.93)^{2.3}$ \\
\hline Albumin $(20 \%)$ & $26.78(15.27)$ & $46.90(33.20)$ & $46.90(33.20)^{2}$ & $25.79(7.89)$ & $25.79(6.46)$ & $26.26(5.17)$ \\
\hline HES $(10 \%)$ & $30.00(14.55)$ & $38.17(17.64)$ & $44.13(17.28)^{2}$ & $28.30(7.65)$ & $27.87(5.73)$ & $30.48(13.06)$ \\
\hline
\end{tabular}

'Data are given in mean (SD). Foream vascular resistance is given in mmHg/mL/dL/min. Venous tone is given in $\mathrm{mmHg} / \mathrm{mL} / \mathrm{dL}{ }^{2} \mathrm{p}<0.05, \mathrm{t}=$ end $\mathrm{vs} . \mathrm{l}=0 .{ }^{3} \mathrm{p}<0.05$, saline vs. albumin.

\section{Laboratory parameters}

The laboratory data are presented in Table 3.3. Plasma sodium was comparable before as well as after the three sessions which could be expected because the dialysate sodium was adjusted according to the serum sodium concentration of the patient. At all sessions there was a significant increase in COP. Osmolality decreased significantly in all sessions. Ionized calcium increased significantly in the three sessions. Among the three sessions there were no significant differences in laboratory parameters.

Table 3.3 Laboratory parameters ${ }^{1}$

\begin{tabular}{|c|c|c|c|c|c|c|c|}
\hline \multirow[t]{2}{*}{ Parameter } & \multicolumn{3}{|c|}{ Saline $(0.9 \%)$} & \multicolumn{2}{|c|}{ Albumin (20\%) } & \multicolumn{2}{|c|}{$\operatorname{HES}(10 \%)$} \\
\hline & & $1=0$ & $t=$ end & $I=0$ & $t=e n d$ & $\imath=0$ & $t=$ end \\
\hline Sodium (mmol/L) & 137.9 & $(3,25)$ & $138.3(3.5)$ & $136.6(2.88)$ & $137.7(2.58)$ & $137.8(3.29)$ & $138.2(3.05)$ \\
\hline Osmol (mosmL $/ \mathrm{kg}$ ) & 305.1 & $(9.39)$ & $288.0(4.76)^{2}$ & $304.1 \quad(7.13)$ & $286.4(4.70)^{2}$ & $305.7 \quad(6.96)$ & $286.7(5.89)^{2}$ \\
\hline COP (kPa) & 3.34 & $(0.43)$ & $4.30(0.48)^{2}$ & $3.22(0.32)$ & $4.40(0.73)^{2}$ & $3.26(0.29)$ & $4.30(0.54)^{2}$ \\
\hline $\mathrm{i}-\mathrm{Ca}(\mathrm{mmol} / \mathrm{L})$ & 1.12 & $(0.10)$ & $1.25(0.08)^{2}$ & $1.14(0.32)$ & $1.27(0.06)^{2}$ & $1.14(0.08)$ & $1.24(0.09)^{2}$ \\
\hline
\end{tabular}

'Data are given in mean $(S D), C O P=$ colloid osmotic pressure: $\mathrm{i} \cdot \mathrm{Ca}=$ ionized calciurn.

${ }^{2} p<0.05, i=$ end vs. $t=0$. 


\section{Discussion}

In this study, we compared the efficacy of isotonic saline $(0.9 \%)$, albumin (20\%) and HES $(10 \%)$ on BV during UF + HD in stable dialysis patients. The fluids were infused when the decrease in BV was more than $10 \%$. The ultrafiltration was continued. After infusion of HES and albumin, there was an immediate and sustained effect on BV, while BV continued to decrease with saline. Intra- and extracellular volume changed comparably during each treatment session. This could be expected because only $100 \mathrm{~mL}$ of intravenous fluid was given, which is approximately $0.6 \%$ of the intracellular and $0.5 \%$ of the extracellular volume. Our results show that HES is an effective solution in preserving $\mathrm{BV}$, being comparable to albumin but superior to saline.

The larger decrease in BV and SBP after treatment with isotonic saline, as shown in our data, was counterbalanced by a higher level of VT. During BV decrease, compensatory mechanisms arise to maintain cardiac output. Because the venous system is a very important blood reservoir (containing approximately 60 to $80 \%$ of total BV), increasing VT by venoconstriction is of utmost importance to maintain venous return and in consequence cardiac output and blood pressure, as was supported by our data ${ }^{32.33}$.

It has been shown that the vascular refilling rate is related to the level of $\mathrm{COP}^{34}$. It can be expected that in dialysis patients with symptomatic hypovolemia (i.e., symptomatic hypotension) an intravenous infusion of an albumin solution or other hyperoncotic fluids will enhance vascular refilling and improve hemodynamic stability. In our study, COP was measured before and at the end of the dialysis and increased comparably between the three treatment sessions, probably caused by hemoconcentration. However, it is conceivable that BV was better preserved with HF S and albumin because of the immediate effect of an increase in COP after intravenous infusion of the colloid fluid and its attendant water binding effect. This is supported by the fact that in another study an immediate increase in COP after infusion of $500 \mathrm{~mL}$ of HES $10 \%$ in hypovolemic volunteers was found ${ }^{35}$. The water binding capacity of HES is $20 \mathrm{~mL}$ of $\mathrm{H}_{2} \mathrm{O} / \mathrm{g}$ HES. So, $100 \mathrm{~mL}$ of HES $10 \%$ bind approximately $200 \mathrm{~mL}$ of water. It is known that after infusion of a hyperoncotic albumin infusion, $\mathrm{COP}$ increases immediately. Albumin has a water binding capacity of $18 \mathrm{~mL}$ of $\mathrm{H}_{2} \mathrm{O} / \mathrm{g}$ albumin, and $100 \mathrm{~mL}$ of albumin $20 \%$ bind approximately $360 \mathrm{~mL}$ of water, which is predominantly caused by an increase in COP. Nevertheless, the effect of HES on BV preservation was at least as effective compared with albumin. The immediate increase in BV after treatment with the three different kinds of fluid in our study could also be caused by an immediate increase in osmolality; however we did not perform measurements of osmolality just before and after initiation of the intravenous fluid. Kohler et al found no changes in osmolality in the previous mentioned study in which $500 \mathrm{~mL}$. of HES 
$10 \%$ was given to healthy volunteers ${ }^{35}$. In our study there were no differences in plasma sodium concentration or plasma osmolality before as well as at the end of the dialysis between isotonic saline, albumin and HES. One liter of HES contains $154 \mathrm{mmol} \mathrm{NaCl}$ and has an osmolality of $308 \mathrm{mosm} / \mathrm{L}$. Albumin contains $145 \mathrm{mmol} \mathrm{NaCl}$ per liter and has an osmolality between 260 and $280 \mathrm{mosmol} / \mathrm{L}$. It cannot be excluded that the higher sodium concentration of HES compared with albumin has an additional beneficial effect on the preservation of BV.

HES $(10 \%)$ is a solution of hydroxyethylstarch with a mean molecular weight of 200,000 daltons and a molar substitution of 0.5 (HES 200/0.5), and was selected because of its prolonged intravascular volume effect ${ }^{13-15}$. The substitution rate of starches is very important for their pharmacodynamics because the hydroxyethyl side chains markedly decelerate the intravascular breakdown by amylase ${ }^{36}$. Although HES may lead to anaphylactic reactions in isolated cases, of all the available colloids it has the lowest incidence of adverse reactions ${ }^{37,38}$. Long-term, daily administration of HES in medium and high doses, and at high molecular weight (400,000 daltons), could lead to prolonged bleeding time, deposition in the reticular endothelial system, and itching ${ }^{39-42}$. This seems to be related to storage of HES in the skin and appears to be dose-dependent, as has been shown in a recent study in which pruritis did occur only if more than $150 \mathrm{~g}$ of HES $(1500 \mathrm{~mL}$ of HES $10 \%$ ) was given every week ${ }^{42}$. In another study, in which the cumulative dose did not exceed the $300 \mathrm{~g}$ in 14 days, the incidence of HES-induced pruritis was very low and comparable with Ringer's solution ${ }^{43}$. Therefore, there appears to be no elevated risk of pruritis if low molecular weight HES is applied in amounts typical for volume substitution ${ }^{44}$. The pharmacokinetics of HES in patients on hemodialysis and hemofiltration were studied by Steinhoff et $\mathrm{al}^{45}$. They infused $300 \mathrm{~mL}$ of HES $10 \%$ in 10 patients on hemodialysis and 9 patients on hemofiltration and compared the elimination half-life period of HES in these patients with renal healthy people. In patients on hemodialysis the elimination halflife period was threefold prolonged and in patients on hemofiltration twice as long compared with renal healthy people. Considering their results, $300 \mathrm{~mL}$ of HES $10 \%$ can be given to hemodialysis patients after every second dialysis, whereas application to hemofiltration patients is possible after every hemofiltration. Therefore, based on the pharmacokinetic results of Steinhoff et al ${ }^{45}$ in patients on dialysis and the fact that side-effects only occur if high doses of HES are given, it seems to be safe to give $100 \mathrm{~mL}$ of HES $10 \%(10 \mathrm{~g})$ to dialysis patients as we did in our study.

We conclude that blood volume was better preserved with albumin and hydroxyethylstarch compared with saline, whereas the efficacy of hydroxyethylstarch was at least comparable to albumin. Therefore, hydroxyethylstarch seems to be a promising fluid in preserving blood volume, comparable to albumin but less expensive. In our study, the effect of $100 \mathrm{~mL}$ of hyperoncotic hydroxyethylstarch 
was rapid in onset, prolonged in duration, and associated with no side-effects. Additional studies in hypotensive-prone patients and cardiac-compromised dialysis patients are needed to look at the clinical effect of hydroxyethylstarch on BP course during hemodialysis. 


\section{References}

1. Zucchelli P, Santoro A. Dialysis-induced hypotension: a fresh look at pathophysiology. Blood Purif 1993;11:981-5.

2. Ritz E, Rambausek M, Mall G, Ruffman K, Mandelbaum A. Cardiac changes to uremia and their possible relation to cardiovascular instability on dialysis. Contrib Nephrol 1990;78:221-9.

3. Henderson LW. Hemodynamic instability during hemodialysis. Kidney Int 1986;30:605-12.

4. Heber ME, Lahari A, Thompson D, Raftery EB. Baroreceptor, not left ventricular dysfunction is the cause of hemodialysis hypotension. Clin Nephrol 1989;32:79-86.

5. PalmerF. Henrich WL. The effect of dialysis on left ventricular contractility. In Parfrey PS, Harnett JD eds. Cardiac dysfunction in chronic uremia. Dordrecht: Kluwer Academic 1992;171-86.

6. Yellin EL, Nikolic S, Frater RWM. Left ventricular filling and diastolic function. Prog Cardiovasc Res 1990;32:247-71.

7. London GM, Marchais SJ, Safar Me. Aortic and large artery compliance in endstage renal failure. Kidney Int 1990;37:137-42.

8. Kooman JP, Gladziwa U, Bocker G, van Bortel LMAB, van Hooff JP, Leunissen KML. Role of the venous system in hemodynamics during ultrafiltration and bicarbonate dialysis. Kidney Int 1992;42:718-26.

9. Mujais SK, Ing $T$, Kjellstrand C. Acute complications of hemodialysis and their prevention and treatment. In: Replacement of Renal Function by Dialysis, $4^{\text {th }}$ ed., edited by Winchester JF, Washington, Kluwer Academic Publishers 1995;698-724.

10. Bergonzi G, Paties C, Vassallo G, Zangrandi A, Poisetti PG, Ballochi S, Fontana F, Scarpioni L. Dextran deposits in tissues of patients undergoing haemodialysis. Nephrol Dial Transplant 1990;5:54-8.

i1. Richter AW, Hedin H. Dextran hypersensitivity. Immunology Today 1982;3:132-8.

12. Better OS, Rubinstein I, Winaver JM, Knochel P. Mannitol therapy revisited (19401997) Kidney Int 1997;51:886-94.

13. Aviram A, Pfau A, Czackes JW, Ullman TD. Hyperosmolality with hyponatremia caused by inappropriate administration of mannitol. Am J Med 1967;42:648-50.

14. Dorman HR, Sondheimer JH, Cadnapaphornchai P. Mannitol-induced acute renal failure. Medicine (Baltimore) 1990;69:153-9.

15. Conte G, Dal Canton A, Imperatore P. De Nicola L, Gigliotti G, Pisanti A, Memoli B, Fuiano G, Esposito C, Andreucci VE. Acute increase in plasma osmolality as a cause of hyperkalemia in patients with renal failure. Kidney Int 1990;38:301-7.

16. Cochrane Injuries Group Albumin Reviewers. Human albumin administration in critically ill patients: systemic review of randomized controlled trials. BMJ 1998;317:235-40. 
17. Hankeln K, Radel C, Beez M, Laniewsky P, Bohmert F. Comparison of hydroxyethylstarch and lactated Ringer's solution on hemodynamics and oxygen transport of critically ill patients in prospective crossover studies. Crit Care Med 1989;17:133-5.

18. Boldt J, Heesen M, Muller M, Pabsdorf M, Hempelmann G. The effects of albumin versus hydroyethyl starch on cardiorespiratory and circulatory variables in critically ill patients. Anest Analg 1996;83:254-61.

19. Weidler B, von Bormann B, Sommermeyer K, Lohmann E, Peil J, Hempelmann G. Pharmakokinetische Merkmal als Kriterien für den klinische Einsatz von Hydroxyethylstarke. Arnzheim.-Forsch Drug Res 1991;41:494-8.

20. Leunissen KML, Kouw P, Kooman JP, Cheriex EC, DeVries PM, Donker AJ, van Hooff JP. New techniques to determine fluid status in hemodialyzed patients. Kidney Int 1993;43:S50-S6.

21. van Kuijk WHM, Wirtz JJJM, Grave W, de Heer F, Menheere PPCA, van Hooff $J P$, Leunissen KML. Vascular reactivity during combined ultrafiltrationhemodialysis: influence of dialysate sodium. Nephrol Dial Transplant 1995;11:323-8.

22. van Kuijk WHM, Luik AJ, de Leeuw PW, van Hooff JP, Niemann FHM, Habets HML, Leunissen KML. Vascular reactivity during hemodialysis and isolated ultrafiltration: thermal influences. Nephrol Dial Transplant 1995;10:1852-8.

23. Edge $G$ and Morgan $M$. The Genius infrared tympanic thermometer; An evaluation for clinical use. Anaesthesia 1993;48:604-7.

24. Maeda K, Morita H, Shizato T, Vega BV, Kobayakawa H, Ishihara $T$, Inagaki $H$, Igarashi $\mathrm{I}$, Kitano $\mathrm{T}$. Role of hypovolemia in dialysis-induced hypotension. Artif Organs 1998;12;116-21.

25. Steuer RR, Harris DH, Conis JM. A new technique for monitoring hematocrit and circulating blood volume: Its application in renal dialysis. Dialysis and Transplantation 1993;22:260-5.

26. Leypoldt JK, Cheung AK, Steuer RR, haris DH, Conis JM. Determination of circulating blood volume by continuously monitoring hematocrit during hemodialysis J Am Soc Nephrol 1995;6;214-9.

27. de Vries PMJM, Meijer JH, Vlaanderen K, Oe PL, Donker AJM, Schneider H. Measurement of transcellular fluid shift during haemodialysis. Part 2. In vitro and clinical evaluation. Med Biol Eng Comput 1989;27:152-8.

28. Kurtin PS, Shapiro AC, Tomita H, Raizman D. Volume status and body composition of chronic dialysis patients : Utility of bioelectric impedance plethysmography. Am J Nephrol 1990;10:363-7.

29. Penaz J. Photoelectric measurement of blood pressure, volume and flow in the finger. Digest 10 th Int Conf Med Biol Engng 104, Dresden 1973.

30. Whitney RJ. The measurements of volume changes in human limbs. J Physiol 1953;12!:1-27.

31. Stevens J. Chapter 13.7: Should we use the univariate or the multivariate approach?. In: Applied multivariate statistics for the social sciences. Hillsdale, New Yersey, Lawrence Erlbaum Associates, Publislıers 1992;454-6. 
32. Daugirdas JT. Dialysis hypotension: A hemodynamic analysis. Kidney Int 1991;39:233-46.

33. Kooman JP, Glad riwa U, Bocker G, van Bortel LMAB, van Horff JP, Leunissen KML. Role of the venous system in hemodynamics during ultrafiltration and bicarbonate dialysis. Kidney Int 1992;42:718-26.

34. Rodriquez M, Llach F, Pederson JA, Palma A. Changes in plasma oncotic pressure during isolated ultrafiltration Kidney Int 1982;21:519-23.

35. Kohler $H$, Zschiedrich $H$, Clasen $R$, Linfante A, Gamm H. Blutvolumen, kolloidosmotischer Druck und Nierenfunktion von Probanden nach Infusion mittelmolekularer 10\% Hydroxyathylstarke $200 / 0.5$ und $10 \%$ Dextran 40 . Anaesthesist 1982:31:61-7.

36. Quon CY. Clinical pharmacokinetics and pharmacodynamics of colloid plasma volume expanders. J Cardiothorac Anaesth 1988;2:S13-S23.

37. Laxenaire MC, Charpentier C, Feldman L. Anaphylactoid reactions to colloid plasma substitutes: frequency, risk factors, mechanisms. Ann Fr Anesth Reanim 1994; 13:301-10.

38. Warren BB, Durieux ME. Hydroxyethyl starch: safe or not ? Anesth Analg 1997;79: 1034-5.

39. Schneeberger $R$, Allbegger $K$, Oberascher $G$, Miller K. Juckreiz-eine nebunwirkung von Hydroxyathylstarke (HES)? HNO 1990;38:298-303.

40. Gall H, Kaufmann R, von Ehr M, Shumann K, Sterry W. Persistierender Pruritis nach Hydroxyethylstarke-Infusionen. Hautartz 1993;44:713-6.

41. Mortelmans YJ, Vermaut G, Verbruggen AM, Arnout JM, Vermylen J, van Aken M, Mortelmans LA. Effects of $6 \%$ Hydroxyethylstarch and 3\% Modified Fluid Gelatin on Intravascular Volume and Coagulation During Intraoperative Hemodilution, Anaesth Analg 1995;81:1235-42.

42. Ginz HF, Gottschall V, Schwarzkopf G, Walter K. Exzessieve Gewebespeicherung von Kolloiden im retikuloendothelialen System. Anaesthesist 1998;47:330-4.

43. Bothner $M$, Georgieff $M$, Vogt $N H$. Assessment of the safety and tolerance of $6 \%$ Hydroxyethyl Starch (200/0.5) solution: A randomized, controlled epidemiology study. Anaesth Analg 1998;86:850-5.

44. Grochenig E, Albegger K, Dieterich HJ, Franke RP, Gerlach E, Jurecka W, Kiesewetter H, Koch G, Ladurner $G$, Polz W, Schimetta W, Schneeberger R, Volgger R, Wilhelm HJ, Zelger J. Hydroxyethylstarch-related pruritis: a prospective multicentre investigation of 544 patients. Perfusion 1998;11:62-9.

45. Steinhoff J, Mansky T, Reitz M, Schultz K, Sack K. Pharmakokinetik von Hydroxyathylstarke bei Patienten unter Haemodialyse and Haemofiltration. Nierenund Hochdruckkrankheiten 1988;17:S411-S4. 


\section{Chapter 4}

\section{Effect of intravenous fluids on blood pressure course during hemodialysis in hypotensive prone patients}

FM van der Sande, AJ Luik, JP Kooman, $V$ Verstappen, KML Leunissen

$J$ Am Soc Nephrol (in press) 


\section{Abstract}

Hypertonic and hyperoncotic solutions are generally used as acute treatment for symptomatic hypotension during dialysis. We recently showed that administration of hydroxyethyistarch (HES), is an effective substitution fluid in preserving blood volume (BV) and systolic blood pressure (SBP) in a group of stable dialysis patients during dialysis. In this study, in 9 cardiac-compromised dialysis patients with frequent symptomatic hypotensive episodes, the efficacy of 3 fluids, hypertonic saline (3\%), albumin (20\%) and HES (10\%) was assessed, during 3 treatment sessions with combined ultrafiltration and hemodialysis, which only differed in the type of fluid given intravenously. Changes in SBP and relative BV were compared. Fluids were given when SBP was less than $100 \mathrm{mmHg}$ or when the decrease in SBP was greater than $25 \mathrm{mmHg}$ versus the start of the treatment. The ultrafiltration was continued at the same rate. When comparing SBP at the end of the dialysis session ( $\mathrm{t}=\mathrm{end}$ ) with that at the time of infusion $(t=i v)$, SBP continued to decrease with saline, increased with albumin, and increased significantly with HES. The change in SBP in $t=e$ end versus $t=i v$ was significantly greater when using saline compared with HES and tended to decrease more when using saline compared with albumin $(p=0.09)$, between albumin and HES there were no significant differences. BV decreased significantly ( $t=e n d)$ versus baseline $(t=0)$ during $\mathrm{UF}+\mathrm{HD}$ in all 3 treatment sessions. The decrease was significantly higher when using saline compared with albumin and saline compared with HES. Between albumin and HES there were no significant differences. When we compared the values at $t=e n d$ of the dialysis sessions with those at $\mathrm{t}=\mathrm{iv}$, BV decreased, although not significantly with saline and albumin, but remained unchanged with HES.

The conclusion is that HES is an effective fluid in maintaining SBP and preserving BV in hypotensive prone dialysis patients, comparable to albumin, but superior to hypertonic saline. 


\section{Introduction}

Despite the growing understanding of the pathophysiological mechanisms that contribute to hemodynamic instability during hemodialysis, hemodialysis associated hypotension still remains one of the most cumbersome complications in dialysis therapy ${ }^{1}$.

Hypotension during dialysis may induce minor but troublesome side-effects in the patient, such as nausea, vomiting, and dizziness, but may also lead to more serious complications, such as cardiac or cerebral ischemia. There are dialysis patients who hardly suffer from hypotensive episodes. However, hemodialysis associated hypotension is especially frequent in elderly people and in those patients with a compromised cardiovascular system ${ }^{2-8}$. Especially in these groups, hypotension may have serious consequences.

The immediate cause of the decrease in blood pressure during hemodialysis is intravascular hypovolemia which is related to the dialysis procedure itself. It has been shown that preventing the reduction in osmolality during hemodialysis could improve hemodynamic stability ${ }^{9}$. Limiting the reduction in extracellular osmolality can be done by injecting hypertonic fluids, for instance hypertonic saline ${ }^{10}$. However because of the side-effects of hypertonic saline, such as thirst, interdialytic weight gain, and hypertension, which could be of great clinical importance in cardiac-compromised patients, this fluid is not without drawbacks. Volume expansion can also be performed by hyperoncotic infusions, such as dextran and mannitol ${ }^{10}$. However, because of their side-effects these fluids are of limited clinical importance ${ }^{11-18}$. An intravenous infusion of albumin, an expensive and widely used fluid, or other hyperoncotic fluids could further enhance vascular refilling and improve hemodynamic stability ${ }^{19}$. Recent data have questioned the safety of albumin infusions, since it was reported that there was an increased risk of death in patients treated wit albumin because of hypovolemia ${ }^{20}$. Furthermore, data on the effect of both hypertonic saline and albumin on systolic blood pressure course in cardiac-compromised dialysis patients with frequent hypotensive periods are even scarce. In a previous study we compared the effectiveness of isotonic saline, hyperoncotic albumin and hydroxyethylstarch (HES) on blood volume and blood pressure during hemodialysis combined with ultrafitration in patients without hypotensive episodes ${ }^{21}$. We showed that blood volume was better preserved when using HES and albumin compared with saline, whereas blood pressure tended to decrease more with saline compared with HES and albumin. HES is a relatively inexpensive synthetic colloid which has, because of its physicochemical qualities, a long-standing volume effect, and in our previous study only $100 \mathrm{~mL}$ of HES had a distinct effect on preservation of blood volume and in consequence systolic blood pressure $^{21-24}$. It can be expected, based on the results of our previous study, that hyperoncotic HES $(10 \%)$ is of even more clinical importance in cardiac- 
compromised dialysis patients who often suffer from hypotensive episodes. In this study, the effectiveness of hypertonic saline (3\%), albumin (20\%) and HES (10\%) on blood pressure course and blood volume (BV) during combined ultrafitration and hemodialysis (UF+HD) in cardiac-compromised dialysis patients was compared.

\section{Patients and methods}

\section{Patients and dialysis}

After obtaining informed consent for participation in the study, 9 patients (5 women. 4 men) undergoing chronic intermittent hemodialysis were included. All patients were cardiac-compromised patients defined as complaining of symptoms with less than normal activity and symptoms at rest (New York Heart Association classifications III and IV) ${ }^{25}$. Moreover, these patients had a mild to severe left ventricular dysfunction defined as an ejection fraction of $40 \%$ or less, which was obtained by performing a two-dimensional echocardiogram after dialysis with the patient in the left lateral decubitus position for measurement of left ventricular ejection fraction according to the method of Dodge ${ }^{26}$. All patients suffered from hypotensive period more than once weekly.

The patient group had a mean age of 70.4 yr (range, 56 to 80) and the mean time on hemodialysis was 22.1 mo (range, 6 to 36). Heart failure was caused by one or more myocardial infarctions ( 8 patients) and ischemic heart disease ( 1 patient). Renal failure was caused by hypertensive nephrosclerosis (5 patients), diabetic nephropathy ( 3 patients), and of unknown cause ( 1 patient). The mean ejection fraction of the patients in our study was $29.83 \pm 7.65 \%$ (range, $22 \%$ to $40 \%$ ).

The dry-weight was estimated by echography of the inferior caval vein ${ }^{27}$. Ultrafiltration rate was prescribed according to the estimated dry-weight and interdialytic weight gain, and was constant during the dialysis session. Dialysis was performed with a Gambro AK-100 module (Gambro, Lund, Sweden) using hemophane membranes (GFS-16; Gambro, Lund, Sweden) or with a Hospal Integra module (Hospal, Uden, The Netherlands) using polysulphon membranes (F6HPS; Fresenius, Den Bosch, The Netherlands). The blood flow was $250 \mathrm{~mL} / \mathrm{min}$ and dialysate flow $500 \mathrm{~mL} / \mathrm{min}$. The dialysate composition was as follows: potassium $2.0 \mathrm{mmol} / \mathrm{L}$, acetate $3.0 \mathrm{mmol} / \mathrm{L}$, magnesium $0.5 \mathrm{mmol} / \mathrm{L}$, and glucose $2.0 \mathrm{~g} / \mathrm{l}(11.2 \mathrm{mmol} / \mathrm{L}$.). Dialysate calcium concentration was $1.75 \mathrm{mmol} / \mathrm{l}$ because in previous studies we and others showed that this leads to a better hemodynamic stability due to an increase in myocardial contractility, especially in cardiac-compromised patients ${ }^{28-31}$.

In order to prevent the effect of large inter-individual changes in serum sodium 
concentrations on changes in blood volume ${ }^{32}$ during dialysis the dialysate sodium concentration was individualized and set to be equal to the predialytic serum sodium concentration in the first treatment session. The dialysate bicarbonate concentration was individualized and adjusted in order to achieve a postdialysis serum bicarbonate level in between $26 \mathrm{mmol} / \mathrm{l}$ and $30 \mathrm{mmol} / \mathrm{l}$. The dialysate temperature was adjusted to the predialytic body temperature of the patient because it has been shown that higher dialysate temperatures may impair vascular reactivity and blood pressure stability, especially in patients with a low predialytic body temperature ${ }^{33-35}$. Dialysate temperature and dialysate composition did not differ between the 3 treatment sessions.

\section{Study protocol}

The patients were studied on the regular day of his or her dialysis schedule with a weekly interval during UF + HD. Each patient served as his or her own control and was studied during 3 hemodialysis sessions which differed only in the type of intravenous fluid given. The study started with the insertion of the needles after which patients were supine for the time of the dialysis session.

An intravenous (iv) infusion of $33 \mathrm{~mL}$ of saline (sodiumchloride-3\%; Baxter ${ }^{R}$, Utrecht, The Netherlands), $100 \mathrm{~mL}$ of albumin (Cealb-20\%; Centraal Laboratorium Bloedtransfusie $^{R}$, Amsterdam, The Netherlands), or $100 \mathrm{~mL}$ of HES (Haes-steril 10\%; Fresenius ${ }^{R}$, Den Bosch, The Netherlands) was given at room temperature $\left(22^{\circ} \mathrm{C}\right.$ ) when systolic blood pressure was less than $100 \mathrm{mmHg}$ or when the decrease in systolic blood pressure was more than $25 \mathrm{mmHg}$ versus the start of $\mathrm{UF}+\mathrm{HD}$, whereas the ultrafiltration was continued at the same rate. The osmolar load of the administered saline $(30.9 \mathrm{mOsmol})$ was similar to the osmolar load of HES (30.8 mOsmol). The order of the intravenous infusions was randomized. Measurements of arterial blood pressure and relative blood volume were performed just before the start of UF +HD ( $t=0)$, when systolic blood pressure was less than $100 \mathrm{mmHg}$ or when the decrease in systolic blood pressure was more than 25 $\mathrm{mmHg}$ versus the start of $\mathrm{UF}+\mathrm{HD}(\mathrm{t}=\mathrm{iv})$, and after $1(\mathrm{t}=1), 5(\mathrm{t}=5)$, and 30 $(t=30)$ min after $t=i v$, and at the end of $U F+H D(t=e n d)$.

\section{Methods}

Arterial blood pressure (systolic blood pressure [SBP], diastolic blood pressure [DBP], and mean arterial blood pressure [MAP]) was measured with an automatic blood pressure monitor (Dinamap 1486 SX, Critikon Inc, USA), and was measured every $10 \mathrm{~min}$. Moreover before the infusion of the fluids $(t=i v)$, and after $1(t=1)$, $5(t=5)$, and $30(t=30)$ min after the infusion, and at the end of UF +HD ( $t=e n d)$ blood pressure was also measured. Changes in relative $B V$ were measured continuously and non-invasively by means of an optical reflection method which 
measured the absorption and scattering properties of red blood cells as they pass trough the hemodialysis circuit (Crit-line, In-Line Diagnostics, Riverdale, UT). The optical sensor was clipped to the in-line blood chamber on the arterial line and trends of hematocrit and \% BV (versus time) were logged over the entire treatment period. In previous studies it has been shown that relative changes in BV can reliably be determined during hemodialysis by the serial monitoring of hematocrit $t^{36-38}$. The baseline value was obtained after $2 \mathrm{~min}$ of extracorporeal circulation at a blood flow of $250 \mathrm{~mL} / \mathrm{min}$ without ultrafiltration to exclude the influence of saline (recirculation) present in the extracorporeal circuit at the start of dialysis.

Before as well as at the end of dialysis, a blood sample was taken for the determination of serum sodium (Beckman CX-7; Brea, CA), ionized calcium (ABL 505 radiometer; Copenhagen, Denmark), and blood urea nitrogen (Beckman CX-7; Brea, CA)

\section{Statistical analysis}

Changes within patients in hemodynamic parameters within each session as well as within patients differences between sessions were analyzed by repeated measurements MANOVA (SPSS-PC version 6.1) ) $^{39}$. If the sphericity of the variance-covariance matrix of repeated measurements appeared to be violated, degrees of frecdom in the univariate MANONA tests were corrected by the Greenhouse-Geisser epsilon to avoid Type I error in testing the F-ratio. Reversed Helmert contrasts were used to test between sessions and next to this orthogonal polynomial contrasts within time were made taking $t=0$ as well as $t=i$ iv as baselines. Predialysis weights, UF-rate, time of infusion of the fluids, interdialytic weight gain after the treatment sessions, and predialysis and postdialysis laboratory parameters were analyzed by Friedmans ANOVA and if appropriate, by Wilcoxon's signed-rank test. A $p$ value of less than 0.05 was considered significant. All values are expressed as mean $\pm \mathrm{SD}$.

\section{Results}

The predialysis weights in the 3 treatment sessions, saline (3\%), albumin (20\%) and HES $(10 \%)$ were $64.71 \pm 14.94,65.16 \pm 12.55$, and $65.71 \pm 12.79 \mathrm{~kg}$ (ns). The mean ultrafiltration-rate (UF-rate) was $0.72 \pm 0.20, \quad 0.66 \pm 0.19$, and $0.71 \pm 0.14 \mathrm{~L} / \mathrm{hr}$, respectively, in the three treatment sessions (ns). The mean dialysate temperature in all the 3 treatment sessions was $36.66 \pm 0.42^{\circ} \mathrm{C}$. 


\section{Blood pressure course}

Data are listed in Table 4.1. Time of intravenous infusion of saline (3\%), albumin $(20 \%)$ and HES (10\%) was respectively $137 \pm 48,134 \pm 60$, and $151 \pm 52 \mathrm{~min}$ (ns). SBP decreased significantly versus baseline $(t=0)$ during UF $+H D$ in all three truatment sessions $(p<0.05)$. The decrease was significantly higher when using saline compared with albumin $(\mathrm{p}<0.05)$, and when using saline compared with HES $(p<0.05)$. Between HES and albumin there were no significant differences.

When we compared the values at $\mathrm{t}=\mathrm{iv}$ with those at $\mathrm{t}=\mathrm{end}$, SBP decreased with saline (change in SBP $-8.71 \pm 16.63 \mathrm{mmHg}$; ns), increased with albumin (change in SBP $+8.66 \pm 16.61 \mathrm{mmHg}$; ns), and increased significantly with HES (change in SBP $+16.11 \pm 19.37 \mathrm{mmHg} ; \mathrm{p}<0.05)$. The change in SBP in $\mathrm{t}=$ end versus $\mathrm{t}=\mathrm{iv}$ was significantly greater when using saline compared with HES $(p<0.05)$ and tended to decrease more when using saline compared with albumin $(\mathrm{p}=0.09)$, between albumin and HES there were no significant differences.

DBP (Table 4.1) decreased significantly versus baseline $(\mathrm{t}=0)$ during UF + HD with saline and albumin $(p<0.05)$ but not with HES. When we compared the values at $\mathrm{t}=\mathrm{iv}$ with those at $\mathrm{t}=\mathrm{end}$, DBP decreased with saline (change in DBP $-5.71 \pm 16.70 \mathrm{mmHg}$; $\mathrm{ns}$ ), increased with albumin (change in DBP $+2.89 \pm 10.05 \mathrm{mmHg}$; ns), and increased significantly with HES (change in DBP $+7.55 \pm 10.38 \mathrm{mmHg} ; \mathrm{p}<0.05)$. The change in DBP in $\mathrm{t}=$ end versus $\mathrm{t}=\mathrm{iv}$ tended to decrease more when using saline compared with HES $(p=0.075)$, between albumin and HES and between albumine and saline there were no significant differences

Table 4.1 Blood pressure course?

\begin{tabular}{lccc}
\hline Treatment & Saline (3\%) & Albumin (20\%) & HES (10\%) \\
\hline Systolic blood pressure & & & \\
$\mathrm{t}=0$ & $156(25)$ & $127(22)$ & $139(29)$ \\
$\mathrm{t}=\mathrm{iv}$ & $107(14)$ & $90(17)$ & $90(16)$ \\
$\mathrm{t}=\mathrm{end}$ & $98(18)^{2,3}$ & $98(14)^{2}$ & $107(14)^{4,3}$ \\
Diastolic blood pressure & & & \\
$\mathrm{t}=0$ & $74(12)$ & $64(8)$ & $68(10)$ \\
$\mathrm{t}=\mathrm{iv}$ & $64(11)$ & $52(10)$ & $53(8)$ \\
$\mathrm{t}=\mathrm{end}$ & $58(16)^{2}$ & $55(6)^{2}$ & $61(6)^{6}$ \\
\hline
\end{tabular}

Data are given in mean (SD). Blood Pressure course before the start of the dialysis $(\mathrm{t}=0)$, hefore the intravenous fluid administration $(t=i v)$ and at the end of the dialysis session ( $t=e n d)$. Systolic and diastolic blood pressure are given in $\mathrm{mmHg}$. HES, hydroxyethylstarch.

${ }^{2} p<0.05, t=$ end versus $t=0,{ }^{3} p<0.05$, saline versus albumin and saline versus HES, $t=e n d$ versus $t=0$. ${ }^{4} p<0.05, t=e$ end versus $t=i v$. " $p<0.05$. HES versus saline, $t=$ end versus $t=i v$.

${ }^{6} \mathrm{p}=0.075$, HES versus saline, $\mathrm{t}=$ end versus $\mathrm{t}=\mathrm{iv}$. 


\section{Changes in relative blood volume}

Data are given in Figure 4.1. BV decreased significantly versus baseline during $\mathrm{UF}+\mathrm{HD}$ in all 3 treatment sessions $(\mathrm{p}<0.05)$. The decrease in $\mathrm{BV}$ in $\mathrm{t}=$ end versus $\mathrm{t}=0$ was significantly higher when using saline compared with albumin $(\mathrm{p}<0.05)$ and when using saline compared with HES $(p<0.05)$. Between albumin and HES there were no significant differences.

When we compared the values, before the fluid administration, at $t=i v$ with those at $\mathrm{t}=\mathrm{end}$, BV decreased, although not significantly with saline (change in BV $-3.19 \pm 2.88 \%$; ns) and albumin (change in BV $-1.04 \pm 6.91 \%$; ns), but remained stable with HES (change in $\mathrm{BV}+0.14 \pm 4.7 \%$; ns).

$\Delta B V(\%)$

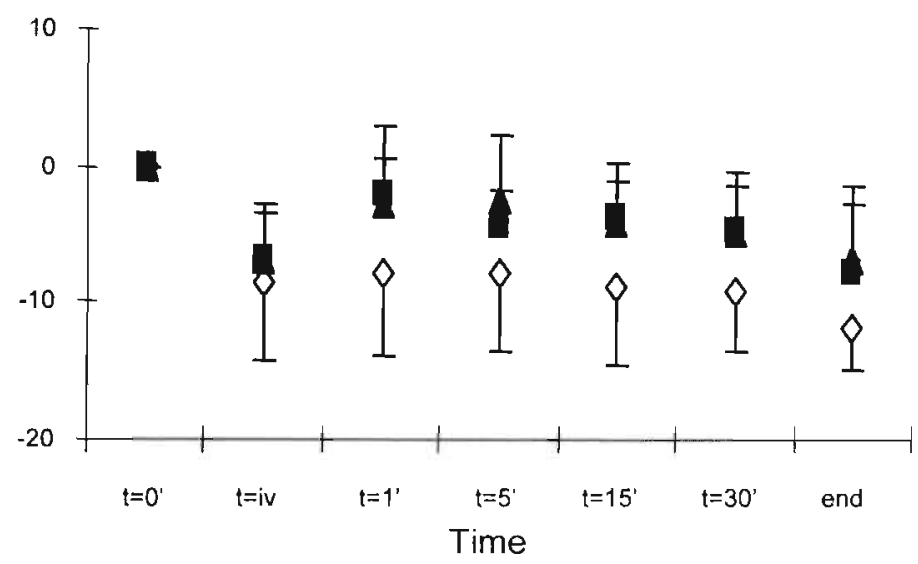

Figure 4.1 Blood volume course: percentage changes in blood volume versus baseline. Closed square is study with intravenous albumin, open diamant is study with intravenous saline, and closed triangle is study with intravenous hydroxyethylstarch.

\section{Laboratory parameters}

The laboratory data are presented in Table 4.2. The change in serum sodium was comparable between the three treatment sessions. At all sessions there was a significant increase in ionized calcium and a significant decrease in blood urea nitrogen (BUN). Among the three sessions there were no significant differences in the change in ionized calcium and BUN. 
Table 4.2 Laboratory parameters

\begin{tabular}{lllllll}
\hline Parameter & \multicolumn{2}{l}{ Saline (3\%) } & \multicolumn{2}{l}{ Albumin $(20 \%)$} & \multicolumn{2}{l}{ HES (10\%) } \\
& $\mathbf{t}=\mathbf{0}$ & $\mathbf{t}=$ end & $\mathbf{t}=\mathbf{0}$ & $\mathbf{t}=$ end & $\mathbf{t = 0}$ & $\mathbf{t = \text { end }}$ \\
\hline Sudium (mmol/L) & 138.2 & 135.8 & 135.6 & 136.8 & 137.5 & 136.4 \\
& $(4.6)$ & $(2.2)$ & $(3.2)$ & $(3.1)$ & $(3.9)$ & $(3.8)$ \\
$\mathrm{j}-\mathrm{Ca}(\mathrm{mmol} / \mathrm{L})$ & 1.20 & 1.31 & 1.24 & 1.31 & 1.20 & 1.34 \\
& $(0.07)$ & $(0.03)^{\mathrm{h}}$ & $(0.11)$ & $(0.07)^{\mathrm{b}}$ & $(0.07)$ & $(0.08)^{\mathrm{b}}$ \\
$\mathrm{BUN}(\mathrm{mmol} / \mathrm{L})$ & 24.23 & 7.03 & 29.30 & 8.77 & 26.78 & 7.88 \\
& $(4.81)$ & $(1.34)^{\mathrm{b}}$ & $(5.78)$ & $(2.27)^{\mathrm{b}}$ & $(4.78)$ & $(2.06)^{\mathrm{b}}$ \\
\hline
\end{tabular}

Data are given in mean (SD). Laboratory data before the start of the dialysis $(t=0)$, and at the end of the dialysis session ( $\mathrm{t}=\mathrm{end}$ ). BUN is blood urea nitrogen; $\mathrm{i}-\mathrm{Ca}$, ionized calcium.

$\mathrm{p}<0.05, \mathrm{t}=$ end versus $\mathrm{t}=0$.

\section{Other parameters}

The interdialytic weight gain after the treatment sessions with saline (3\%), albumin $(20 \%)$ and HES (10\%) was respectively $2.63 \pm 0.38 \mathrm{~kg}, 2.43 \pm 0.34 \mathrm{~kg}$, and $2.63 \pm 0.71 \mathrm{~kg}$. Between the 3 treatment sessions there were no significant differences in interdialytic weight gain. Three patients experienced a hypotensive episode when using saline and one patient when using albumin. However, ultrafiltration could be continued when the patients were placed in the Trendelenburg position.

\section{Discussion}

In this study we compared the efficacy of hypertonic saline (3\%), albumin (20\%) and HES (10\%) on systolic blood pressure course during UF+HD in cardiaccompromised dialysis patients, who often suffered of hypotensive episodes. Our results show that HES is an effective solution in maintaining the SBP course, similar to albumin but superior to hypertonic saline.

It has been shown that preventing the reduction in plasma osmolality during hemodialysis could improve hemodynamic instability, because it avoids or decreases the water inflow into the intracellular compartment and preserves the available amount of interstitial fluid to compensate for the intravascular hypovolemia ${ }^{9}$. Limiting the reduction in extracellular osmolality by injecting hypertonic fluids is generally advocated as an efficient treatment of symptomatic hypotension ${ }^{10}$. However, repeated intravenous injections of saline may lead to an increase in the exchangeable sodium pool, and as a consequence of thirst, in an increase in interdialytic weight gain and hypertension which may be of great clinical importance in vulnerable cardiac-compromised dialysis patients ${ }^{11.12}$. In an 
earlier study in stable dialysis patients, we showed a superior preservation of BV with HES compared with isotonic saline, without any side-effect ${ }^{21}$. Therefore, we compared in this study 2 hypertonic fluids: saline (3\%) and HES (10\%), which is also a hyperoncotic fluid, and albumin, a hyperoncotic fluid with an osmolality in between 260 and $280 \mathrm{mOsmol} / \mathrm{L}$ regarding their effect on SBP and BV. Saline (3\%) and HES (10\%) were administered in such amounts that a similar osmolar load was given. We found that SBP was better maintained with HES compared with saline, which suggests that it is not only the effect on osmolality but also the additional oncotic effect of HES which is responsible for the distinct and prolonged effect on SBP course. This has also been observed by Gong et $\mathrm{al}^{40}$, who compared hypertonic saline solutions with dextran, which has also oncotic effects. They found that the blood pressure response was more prolonged with $23 \%$ saturated hypertonic saline and dextran compared with hypertonic saline alone (7.5\%). However, in their study, in a great number of patients repeated intravenous infusions were needed to maintain SBP, whereas we only gave a single infusion. This difference could be explained by differences in the ultrafiltration rates between their study and ours. Unfortunately, data on the ultrafiltration rate is lacking in the study of Gong et $\mathrm{al}^{40}$.

In the present study SBP was also better maintained with albumin compared with hypertonic saline, which could be caused by the oncotic effects of albumin. These data are also comparable with the results of our previous study in which we showed that SBP, although statistically not significant, was better maintained with albumin compared with isotonic saline ${ }^{21}$. When we compared the effect of HES with albumin, we found that there were no significant differences in SBP course after the intravenous infusion of either of the 2 fluids. However, the increase in SBP, although not significant, was greater with HES compared with albumin. It cannot be excluded that the higher sodium concentration of HES compared with albumin has an additional beneficial effect on the SBP course ${ }^{21}$. Nevertheless, this difference in sodium concentration does not appear to introduce untoward clinical effects, as the change in serum sodium during dialysis and inter-dialytic weight gain the days after the treatment were comparable between the three sessions.

Regarding the decrease in BV volume from baseline to the end of the dialysis treatment, the decrease in BV was significantly more pronounced with hypertonic saline compared with HES and albumin, which could also be explained by the oncotic effect of HES and albumin. When we compared the changes in BV from the time of infusion versus the end of the dialysis session, BV also decreased with saline and albumin and remained unchanged with HES. However, these differences did not reach statistical significance.

Comparable to our previous study, also in this study none of the patients experienced side-effects with either of the fluids during or after the dialysis session $^{21}$. HES also did not cause intravascular volume overload in these cardiac- 
compromised patients, as blood volume declined gradually to the pre-infusion values during the remaining time of the dialysis session.

From this study we conclude that HES is an effective fluid in maintaining systolic blood pressure and preserving blood volume in hypotensive prone dialysis patients comparable to albumin, but superior to hypertonic saline. Given the costs and sideeffects of albumin, HES should be preferred. 


\section{References}

1. Zucchelli P, Santoro A. Dialysis-induced hypotension: a fresh look at pathophysiology. Blood Purif 1993;11:981-5.

2. Ritz E, Rambausek M, Mall G, Ruffman K, Mandelbaum A. Cardiac changes to uremia and their possible relation to cardiovascular instability on dialysis. Contrib Nephrol 1990;78:221-9.

3. Henderson LW. Hemodynamic instability during hemodialysis. Kidney Int 1986;30:605-12.

4. Palmer F, Henrich WL. The effect of dialysis on left ventricular contractility. In Parfrey PS, Harnett JD eds. Cardiac dysfunction in chronic uremia. Dordrecht; Kluwer Academic, 1992;171-86.

5. Yellin EL, Nikolic S, Frater RWM. Left ventricular filling and diastolic function. Prog Cardiovasc Res 1990;32:247-71.

6. Leunissen KML, Kooman JP, van Kuijk WHM, Luik AJ, van der Sande FM, van Hooff JP Preventing haemodynamic instability in patients at risk for intra-dialytic hypotension. Nephrol Dial Transplant 1996;11(2):S11-S5.

7. Hinds CJ, Watson D. Intensive care. WB Saunders Co 1996;72.

8. Mann H, Ernst E, Gladziwa U, Schallenberg U, Stiller S. Changes in blood volume during dialysis are dependent upon the rate and amount of ultratiltrate. Trans Am Soc Art. Org 1989;35;250-2.

9. Rodrigo F, Shideman J, McHugh R, Buselmeier T, Kjellstrand C. Osmolality changes during haemodialysis: nitural history, clinical correlations, and influence of dialysate glucose and intravenous mannitol. Ann Int Med 1977;86:554-61.

10. Mujais SK, Ing T, Kjellstrand C. Acute complications of hemodialysis and their prevention and treatment. In: Replacement of Renal Function by Dialysis, $4^{\text {th }}$ ed., edited by Winchester JF, Washington, Kluwer Academic Publishers, 1995;698-724.

11. Rohson M, Oren A, Ravid M. Dialysate sodium concentration, hypertension, and pulmonary cuema in haemodialysis patients. Dial Transplant 1978;7:678-9.

12. Wilkinson R, Barber SG, Robson V. Cramps, thirst and hypertension in hatmodialysis patients- the influence of dialysate sodium concentration. Clin Nephrol 1977;7:101-5.

13. Bergonzi G, Paties C, Vassallo G, Zangrandi A, Poisetti PG, Ballochi S, Fontana F. Scarpioni L. Dextran deposits in tissues of patients undergoing haemodialysis. Nephrol Dial Transplant 1990;5:54-8.

14. Richter AW, Hedin H. Dextran hypersensitivity. Immunology Today 1982;3:132-8.

15. Better OS, Rubinstein I, Winaver JM, Knochel P. Mannitol therapy revisited (19401997) Kidney Int 1997;51:886-94.

16. Aviram A, Pfau A, Czackes JW, Ullman TD. Hyperosmolality with hyponatremia caused by inappropriate administration of mannitol. Am J Med 1967;42:648-50.

17. Dorman HR, Sondheimer JH, Cadnapaphornchai P. Mannitol-induced acute renal failure. Medicine (Baltimore) 1990;69:153-9. 
18. Conte G, Dal Canton A, Imperatore P, De Nicola L, Gigliotti G, Pisanti A, Memoli B, Fuiano G, Esposito C, Andreucci VE. Acute increase in plasma osmolality as a cause of hyperkalemia in patients with renal failure. Kidney Int 1990;38:301-7.

19. Rodriquez M, Llach F, Pederson JA, Palma A. Changes in plasma oncotic pressure during isolated ultrafiltration Kidney Int 1982;21:519-23.

20. Cochrane Injuries Group Albumin Reviewers. Human albumin administration in critically ill patients: systemic review of randomised controlled trials. BMJ 1998;317:235-40.

21. van der Sande FM, Kooman JP, Barendregt JNM, Nieman FHM, Leunissen KML. Effect of intravenous saline, albumin or hydroxyethylstarch on blood volume during combined ultrafiltration and hemodialysis. J Am Soc Nephrol 1999;10:1303-8.

22. Hankeln K, Radel C, Beez M, Laniewsky P, Bohmert F. Comparison of hydroxyethylstarch and lactated Ringer's solution on hemodynamics and oxygen transport of critically ill patients in prospective crossover studies. Crit Care Med 1989; 17:133-5.

23. Boldt J, Heesen M, Muller M, Pabsdorf M, Hempelmann G. The effects of albumin versus hydroxyethyl starch on cardiorespiratory and circulatory variables in critically ill patients. Anest Analg 1996;83:254-61.

24. Weidler B, von Bormann B, Sommermeyer K, Lohmann E, Peil J, Hempelmann G. Pharmakokinetische Merkmal als Kriterien für den klinische Einsatz von Hydroxyethylstarke. Arnzheim.-Forsch Drug Res 1991;41:494-8.

25. The Criteria Committee of the New York Heart Association. Diseases of th Heart and Blood Vessels; Nomenclature and Criteria for Diagnosis. 1964 6th Ed. Little, Brown, Boston.

26. Dodge HT, Sheehan H. Quantitative contrast angiography for assessment of ventricular performance in heart disease. J Am Coll Cardiol 1983;1:73-81.

27. Leunissen KML, Kouw P, Kooman JP, Cheriex EC, DeVries PM, Donker AJ, van Hooff JP. New techniques to determine fluid status in hemodialyzed patients. Kidney Int 1993;43:S50-S6.

28. Maynard JC, Cruz C, Kleerekoper M, Levin NW: Blood pressure response to changes in serum ionized calcium during haemodialysis. Ann Intern Med 1986; 104:358-61.

29. Fellner SK, Lang RM, Neumann A, Spencer KT, Bushinsky DA, Borow KM: Physiological mechanism for calcium-induced changes in systemic arterial pressure in stable dialysis patients. Hypert 1989;13:213-8.

30. Henrich WL, Hunt JM, Nixon JV: Increased ionized calcium and left ventricular contractility during haemodialysis. N Eng J Med 1984:310:19-23.

31. van der Sande FM, Cheriex EC, van Kuijk WHM, Leunissen KML. Effect of dialysate calcium concentrations on intradialytic blood pressure course in cardiaccompromised patients. Am J Kidney Dis 1998;32:125-31. 
32. van Kuijk WHM, Wirtz JJJM, Grave W, de Heer F, Menheere PPCA, van Hooff JP, Leunissen KML. Vascular reactivity during combined ultrafiltrationhemodialysis: influence of dialysate sodium. Nephrol Dial Transplant 1995;11:323-8.

33. van Kuijk WHM, Luik AJ, de Leeuw PW, van Hooff JP, Niemann FHM, Habets HML, Leunissen KML. Vascular reactivity during hemodialysis and isolated ultrafiltration: thermal influences. Nephrol Dial Transplant 1995;10:1852-8.

34. Fine A, Penner B. The protective effect of cool temperature dialysate is dependent on patients' predialysis temperature. Am J Kidney Dis 1996;28:262-5.

35. van der Sande FM, Kooman JP, Burema JHGA, Hameleers P, Kerkhofs AMM, Barendregt JM, Leunissen KML. Effect of dialysate temperature on energy balance during haemodialysis; quantification of energy transfer from the extracorporeal circuit to the patient. Am J Kidney Dis 1999;33:1115-21.

36. Maeda $K$, Morita $H$, Shizato $T$, Vega $B V$, Kobayakawa $H$, Ishihara $T$, Inagaki $H$, Igarashi I, Kitano T. Role of hypovolemia in dialysis-induced hypotension. Artif Organs $1988 ; 12 ; 116-21$.

37. Steuer RR, Harris DH, Conis JM. A new technique for monitoring hematocrit and circulating blood volume: Its application in renal dialysis. Dialysis and Transplantation 1993;22:260-5.

38. Leypoldt JK, Cheung AK, Steuer RR, Haris DH, Conis JM. Determination of circulating blood volume by continuously monitoring hematocrit during hemodialysis J Am Soc Nep̣hrol 1995:6:214-9.

39. Stevens J. Chapter 13.7: Should we use the univariate or the multivariate approach? In: Applied multivariate statistics for the social sciences. Hillsdale, New Yersey, Lawrence Erlbaum Associates, Publishers 1992;454-6.

40. Gong R, Lindberg J, Abrams J, Whitaker WR, Wade CE, Gouge S. Comparison of hypertonic saline and dextran in dialysis-induced-hypotension. J Am Soc Neplirol 1993:3: 1808-12. 


\section{Chapter 5}

Effect of dialysate calcium concentrations on intradialytic blood pressure course in cardiac-compromised patients

FM van der Sande, EC Cheriex, WHM van Kuijk, KML Leunissen

Am J Kidney Dis 1998;32:125-31 


\section{Abstract}

To prevent hypercalcemia in the treatment of secondary hyperparathyroidism, low calcium (L-Ca) dialysate is advocated. However, changes in ionized calcium (i-Ca) levels have a pivotal role in myocardial contraction and could influence blood pressure stability during dialysis. Recently, our group found in patients with a normal cardiac function a significant decrease in blood pressure (decrease in systolic blood pressure (SBP): $-13 \mathrm{mmHg}$ and decrease in mean arterial pressure (MAP): $-7 \mathrm{mmHg}$ ) during dialysis with $\mathrm{L}-\mathrm{Ca}$ dialysate compared with high calcium $(\mathrm{H}-\mathrm{Ca})$ dialysate, and this was mainly related to a decreased left ventricular contractility with use of $\mathrm{L}-\mathrm{Ca}$ dialysate. On the basis of these data, it could be expected that changes in i-Ca levels during dialysis are of more clinical importance in cardiac-compromised patients (CCpts), New York Heart Association classifications III and IV. In this study, the effects of L-Ca dialysate $(1.25 \mathrm{mmol} / \mathrm{L})$ and $\mathrm{H}-\mathrm{Ca}$ dialysate $(1.75 \mathrm{mmol} / \mathrm{L})$ on arterial blood pressure parameters (systolic (SBP), diastolic (DBP), and mean arterial blood pressure (MAP)), heart rate, stroke distance (SDist) and minute distance (MDist) during 3 hrs of a standardized ultrafiltration / hemodialysis (UF $+\mathrm{HD}$ ) in nine CCpts was investigated. i-Ca levels increased significantly with $\mathrm{H}-\mathrm{Ca}$ dialysate $\mathrm{UF}+\mathrm{HD}$, whereas there was no change with L-Ca dialysate. SBP, DBP, and MAP decreased statistically and clinically significantly during UF + HD with the use of L-Ca dialysate and were significantly lower with the use of $\mathrm{L}-\mathrm{Ca}$ dialysate compared with $\mathrm{H}-\mathrm{Ca}$ dialysate. SDist and MDist decreased significantly with L-Ca dialysate, whereas there were no changes in SDist and MDist with $\mathrm{H}-\mathrm{Ca}$ dialysate. The predialysis and postdialysis index of systemic vascular resistance (SVRi) was similar between L-Ca dialysate and $\mathrm{H}-\mathrm{Ca}$ dialysate use. Between the two groups, there were no significant differences in changes in SVRi.

From this study, we can conclude that changes in i-Ca levels are a very important determinant of the blood pressure response during UF+HD in CCpts, and this response is mediated by changes in myocardial contractility. 


\section{Introduction}

Hemodialysis associated hypotension remains a significant cause of patient morbidity. With an increasing number of elderly dialysis patients and an increasing number of cardiovascular-compromised dialysis patients, the incidence of intradialytic hypotension is expected to increase ${ }^{1,2}$. The pathophysiological mechanism of hypotensive periods during hemodialysis is multifactorial, but the two major factors involved are the decrease in plasma volume and the inability of various cardiovascular regulatory mechanisms to compensate for the decrease in blood pressure ${ }^{3.4}$. It is expected that especially in patients with a compromised cardiovascular system, the risk of symptomatic hypotension is high ${ }^{5.7}$. Symptomatic hypotension will not only endanger the patient, but will also reduce the efficacy of the dialysis therapy.

The concentration of calcium in the dialysate can vary over a wide range. Increased use of calcium salts instead of aluminum salts as a phosphate binder has increased the incidence of hypercalcemia in the chronic hemodialysis population ${ }^{8}$. It is advised to use lower dialysate calcium concentrations (L-Ca) to prevent or to treat hypercalcemia ${ }^{8.13}$. It is also known that calcium ions can have a pivotal role in the contractile process of both vascular smooth muscle cells and cardiac myocytes. Recent studies have shown that changes in ionized calcium (i-Ca) levels have significant hemodynamic effects ${ }^{14,15}$. This effect of dialysate calcium concentration on blood pressure seems to be mediated predominantly through changes in myocardial contractility, although several investigators also found a change in vascular reactivity ${ }^{14-18}$. Recently van Kuijk et al ${ }^{19}$ reported a statistically significant decrease in blood pressure during dialysis with L-Ca dialysate compared with high calcium ( $\mathrm{H}-\mathrm{Ca}$ ) dialysate in patients with normal cardiac function, and this difference was mainly related to a decreased left ventricular contractility during the use of L-Ca dialysate. Although statistically significant, the differences in blood pressure were clinically not very striking. However, on the basis of data in patients with normal cardiac function, it could be expected that changes in $\mathrm{i}-\mathrm{Ca}$ levels during dialysis are of more clinical importance in cardiac-compromised patients (CCpts). Therefore, in this clinical study, we investigated, as an acute intervention, the effects of changes in $\mathrm{i}-\mathrm{Ca}$ levels at two different dialysate calcium concentrations on hemodynamic parameters and on cardiac reactivity during combined ultrafiltration / hemodialysis (UF +HD) in CCpts. 


\section{Material and methods}

\section{Subjects and dialysis}

After obtaining informed consent for participation in the study, 9 patients undergoing intermittent hemodialysis were included. All patients were CCpts defined as complaining of symptoms with less than normal activity and symptoms at rest (New York Heart Association classifications III and IV). Moreover, these patients had a mild to severe left ventricular dysfunction defined as an ejection fraction of less than $40 \%{ }^{20}$.

The study included one woman and eight men with a mean age of 70.5 years (range, 55 to 77), and a mean time on hemodialysis of 21 months (range, 2 to 48). The cause of renal failure was chronic glomerulonephritis (1 patient), antiglomerular basement membrane nephritis (1 patient), bilateral renal artery stenosis (2 patients), nephrosclerosis (4 patients) and unknown diagnosis (1 patient). The cause of cardiac failure was anterior myocardial infarction (3 patients), posterior myocardial infarction (1 patient), inferior myocardial infarction (1 patient), inferior and anterior myocardial infarction (1 patient), inferior and posterior myocardial infarction (1 patient) and concentric left ventricular hypertrophy ( 2 patients).

The patients received the following medications: angiotensin-converting, enzyme, inhibitors ( 3 patients), $\beta$-blocking agents ( 4 patients), calcium channel blocking agents (4 patients), $\alpha$-blocking agents ( 3 patients), nitrates (5 patients), no medication (2 patients).

With each patient serving as his or her own control, measurements during this acute intervention study were performed in each patient during two standardized dialysis sessions of $3 \mathrm{hrs}$ UF + HD that only differed in the dialysate calcium concentration: $1.25 \mathrm{mmol} / \mathrm{L}$ (L-Ca dialysate) and $1.75 \mathrm{mmol} / \mathrm{L}$ (H-Ca dialysate). The order of the treatment was randomized. Only the technician of the dialysis department knew the dialysate calcium concentration. In daily clinical practice, our patients are treated three times a week for at least $4 \mathrm{hrs}$ to achieve a $\mathrm{Kt} / \mathrm{V}$ of greater than 1.1 .

The patients were studied on their regular day of dialysis. Interdialytic weight gain was $2 \mathrm{~kg}$ greater than their dry weight that was estimated by echography of the inferior caval vein, to achieve a standardized ultrafiltration rate of $0.7 \mathrm{~L} / \mathrm{hr}^{2}$. In order to prevent the bias of the hemodynamic effects of underhydration, the patients were ultrafiltrated to $\pm 500 \mathrm{~g}$ above their dry weight. All vasoactive medication was continued to study daily clinical practice in the treatment of severely CCpts who were dependent on cardiovascular medication. The patients also received their medication on the day of the study. Dialysis was performed with an AK-100 dialysis monitor (Gambro, Lund, Sweden) using hemophane 
membranes (GFS-16; Gambro) in all treatments. The composition of the dialysate was sodium $141 \mathrm{mmol} / \mathrm{L}$, potassium $2.0 \mathrm{mmol} / \mathrm{L}$, bicarbonate was individualized (between 30 and $34 \mathrm{mmol} / \mathrm{L}$ ), acetate $3 \mathrm{mmol} / \mathrm{L}$, magnesium $0.5 \mathrm{mmol} / \mathrm{L}$ and chloride $108 \mathrm{mmol} / \mathrm{L}$. The dialysate calcium concentration was $1.25 \mathrm{mmol} / \mathrm{L}$ or $1.75 \mathrm{mmol} / \mathrm{L}$. The dialysate temperature was $37.5^{\circ} \mathrm{C}$ in both study periods. Blood flow was $250 \mathrm{~mL} / \mathrm{min}$ and dialysate flow $500 \mathrm{~mL} / \mathrm{min}$.

\section{Methods}

Arterial blood pressure (systolic blood pressure (SBP), diastolic blood pressure (DBP), and mean arterial blood pressure (MAP)) was measured with an automatic blood pressure monitor (Dinamap 1486 SX, Critikon Inc, a division of Johnson \& Johnson Medical Inc, Arlington, TX). Measurements were performed before dialysis and every $10 \mathrm{~min}$ during dialysis. The mean value of three consecutive measurements was calculated.

Before as well as immediately after dialysis, a two-dimensional echocardiogram was obtained with the patient in the left lateral decubitus position for determination of stroke volume and cardiac output. For serial calculation of cardiac output in patients we routinely used continuous Doppler echocardiography, using a standalone $1.9-\mathrm{MHz}$ transducer placed at the point of maximal apical impulse or more to the left of that apical impulse, guided by signal intensity and maximal velocity. The total velocity integral (TVI) of blood flow across the aortic valve is nomially combined with the aortic valve orifice diameter to calculate struke volume. The reported variability for this method is estimated to be $2 \%$. Because patients undergoing chronic hemodialysis tend to have more calcifications in the aortic valve, or even have a clearly decreased orifice caused by calcifications, we did not use the valve area for calculation of cardiac output, but only calculated the TVI and heart rate to get intormation about relative changes in cardiac output. This TVI method is called stroke distance (SDist) and, if multiplied by heart rate, minute distance (MDist) ${ }^{23-25}$. The index of systemic vascular resistance (SVRi) can be obtained by dividing MAP by the MDist. This figure is then multiplied by 10,000 to achieve approximate numerical equivalents to the SVRi that is derived invasively ${ }^{26}$. The ejection fraction was measured according to the method of Dodge ${ }^{27}$.

Changes in relative blood volume (BV) were measured continuously and noninvasively by means of an optical reflection method. The optical sensor was clipped on the arterial line (Haemoguard 2000, Sanofi Sante, Maassluis, the Netherlands). The amount of reflected light has been shown to correlate well with the erythrocyte concentration $(r=0.95 ; p<0.001)^{2 k}$. The baseline value was obtained after $2 \mathrm{~min}$ of extracorporeal circulation at a blood flow of $250 \mathrm{~mL} / \mathrm{min}$ without ultrafiltration to exclude the influence of saline (recirculation) present in the extracorporeal circuit at the start of the dialysis. 
Before as well as after $3 \mathrm{hrs}$ of $\mathrm{UF}+\mathrm{HD}$, blood was withdrawn for the determination of: total $\mathrm{CO}_{2}$, osmolality (Fiske 2400, Copenhagen, Denmark), sodium, and colloid osmotic pressure. Plasma i-Ca was determined (ABL 505; Radiometer, Bronshoj, Denmark) at predialysis as well as after 3 hrs of UF +HD. The normal range of $\mathrm{i}-\mathrm{Ca}$ in our hospital is between 1.10 and $1.30 \mathrm{mmol} / \mathrm{L}$.

\section{Statistical analysis}

The comparison between predialysis hemodynamic parameters, changes in hemodynamic parameters within each treatment, and differences between treatments were analyzed by repeated measurements multivariate analysis of variance (SPSS$\mathrm{pc}$ version 6.1). All laboratory parameters were analyzed by Friedman analysis of variance, and if appropriate, by the Wilcoxon's signed rank test. All values are expressed as mean \pm standard deviation.

\section{Results}

The predialysis weights in $\mathrm{L}-\mathrm{Ca}$ and $\mathrm{H}-\mathrm{Ca}$ dialysate groups were respectively $70.81 \pm 7.23 \mathrm{~kg}$ and $70.94 \pm 7.15 \mathrm{~kg}$, respectively. The mean ultrafiltration rate was $0.70 \pm 0.13 \mathrm{~L} / \mathrm{hr}$ and $0.72 \pm 0.13 \mathrm{~L} / \mathrm{hr}$ in both groups. Between the two groups, there were no significant differences in predialysis weight and ultrafiltration rate.

In Table 5.1 the predialysis echocardiographic data are listed. The patients had increased left ventricular end-diastolic and systolic diameter, increased left atrial diameter, and increased diastolic left ventricular septal and diastolic posterior wall thickness. Moreover, all patients had an increased left ventricular mass and mass index. In all patients there were severe aortic and mitral valves insufficiencies.

\section{Changes in laboratory parameters}

Plasma i-Ca levels remained unchanged during L-Ca dialysate (before $1.25 \pm 0.08 \mathrm{mmol} / \mathrm{L}$; after $1.20 \pm 0.06 \mathrm{mmol} / \mathrm{L}$ ) and increased significantly during $\mathrm{H}$-Ca dialysate (before $1.22 \pm 0.11 \mathrm{mmol} / \mathrm{L}$; after $1.41 \pm 0.06 \mathrm{mmol} / \mathrm{L}$ ). As a result, the increase in plasma $\mathrm{i}-\mathrm{Ca}$ levels was significantly higher during $\mathrm{H}$-Ca dialysate compared with L-Ca dialysate (Table 5.2). The total $\mathrm{CO}_{2}$ concentration increased significantly during L-Ca dialysate (before, $24 \pm 2 \mathrm{mmol} / \mathrm{L}$; after $29 \pm 1 \mathrm{mmol} / \mathrm{L}$ ) and $\mathrm{H}$-Ca dialysate (before, $24 \pm 2 \mathrm{mmol} / \mathrm{L}$; after $28 \pm 2 \mathrm{mmol} / \mathrm{L}$ ). The predialysis total $\mathrm{CO}_{2}$ concentration and increase in total $\mathrm{CO}_{2}$ were similar between L-Ca and $\mathrm{H}$-Ca dialysate groups. All other changes in laboratory parameters were also similar during both treatments, and between the two groups there were no significant differences. 
Table 5.1 Predialysis echocardiographic parameters.

\begin{tabular}{lrlc}
\hline Parameter & \multicolumn{2}{c}{ Patient data } & Normal values \\
\hline Left ventricular & 58.8 & $(4.2)$ & $<55$ \\
End-diastolic diameter (mm) & 47.6 & $(4.3)$ & $<41$ \\
End-systolic diameter (mm) & 9.9 & $(0.9)$ & $<8$ \\
IVSEDWT (mm) & 9.8 & $(0.7)$ & $<8$ \\
PWEDWT (mm) & 50.1 & $(4.8)$ & $<40$ \\
Left atrial diameter (mm) & 175.6 & $(35.4)$ & \\
End-diastolic volume (mL) & 105.5 & $(27.5)$ & $<120$ \\
End-systolic volume (mL) & 165.0 & $(35.1)$ & $>55^{20,35}$ \\
LV-mass index (g/m²) & 291.6 & $(50.9)$ & Variable \\
LV-mass (g) & 34.1 & $(8.5)$ & 0 \\
LVEF (\%) & 0.67 & $(0.32)$ & 0 \\
E/A ratio (MV flow) & 11.2 & $(8.8)$ & 0 \\
LV wall motion score & 2.0 & $(0.8)$ & \\
Aortic valve insufficiency & 3.0 & $(0.5)$ & \\
Mitral valve insufficiency & & & \\
\hline
\end{tabular}

Data are expressed as mean (SD). IVSEDWT $=$ intraventricular septal end-diastolic wall thickness; PWEDWT $=$ posterior wall end-diastolic wall thickness; $E F=$ ejection fraction; $M V$ flow $=$ mitral valve flow; $\mathrm{LV}=$ left ventricular; $\mathrm{E} / \mathrm{A}=$ early to late atrial peak. " Depending on patient conditions and intrinsic factors ${ }^{36}$.

Table 5.2 Predialysis and postdialysis laboratory parameters.

\begin{tabular}{lclllllll}
\hline & \multicolumn{3}{c}{ L-Ca dialysate } & \multicolumn{5}{c}{ H-Ca dialysate } \\
& \multicolumn{1}{c}{ Predialysis } & Postdialysis & \multicolumn{2}{c}{ Predialysis } & Postdialysis \\
\hline i-Ca $(\mathrm{mmol} / \mathrm{L})$ & 1.25 & $(0.08)$ & 1.20 & $(0.06)$ & 1.22 & $(0.11)$ & 1.41 & $(0.06)^{\prime .2}$ \\
Sodium (mmol/L) & 140 & $(3)$ & 139 & $(2)$ & 139 & $(3)$ & 139 & $(3)$ \\
$\mathrm{COP}(\mathrm{mmHg})$ & 25.1 & $(4.6)$ & 28.1 & $(6.1)^{\prime}$ & 25.1 & $(3.8)$ & 29.6 & $(6.1)^{\prime}$ \\
Osmol $(\mathrm{mOsmol} / \mathrm{kg})$ & 308 & $(11)$ & 289 & $(8)^{\prime}$ & 307 & $(9)$ & 284 & $(9)^{\prime}$ \\
$\mathrm{tCO}_{2}(\mathrm{mmol} / \mathrm{L})$ & 24 & $(2)$ & 29 & $(1)^{\prime}$ & 24 & $(2)$ & 28 & $(2)^{\prime}$ \\
\hline
\end{tabular}

Values are expressed as mean (SD). $\mathrm{COP}=$ colloid osmotic pressure; $\mathrm{tCO}_{2}=$ total carbon dioxide.

Post vs. pre: ${ }^{1} \mathrm{p}<0.05$. L-Ca dialysate vs. H-Ca dialysate: ${ }^{2} \mathrm{p}<0.001$.

\section{Changes in hemodynamic parameters}

There were no significant differences in predialysis SBP, DBP, and MAP between $\mathrm{L}-\mathrm{Ca}$ and $\mathrm{H}-\mathrm{Ca}$ dialysate groups. MAP decreased significantly during $\mathrm{L}-\mathrm{Ca}$ 
dialysate and was significantly lower compared with dialysis with $\mathrm{H}$-Ca dialysate (Figure 5.1 and 5.2). Table 5.3 shows the changes in hemodynamic parameters and BV. During L-Ca dialysate dialysis SBP, DBP, and MAP decreased significantly: 27 (4), 7 (2) and 15 (4) $\mathrm{mmHg}$. During H-Ca dialysate dialysis only SBP decreased significantly, by 10 (5) $\mathrm{mmHg}$, whereas $\mathrm{DBP}$ and MAP remained unchanged. However, with similar changes in BV, SBP, DBP and MAP were all significantly higher during dialysis with $\mathrm{H}-\mathrm{Ca}$ dialysate compared with $\mathrm{L}-\mathrm{Ca}$ dialysate. Moreover, during the L-Ca intervention treatment, blood pressure continued to decrease, whereas during $\mathrm{H}-\mathrm{Ca}$ treatment blood pressure stabilized after $60 \mathrm{~min}$ and increased thereafter (Figure 5.1), whereas BV changes were similar (Table 5.2). Therefore, there is a significantly different course of blood pressure during $\mathrm{L}-\mathrm{Ca}$ and $\mathrm{H}-\mathrm{Ca}$ dialysis in the same patients.

Looking at the use of a particular class of antihypertensive medication given in our patients and changes in MAP, we could not find a relation in changes in MAP during dialysis with $\mathrm{L}-\mathrm{Ca}$ or $\mathrm{H}-\mathrm{Ca}$ dialysate in those patients who used antihypertensive medication compared with those who did not.

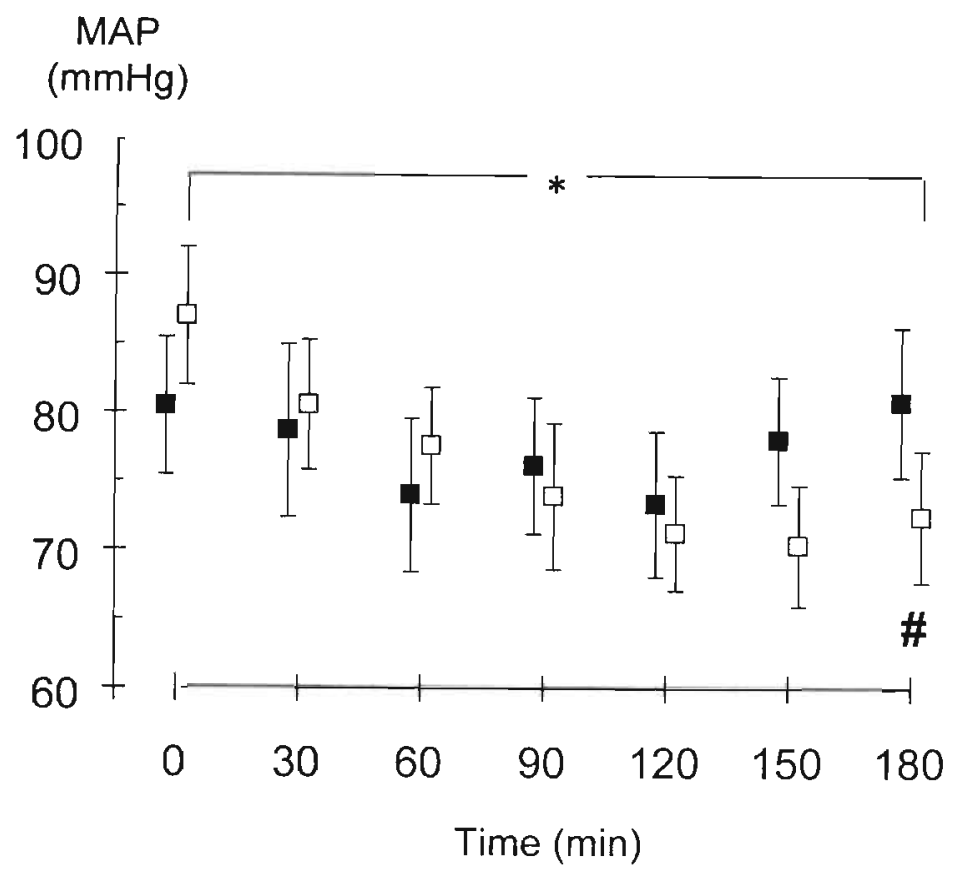

Figure 5.1 MAP in millimeters of mercury with L-Ca dialysate (open squares) and $\mathrm{H}-\mathrm{Ca}$ dialysate (closed squares) during 3 hrs of UF +HD. Measurements are given every $30 \mathrm{~min}$ (time). Averages and standard error of mean.

Post vs. pre: $" \mathrm{p}<0.05 . \mathrm{L}=\mathrm{Ca}$ dialysate vs. $\mathrm{H}-\mathrm{Ca}$ dialysate $\#<<0.05$. 


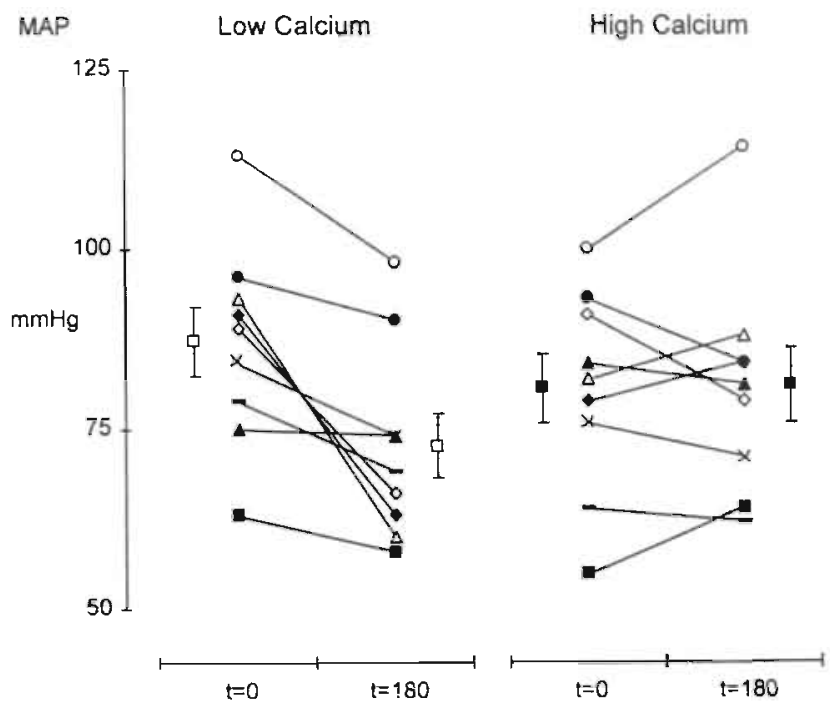

Figure 5.2 MAP in millimeters of mercury hetore and after 3 hrs of combined UF + HD with (left) $\mathrm{L}-\mathrm{Ca}$ dialysate and (right) $\mathrm{H}-\mathrm{Ca}$ dialysate. Individual parameters, averages, and standard error of mean are indicated aside.

Table 5.3

Predialysis and postdialysis hemodynamic parameters.

L-Ca dialysate

$\mathrm{H}-\mathrm{Ca}$ dialysate

\begin{tabular}{|c|c|c|c|c|c|c|c|c|}
\hline \multirow[b]{2}{*}{$\mathrm{SBP}(\mathrm{mmHg})$} & \multicolumn{2}{|c|}{ Predialysis } & \multicolumn{2}{|c|}{ Postdialysis } & \multicolumn{2}{|c|}{ Predialysis } & \multicolumn{2}{|c|}{ Postdialysis } \\
\hline & 129 & (27) & 101 & $(21)^{t}$ & 120 & (28) & 109 & $(22)^{1,2}$ \\
\hline $\mathrm{DBP}(\mathrm{mmHg})$ & 62 & $(10)$ & 55 & $(13)^{!}$ & 61 & (10) & 60 & $(11)^{2}$ \\
\hline MAP (mmHg) & 87 & (14) & 72 & $(14)^{l}$ & 80 & (14) & 81 & $(15)^{3}$ \\
\hline HR (beats/min) & 71 & (13) & 73 & (12) & 74 & (14) & 76 & (11) \\
\hline BV $(\%)$ & 100 & & 93 & (4) & 100 & & 91 & (5) \\
\hline
\end{tabular}

$\mathrm{SBP}=$ systolic blood pressure; $\mathrm{DBP}=$ diastolic blood pressure; $\mathrm{MAP}=$ mean arterial pressure; $\mathrm{HR}=$ heart rate: $\mathrm{BV}=$ blood volume. Mean (SD). Post vs. pre: ${ }^{1} \mathrm{p}<0.01 .^{2} \mathrm{p}<0.05$. L-Ca dialysate vs. H-Ca dialysate: ${ }^{3} \mathrm{p}<0.001$.

\section{Changes in echocardiographic parameters}

The echocardiographic parameters are shown in Table 5.4. With a similar predialysis SDist and MDist with both L-Ca and $\mathrm{H}-\mathrm{Ca}$ dialysate, SDist and MDist. decreased significantly in the L-Ca dialysate group, whereas in the $\mathrm{H}$-Ca dialysate group SDist and MDist remained unchanged. Between the two groups the changes in SDist and MDist did not reach statistical significance. 
The predialysis and postdialysis SVRi's were similar between $\mathrm{L}-\mathrm{Ca}$ and $\mathrm{H}-\mathrm{Ca}$ dialysate groups. Between the two groups, there were no significant differences in changes in SVRi.

Table 5.4 Predialysis and postdialysis echocardiugraphic parameters.

\begin{tabular}{lrlrlrlll}
\hline & \multicolumn{3}{c}{ L-Ca dialysate } & \multicolumn{4}{c}{ H-Ca dialysate } \\
& \multicolumn{2}{c}{ Predialysis } & Postdialysis & \multicolumn{2}{c}{ Predialysis } & Postdialysis \\
\hline Sdist (cm) & 41 & $(16)$ & 35 & $(21)^{\prime}$ & 39 & $(19)$ & 37 & $(14)$ \\
Mdist (cm.min) & 2817 & $(1025)$ & 2546 & $(1149)^{\prime}$ & 2761 & $(1188)$ & 2778 & $(1041)$ \\
SVRi (mmHg/cm.min) & 336 & $(106)$ & 327 & $(120)$ & 330 & $(120)$ & 315 & $(91)$ \\
\hline
\end{tabular}

Values expressed as mean (SD). Post vs. pre: ${ }^{1} p<0.05$.

\section{Discussion}

In this study, the effect of L-Ca and $\mathrm{H}-\mathrm{Ca}$ dialysate during UF $+\mathrm{HD}$ on hemodynamic parameters and cardiac reactivity in CCpts patients was investigated. Our results showed that dialysis with $\mathrm{H}$-Ca dialysate maintained intradialytic blood pressure stability, whereas during dialysis with L-Ca dialysate, arterial blood pressure decreased significantly. This was mainly based on differences in myocardial contractility during the clinical intervention with $\mathrm{L}-\mathrm{Ca}$ compared with H-Ca dialysate.

Calcium ions have a critical role in the contractile process of both cardiac and vascular smooth muscle cells, as well as in the release of catecholamines from adrenergic nerves ${ }^{29,30}$. In healthy individuals, serum calcium can effect blood pressure by changes in SVRi and cardiac output mediated through a change in myocardial contractility. Therefore, changes in i-Ca are potentially important denominators of the cardiovascular response during different dialysis strategies.

In our study, plasma i-Ca remained unchanged during L-Ca dialysate and increased significantly during dialysis with $\mathrm{H}-\mathrm{Ca}$ dialysate, and were significantly greater during dialysis with $\mathrm{H}$-Ca dialysate compared with $\mathrm{L}-\mathrm{Ca}$ dialysate. These data are similar with the results of previous studies, showing an increase in i-Ca levels when using a dialysate calcium concentration of $\pm 1.50 \mathrm{mmol} / \mathrm{L}$ or greater ${ }^{9.9 .19 .31-33}$. Total $\mathrm{CO}_{2}$ increased significantly during both treatments, and the increase was similar between the two treatments. Postdialysis values in our study were all greater than $25 \mathrm{mmol} / \mathrm{L}$ and less than $32 \mathrm{mmol} / \mathrm{L}$ (to prevent alkalosis) and constitute a normal correction of acidosis. It has been shown that the increase in $\mathrm{i}$-Ca levels is dependent on the degree of acidosis correction with a negative 
correlation between changes in i-Ca and changes in total $\mathrm{CO}_{2} \quad(r=-0.70$; $p<0.001)^{16}$. Therefore, in our study the effect of an inaccurate acidosis correction on the different changes in i-Ca levels could be ruled out, and the increase in $\mathrm{i}-\mathrm{Ca}$ levels must be because of the $\mathrm{H}$-Ca dialysate.

With all dialysis parameters standardized and with similar changes in relative BV, SBP, DBP, and MAP were all significantly and clinically greater during dialysis with $\mathrm{H}$-Ca dialysate compared with $\mathrm{L}-\mathrm{Ca}$ dialysate. In CC.pts, selected for their poor cardiac function, changes in i-Ca levels are a very important determinamt of the blood pressure response during UF $+\mathrm{HD}$. These results agree with observations in patients with a normal cardiac function. The authors found a positive correlation ( $\mathrm{r}$ between 0.69 and 0.74 ) between changes in i-Ca levels and arterial blood pressure during dialysis therapy ${ }^{14-16}$. In contrast, Sherman et $\mathrm{al}^{8}$, and Argiles et $\mathrm{al}^{34}$ observed a significant but small decrease in arterial blood pressure during dialysis with $\mathrm{L}-\mathrm{Ca}$ dialysate compared with $\mathrm{H}-\mathrm{Ca}$ dialysate. They concluded that their results were of clinical irrelevance. However, according to the results of the present study in cardiovascular-compromised dialysis patients it appeared that changes in i-Ca levels have a pronounced effect on the blood pressure response during dialysis, it must be considered that lowering the dialysate calcium concentration can induce severe hypotensive episodes in this group of patients.

In our study SDist and MDist as linear parameters of stroke volume and cardiac output remained unchanged during dialysis with $\mathrm{H}$-Ca dialysate and decreased significantly during dialysis with L-Ca dialysate. Other studies have also shown that increases in dialysate calcium concentrations were associated with an increase in myocardial performance (left ventricular stroke volume and cardiac output) and a significant decrease in left ventricular volume, whereas peripheral resistance remained unchanged ${ }^{15,17.19}$. In our study the calculated SVRi was similar between the $\mathrm{L}-\mathrm{Ca}$ and $\mathrm{H}-\mathrm{Ca}$ dialysate groups, before as well as after the two treatments. These data are similar with previous results from several investigators who found no significant differences in measured peripheral vascular tone and SVRi and calculated SVRi despite a significant difference in $\mathrm{i}$-Ca levels ${ }^{7.15} \cdot 18.19$. Therefore, in our study, with similar changes in relative BV and predialysis SDist and MDist, arterial blood pressure was significantly higher during dialysis with $\mathrm{H}$-Ca dialysate as a result of a stable myocardial contractility.

In conclusion, increasing the dialysate calcium concentration has a clinically important positive effect on the blood pressure response during UF+HD in CCpts. Although it is advised to use L-Ca dialysate in the treatment of hypercalcemia, on the basis of these data, H-Ca dialysate is indicated during UF + HD in CCpts. 


\section{References}

1. Laupacis A, Muirhead N, Keown P, Wong C. A disease-specific questionnaire for assessing quality of life in patients on haemodialysis. Nephron 1992;60:302.

2. Zucchelli P, Santoro A. Dialysis induced hypotension: a fresh look at pathophysiology. Blood Purif 1993;11:975-81.

3. Leunissen KML, Noordzij TC, van Hooff JP. Pathophysiological aspects of plasma volume preservation. Contrib Nephrol 1990;78:201-11.

4. Daugirdas JT. Dialysis induced hypotension; a hemodynamic analysis. Kidney Int 1991;39:233-46.

5. Tufvesion G, Geerlings W, Brumer FP, Brynger H, Dijkes SR, Ehrich JHH, Fassbinder W, Gizzoni G, Schroedt HH, Wing AJ. Combined report on regular dialysis and transplantation in Europe, XXI, 1990. Nephrol Dial Transplant 1991;6:S5-S29.

6. Ritz E, Rambausek M, Mall G, Ruffman K, Mandelbaum A. Cardiac changes to uremia and their possible relation to cardiovascular instability on dialysis. Contrb Nephrol 1990;78:221-9.

7. Kooman JP, Gladziwa U. Bocker G, van Bortel LMAB, van Hooff JP, Leunissen KML. Role of the venous system in hemodynamics during ultrafiltration and bicarbonate dialysis. Kidney Int 1992;42:718-26.

8. Argiles A, Kerr PG, Canaud B, Flavier JC, Mion C. Calcium kinetics and the longterm efficts of lowering dialysate calcium concentration. Kidney Int 1993:43:630-40.

9. Johnson WJ. Optimum dialysate calcium concentration during maintenance haemodialysis. Nephron 1976;17:241-58.

10. Slatopolsky E, Weerts C, Lopez-Hilken S, Norwood K, Zink M, Windus D, Delmez J. Calcium carbonate as a phosphate binder in patients with chronic renal failure undergoing dialysis. N Engl J Med 1986;315:157-61.

11. Mactier RA, VanStone J, Cox A, VanStone M, Twardowski Z. Calciumcarbonate is an effective phosphate binder when dialysate calcium concentration is adjusted to control hypercalcemia. Clin Nephrol 1987;28:222-6.

12. Sherman RA. On lowering dialysate calcium. Semin Dial 1988;1:78-9.

13. Sawyer N, Noonan K, Altmann P, Marsh F, Cunningham J. High-dose calcium carbonate with stepwise reduction in dialysate calcium concentration: Effective phosphate control and aluminium avioidance in haemodialysis patients. Nephrol Dial Transplant 1989:4:105-9.

14. Maynard JC, Cruz C, Kleerekoper M, Levin NW. Blood pressure response to clianges in serum ionized calcium during haemodialysis. Ann Intern Med 1986; 104:358-61.

15. liellner SK. Lang RM. Neumann A, Spencer KT, Bushinsky DA, Borow KM. Physiological mechanism for calcium-induced changes in systemic arterial pressure in stable dialysis patients. Hypert 1989;13:213-8.

16. Leunissen KML, van den Berg BW, van Hooff JP. Ionized calcium plays a pivotal role in controlling blood pressure during haemodialysis. Blood Purif 1989;7:233-9. 
17. Henrich WL, Hunt JM, Nixon JV. Increased ionized calcium and left ventricular contractility during haemodialysis. N Eng J Med 1984;310:19-23.

18. Lang RM, Fellner SK, Neumann A, Budshinsky DA, Borow KM. Left ventricular contractility varies directly with blood ionized calcium. Ann Intern Med 1988; 108:524-9.

19. van Kuijk WHM, Mulder AW, Peels $\mathrm{CH}$, Harff GH, Leunissen KML. Influence of changes in ionized calcium on cardiovascular reactivity during haemodialysis. Clin Nephrol 1997;47:190-6.

20. The Criteria Committee of the New York Heart Association: Diseases of the Heart and Blood Vessels; Nomenclature and Criteria for Diagnosis. 6th Ed. Little, Brown, Boston, 1964.

21. Leunissen KML, Kouw P, Kooman JP, Cheriex EC, de Vries PMJM, Donker AJM, van Hooff JP. New techniques to determine fluid status in hemodialyzed patients. Kidney Int 1993;43:S50-S6.

22. Kusumoto F, Venet Th, Schiller NB. Measurement of aortic blood flow by Doppler echocardiography: temporal, technician, and reader variability in normal subjects and the application of generalizability theory in clinical research. J Am Soc Echocardiogr 1995;8:647-53.

23. Magnin PA, Stewart JA, Myers S, Von Ramm O, Kisslo JA. Combined and phased array echocardiographic estimation of cardiac output. Circulation 1981;63:388-92.

24. Huntsman LL, Stewart DK, Barnes SR, Franklin SB, Colocousis JS, Hessel EA. Noninvasive Doppler determination of cardiac output in man. Circulation 1983;67:593-602.

25. Mayo A, Rawles J. Comparison of four different Doppler instruments used to measure linear an volumetric cardiac output: a study of reproducibility and agreement. Ultrasound in Med and Biol 1991;17:347-53.

26. Singer $M$, Allen MJ, Webb AR, Bennett ED. Effects of alterations in left ventricular filling, contractility, and systemic vascular resistance on the ascending aortic blood velocity waveform of normal subjects. Crit Care Med 1991;19:1138-45.

27. Dodge HT, Sheehan H. Quantitative contrast angiography for assessment of ventricular performance in heart disease. J Am Coll Cardiol 1983;1:73.

28. de Vries JPPM, Olthof CG, Visser V, Kouw PM, van Es A, Donker AJM, de Vries PMJM. Continuous measurement of blood volume during haemodialysis by an optical reflection method. ASAIO Journal 1992;38:M181-M5.

29. Rubin RP. Neurotransmitter substances and hormones. Pharmacol Rev 1970;22:389-428.

30. Marone C, Beretta-Picolli C, Weidmann P. Acute hypercalcemic hypertension in man: role of hemodynamics, catecholamines and renin. Kidney Int 1981;20:92-6.

31. Carney SL, Gillies AHG. Effect of an optimum dialysis fluid calcium concentration on calcium mass transfer during maintenance haemodialysis. Clin Nephrol 1985:24:28-30.

32. Hou SH, Zhao J, Ellmann CF. Calcium and phosphorus fluxes during haemodialysis with low calcium dialysate. Am J Kidney Dis 1991;18:217-24. 
33. Avis L, Carney SL, Gillies AHG, Jones B, Nanra R, Shaw R, Trevillian P, Webb C. An optimal potassium, calcium, and magnesium dialysate for general use? Dial Transplant 1996;25:354-8.

34. Sherman RA, Bialy GB, Gazinsky B, Bernholc AS, Eisinger RP. The effect of dialysate calcium levels on blood pressure during haemodialysis. Am J Kidney Dis 1986;8:244-7.

35. Willerson JT, Cohn JN. Heart failure, Cardiovascular Medicine, 1th Ed., Churchill Livingstone, New York 1995;947-79.

36. Ohno $M$, Cheng $C P$, Little WC. Mechanism of altered filling patterns of left ventricular filling during the development of congestive heart failure. Circulation 1994;89:2241-50. 


\section{Chapter 6}

\section{Effect of dialysate temperature on energy balance during hemodialysis: quantification of extracorporeal energy transfer}

FM van der Sande, JP Kooman, JHGA Burema, PH Hameleers, AMM Kerkhofs, JNM Barendregt, KML Leunissen

Am J Kidney Dis 1999; 33: 1115-21 


\section{Abstract}

An impaired vascular response is implicated in the pathogenesis of dialysis-induced hypotension, which is at least partly related to changes in extracorporeal blood temperature. However, little is known about changes in core temperature and differences in energy balance between standard and cool dialysis. In this study, core temperature and energy transfer between extracorporeal circuit and the patient, as well as the blood pressure response, were assessed during dialysis with standard $\left(37.5^{\circ} \mathrm{C}\right)$ and cool $\left(35.5^{\circ} \mathrm{C}\right.$ ) temperature of the dialysate. Nine patients (4 men, 5 women; mean age $69 \pm 10$ (=SD) years) were studied during low and standard temperature dialysis, each serving as his/her own control. Bicarbonate dialysis and hemophane membranes were used. Energy transfer was assessed by continuous measurement of temperature in the arterial $\left(T_{\text {art }}\right)$ and venous side $\left(T_{v e n}\right)$ of the extracorporeal system according to the formula:

c $\mathrm{x} \rho \mathrm{x} \mathrm{Qb} \times\left(\mathrm{T}_{\mathrm{ven}}-\mathrm{T}_{\mathrm{sit}}\right) \times \mathrm{t}$, with $\mathrm{c}=$ specific thermal capacity $\left(3.64 \mathrm{~kJ} / \mathrm{kg} \times{ }^{\circ} \mathrm{C}\right)$, $\mathrm{Qb}=$ extracorporeal blood flow, $\rho=$ density of blood $\left(1052 \mathrm{~kg} / \mathrm{m}^{3}\right)$, and $\mathrm{t}=$ dialysis time $(\mathrm{hr})$. Core temperature was also measured by Blood Temperature Monitoring (BTM ${ }^{\mathrm{r}}$; Fresenius). Core temperature increased during standard temperature dialysis $\left(36.7 \pm 0.3^{\circ} \mathrm{C}\right.$ to $\left.37.2 \pm 0.2^{\circ} \mathrm{C} ; \mathrm{p}<0.05\right)$ despite a small negative energy balance $(-85 \pm 43 \mathrm{~kJ})$ from the patient to the extracorporeal circuit. During cool temperature dialysis, energy loss was much more pronounced $(-286 \pm 73 \mathrm{~kJ} ; \mathrm{p}<0.05)$. However, mean core temperature remained stable $\left(36.4 \pm 0.6^{\circ} \mathrm{C}\right.$ to $\left.36.4 \pm 0.3^{\circ} \mathrm{C} ; \mathrm{ns}\right)$, and even increased in some patients with a low predialytic core temperature. Both during standard and cool temperature dialysis, the increase in core temperature during dialysis was significantly related to predialytic core temperature $(r=0.88$ and $r=0.77 ; p<0.05)$. Systolic blood pressure decreased to a higher degree during standard dialysis compared with cool temperature dialysis $(43 \pm 21$ vs. $22 \pm 26 \mathrm{mmHg} ; p<0.05)$, whereas diastolic blood-pressure tended to decrease more ( $15 \pm 10$ vs. $0 \pm 19 \mathrm{mmHg} ; \mathrm{p}=0.07)$. Core temperature increased in all patients during standard temperature dialysis despite a small netto energy transfer from the patient to the extracorporeal system. Core temperature remained generally stable during cool temperature dialysis despite significant energy loss from the patient to the extracorporeal circuit, and even increased in some patients with a low predialytic core temperature. The change in core temperature during standard and cool dialysis was significantly related to the predialytic blood temperature of the patient, both during cool and standard temperature dialysis.

The result suggests that the hemodialysis procedure itself affects core temperature regulation, which may have important consequences for the vascular response during hypovolemia. The removal of heat by the extracorporeal circuit and/or the activation of autoregulatory mechanisms attempting to preserve core temperature might be responsible for the beneficial hemodynamic effects of cool dialysis. 


\section{Introduction}

Hemodynamic instability frequently occurs during hemodialysis. In addition to a decline in blood volume, an impaired cardiovascular response is implicated in the pathogenesis of intradialytic hypotension. The latter phenomenon appears to be at least partly related to changes in extracorporeal blood temperature'. Various studies have shown a decrease in symptomatic hypotensive periods with the use of low temperature dialysate $\left(35^{\circ} \mathrm{C}\right.$ to $\left.36^{\circ} \mathrm{C}\right)$ compared with standard temperature $\left(37^{\circ} \mathrm{C}\right.$ to $38^{\circ} \mathrm{C}$ ) dialysate ${ }^{2.3}$. This was associated with an improved reactivity of the capacitance and resistance vessels and an increase in cardiac contractility ${ }^{4,5}$, possibly mediated by an increased activity of the sympathetic nervous system ${ }^{4-6}$.

Although the effect of dialysate temperature on hemodynamics is well recognized, information on the energy transfer between the patient and the extracorporeal system is scarce. It has been observed that core temperature increases with the use of a dialysate temperature between $37^{\circ} \mathrm{C}$ and $38^{\circ} \mathrm{C}^{3.7}$. However, whether this is caused by heat load from the extracorporeal system or by an effect of the dialysis procedure on body temperature regulation is not known. Moreover, there is little detailed information in energy balance between standard temperature and low temperature dialysate.

To gain more insight into this phenomenon, we assessed the energy transfer between extracorporeal circuit and patient, as well as the blood pressure response during hemodialysis with the use of low temperature $\left(35.5^{\circ} \mathrm{C}\right)$ and standard temperature $\left(37.5^{\circ} \mathrm{C}\right)$ dialysate.

\section{Patients and methods}

\section{Patients}

Nine patients ( 4 men, 5 women) treated with chronic intermittent hemodialysis were studied. Mean age was $68.7 \pm 10.4$ years (range, 49 to 82 ). Renal disease was caused by diabetes mellitus in 4 patients, nephrosclerosis in 3 patients, analgetic nephropathy in 1 patient and chronic pyelonephritis in 1 patient. In 3 patients, frequent episodes of symptomatic hypotension occurred during chronic dialysis treatunent, defined as a systolic blood pressure lower than $100 \mathrm{mmHg}$, together with symptoms for which infusion of saline $0.9 \%$ was necessary.

All patients gave informed consent for the study.

\section{Methods}

Study protocol

Patients were assessed during 2 dialysis sessions, differing only in dialysate 
temperature $\left(35.5^{\circ} \mathrm{C}\right.$ or $\left.37.5^{\circ} \mathrm{C}\right)$. Each patient served as his/her own control. Dialysis treatments were performed at the same time and day of the week, to prevent large differences in ultrafiltration volume between the 2 sessions. Patients were ultrafiltrated until at dry weight, assessed by echography of the inferior caval vein performed one and a half hour after the end of dialysis ${ }^{8}$. Treatment sessions with a dialysate temperature of $35.5^{\circ} \mathrm{C}$ or $37.5^{\circ} \mathrm{C}$ were performed in random order. The ambient temperature was constant $\left(22^{\circ} \mathrm{C}\right)$. Patients were allowed only a light snack during the dialysis procedure.

During each treatment session, body temperature, and temperature at the arterial $\left(\mathrm{T}_{\mathrm{ar}}\right)$ and venous $\left(\mathrm{T}_{\text {ven }}\right)$ side of the fistula, as well as energy transfer between the extracorporeal circuit and the patient were monitored at 10 -second intervals using the method described in Energy Transfer.

\section{Blood pressure}

Blood pressure and heart rate were assessed every $15 \mathrm{~min}$ with the use of an automated oscillometric blood pressure monitor (Dinamap ${ }^{r}$ ). Blood pressure before and after the dialysis treatment, and the lowest blood pressure during the dialysis treatment were included in the analysis.

\section{Energy transfer}

Energy transfer was defined as the amount of thermal energy which was transferred from the extracorporeal circuit to the patient, or vice versa. A positive value indicates net energy transfer from the extracorporeal circuit to the patient, and a negative value indicates net energy transfer from the patient to the extracorporeal circuit.

Energy transfer (in kilojoules) was calculated by the use of the following formula: $\mathrm{c} \times \rho \times \mathrm{Qb} \times\left(\mathrm{T}_{\mathrm{ven}}-\mathrm{T}_{\text {art }}\right) \times \mathrm{t}$, with $\mathrm{c}=$ specific thermal capacity $\left(3.64 \mathrm{~kJ} / \mathrm{kg} \times{ }^{\circ} \mathrm{C}\right)$, $\mathrm{Qb}=$ extracorporeal blood flow, $\rho=$ density of blood $\left(1,052 \mathrm{~kg} / \mathrm{m}^{3}\right), \mathrm{t}=$ dialysis time $(\mathrm{hr})^{9}$. Energy transfer rate is expressed in watts $(1 \mathrm{Watt}=3.6 \mathrm{~kJ} / \mathrm{h})$.

$T_{\text {art }}$ and $T_{\text {ven }}$ were assessed with the use of continuous temperature monitoring at the arterial and venous side of the extracorporeal system by an air-filled head with a platinum sensor (Blood Temperature Monitoring (BTM $\left.{ }^{r}\right)$ ); Fresenius) around the arterial and venous blood catheters.

Resting energy expenditure (REE) was predicted according to the Harris-Benedict equation: Men: $\mathrm{REE}=66+13.8^{*}$ Weight $+5 *$ Height $-6.8^{*}$ Age $(\mathrm{kcal} / 24 \mathrm{~h})$

Women: $\mathrm{REE}=655+9.7 *$ weight $+1.8^{*}$ Height $-4.7^{*} \mathrm{Age}(\mathrm{kcal} / 24 \mathrm{~h})$.

To obtain values in watts ( $1 \mathrm{Watt}=0.86 \mathrm{kCal} / \mathrm{h}$ ), values were divided by 20.64 .

\section{Body temperature}

Body temperature was assessed in two different ways. The BTM measures 
temperature at the arterial side of the fistula and calculates central venous blood temperature by correcting for fistula and cardiopulmonary recirculation. This temperature is referred to as core temperature (BTM). This correction is necessary because the arterial blood temperature is determined by the core temperature as well as by the temperature of the recirculated venous blood. Recirculation is measured by the BTM with a temperature bolus produced by a temporary change in blood temperature. The change in temperature is recorded by the venous sensor head of the BTM and finally by the arterial sensor head. From the ratio in bolus sizes, recirculation can be calculated ${ }^{10}$. Predialytic core temperature (BTM) is defined as the first reliable temperature obtained with the BTM (in all patients within $5 \mathrm{~min}$ ) after the start of dialysis.

For confirmation, body temperature was also measured with a tympanic thermometer (Genius ${ }^{\mathrm{T}}$ ). In another study, tympanic temperatures with the Genius ${ }^{\mathrm{r}}$ device correlates well with pulmonary artery temperatures ${ }^{\prime \prime}$. In our study, the correlation-coefficient between core temperature (BTM) and tympanic temperature was $0.75(\mathrm{p}<0.05)$.

\section{Dialysis prescription}

Dialysis was performed with bicarbonate as dialysate buffer, which was individualized between 30 and $36 \mathrm{mmol} / \mathrm{l}$. The composition of the dialysate was sodium, $140 \mathrm{mmol} / \mathrm{L}$; calcium, $1.5 \mathrm{mmol} / \mathrm{L}$; acetate, $3 \mathrm{mmol} / \mathrm{L}$; potassium, $2 \mathrm{mmol} / \mathrm{L}$; magnesium, $0.5 \mathrm{mmol} / \mathrm{L}$; chloride, $108 \mathrm{mmol} / \mathrm{L}$; and glucose, $2 \mathrm{~g} / \mathrm{L}$. Blood flow rate was $300 \mathrm{~mL} / \mathrm{min}$ in all patients. Treatment time was $180 \mathrm{~min}$ in three patients, $210 \mathrm{~min}$ in three patients and $240 \mathrm{~min}$ in three patients. Bacterial contamination of the dialysate was negligible: in all patients, less than $100 \mathrm{CFU} / \mathrm{mL}$ were measured.

\section{Statistics}

Parameters assessed during the different treatments were analyzed with a paired Student's t-test. Pearson's $r$ was used for assessing the correlation between two variables. Backward multiregression analysis was used to analyse the determinants of the energy transfer rate during dialysis. P-value less than 0.05 was considered significant.

\section{Results}

\section{Hemodynamics}

As listed in Table 6.1, systolic blood pressure decreased to a larger degree during treatment with dialysate temperature $37.5^{\circ} \mathrm{C}$ compared with dialysate temperature 
$35.5^{\circ} \mathrm{C}(\mathrm{p}<0.05)$, whereas diastolic RR tended to decrease more during treatment with dialysate temperature $37.5^{\circ} \mathrm{C}(\mathrm{p}=0.07)$. Postdialytic blood pressure did not differ significantly between the different treatment sessions. One symptomatic hypotensive period occurred during treatment with dialysate temperature $37.5^{\circ} \mathrm{C}$ versus none with dialysate temperature $35.5^{\circ} \mathrm{C}$. Maximal heart rate was significantly greater during treatment with dialysate temperature $37.5^{\circ} \mathrm{C}$ compared with temperature $35.5^{\circ} \mathrm{C}(\mathrm{p}<0.05)$. The decline in systolic and diastolic blood pressure during treatment with dialysate temperature $35.5^{\circ} \mathrm{C}$ was not significantly related to the predialytic core temperature (BTM) of the patient $(r=0.24$ and $\mathrm{r}=0.11 ; \mathrm{p}=\mathrm{ns})$ respectively. Also during treatment with dialysate temperature $37.5^{\circ} \mathrm{C}$, no significant correlation was observed between predialytic core temperature (BTM) and the decline in systolic and diastolic blood pressure, although the relation tended to be stronger $(r=0.54$ and $r=0.52, p=n s)$. Also, the relation between predialytic tympanic temperature and the decline in systolic and diastolic blood pressure did not reach significance, neither during treatment with dialysate temperature $37.5^{\circ} \mathrm{C} \quad(\mathrm{r}=0.19$ and $\mathrm{r}=0.34 ; \mathrm{p}=\mathrm{ns})$, nor dialysate temperature $35.5^{\circ} \mathrm{C}(r=0.33$ and $r=0.28 ; p=n s)$

Table 6.1 Predialysis hemodynamic parameters.

\begin{tabular}{lcllll}
\hline Hemodynamic parameters & \multicolumn{2}{c}{ Temperature 37.5 $\mathrm{C}$} & \multicolumn{2}{c}{ Temperature 35.5 $\mathrm{C}$} \\
\hline SBP before HD (mmHg) & $144.4 \pm 25.9$ & $(100-176)$ & $130.3 \pm 21.7$ & $(99-178)$ \\
DBP before HD (mmHg) & $72.2 \pm 10.2$ & $(60-92)$ & $68.1 \pm 17.3$ & $(43-92)$ \\
Maximal fall in SBP (mmHg) & $43.2 \pm 20.6$ & $(7-71)$ & $21.8 \pm 26.1$ & $(-15-69)^{!}$ \\
Maximal fall in DBP (nunHg) & $14.9 \pm 9.6$ & $(3-32)$ & $-0.1 \pm 19.2$ & $(-22-28)$ \\
SBP after HD (mmHg) & $117.3 \pm 26.1$ & $(82-158)$ & $131.6 \pm 21.4$ & $(95-159)$ \\
DBP after HD (mmHg) & $67.0 \pm 10.9$ & $(54-83)$ & $63.7 \pm 9.0$ & $(52-82)$ \\
Heart rate before HD (beats/min) & $84.8 \pm 17.0$ & $(62-104)$ & $87.1 \pm 31.1$ & $(44-133)$ \\
Maximal heart rate (beatsimin) & $85.9 \pm 23.4$ & $(50-111)$ & $76.3 \pm 19.5$ & $(40-104)^{\prime}$ \\
Heart rate after HD (beats/min) & $81.0 \pm 24.2$ & $(43-108)$ & $76.7 \pm 21.8$ & $(42-105)$ \\
Ultrafiltration volume (mL) & $2337 \pm 650$ & $(1600-3400)$ & $2089 \pm 486$ & $(1500-2800)$ \\
Ultrafiltration rate (mL/hr) & $800 \pm 199$ & $(530-1130)$ & $723 \pm 171$ & $(480-930)$ \\
\hline
\end{tabular}

Values as mean $\pm \mathrm{SD}$ (range). $\mathrm{SBP}=$ systolic blood pressure; $\mathrm{DBP}=$ diastolic blood pressure; $\mathrm{HD}=$ hemodialysis. ' $\mathrm{p}<0.05$, temperature $37.5^{\circ} \mathrm{C}$ vs. $35.5^{\circ} \mathrm{C}$. 


\section{Energy transfer}

As listed in Table 6.2, significant net energy loss from the patient to the extracorporeal circuit was observed during treatment with dialysate temperature $35.5^{\circ} \mathrm{C}$. When a multiregression model that included energy transfer rate (in watts) as the dependent variable and dialysis time, the predialytic core temperature (BTM), the interdialytic change in core temperature (BTM) as independent variables, predialytic $T_{a r t}$ was the most important predictor for energy transfer $(\mathrm{t}=-3.0 ; \mathrm{p}<0.05)$.

Also during treatment with dialysate temperature $37.5^{\circ} \mathrm{C}$, net energy loss from the extracorporeal circuit to the patient occurred, although this loss was significantly smaller compared with temperature $35.5^{\circ} \mathrm{C}(\mathrm{p}<0.05)$.

When the previously mentioned multiregression model was used to assess the determinants of the energy transfer during treatment with dialysate temperature $37.5^{\circ} \mathrm{C}$, the predialytic core temperature (BTM) and the intradialytic change in core temperature (BTM) were significant predictors of energy transfer $(\mathrm{t}=-4.5 ; \mathrm{p}<0.05$ and $\mathrm{t}=-5.2 ; \mathrm{p}<0.05)$.

The predicted basal REE is listed in Table 6.2.

Table 6.2 Thermal parameters.

\begin{tabular}{llllc}
\hline & \multicolumn{2}{c}{ Temperature $37.5^{\circ} \mathrm{C}$} & \multicolumn{2}{c}{ Temperature 35.5 ${ }^{\circ} \mathrm{C}$} \\
\hline Core Temp (BTM) before HD $\left({ }^{\circ} \mathrm{C}\right)$ & $36.7 \pm 0.3$ & $(36.3-37.0)$ & $36.4 \pm 0.6$ & $(35.6-37.3)$ \\
Core Temp (BTM) after HD $\left({ }^{\circ} \mathrm{C}\right)$ & $37.2 \pm 0.2$ & $(36.9-37.4)$ & $36.4 \pm 0.3$ & $(36.0-36.8)^{1}$ \\
Tympanic Temp before HD $\left({ }^{\circ} \mathrm{C}\right)$ & $36.1 \pm 0.5$ & $(35.6-37.0)$ & $36.0 \pm 0.5$ & $(35.2-36.9)^{1}$ \\
Tympanic Temp after HD $\left({ }^{\circ} \mathrm{C}\right)$ & $36.6 \pm 0.6$ & $(36.0-37.4)$ & $36.2 \pm 0.4$ & $(35.7-36.9)^{\prime}$ \\
$\mathrm{T}_{\text {ari }}$ after HD $\left({ }^{\circ} \mathrm{C}\right)$ & $37.1 \pm 0.2$ & $(36.8-37.3)$ & $36.4 \pm 0.4$ & $(35.6-37)^{1}$ \\
$\mathrm{~T}_{\text {veri }}$ after HD $\left({ }^{\circ} \mathrm{C}\right)$ & $36.7 \pm 0.1$ & $(36.4-36.8)$ & $35.0 \pm 0.2$ & $(34.8-35.6)^{1}$ \\
Total energy transfer $(\mathrm{kJ})$ & $-84.5 \pm 43.0$ & $(-128.0-4.1)$ & $-286 \pm 73.6$ & $(-412-167.3)^{1}$ \\
Energy transfer rate $(\mathrm{W})$ & $-7.0 \pm 3.7$ & $(010.8--0.3)$ & $-22.7 \pm 4.9$ & $(-29.2-13.3)^{\prime}$ \\
Estimated REE $(\mathrm{W})$ & $68.7 \pm 9.6$ & $(55.5-83.1)$ & & \\
\hline
\end{tabular}

Values as mean $\pm \mathrm{SD}$ (range). REE = resting energy expenditura (estimated by the Harris-Benedict equation); $\mathrm{HD}=$ hemodialysis; $\mathrm{BTM}=$ measured by blood temperature monitoring. ${ }^{1} \mathrm{p}<0.05$, temperature $37.5^{\circ} \mathrm{C}$ vs. $35.5^{\circ} \mathrm{C}$.

\section{Core and fistula temperatures}

Predialytic core temperature (BTM) and tympanic temperature did not differ before the session with dialysate temperature $35.5^{\circ} \mathrm{C}$ versus temperature $37.5^{\circ} \mathrm{C}$.

Mean core temperature (BTM) remained stable during treatment with dialysate temperature $35.5^{\circ} \mathrm{C}$ and increased significantly during temperature $37.5^{\circ} \mathrm{C}$ (Table 6.2 ). The change in core temperature (BTM) during hemodialysis was highly 
significantly related to predialytic core temperature (BTM), both during treatment with dialysate temperature $35.5^{\circ} \mathrm{C}(\mathrm{r}=0.88 ; \mathrm{p}<0.05)$, and temperature $37.5^{\circ} \mathrm{C}$ $(\mathrm{r}=0.77 ; \mathrm{p}<0.05$; Figure 6.1).

During treatment with dialysate temperature $37.5^{\circ} \mathrm{C}$ core temperature (BTM) increased in all patients, whereas with temperature $35.5^{\circ} \mathrm{C}$, core temperature (BTM) increased in some patients but decreased in others, depending on predialytic core temperature (Figure 6.1).

Although the tympanic temperature was lower compared with the core temperature (BTM), the trends were similar (Table 6.2): body temperature measured by the tympanic thermometer remained stable during treatment with dialysate temperature $35.5^{\circ} \mathrm{C}$ and increased during temperature $37.5^{\circ} \mathrm{C} . \mathrm{T}_{\text {art }}$ and $\mathrm{T}_{\text {ven }}$ were significantly greater after treatment with dialysate temperature $37.5^{\circ} \mathrm{C}$ compared with temperature $35.5^{\circ} \mathrm{C}(\mathrm{p}<0.05)$ (Table 6.2).

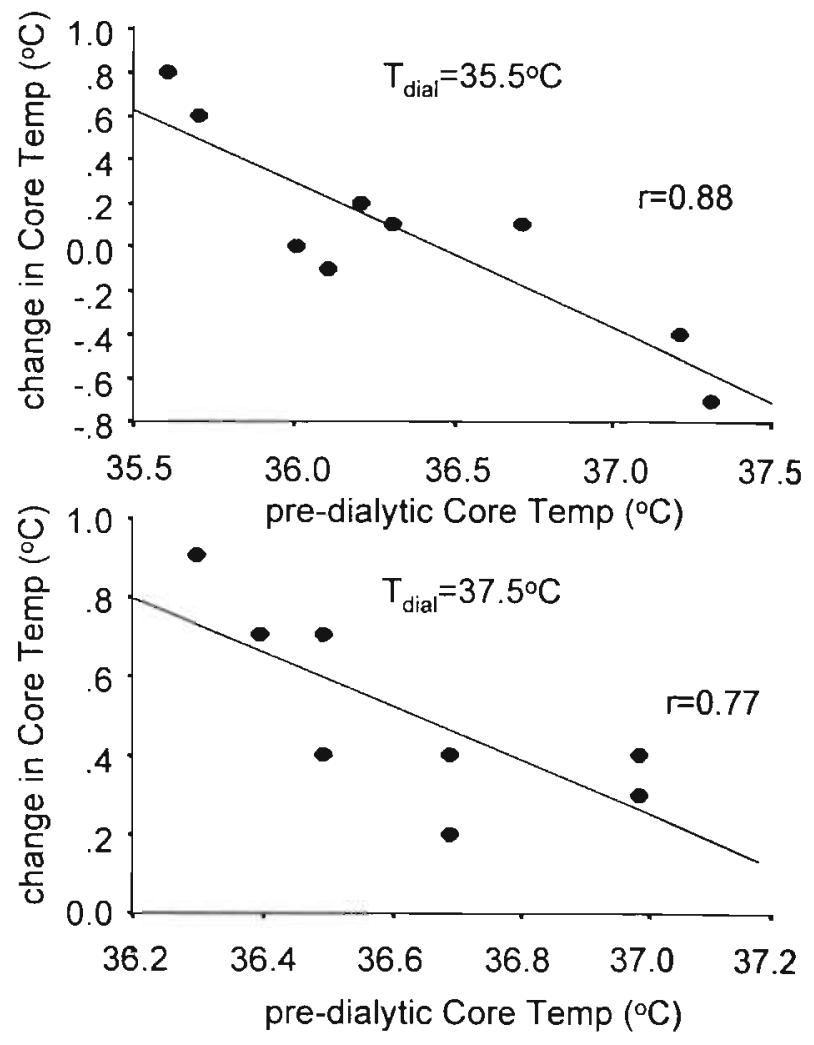

Figure 6.1 Relation between predialysis core temperature and the change in core temperature during dialysis $\left(\mathrm{T}_{\mathrm{dia}}\right)$ at temperature $35.5^{\circ} \mathrm{C}$ and temperature $37.5^{\circ} \mathrm{C}$. 


\section{Other parameters}

Netto weight loss was not significantly different between treatment with dialysate temperature $35.5^{\circ} \mathrm{C}$, nor was the ultrafiltration rate (Table 6.1).

\section{Discussion}

In this study, we assessed the energy transfer between the extracorporeal system to the patient, as well as the blood pressure response during dialysis with a cool $\left(35.5^{\circ} \mathrm{C}\right)$ and standard $\left(37.5^{\circ} \mathrm{C}\right)$ temperature of the dialysate. Measurements were performed by continuous blood temperature monitoring with the use of platinum sensors around the arterial and venous blood catheters of the extracorporeal circuit (BTM). Core temperature (BTM) is derived from the temperature at the arterial side of the fistula corrected for fistula and cardiopulmonary recirculation ${ }^{9,10}$. The correlation between core temperature (BTM) and tympanic temperature was significant but did not reach uniformity. Moreover, tympanic temperature was generally less than core temperature (BTM). This phenomenon might be explained by the fact that tympanic temperature can be influenced by the properties of the ear canal or the presence of cerumen ${ }^{12}$. Nevertheless, the trend of the results obtained with the tympanic thermometer were similar to those obtained by the BTM.

Core temperature (BTM) and tympanic temperature increased during standard temperature dialysis, which is in accordance with previous reports ${ }^{4,7}$. The change in core temperature (BTM) during dialysis was significantly related to the predialytic core temperature (BTM). During treatment with dialysate temperature $37.5^{\circ} \mathrm{C}$, dialysate temperature was higher than core temperature (BTM) in all patients. However, instead of the expected heat load from the dialysis system to the patient, all patients lost a small amount of energy to the extracorporeal circuit during dialysis at temperature $37.5^{\circ} \mathrm{C}$. This appeared to be caused by heat loss from the blood catheters, because temperature at the venous side of the fistula was less than core temperature (BTM), as well as dialysate temperature in all patients.

The increase in core temperature despite net energy loss suggests an effect of the dialysis procedure on body temperature regulation. This phenomenon could very well contribute to the impaired vascular response during standard temperature dialysis. Skin circulation is controlled both by volume and temperature defense mechanisms. Under thermoneutral circumstances, hypovolemia would result in baroreflex-mediated cutaneous vasoconstriction. Although baroreflexes continue to modulate skin blood flow even under conditions of heat stress, an increase in core temperature will lead to cutaneous vasodilatation, antagonizing the normal vascular response to hypovolemia ${ }^{13-15}$.

The pathophysiologic mechanism behind the increase in core temperature during 
standard dialysis remains speculative. It was hypothesized by Gotch et $\mathrm{al}^{16}$ that this phenomenon was caused by initial peripheral vasoconstriction resulting in a reduction in surface heat loss, leading to an increase in core temperature. In turn, this increase in core temperature would lead to cutaneous vasodilatation by the mechanisms discussed previously.

In agreement, Baldamus et $\mathrm{al}^{17}$, observed an increase in systemic vascular resistance during the first 2 hrs of dialysis treatment, after which it tended to decrease. We observed only minor changes in forearm vascular resistance and venous tone during hemodialysis at temperature $37.5^{\circ} \mathrm{C}$ during the whole dialysis treatment, in contrast to isolated ultrafiltration and cool dialysis, during which the vascular response was much more distinct, ${ }^{4,18,19}$.

The dialysis procedure might also influence core temperature regulation in other ways. Complement activation and cytokine production, e.g., because of bacterial contamination or the use of bioincompatible membranes, could affect the body temperature setpoint $t^{20}$. However, no significant bacterial contamination in the dialysate was observed in the present study, whereas hemophane membranes were used, which have less complement activating characteristics compared with unmodified cellulosic membranes. Data on the influence of dialysis on energy expenditure are scarce. Ikizler et $\mathrm{al}^{21}$ found an increase in resting energy expenditure during bicarbonate dialysis of approximately $8 \mathrm{~W}$. In their study, no difference was observed between patients treated with biocompatible or bioincompatible membranes. As in our study, those authors also used glucose in the dialysate. However, they calculated that the absorption of glucose could account for less than $10 \%$ of the observed increase in resting energy expenditure during dialysis. In contrast to their results, Schneeweiss et $\mathrm{al}^{22}$ did not observe an increase in resting energy expenditure in hemodialysis patients. However, these investigators did not perform metabolic measurements during the dialysis procedure itself. Another possible mechanism is an increase in the temperature set point because of the removal of uremic toxins ${ }^{23}$. Finally, the normal temperature rhythm of the patient has to be taken into account as well. Nevertheless, core temperature increased during treatment with dialysate temperature $37.5^{\circ} \mathrm{C}$ in all patients, whether they were treated during a moming or an afternoon session.

Comparing our study with the few reports on energy transfer during hemodialysis in the literature. our results do not completely agree with the study of Provenzano et $\mathrm{al}^{7}$, who observed a net energy load from the extracorporeal circuit to the patient with a dialysate temperature of $37^{\circ} \mathrm{C}$, despite a lower blood flow $(190 \mathrm{~mL} / \mathrm{min})$ in their study. Although a lower blood flow increases the contact time between blood and dialysate, it also augments energy loss from the blood catheters to the environment ${ }^{9}$. Possible explanations for the discrepant results could be a difference in predialytic blood temperature between their and our patients or the use of acetate in their study, which might induce larger heat loss from the body to the 
environment because of excessive peripheral vasodilatation, provoking more energy influx from the extracorporeal circuit to the patient ${ }^{1}$. Our results, however, are in agreement with the study of Schneditz et al ${ }^{9}$ who also observed a net energy loss from the patient to the extracorporeal circuit during dialysis with a dialysate temperature of $\pm 37.3^{\circ} \mathrm{C}$ at blood flow rates of $\pm 250 \mathrm{~mL} / \mathrm{min}$.

During cool dialysis, the mean net energy loss from the patient to the extracorporeal circuit amounted $290 \mathrm{~kJ}$ at a mean heat transfer rate of $23 \mathrm{~W}$. This approximates $33 \%$ of the estimated REE of these patients. Despite this significant energy loss, mean core temperature (BTM) remained constant, whereas core temperature even increased in some patients with a low predialytic body temperature (Figure 6.1). The latter phenomenon might be explained by the thermal effects of hemodialysis as discussed previously. However, in most patients, removal of the accumulated heat through the extracorporeal circuit will prevent an increase in core temperature during cool dialysis.

In accordance with the literature, blood pressure was more stable during low temperature dialysis compared with standard dialysis. From a hemodynamic point of view, at least part of the beneficial effects of cool dialysis are caused by a beneficial effect on vascular reactivity. In a previous study, we observed an increased constriction of the capacitance and resistance vessels in the forearm vascular bed with cool dialysate $\left(35^{\circ} \mathrm{C}\right)$ compared with standard temperature $\left(37.5^{\circ} \mathrm{C}\right)$ dialysate ${ }^{4}$. This phenomenon could be explained by preventing the negative hemodynamic effects of the accumulated heat during standard hemodialysis. An alternative explanation is that, especially in patients with a greater predialytic core temperature, the beneficial hemodynamic effects of cool dialysate are also caused by an increased peripheral vasoconstriction to preserve core temperature despite energy loss.

The relation between predialytic core temperature (BTM) and the change in core temperature (BTM) might provide an explanation for the findings of Fine and Penner $^{25}$ that cool dialysis is most effective in patients with a low predialytic body temperature, because in these patients during standard hemodialysis, the increase in body temperature is most distinct.

In conclusion, core temperature remained generally stable, but even increased in some patients during cool dialysis, despite significant energy loss from the patient to the extracorporeal circuit, and increased in all patients during standard temperature dialysis despite a small net energy transfer from the patient to the extracorporeal system. The change in core temperature during dialysis was related to the predialytic core temperature of the patient, both during low and standard temperature dialysis.

The increase in core temperature suggests that the dialysis procedure itself affects body temperature regulation in the patient. The pathogenesis of this phenomenon remains to be elucidated. The removal of heat by the extracorporeal circuit and/or 
the activation of autoregulatory mechanisms attempting to preserve core temperature might be responsible for the beneficial hemodynamic effects of cool dialysis. 


\section{References}

1. Leunissen KML, Kooman JP, van Kuijk WHM, van der Sande FM, Luik AJ. Preventing haemodynamic instability in patients at risk for dialysis associated hypotension. Nephrol Dial Transplant 1996;11:S11-S5.

2. Jost CMT, Agrawal R, Khair-El-Din T; Grayburn PA, Victor RG, Henrich WL. Effects of cooler temperature dialysate on hemodynamic stability in problem dialysis patients. Kidney Int 1993;44:606-12.

3. Maggiore Q, Pizzarelli F, Sisca S, Zoccalli C, Parlongo S, Nicolo F, Creazzo G. Blood temperature and vascular stability during hemodialysis and hemofiltration. Trans Am Soc Artif Intern Organs 1982;28:523-7.

4. van Kuijk WHM, Luik AJ, de Leeuw PW, van Hooff JP, Nieman FHM, Habets HML, Leunissen KML. Vascular reactivity during hemodialysis and isolated ultrafiltration: thermal influences. Nephrol Dial Transplant 1995;16:1852-8.

5. Levy FL, Grayburn PA, Foulks CJ, Brickner ME, Henrich WL. Improved left ventricular contractility with cool temperature hemodialysis. Kidney Int 1992;41:961-5.

6. Mahida BH, Dumler F, Zasuwa G, Fleig G, Levin NW. Effect of cooler dialysate on serum catecholamines and blood pressure stability. Trans Am Soc Artif Intern Organs $1983 ; 24: 383-9$.

7. Provenzano R, Sawaya B, Frinak S, Polashegg HD, Roy T, Zasuwa G, Dumler F, Levin NW. The effect of cooled dialysate on thermal energy balance in hemodialysis patients. ASAIO Trans 1988;34:515-8.

8. Leunissen KML, Kouw P, Kooman JP, Cheriex EC, de Vries PMJM, Donker AJM, van Hooff JP. New techniques to determine fluid status in hemodialyzed patients. Kidney Int 1993;41:S50-S6.

9. Schneditz D, Martin K, Krämer M, Kenner T, Skrabal F. Effect of controlled extracorporeal blood cooling on ultrafiltration-induced blood volume changes during hemodialysis. J Am Soc Nephrol 1997;8:956-64.

10. Krämer M, Polaschegg HD. Control of blood temperature and thermal energy balance during hemodialysis. Proc Annu Int Conf IEEE-EMBS 1992;14:2299-300.

11. Shinozaki T, Deane R, Perkins FM. Infrared tympanic thermometer: evaluation of a new clinical thermometer. Crit Care Med 1988;16:148-50.

12. Ducharme MB. Evaluation of infrared tympanic thermometers during normothermia and hypothermia in humans. In: thermoregulation. CM Blatteis (Ed). Annals of the New York Academy of Sciences 1997;813:225-9.

13. Gotch FA, Keen ML, Yarian SR. An analysis of thermal regulation in hemodialysis with one and three compartment models. Trans Am Soc Artif Intern Organs $1989 ; 35: 622-4$.

14. Daugirdas JT. Dialysis hypotension: a hemodynamic analysis. Kidney Int 1991;39:233-46.

15. Tripathi A, Shi X, Wenger CB, Nadel ER. Effect of temperature and baroreceptor stimulation on reflex venomotor responses. J Appl Physiol 1984;57:1384-92. 
16. Johnson JM. Nonthermoregulatory control of human skin blood flow. J Apll Physiol 1986;61:1613-22.

17. Baldamus CA, Ernst W, Frei UW, Koch KM. Sympathetic and hemodynamic response to volume removal during different forms of renal replacement therapy. Nephron 1982;31:324-32.

18. van Kuijk WA, Hillion D, Savoiu C, Leunissen KML. Critical role of the extracorporeal blood temperature in the hemodynamic response during hemofiltration. J Am Soc Nephrol 1997;8:949-55.

19. Kooman JP, Gladziwa U, Böcker G, Wijnen JAG, van Bortel LMAB, Luik AJ, de Leeuw PW, van Hooff JP, Leunissen KML. Role of the venous system in hemodynamics during ultrafiltration and bicarbonate dialysis. Kidney Int 1992:42:718-26.

20. Henderson LW, Koch KM, Dinarello CA, Shaldon S. Hemodialysis hypotension: the interleukin-1 hypothesis. Blood Purif 1983;1:3-8.

21. Ikizler TA, Wingard RL, Sun M, Harvell J, Parker RA, Hakim RM. Increased energy expenditure in hemodialysis patients. J Am Soc Nephrol 1996;7:2646-53.

22. Schneeweiss B, Graninger W, Stockenhuber F, Druml W, Ferenci P, Eichinger S, Grimm G, Laggner AN, Lenz K. Energy metabolism in acute and chronic renal failure. Am J Clin Nutr 1990;52:596-601.

23. Ash S. An explanation for uremic hypothermia. Int J Artif Organs 1991;14:67-9.

24. Fauci AS, Branwald E, Isselbacher KJ, Wilson JP, Martin JB, Kasper DL, Hauser SL, Longo DL (eds). Harrison's principles of Internal Medicine ( ed 14), McGraw Hill. 1998;446.

25. Fine A, Penner B. The protective effect of cool dialysate is dependent on patients' predialysis temperature. Am J Kidney Dis 1996;28:262-5. 


\section{Chapter 7}

\section{Thermal energy balance and body temperature: comparison between isolated ultrafiltration and hemodialysis at different dialysate temperatures}

JMG Keijman, FM van der Sande, JP Kooman, KML Leunissen

Nephrol Dial. Transplant 1999;14:2196-2000 


\section{Abstract}

Hemodynamic stability is better maintained during isolated ultrafiltration (i-UF) than with combined ultrafiltration / hemodialysis (UF+HD). which difference might be explained by differences in thermal energy balances. In this study we compared the thermal energy balance of $\mathrm{i}$-UF with UF + HD at different dialysate temperatures (Td) and determined the $\mathrm{Td}$ at which the thermal energy balance during UF +HD is similar to the thermal energy balance during i-UF.

In the first part of the study ten chronic hemodialysis patients were compared during 3 different treatment sessions, i-UF, UF+HD at Td of $35.5^{\circ} \mathrm{C}$ and $\mathrm{UF}+\mathrm{HD}$ at $\mathrm{Td}$ of $37.5^{\circ} \mathrm{C}$. The second part of the study consisted of one session of one hr of UF+HD (UF + HD ET-set) with a pre-set energy transfer (ET) at the same level of ET found for that particular patient during $\mathrm{i}-\mathrm{UF}$ in the first part of the study. In the first part of the study, body temperature (BT) decreased significantly during i-UF $\left(-0.25 \pm 0.25^{\circ} \mathrm{C}\right.$, $\mathrm{p}<0.05)$ and $U F+H D 35.5^{\circ} \mathrm{C} \quad\left(-0.24 \pm 0.18^{\circ} \mathrm{C}, \mathrm{p}<0.05\right)$ and increased significantly during UF $+H D 37.5^{\circ} \mathrm{C}\left(+0.18 \pm 0.19^{\circ} \mathrm{C}, \mathrm{p}<0.05\right)$. The differences between the change in $\mathrm{BT}$ during UF+HD $37.5^{\circ} \mathrm{C}$ compared with the other treatments were significant $(p<0.05)$. ET gave a significant more negative value during i-UF $(-30.8 \pm 3.1 \mathrm{~W}$, $\mathrm{p}<0.05)$ than during $U F+H D 35.5^{\circ} \mathrm{C}(-23.6 \pm 4.1 \mathrm{~W}, \mathrm{p}<0.05)$. A slightly positive ET was found during $\mathrm{UF}+\mathrm{HD} 37.5^{\circ} \mathrm{C}(+0.4 \pm 4.7 \mathrm{~W}$, ns). In the second part of the study, there was a slight, but not significant, decrease in BT during UF+HD ET-set $\left(-0.17 \pm 0.26^{\circ} \mathrm{C}\right)$. The changes in BT did not differ significantly between $\mathrm{i}-\mathrm{UF}$ and $\mathrm{UF}+\mathrm{HD}$ ET-set. After one hr of UF+HD ET-set, the mean Td was $34.75^{\circ} \mathrm{C}$ (range, $34.0^{\circ} \mathrm{C}$ to $36.0^{\circ} \mathrm{C}$ ). The correlation between predialysis $\mathrm{BT}$ and $\mathrm{Td}$ during UF+HD ET-set was significant $(r=0.764, p<0.05)$.

From this study it is concluded that ET gives a more negative value during $i-U F$ than during UF $+\mathrm{HD} 35.5^{\circ} \mathrm{C}$ and than during UF $+\mathrm{HD} 37.5^{\circ} \mathrm{C}$. To obtain the same thermal ET during UF+HD as that achieved during $\mathrm{i}-\mathrm{UF}$, a mean $\mathrm{Td}$ of $34.75^{\circ} \mathrm{C}$ is needed, depending on the predialytic BT of the patient. The results of this study may be of relevance in relation to future clinical investigations which can elucidate whether differences in vascular response between $\mathrm{i}-\mathrm{UF}$ and UF+HD are only related to differences in thermal balance. 


\section{Introduction}

Hemodynamic instability is a frequently occurring problem during a dialysis procedure. A decline in blood volume is the initial etiologic factor which is related to an imbalance between ultrafiltration and blood volume preservation. However, impaired reactivity of resistance and capacitance vessels in reaction to the blood volume decline also plays a major role $e^{1.2}$.

During standard temperature dialysis $\left(37^{\circ} \mathrm{C}\right.$ to $\left.38^{\circ} \mathrm{C}\right)$ body temperature increases despite a net energy loss to the extracorporeal system ${ }^{5.4}$. This suggests an effect of the dialysis treatment on the regulation of body temperature ${ }^{5-7}$. An increase in body temperature causes vasodilatation and might thus interfere with the normal vascular response to a decrease in blood volume ${ }^{8}$.

Since the early 1980's the effects of different dialysate temperatures (Td) on hemodynamic stability have been investigated and cool temperature dialysis $\left(35^{\circ} \mathrm{C}\right.$ to $36^{\circ} \mathrm{C}$ ) has been shown to improve hemodynamic stability ${ }^{9.12}$. We and others found that cool temperature dialysis has a beneficial effect not only on peripheral vascular resistance but also on venous reactivity ${ }^{2}$. Moreover, cardiac contractility appears to be increased during cool temperature dialysis ${ }^{13}$. Isolated ultrafiltration (i-UF) has been shown to improve vascular reactivity even more as compared to cool temperature dialysis $\left(35.5^{\circ} \mathrm{C}\right)^{2}$. This might, among other things, be caused by differences in energy transfer (ET) between the two treatment modalities.

New devices enable us to study the extracorporeal ET rather than studying Td, and give us the opportunity to compare thermal energy effects of i-UF with combined ultrafiltration / hemodialysis (UF+HD) using different Td. Although ET has been studied in hemodialysis with different $\mathrm{Td}$, no studies have been done measuring $\mathrm{ET}$ during $\mathrm{i}-\mathrm{UF}^{3.14}$.

Therefore, in this study we compared the thermal effects of i-UF, UF +HD at a Td of $35.5^{\circ} \mathrm{C}$ (UF+HD $35.5^{\circ} \mathrm{C}$ ) and $\mathrm{UF}+\mathrm{HD}$ at a Td of $37.5^{\circ} \mathrm{C}$ (UF+HD $37.5^{\circ} \mathrm{C}$ ). After that, we determined which $\mathrm{Td}$ is needed to obtain the same extracorporeal energy transfer as compared to $\mathrm{i}-\mathrm{UF}$.

\section{Patients and methods}

\section{Patients}

Ten patients ( 5 women, 5 men) were selected from the chronic hemodialysis population in our university hospital. They had an average age of 66.4 years (range, 49 to 79) and an average time on renal replacement therapy of 25.9 months (range, 7 to 65 ). Renal disease was caused by nephrosclerosis ( 5 patients), diabetes mellitus ( 2 patients), hypertension ( 1 patient), nephrolithiasis (1 patient) and 
polycystic kidney disease (1 patient).

During each hemodialysis (HD) session blood flow (Qb) was $300 \mathrm{~mL} / \mathrm{min}$, dialysate flow (Qd) was $500 \mathrm{~mL} / \mathrm{min}$. Dialysate composition was individualized: bicarbonate, (28-36 mmol/L); sodium, (136-140 mmol/L); calcium, (1.50-1.75 $\mathrm{mmol} / \mathrm{L})$; acetate, $3 \mathrm{mmol} / \mathrm{L}$; potassium, $2 \mathrm{mmol} / \mathrm{L}$; magnesium, $0.5 \mathrm{mmol} / \mathrm{L}$; and chloride, $108 \mathrm{mmol} / \mathrm{L}$. The membranes used were the GFS 16 (Gambro, Lund, Sweden) in nine patients and the Polyflux 14S (Gambro, Lund, Sweden) in one patient. Optimal dry-weight was estimated by echography of the inferior caval vein ${ }^{15}$. Room temperature was kept constant between $22^{\circ} \mathrm{C}$ to $23^{\circ} \mathrm{C}$ by climate control. All patients gave informed consent for the study.

\section{Methods}

The Fresenius $^{\mathrm{R}} 4008 \mathrm{H}$ Dialysis Monitor was used during all measurements. The Fresenius ${ }^{\mathrm{R}}$ Blood Temperature Monitor (BTM) was used to measure venous $\left(\mathrm{T}_{\text {ven }}\right)$ and arterial $\left(T_{\text {arn }}\right)$ blood temperatures. By measuring $T_{\text {ven }}$ and $T_{a r}$, ET can be calculated according to the following formula:

\section{Formula 7.1: $\quad E T$ (in Watts) $=c x \rho x Q b x\left(T_{v e n}-T_{a r r}\right)$}

With $\mathrm{c}$ being the specific heat capacity of blood $\left(3.64 \mathrm{~kJ} /\left(\mathrm{kg} \mathrm{x}{ }^{\circ} \mathrm{C}\right), \rho\right.$ the blood density $\left(1052 \mathrm{~kg} / \mathrm{m}^{3}\right), \mathrm{Qb}$ the blood flow rate, $\mathrm{T}_{\mathrm{ven}}$ the temperature of the venous blood and $\mathrm{T}_{\text {art }}$ the temperature of the arterial blood. This shows that ET can be controlled by controlling $T_{v e n}$, which in turn can be controlled by changing the $\mathrm{Td}$. The BTM has control over the Td and its software offers a feedback control mechanism over the $\mathrm{ET}^{17}$. A negative ET means that energy is withdrawn from the patient (cooling), a positive ET means that energy is transferred to the patient (heating).

The body temperature (BT) of the patient was measured with an ear thermometer (Genius First Temp Model 3000A, Sherwood Medical, Northern Ireland) which correlates well with intra-arterial measured temperature $\left(r^{2}=0.999, p=0.0001\right)^{18}$.

The first part of the study consisted of three measurement sessions (i-UF, UF+HD $35.5^{\circ} \mathrm{C}$ and $\mathrm{UF}+\mathrm{HD} 37.5^{\circ} \mathrm{C}$ ) per patient in 10 patients and were done during 3 different dialysis sessions in a randomized order. Each patient served as his or her own control and measurements were done on the same day of the week for each patient, thus eliminating as much bias as possible.

In the first part of the study we determined the ET, $T_{\text {ven }}$ and BT during i-UF, $\mathrm{UF}+\mathrm{HD} 35.5^{\circ} \mathrm{C}$ and $\mathrm{UF}+\mathrm{HD} 37.5^{\circ} \mathrm{C}$. All other parameters were kept constant. Pilot studies showed that the ET reached a plateau within $15 \mathrm{~min}$, so all measurements were done during the first hr, after which the Td was reset to the patients regular treatment temperature.

The second part of the study consisted of one session of one hr with a pre-set ET 
(UF + HD ET-set) at the same level of ET found for that particular patient during i-UF in the first part of the study. During these measurements we determined the ET and $T_{\text {ven }}$ by using the BTM and BT by using the ear thermometer. The Td was assessed using the display of the Fresenius monitor (accuracy $\pm 0.1^{\circ} \mathrm{C}$ ). All other parameters were the same as in the first part of the study. The treatment session would be terminated when BT dropped more than $1.0^{\circ} \mathrm{C}$, Td went below $34.0^{\circ} \mathrm{C}$ or the patient experienced severe cold or shivers.

BT and Td were recorded manually every $30 \mathrm{~min}$. All other parameters were registered and recorded continuously via the data-acquisition possibilities of the Fresenius monitor, using a lap-top PC and recorded manually every $30 \mathrm{~min}$.

\section{Statistical analysis}

Parameters assessed during the different treatments were analyzed with a paired Student's t-test. Pearson's was used for assessing the correlation between two variables. Data are given in mean $\pm S D$ (range). $P$ value less than 0.05 was considered statistical significant. Calculations were done using SPSS for Windows, release 7.5 .

\section{Results}

\section{Baseline values}

In Table 7.1 the baseline values of the four treatment sessions are given. There were no significant differences in $\mathrm{BT}$ and $\mathrm{T}_{\text {ven }}$. The mean ultrafiltration rate during i-UF, UF + HD $35.5^{\circ} \mathrm{C}, \mathrm{UF}+\mathrm{HD} 37.5^{\circ} \mathrm{C}$ and UF+HD ET-set were respectively $726 \pm 75 \mathrm{~mL} / \mathrm{hr}, 685 \pm 128 \mathrm{~mL} / \mathrm{hr}, 786 \pm 108 \mathrm{~mL} / \mathrm{hr}$ and $684 \pm 260 \mathrm{~mL} / \mathrm{hr}$ (ns).

\section{First part of the study}

Changes in body temperature $(\triangle B T)$

The BT decreased significantly during i-UF $\left(-0.25 \pm 0.26^{\circ} \mathrm{C}, \mathrm{p}<0.05\right)$ and $\mathrm{UF}+\mathrm{HD} 35.5^{\circ} \mathrm{C} \quad\left(-0.24 \pm 0.18^{\circ} \mathrm{C}, \quad \mathrm{p}<0.05\right)$ and increased significantly during $\mathrm{UF}+\mathrm{HD} 37.5^{\circ} \mathrm{C}\left(+0.18 \pm 0.19^{\circ} \mathrm{C}, \mathrm{p}<0.05\right)$ (Table 7.2). The differences between $\triangle \mathrm{BT}$ during UF $+\mathrm{HD} 37.5^{\circ} \mathrm{C}$ compared with the other treatments are significant $(p<0.05)$. Differences between other combinations of treatment sessions are not significant. 
Table 7.1

Baseline values

\begin{tabular}{llc}
\hline & \multicolumn{1}{c}{ Body Temperature } & Venous Temperature \\
\hline First part of the study & & \\
i-UF & $36.49 \pm 0.39(35.80-37.10)$ & $36.48 \pm 0.32(36.02-37.06)$ \\
UF + HD $35.5^{\circ} \mathrm{C}$ & $36.53 \pm 0.50(36.00-37.70)$ & $36.50 \pm 0.22(36.23-36.88)$ \\
UF + HD $37.5^{\circ} \mathrm{C}$ & $36.48 \pm 0.52(35.30-37.30)$ & $36.54 \pm 0.32(36.21-37.29)$ \\
Second part of the study & & \\
UF + HD ET-set & $36.58 \pm 0.42(35.90-37.10)$ & $36.59 \pm 0.39(36.15-37.40)$ \\
\hline
\end{tabular}

Body - and venous temperatures at the beginning of measurements during isolated ultrafiltration ( $\mathrm{i}$-UF), combined ultrafiltration / hemodialysis with $35.5^{\circ} \mathrm{C}$ (UF $+\mathrm{HD} 35.5^{\circ} \mathrm{C}$ ) and $37.5^{\circ} \mathrm{C}$ temperature of the dialysate (UF $+\mathrm{HD} 37.5^{\circ} \mathrm{C}$ ) and combined ultrafiltration / hemodialysis with a pre-set energy transfer (UF+HD ET-set) $(n=10)$. Values are given in mean $\pm S D$ (range).

Table 7.2 Changes in temperature parameters and energy transfer

\begin{tabular}{lccc}
\hline & $\Delta \mathbf{B T}\left({ }^{\circ} \mathbf{C}\right)$ & $\Delta \mathbf{T}_{\text {ven }}\left({ }^{\circ} \mathrm{C}\right)$ & $\Delta \mathbf{E T}(\mathbf{W})$ \\
\hline First part of the study & & & \\
i-UF & $-0.25 \pm 0.26^{1}$ & $-2.02 \pm 0.22^{1}$ & $-30.8 \pm 3.1^{1}$ \\
& $(-0.60-0.20)$ & $(-2.51--1.81)$ & $(-36.6--28.1)$ \\
UF+HD 35.5 $5^{\circ} \mathrm{C}$ & $-0.25 \pm 0.18^{1}$ & $-1.53 \pm 0.19^{1}$ & $-23.6 \pm 4.1^{1}$ \\
& $(-0.50-0.00)$ & $(-1.89--1.34)$ & $(-31.7--20.1)$ \\
UF+HD 37.5 $\mathrm{C}$ & $0.18 \pm 0.19^{1}$ & $0.01 \pm 0.30$ & $0.4 \pm 4.7$ \\
& $(0.00-0.50)$ & $(-0.65-0.38)$ & $(-9.1-7.47)$ \\
Second part of the study & & & \\
UF+HD ET-set & & & $-32.7 \pm 4.9^{1}$ \\
& $(-0.17 \pm 0.26$ & $-2.20 \pm 0.37^{\prime}$ & $(-41.7--25.1)$ \\
\hline
\end{tabular}

Changes in body- $(\Delta \mathrm{BT})$ and venous-temperatures $\left(\Delta \mathrm{T}_{\mathrm{ven}}\right)$ and energy transfer $(\Delta \mathrm{ET})$ during one hr of isolated ultrafiltration (i-UF), combined ultrafiltration / hemodialysis with $35.5^{\circ} \mathrm{C}\left(\mathrm{U} \mathrm{F}+\mathrm{HD} 35.5^{\circ} \mathrm{C}\right.$ ) and $37.5^{\circ} \mathrm{C}$ dialysate (UF $+\mathrm{HD} 37.5^{\circ} \mathrm{C}$ ) and combined ultrafiltration / hemodialysis with a pre-set energy transfer (UF+HD ET-set) $\left(n=10,{ }^{\prime} p<0.05\right)$. Values are given in mean $\pm S D$ (range)

\section{Changes in venous temperature $\left(\Delta T_{\text {ven }}\right)$}

The $\mathrm{T}_{\text {ven }}$ decreased significantly during i-UF $\left(-2.02 \pm 0.22^{\circ} \mathrm{C}, \mathrm{p}<0.05\right)$ and $\mathrm{UF}+\mathrm{HD} 35.5^{\circ} \mathrm{C}\left(-1.53 \pm 0.19^{\circ} \mathrm{C}, \mathrm{p}<0.05\right)$. The increase in $\mathrm{T}_{\mathrm{ven}}$ found during UF $+H D 37.5^{\circ} \mathrm{C}$ was not significant (Table 7.2). The differences in $\Delta T_{\text {ven }}$ between all possible combinations of treaument sessions are all significant $(\mathrm{p}<0.05)$.

\section{Changes in energy transfer ( $\triangle E T$ )}

A significant negative ET was measured during i-UF $(-30.8 \pm 3.1 \mathrm{~W} ; \mathrm{p}<0.05)$ and $\mathrm{UF}+\mathrm{HD} 35.5^{\circ} \mathrm{C}(-23.6 \pm 4.1 \mathrm{~W} ; \mathrm{p}<0.05)$. A slightly positive ET was found during UF+HD $37.5^{\circ} \mathrm{C}(+0.4 \pm 4.7 \mathrm{~W})$ which is not significant (Table 7.2). The 
differences in ET between, all combinations of treatments are again significant $(p<0.05)$.

\section{Second part of the study}

\section{Thermal effects}

The negative ET during one hr of UF+HD ET-set $(-32.7 \pm 4.9 \mathrm{~W})$ was indeed comparable with the negative ET of i-UF $(-30.8 \pm 3.1 \mathrm{~W})$. In order to realize this negative ET during UF + HD ET-set, the Td had to be decreased to a mean Td of $34.75^{\circ} \mathrm{C}\left(34.0^{\circ} \mathrm{C}\right.$ to $\left.36.0^{\circ} \mathrm{C}\right)$. This resulted in a significant decrease of the $\mathrm{T}_{\text {ven }}$ $\left(-2.20 \pm 0.37^{\circ} \mathrm{C}, \mathrm{p}<0.05\right)$, and a decrease of BT $\left(-0.17 \pm 0.26^{\circ} \mathrm{C}\right)$ which was not significant. Changes in $\mathrm{BT}, \mathrm{T}_{\mathrm{ven}}$ and $\mathrm{ET}$ do not differ significantly between $\mathrm{i}-\mathrm{UF}$ and UF +HD ET-set. We found a significant correlation between predialysis BT and Td during UF+HD ET-set $(r=0.764, p<0.05)$. None of the treatment sessions had to be terminated.

\section{Discussion}

In earlier studies we found a difference in vascular reactivity between i-UF and $\mathrm{UF}+\mathrm{HD}$ at cool-dialysate temperatures ${ }^{2}$. Because we wondered whether these differences could be related to quantitative differences in thermal balance, we compared in this study the thermal effects of $\mathrm{i}-\mathrm{UF}$ and cool temperature dialysis $\left(35.5^{\circ} \mathrm{C}\right)$ using standard temperature dialysis $\left(37.5^{\circ} \mathrm{C}\right)$ as control.

We found that the ET from the extracorporeal system to the patient gave a significant more negative value during i-UF than during UF+HD $35.5^{\circ} \mathrm{C}$. Comparing the ET found during cool temperature dialysis in our study to those described in other studies there were some differences. In the study by Provenzano et al ${ }^{14}$, the ET found with a Td of $34^{\circ} \mathrm{C}$ is not as low as would be expected when extrapolating our results to a $\mathrm{Td}$ of $34^{\circ} \mathrm{C}$. This difference during low temperature dialysis between the two centres could be explained by the fact that the $\mathrm{Qb}$ is only $190 \mathrm{~mL} / \mathrm{min}$ in their study compared to $300 \mathrm{~mL} / \mathrm{min}$ in our study, thus giving a less negative ET according to formula 7.1. Another explanation might be the use of acetate in their study, which might induce larger heat loss from the body to the environment because of excessive peripheral vasodilatation, provoking more encrgy influx from the extracorporeal circuit to the patient ${ }^{14}$. However our results are in agreement with the study of Schneditz et $\mathrm{al}^{4}$, who also used a mean pre-set ET of $-30.2 \pm 3.7 \mathrm{~W}$, which led to a mean $\mathrm{Td}$ of $35.3 \pm 0.2^{\circ} \mathrm{C}$. The differences are small and might be caused by the slightly lower $\mathrm{Qb}(250 \mathrm{~mL} / \mathrm{min})$ or a difference in $\mathrm{BT}$ at the start of treatment. The conditions in our earlier study are comparable with the present study resulting in the same changes of $\mathrm{ET}^{3}$. 
In our study BT decreased significantly during i-UF and cool dialysis without significant differences between the two treatments. These data are in accordance with previous studies from our group ${ }^{2,3}$.

When we compared cool temperature dialysis with the standard temperature dialysis treatment (UF $+\mathrm{HD} 37.5^{\circ} \mathrm{C}$ ) we found that the ET from the extracorporeal system to the patient gave a significant more negative value during cool-dialysis. whereas the ET during the standard treatment was only $0.4 \mathrm{~W}$. These data are almost in agreement with the data of Schneditz et $\mathrm{al}^{4}$, who found a net energy loss of $-13.4 \mathrm{~W}$, although in their study $\mathrm{Td}$ was set at $37.3^{\circ} \mathrm{C}$. The higher value ET in the study of Provenzano could be explained by, as previously mentioned, a difference in predialysis body temperature ${ }^{14}$.

However, despite the fact that ET was only slightly positive during UF +HD $37.5^{\circ} \mathrm{C}$ there was a significant increase in BT. This significant increase in BT despite a very minor ET from the extracorporeal system to the patient suggests an effect of dialysis on BT, which is in accordance with other studies ${ }^{2-4}$. It has been suggested that the increase in BT might be caused by a BT increasing factor derived from contact with a bioincompatible membrane or 'unpure' dialysate. It has also been hypothesized that a BT decreasing factor might be removed during dialysis $^{5-7}$. Another contributing factor might be a reduced loss of thermal energy through the skin, caused by increased vasoconstriction as suggested by Gotch, although in earlier studies by our group only minor changes in arterial and venous reactivity during dialysis at a temperature of $37.5^{\circ} \mathrm{C}$ were observed ${ }^{3.19-21}$.

In the second part of this study we assessed which Td is needed to obtain the same ET during UF $+H D$ as found during $\mathrm{i}-\mathrm{UF}$. The mean $\mathrm{Td}$ at which the ET is comparable is $34.75^{\circ} \mathrm{C}$ and varied from $34^{\circ} \mathrm{C}$ to $36^{\circ} \mathrm{C}$. During this session none of the patients complained of side-effects. The Td needed to obtain the same ET compared with i-UF, was strongly dependent on the predialytic body temperature.

From this study we conclude that ET from the extracorporeal system to the patient gives a significant more negative value during i-UF than during cool-dialysis at a $\mathrm{Td}$ of $35.5^{\circ} \mathrm{C}$. To achieve the same thermal energy balance a $\mathrm{Td}$ between $34^{\circ} \mathrm{C}$ and $36^{\circ} \mathrm{C}$ is needed depending on the predialytic body temperature. The results of this study may be of relevance for further clinical investigations answering the questions whether differences in vascular response between $\mathrm{i}-\mathrm{UF}$ and UF + HD are only related to differences in thermal energy balances or whether they imply more complex regulatory mechanisms.

\section{Metric conversion}

Temperature: ${ }^{\circ} \mathrm{C}=\left({ }^{\circ} \mathrm{F}-32\right) / 1.8$

Energy Transfer: $1 \mathrm{~W}=1 \mathrm{~J} / \mathrm{s}=3.6 \mathrm{~kJ} / \mathrm{h}=0.239 \mathrm{cal} / \mathrm{s}$ 


\section{References}

1. Fox SD, Henderson LW. Cardiovascular response during haemodialysis and haemofiltration: thermal, membrane and catecholamine influences. Blood Purif 1993;11:224-36.

2. van Kuijk WHM, Luik AJ, de Leeuw PW. van Hooff JP, Niemann FHM, Habets HML, Leunissen KML. Vascular reactivity during haemodialysis and isolated ultrafiltration: thermal influences. Nephrol Dial Transplant 1995;10:1852-8.

3. van der Sande FM, Kooman JP, Burema JHGA, Hameleers P, Kerkhofs AMM, Barendregt JM, Leunissen KML. Effect of dialysate temperature on energy balance during haemodialysis; quantification of energy transfer from the extracorporeal circuit to the patient. Am J Kidney Dis 1999;33:115-21.

4. Schneditz D, Martin K, Krämer M, Kenner T, Skrabal F. Effect of controlled extracorporeal blood cooling on ultrafiltration-induced blood volume changes during haemodialysis. J Am Soc Nephrology 1997;8:956-64.

5. Davenport A, Davison A, Will E. Membrane biocompatability: effects on cardiovascular stability in patients on hemofiltration. Kidney Int 1993;43:S230-S4.

6. Fine A, Penner B. The protective effect of cool temperature dialysate is dependent on patients' predialysis temperature. Am J Kidney Dis 1996;28:262-5.

7. Kluger $M$, Turnbull A, Cranston W, Wing A, Gross M, Rothenburg B. Endogenous cryogen excreted by the kidneys. Am J Physiol 1981;241:R271-R6.

8. Daugirdas JT. Dialysis hypotension: a haemodynamic analysis. Kidney Int 1991;39:233-46.

9. Maggiore Q, Pizzarelli F, Sisca S, Zocalli C, Parlongo S, Nicolo F, Creazzo G. Blood temperature and vascular stability during haemodialysis and haemofiltration. Trans Am Soc Artif Intern Organs 1982;28:523-7.

10. Coli U, Landini S, Locatello S, Fracasso A, Morachiello P, Righctto F, Scanferla F, Onesti $G$, Bazzato $G$. Cold as cardiovasular stabilizing factor in haemodialysis: Haemodynamic evaluation. Trans Am Soc Artif Intern Organs 1983:29:71-5.

11. Mahida BH, Dumler F, Zasuwa G, Flieg G, Levin NW. Effect of cooled dialysate on serum catecholamines and blood pressure stability. Trans Am Soc Artif Intern Organs 1983;29:384-9.

12. Sherman RA, Faustino EF, Bernholc AS, Eisinger RP. Effect of variations in dialysate temperature on blood pressure during haemodialysis. Am J Kidney Dis $1984: 4: 66-8$.

13. Levy FL, Grayburn PA, Foulks CJ, Brickner ME. Henrich WL. Improved left ventricular contractility with cool temperature haemodialysis. Kidney Int 1992;41:961-5.

14. Provenzano R, Sawaya B, Frinak S, Polashegg HD, Roy T, Zasuwa G, Dumler F, Levin NW. The effect of cooled dialysate on thermal energy balance in haemodialysis patients. Trans Am Soc Artif Organs 1988:34:515-8.

15. Leunissen KML, Kouw P, Kooman JP, Cheriex EC, de Vries PMJM, Donker AJM, $\operatorname{van}$ Hooff JP. New techniques to determine fluid status in hemodialyzed patients. Kidney Int 1993;43:S50-S6. 
16. Krämer M, Steil H, Polaschegg HD. Optimization of a sensor head for blood temperature measurement during haemodialysis. Proc Ann Int Conf IEEE-EMBS 1992;14:1610-1.

17. Krämer $M$, Polaschegg HD. Control of blood temperature and thermal energy balance during haemodialysis. Proc Ann Int Conf IEEE-EMBS 1992;14:2299-300.

18. Edge G, Morgan M. The Genius infrared tympanic thermometer. Anaesthesia 1993;48:604-7.

19. Gotch FA, Keen ML, Yarian SR. An analysis of thermal regulation in haemodialysis with one and three compartment models. Trans Am Soc Artif Intern Organs 1989;35:622-4.

20. van Kuijk WHM, Hillion D, Savoiu C, Leunissen KML. Critical role of the extracorporeal blood temperature in the Haemodynamic response during haemofiltration. J Am Soc Nephrol 1997;8:949-55.

21. Kooman JP, Gladziwa U, Böcker G, Wijnen JAG, van Bortel LMAB, Luik AJ, de Leeuw PW, van Hooff JP, Leunissen KML. Role of the venous system in haemodynamics during ultrafiltration and bicarbonate dialysis. Kidney Int 1992;42:718-26. 


\section{Chapter 8}

\section{Energy transfer is the single most important factor for the difference in vascular response between isolated ultrafiltration and hemodialysis}

FM van der Sande, U Gladziwa, JP Kooman, G Böcker, KML Leunissen 


\section{Abstract}

Differences in vascular reactivity between isolated ultrafiltration (i-UF) and hemodialysis (UF+HD) have been attributed to various factors including differences in core temperature (CT) and energy transfer (ET). However, the relative importance of these thermal factors is not known. The aim of this study was to elucidate to what extent differences in ET are responsible for the divergent vascular response between i-UF and $\mathrm{UF}+\mathrm{HD}$.

During 4 different dialysis treatments in 15 patients, 4 measurements were performed which consisted of $\mathrm{I} \mathrm{hr}$ of $\mathrm{i}-\mathrm{UF}, \mathrm{UF}+\mathrm{HD}$ at a dialysate temperature (Td) of $37.5^{\circ} \mathrm{C}$ (UF $\left.+\mathrm{HD}^{37.5}\right), \mathrm{UF}+\mathrm{HD}$ at $\mathrm{Td} 35.5^{\circ} \mathrm{C}\left(\mathrm{UF}+\mathrm{HD}^{35.5}\right)$, and $\mathrm{UF}+\mathrm{HD}$ with a similar ET found for that particular patient during $\mathrm{i}-\mathrm{UF}\left(\mathrm{UF}+\mathrm{HD}^{\mathrm{ET}-\mathrm{sec}}\right)$. The UF-rate in all sessions was $1 \mathrm{~L} / \mathrm{hr}$. Changes in CT $\left({ }^{\circ} \mathrm{C}\right)$ and ET (W) were assessed by use of a blood temperature monitor. Forearm vascular reactivity (FVR) and venous tone (VT) were assessed by strain-gauge plethysmography.

$C T$ decreased significantly during $\mathrm{i}$-UF and $U F+\mathrm{HD}^{\mathrm{ET}-\mathrm{set}} \quad(p<0.05)$, increased significantly during $U F+H D^{37.5}(p<0.05)$, and remained unchanged during $U F+H D^{35.5}$ (ns). FVR increased significantly during i-UF, UF $+H D^{\mathrm{ET} \text {-set }}$, and $U F+\mathrm{HD}^{35.5}(\mathrm{p}<0.05)$, but not during UF+HD ${ }^{37.5}(\mathrm{~ns})$. Between $U F+\mathrm{HD}^{37.5}$ and the other 3 measurements the change in FVR was significant $(p<0.05)$. VT increased significantly during $i-U F$, $\mathrm{UF}+\mathrm{HD}^{35.5}$, and $\mathrm{UF}+\mathrm{HD}^{\mathrm{Er}-\text { sel }}(\mathrm{p}<0.05)$, and decreased significantly during $\mathrm{UF}+\mathrm{HD}^{37.5}$ $(p<0.05)$. The change in VT was signiticantly lower during UF $+\mathrm{HD}^{37.5}$ compared to the other 3 measurements $(p<0.05)$.

When i-UF and UF+HD are matched for ET, all differences in vascular response disappear, showing that the difference in ET is the single most important factor for the observed difference in vascular response between $\mathrm{i}-\mathrm{UF}$ and UF+HD. In contrast to $\mathrm{UF}+\mathrm{HD}^{37.5}$, vascular reactivity was improved when the increase in CT was prevented during UF $+\mathrm{HD}^{35.5}$ and appeared to increase more when CT was lowered. Preventing the increase in $\mathrm{CT}$ during UF+HD appears to be mandatory for optimisation of hemodynamic stability during dialysis. 


\section{Introduction}

Hypotensive periods are common during hemodialysis, which may lead from minor discomfort to the patient to serious clinical events, resulting from myocardial and cerebral ischemia ${ }^{1}$. The primary initiating factor for hemodialysis associated hypotension is a decline in blood volume $e^{2.3}$. However, arterial and venous reactivity are impaired as well during hemodialysis ${ }^{4.5}$. An increase in systemic vascular resistance as well as venoconstriction, both favouring the return of blood from peripheral vessels to the heart, are of prime importance for the maintenance of hemodynamic stability during a decline in blood volume ${ }^{6-8}$. Research towards the pathophysiologic mechanisms behind the impaired vascular response during hemodialysis has been going on for more than 20 years. However, until now, the primary responsible factor has not been elucidated. Diffusive removal of vasopressor substances during dialysis has been implicated, as well as changes in electrolyte status or increased nitric oxide production by activated monocytes, stimulated by contact between (contaminated) dialysate and the artificial kidney ${ }^{5-16}$. However, none of the above mechanisms were found to be the sole explanatory factor for the reduced vascular reactivity during hemodialysis. Energy transfer (ET) may be an important contributory factor to this phenomenon ${ }^{17-20}$. During hemodialysis with standard temperature dialysate $\left(37^{\circ} \mathrm{C}\right.$ to $\left.38^{\circ} \mathrm{C}\right)$, core temperature (CT) increases which may lead to peripheral vasodilatation counteracting the normal vascular response to a decline in blood volume ${ }^{21}$. In earlier studies an improved vascular response was observed during dialysis with cool temperature dialysate $\left(35^{\circ} \mathrm{c}\right.$ to $36^{\circ} \mathrm{c}$ ) and isolated ultrafiltration (i-UF) compared to standard temperature dialysate $e^{22,23}$. CT generally remains stable during cool dialysis and decreases during i-UF due to pronounced energy loss from the patient to the extracorporeal circuit ${ }^{24}$. Thermal factors may therefore be of great importance in this respect. However, until now, it is not known to what extent differences in extracorporeal energy transfer (ET) or changes in CT are responsible for the divergent vascular response between i-UF and hemodialysis. New techniques enable us to measure CT and ET during i-UF and dialysis, and to model exactly the desired amount of ET during a dialysis session ${ }^{17,18,25}$. The airm of the present study was to assess whether differences in vascular response between i-UF and hemodialysis combined with ultrafiltration (UF $+\mathrm{HD}$ ) are primarily caused by differences in extracorporeal ET between these techniques. Furthermore, we wanted to know whether the CT should be lowered or whether it is sufficient to prevent the increase in $C T$ during dialysis in order to obtain an optimal vascular response. 


\section{Methods}

\section{Study population}

Fifteen patients ( 8 women, 7 men) were selected from the chronic hemodialysis population from the Kuraturium für Dialyse und Nierentransplantation in Würselen, Germany. The patient group had a mean age of $55 \mathrm{yr}$ (range, 21 to 77) and an average time on renal replacement therapy of 43.9 mo (range, 4 to 252). Renal disease was caused by chronic glomerulonephritis (2 patients), hypertensive nephrosclerosis (5 patients), nephrolithiasis (1 patient), reflux nephropathy (3 patients), juvenile nephronophtisis (1 patient), rapidly progressive glomerulonephritis (2 patients), and analgetic nephropathy (1 patient). Dialysis patients with diabetes mellitus, severe coronary heart disease (New York Heart Association classifications II or more), and a compromised left ventricular function (ejection fraction $30 \%$ or less) were excluded from the study for ethical reasons, as they were thought to be more prone to hypotensive periods with an increased CT at a higher $\mathrm{Td}^{26-33}$. The following antihypertensive medication was used on the patients: angiotensin converting enzyme inhibitors (4 patients), B-blocking agents ( 8 patients), calcium-channel blocking agents (7 patients), diuretics (5 patients), angiotensin-II receptor antagonist ( 3 patients), and $\alpha$-blocking agents ( 3 patients).

All medication was continued to study daily clinical practice in the treatment of dialysis patients who were dependent on antihypertensive medication. The patients also received their medication on the day of the study. All patients gave informed consent for the study.

\section{Study design}

The study consisted of four sessions each of one hr of i-UF, UF + HD at a dialysate temperature (Td) of $37.5^{\circ} \mathrm{C}\left(\mathrm{UF}+\mathrm{HD}^{37.5}\right), \mathrm{UF}+\mathrm{HD}$ at a $\mathrm{Td}$ of $35.5^{\circ} \mathrm{C}$ $\left(\mathrm{UF}+\mathrm{HD}^{35.5}\right.$ ), and $\mathrm{UF}+\mathrm{HD}$ in which the energy transfer (ET) was similar $\left(\mathrm{UF}+\mathrm{HD}^{\mathrm{ET}-\mathrm{set}}\right.$ ) for that particular patient as during i-UF. A dialysate temperature of $35.5^{\circ} \mathrm{C}$ was chosen because previous studies showed that $\mathrm{CT}$ remained unchanged with this temperature ${ }^{20.22 .23}$. The sessions were performed in a randomised order. The ultrafiltration-rate (UF-rate) in all sessions was 1 litre during the first hr. Each patient served as his or her own control and measurements were done on the same day of the week for each patient, thus eliminating as much bias as possible. The study was performed during one $\mathrm{hr}$ in order to prevent too large a decrease in CT during $\mathrm{i}-\mathrm{UIF}$ and $\mathrm{UF}+\mathrm{HD}^{\mathrm{ET} \text {-set }}$. We recently showed that the ET and CT during i-UF reached a stable level within $15 \mathrm{~min}$ after starting the treatment ${ }^{20.24}$. Furthermore, earlier studies already showed a large difference in vascular reactivity between UF $+\mathrm{HD}^{37.5}$, UF $+\mathrm{HD}^{35.0}$ and $\mathrm{i}$-UF $15 \mathrm{~min}$ after starting the treatment ${ }^{4.5 .16 .23}$. 
During all measurement sessions $C T$, the temperature at the arterial $\left(\mathrm{T}_{a r}\right)$ and venous $\left(T_{\text {ven }}\right)$ side of the fistula, as well as the ET between the extracorporeal circuit and the patient, and during UF $+\mathrm{HD}^{\mathrm{ET} \text {-set }}$ the Td was monitored at 10 -second intervals using the method described below.

\section{Energy transfer}

ET was defined as the amount of thermal energy being transferred from the extracorporeal circuit to the patient or vice versa. A positive value indicates net energy gain from the extracorporeal circuit to the patient, a negative value indicates net energy loss from the patient to the extracorporeal circuit. $\mathrm{T}_{\text {ar }}$ and $\mathrm{T}_{\text {ven }}$ were assessed with the use of continuous blood temperature monitoring $\left(\mathrm{BTM}^{\mathrm{R}}\right.$, Fresenius Medical Care, Den Bosch, The Netherlands) at the arterial and venous side of the extracorporeal system by an air-filled head with platinum sensor fitted around the arterial and venous catheters. By measuring $T_{\text {art }}$ and $T_{\text {ven }}$, ET can be calculated according to the following formula 1: $\mathrm{c} \times \rho \times \mathrm{Qb} \times\left(\mathrm{T}_{\mathrm{ven}}-\mathrm{T}_{\mathrm{ar}}\right) \times \mathrm{t}$, with $\mathrm{c}=$ specific thermal capacity $\left(3.64 \mathrm{~kJ} / \mathrm{kg} \times{ }^{\circ} \mathrm{C}\right), \mathrm{Qb}=$ extracorporeal blood flow, $\rho=$ density of blood $\left(1052 \mathrm{~kg} / \mathrm{m}^{3}\right), \mathrm{t}=$ dialysis time $(\mathrm{hr})^{34}$.

The BTM can not only passively calculate but also actively model the ET in the extracorporeal circuit. The rate at which thermal energy is to be fed or withdrawn from the patient via the extracorporeal circuit is achieved automatically by the thermal flux option of the BTM, which measures $T_{31}, T_{\text {ven }}$, and $Q b$ in 15-second intervals and which actually calculate the actual ET according to the above mentioned equation. The information of the actual ET is used by the algorithm of the BTM to automatically set and continuously adjust the Td to reach and to maintain the target ET. The ET rate is expressed in watts $(1 \mathrm{Watt}=3.6 \mathrm{~kJ} / \mathrm{hr})$.

\section{Core temperature}

The CT was measured by using the BTM described above. The BTM measures the temperature at the arterial side of the fistula and calculates central venous blood temperature by correcting for fistula and cardiopulmonary recirculation. This temperature is referred to as CT. This correction is necessary because the arterial blood temperature is determined by the CT as well as by the temperature of the recirculated venous blood. Recirculation is measured by the BTM with a temperature bolus which is produced by a temporary change in Td. The change in temperature is recorded by the venous sensor head of the ВTM and finally by the arterial sensor head. From the ratio in bolus sizes, recirculation can be calculated ${ }^{18}$. Predialytic $C T$ is defined as the first reliable temperature obtained (in all patients within $5 \mathrm{~min}$ ) after the start of dialysis. The accuracy of the CT is less than $0.1{ }^{\circ} \mathrm{C}$ as given by the manufacturer $\left(\mathrm{BTM}^{\mathrm{R}}\right.$, Fresenius Medical Care, Den Bosch, The Netherlands). By using the display of the BTM it is possible to read the 
instantaneous Td. The treatment session would be terminated when CT dropped more than $1.0^{\circ} \mathrm{C}$, $\mathrm{Td}$ went below $34.0^{\circ} \mathrm{C}$ or the patient experienced severe cold or shivers.

\section{Vascular reactivity}

Mean arterial blond pressure (MAP) and heart rate (HR) were measured with the Finapres method (Finapres. Ohmeda 2300, Lameris, The Netherlands). The mean value of $3 \mathrm{~min}$ was calculated. With the Finapres device, MAP and HR were measured beat to beat at zero transmural pressure by the use of a small finger cuff equipped with an infrared photoplethysmograph ${ }^{35}$. The Finapres cuff was applied to the third finger. Vascular reactivity was studied at the non-fistula arm which was positioned just above heart level using strain-gauge plethysmography as described by Whitney (Periflow; Janssen Scientific Instruments, Beerse, Belgium) ${ }^{36}$. An inflatable cuff was applied to the upper arm while the mercury-filled strain gauge was positioned at the thickest part of the forearm. In addition, an antecubital vein was cannulated (Venflon, $1 \mathrm{~mm}$ diameter) for the recording of direct intravenous pressure (Hewlett-Packard 78205C pressure monitor). Venous tone (VT, $\mathrm{mmHg} / \mathrm{mL} / 100 \mathrm{~mL}$ ) (pressure/volume ratio pointing to active venous constriction) and forearm vascular resistance (FVR, $\mathrm{mmHg} / \mathrm{mL} / 100 \mathrm{~mL} / \mathrm{min}$ ) were measured as previously described by van Kuijk et al. ${ }^{22}$. The coefficient of variation of consecutive measurements is $11.9 \%^{\circ}$.

\section{Blood volume}

Changes in relative blood volume (BV) were measured continuously and noninvasively by means of an optical reflection method which measures the absorption and scattering properties of red blood cells as they pass trough the hemodialysis circuit (Crit-line, In-I.ine Diagnostics, Riverdale, UT). The optical sensor was clipped to the in-line blood chamber on the arterial line and trends of hematocrit and $\% \mathrm{BV}$ (vs. time) were logged over the entire treatment period. In previous studies it has been shown that relative changes in BV can reliably be determined during hemodialysis by the serial monitoring of hematocrit ${ }^{37-3 y}$. The baseline value was obtained after $2 \mathrm{~min}$ of extracorporeal circulation at a blood flow of $250 \mathrm{~mL} / \mathrm{min}$ without ultrafiltration to exclude the influence of saline (recirculation) present in the extracorporeal circuit at the start of dialysis.

\section{Dialysis prescription}

During each of the 4 treatment sessions blood flow (Qb), dialysate flow (Qd), and dialysate composition were the same. The composition of the dialysate was: bicarbonate $28 \mathrm{mmol} \mathrm{L}$ to $36 \mathrm{mmol} / \mathrm{L}$, sodium $136 \mathrm{mmol} / \mathrm{L}$ to $140 \mathrm{mmol} / \mathrm{L}$, calcium $1.75 \mathrm{mmol} / \mathrm{L}$, acetate $3 \mathrm{mmol} / \mathrm{L}$, potassium $1 \mathrm{mmol} / \mathrm{L}$ to $3 \mathrm{mmol} / \mathrm{L}$, 
magnesium $0.5 \mathrm{mmol} / \mathrm{L}$, chloride $108 \mathrm{mmol} / \mathrm{L}$. The membranes used in our study were, a polysulfone membrane (F60S; Fresenius, Bad Homburg, Germany) in 2 patients, an excebrane membrane (E15; Terumo, Leuven, Belgium) in 2 patients, and a cellulose membrane (S12; Terumo, Leuven, Belgium) in 11 patients. Room temperature was kept constant between $22^{\circ} \mathrm{C}$ to $23^{\circ} \mathrm{C}$ by climate control.

\section{Statistical analysis}

The comparison between the values before the start and after one hr of the treatment within each treatment, as well as changes in predialysis weight, interdialytic weight gain, blood volume, CT, ET and vascular reactivity (FVR and VT) between the different treatments were analyzed by Friedman's analysis of variance and, if appropriate, by the Wilcoxon's signed rank test (SPSS-PC version $7.5)^{40}$. A P value less than 0.05 was considered significant. Data are expressed as mean \pm standard deviation.

\section{Results}

The predialysis weight in the 4 treatment sessions, $\mathrm{i}-\mathrm{UF}, \mathrm{UF}+\mathrm{HD}^{37.5}, \mathrm{UF}+\mathrm{HD}^{35.5}$ and UF $+\mathrm{HD}^{\mathrm{r} \text {-seser }}$ was, respectively, $73.78 \pm 17.15 \mathrm{~kg}, 73.95 \pm 17.31 \mathrm{~kg}$, $74.15 \pm 17.55 \mathrm{~kg}$ and $74.45 \pm 17.61 \mathrm{~kg}$ (ns). The interdialytic weight gain was $2.54 \pm 0.81 \mathrm{~kg}, 2.74 \pm 0.95 \mathrm{~kg}, 2.77 \pm 1.14 \mathrm{~kg}$, and $3.02 \pm 1.23 \mathrm{~kg}$ in the 4 treatment sessions (ns).

\section{Changes in energy transfer}

ET (Table 8.1, Figure 8.1) decreased significantly during i-UF, UF+H $\mathrm{HD}^{\mathrm{Fi}-\mathrm{set}}$, and $\mathrm{UF}+\mathrm{HD}^{35.5}(\mathrm{p}<0.05)$, and remained unchanged during $\mathrm{UF}+\mathrm{HD}^{57.5}(\mathrm{~ns})$. Between $\mathrm{i}-\mathrm{UF}$ and UF+HD ${ }^{\mathrm{ET} \text {-set }}$ the difference in ET was not significant, whereas between all other possible combinations of treatments the change in ET was significant $(\mathrm{p}<0.05)$. 
Table 8.1 Thermal Parameters ${ }^{1}$

\begin{tabular}{lcccc}
\hline & \multicolumn{2}{c}{$\Delta \mathrm{CT}\left({ }^{\circ} \mathrm{C}\right)$} & \multicolumn{2}{c}{$\Delta \mathrm{ET}(\mathrm{W})$} \\
\hline $\mathrm{i}-\mathrm{UF}$ & -0.56 & $(0.31)^{2,3}$ & -27.17 & $(3.44)^{2,3}$ \\
$\mathrm{UF}+\mathrm{HD}^{35.5}$ & -0.03 & $(0.19)^{3}$ & -17.61 & $(3.19)^{2,3}$ \\
$\mathrm{UF}+\mathrm{HD}^{37.5}$ & +0.15 & $(0.10)^{2}$ & +0.88 & $(3.85)$ \\
$\mathrm{UF}+\mathrm{HD}^{\mathrm{ET} \text {-set }}$ & -0.27 & $(0.21)^{2.3}$ & -28.69 & $(4.47)^{2,3}$ \\
\hline
\end{tabular}

" Data are expressed as mean (standard deviation). $\triangle \mathrm{CT}$ stands for changes in core temperature. $\Delta \mathrm{ET}$ stands for changes in energy transfer. $\mathrm{i}$-UF is isolated ultrafiltration; UF $+\mathrm{HD}^{37.5}$ is ultrafiltration combined with hemodialysis at a dialysate temperature of $37.5^{\circ} \mathrm{C}$; UF $+\mathrm{HD}^{35.5}$ is ultrafiltration combined with hemodialysis at a dialysate temperature of $35.5^{\circ} \mathrm{C}$; UF $+\mathrm{HD}^{\mathrm{ET}}$-set is ultrafiltration combined with hemodialysis in which the ET was similar for that particular patient as during i-UF. ${ }^{2} \mathrm{p}<0.05$ : changes vs. baseline. ${ }^{3} \mathrm{p}<0.05$; vs. UF $+\mathrm{HD}^{37.5}$.
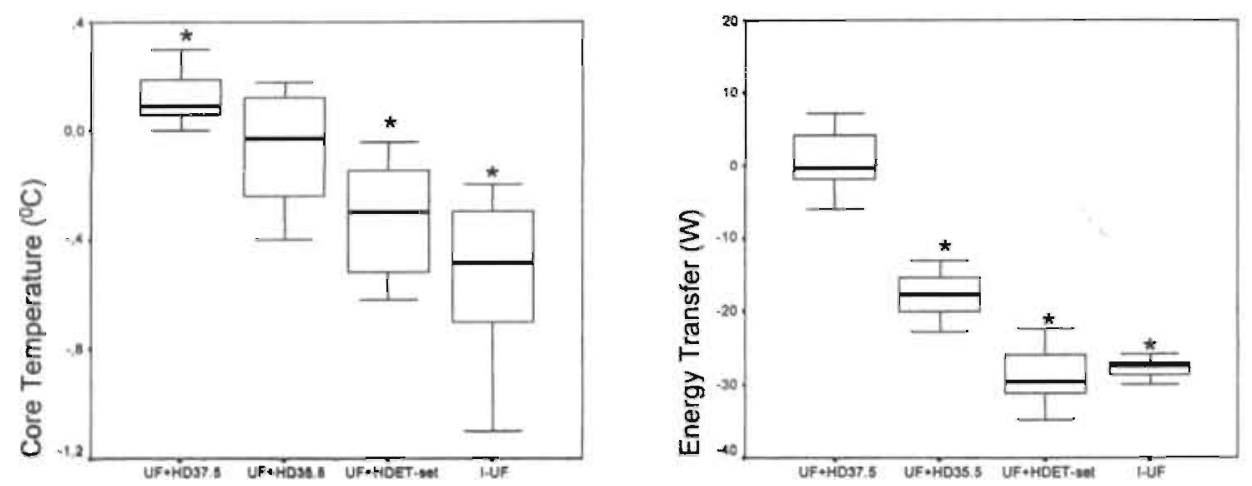

Figure 8.1 Changes in core temperature and energy transfer.

Box indicate the $25^{\text {th }}-75^{\text {th }}$ percentile range, capped bar indicate the $10^{\text {th }}-90^{\text {th }}$ percentile range. median. $\mathrm{i}-\mathrm{UF}$ is isolated ultrafiltration; $\mathrm{UF}+\mathrm{HD}^{37.5}$ is ultrafiltration combined with hemodialysis at a dialysate temperature of $37.5^{\circ} \mathrm{C}$; UF $+\mathrm{HD}^{35.5}$ is ultrafiltration combined with hemodialysis at a dialysate temperature of $35.5^{\circ} \mathrm{C}$; $\mathrm{UF}+H D^{\mathrm{ET} \text {-set }}$ is ultrafiltration combined with hemodialysis in which the ET was similar for that particular patient as during i-UF, $* p<0.05$; changes versus baseline.

\section{Changes in core temperature}

The predialysis $\mathrm{CT}$ in the 4 treatment sessions $\mathrm{i}-\mathrm{UF}, \mathrm{UF}+\mathrm{HD}^{37.5}, \mathrm{UF}+\mathrm{HD}^{35.5}$ and $\mathrm{UF}+\mathrm{HD}^{\mathrm{ET} \text {-set }}$ was, respectively, $36.44 \pm 0.39^{\circ} \mathrm{C}, 36.54 \pm 0.31^{\circ} \mathrm{C}, 36.42 \pm 0.35^{\circ} \mathrm{C}$ and $36.53 \pm 0.37^{\circ} \mathrm{C}$ (ns). In Table 8.1 and Figure 8.1 changes in CT are listed. CT decreased significantly during $\mathrm{i}-\mathrm{UF}$ and $\mathrm{UF}+\mathrm{HD}^{\mathrm{ET} \text {-set }}(\mathrm{p}<0.05)$, increased significantly during $U F+\operatorname{HD}^{37.5}(p<0.05)$, and remained unchanged during $\mathrm{UF}+\mathrm{HD}^{35.5}$ (ns). Between $\mathrm{i}-\mathrm{UF}$ and $\mathrm{UF}+\mathrm{HD}^{37.5}, \mathrm{i}-\mathrm{UF}$ and $\mathrm{UF}+\mathrm{HD}^{\mathrm{ET} \text {-set }}, \mathrm{i}-\mathrm{UF}$ and 
$\mathrm{UF}+\mathrm{HD}^{35.5}, \quad \mathrm{UF}+\mathrm{HD}^{37.5}$ and $\mathrm{UF}+\mathrm{HD}^{\mathrm{ET}-\mathrm{set}}, \quad \mathrm{UF}+\mathrm{HD}^{37.5}$ and $\mathrm{UF}+\mathrm{HD}^{35.5}$, $\mathrm{UF}+\mathrm{HD}^{35.5}$ and $\mathrm{UF}+\mathrm{HD}^{\mathrm{ET}-\text {-set }}$ changes in CT were significant $(\mathrm{p}<0.05)$.

\section{Changes in blood volume}

The decrease in blood volume versus baseline in the 4 treatment sessions was $-5.79 \pm 3.96 \%(p<0.05),-7.23 \pm 3.55 \%(p<0.05),-5.75 \pm 3.12 \%(p<0.05)$, and $-7.14 \pm 4.98 \% \quad(p<0.05)$. Between the 4 treatment sessions there were no significant differences (ns).

\section{Changes in vascular reactivity}

FVR increased significantly during i-UF, UF $+\mathrm{HD}^{\mathrm{tT}-\mathrm{set}}$, and $\mathrm{UF}+\mathrm{HD}^{* 5}(\mathrm{p}<0.05)$, but not during $U F+H^{3.5}$ (ns) (Table 8.2, Figure 8.2). Between $\mathrm{i}$-UF: and $\mathrm{UF}+\mathrm{HD}^{37.5}, \mathrm{UF}+\mathrm{HD}^{\mathrm{ET}-\mathrm{set}}$ and $\mathrm{UF}+\mathrm{HD}^{37.5}, \mathrm{UF}+\mathrm{HD}^{35.5}$ and $\mathrm{UF}+\mathrm{HD}^{37.5}$ the change in FVR was significant $(p<0.05)$, whereas between all other possible combinations there were no significant differences.

VT increased significantly during i-UF, UF $+H^{E T-s e t}$, and $U F+H^{35.5}(p<0.05)$, and decreased significantly during UF $+\mathrm{HD}^{37.5}(\mathrm{p}<0.05)$ (Table 8.2, Figure 8.2). Between $\mathrm{i}-\mathrm{UF}$ and $\mathrm{UF}+\mathrm{HD}^{3 ? 5}$. UF $+\mathrm{HD}^{35.5}$ and $\mathrm{UF}+\mathrm{HD}^{37.5}, \mathrm{UF}+\mathrm{HD}^{\mathrm{ET} \text {-set }}$ and $\mathrm{UF}+\mathrm{HD}^{37.5}$ the change in VT was significant $(\mathrm{p} \therefore 0.05)$.

\section{Changes in mean arterial pressure}

MAP decreased significantly during UF $+\mathrm{HD}^{37.5} \quad(\mathrm{p}<0.05)$ and remained unchanged in the other 3 treatment sessions (Table 8.2). There were no significant differences in changes in MAP between the 4 treatment sessions.

Table 8.2 Vascular Parameters ${ }^{1}$

\begin{tabular}{lrlrlll}
\hline & \multicolumn{2}{c}{$\Delta$ MAP } & \multicolumn{2}{c}{$\Delta$ FVR } & \multicolumn{2}{c}{$\Delta$ VT } \\
\hline i-UF & -0.13 & $(9.97)$ & +19.57 & $(13.87)^{2.3}$ & +6.06 & $(4.03)^{2.3}$ \\
UF $+H^{35.5}$ & +6.93 & $(13.00)$ & +16.87 & $(15.79)^{2.3}$ & +4.67 & $(3.74)^{2.3}$ \\
UF+HD & -7.80 & $(13.92)^{2}$ & +9.54 & $(18.08)$ & -3.49 & $(4.81)^{2}$ \\
UF+HD & +1.20 & $(9.59)$ & +26.51 & $(26.16)^{2.3}$ & +7.14 & $(8.66)^{2.3}$ \\
& & & & & & \\
\hline
\end{tabular}

'Data are expressed as mean (standard deviation). $\triangle M A P$ stands for changes in meari arierial pressure $(\mathrm{mmHg}), \triangle F V R$ stands for changes in forearm vascular resistance $(\mathrm{mmHg} / \mathrm{mL} / 100 \mathrm{~mL} / \mathrm{min})$. $\Delta V T$ stands for changes in venous tone $(\mathrm{mmHg} / 100 \mathrm{~mL} / \mathrm{mL})$. $\mathrm{i}-\mathrm{UF}$ is isolated ultrafiltration; UF $+\mathrm{HD}^{37.3}$ is ultrafiltration combined with hemodialysis at a dialysate temperature of $37.5^{\circ} \mathrm{C}$; $\mathrm{UF}+\mathrm{HD}^{35.5}$ is ultrafiltration combined with hemodialysis at a dialysate temperature of $35.5^{\circ} \mathrm{C}$; UF $+\mathrm{HD}^{\mathrm{ET} \text {-uet }}$ is ultrafiltration combined with hemodialysis in which the ET was similar for that particular patient as during i-UF. ${ }^{2} p<0.05$; changes vs, baseline. ${ }^{3}$ $\mathrm{p}<0.05 ;$ vs. UF $+\mathrm{HD}^{37.5}$. 

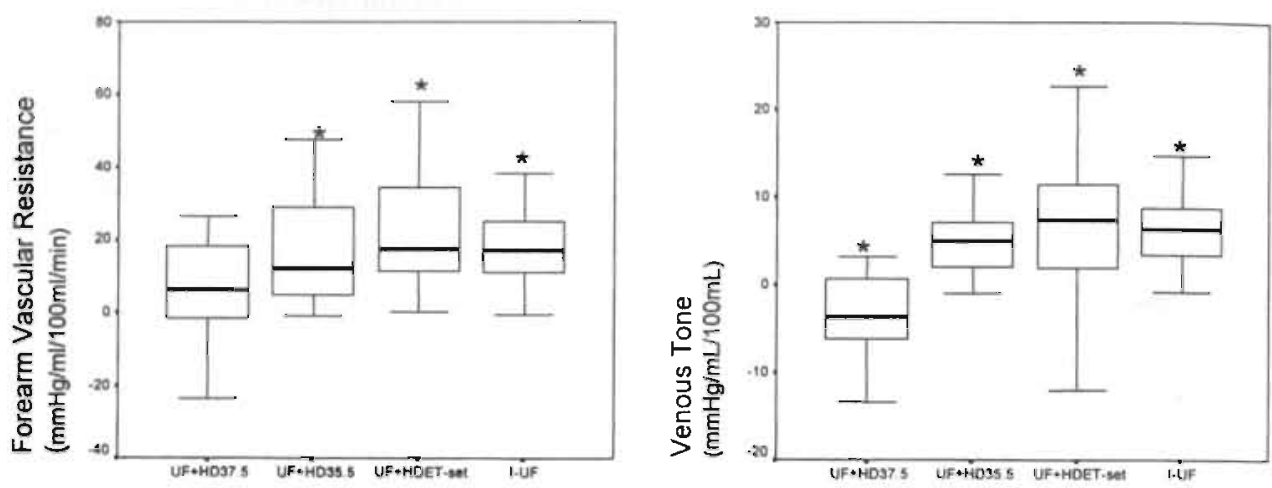

Figure 8.2 Changes in forearm vistular resistance and venous tone.

Box indicate the $25^{\text {th }}-75^{\text {th }}$ percentile range, capped bar indicate the $10^{\text {th }}-90^{\text {th }}$ percentile range. - median. $\mathrm{i}-\mathrm{UF}$ is isolated ultrafiltration; UF $+\mathrm{HD}^{37.5}$ is ultrafiltration combined with hemodialysis at a dialysate temperature of $37.5^{\circ} \mathrm{C}$; UF $+\mathrm{HD}^{\text {s.5. }}$ is ultrafiltration combined with hemodialysis at a dialysate temperature of $35.5^{\circ} \mathrm{C}$ : $\mathrm{UF}+\mathrm{HD}^{\mathrm{ET}-\mathrm{set}}$ is ultrafiltration combined with hemodialysis in which the LT was similar for that particular patient as during i-UF. $* p<0.05$; changes versus baseline

\section{Discussion}

Our study is the first to show that the difference in vascular reactivity between $\mathrm{i}$-UF and hemodialysis disappears when both treatment modalities are matched for extracorporeal ET, suggesting that this is the single most important factor for the divergent vascular response between i-UF: and UF-HD.

During $\mathrm{UF}+\mathrm{HD}^{37.5} \mathrm{CT}$ increased, whereas during $\mathrm{i}-\mathrm{UF}$ and $\mathrm{UF}+\mathrm{HD}^{\mathrm{FT}}=\mathrm{CT}$ decreased and during UF $+\mathrm{HD}^{35.5} \mathrm{CT}$ remained unchanged. These changes in $\mathrm{CT}$ are in accordance with previous studies ${ }^{1720,41,42}$. In this and earlier studies, the increase in CT during UF $+\mathrm{HD}^{37.5}$ occurred in the absence of heat transfer from the extracorporeal circuit to the patient, suggesting that the dialysis treatment itself has an effect on $\mathrm{CT}$ regulation ${ }^{20,41}$. This would also explain the fact that the decrease in CT was more distinct during i-UF compared to UF $+\mathrm{HD}^{\mathrm{ET}-\mathrm{sec}}$. The potential mechanisms behind this phenomenon remain to be elucidated. Possible explanations have been discussed previously and include the production of a CT increasing factor derived from contact with a bioincompatible membrane or 'unpure' dialysate, or the removal of a CT decreasing factor during dialysis ${ }^{42-44}$. It has also been hypothesised that peripheral vasoconstriction during a decline in BV results in reduced heat loss of the skin and therefore in an increase in $\mathrm{CT}^{24}$. However, the 
fact that in this and earlier studies, only minor changes in FVR and VT were observed during UF $+\mathrm{HD}^{37.5}$ could contradict this hypothesis ${ }^{16,22}$.

Regarding the hemodynamic response, FVR did not increase significantly during $\mathrm{UF}+\mathrm{HD}^{37.5}$, in contrast to the other treatment modalities. This strongly suggests that the increase in CT during UF $+H^{37.5}$ is the most important factor for the impaired vascular response during UF-HD. This could be explained by a conflict between thermal regulatory mechanisms, favouring peripheral vasodilatation in order to lose excess heat, and circulatory homeostatic mechanisms favouring vasoconstriction ${ }^{7.21 .45 .45}$. Indeed. the increase in FVR was significantly higher when the increase in $C T$ was prevented during UF $+\mathrm{HD}^{35.5}$. The increase in FVR even appeared to be more distinct with the further lowering of $\mathrm{Cr}$ during $\mathrm{i}-\mathrm{UF}$ and $\mathrm{UF}+\mathrm{HD}^{\mathrm{ET}-\mathrm{set}}$, although the difference was not statistically significant. Regarding the reactivity of the venous system, VT even decreased during UF $+\mathrm{HD}^{37.5}$, suggesting that the peripheral venous system even appears to be more susceptible to changes in CT. It has indeed been shown in earlier studies that during an increase in CT, venodilation precedes arteriolar dilatation ${ }^{47}$. The effect of UF+HD on the venous system is possibly of great clinical importance since the centralisation of blood from the peripheral compartment during a decline in blood volume is partly mediated by changes in $\mathrm{VT}^{3.48}$.

During UF $+\mathrm{HD}^{37.5}$ MAP decreased significantly versus baseline, whereas during the other treatments there were no significant differences, which is in accordance with the directly measured changes in FVR and VT.

It is concluded that differences in vascular response between i-UF and UF + HD disappear when treatment modalities are matched for the extracorporeal ET, suggesting that this is the single most important factor for the divergent vascular response between UF $+\mathrm{HD}$ and $\mathrm{i}-\mathrm{UF}$. Prevention of the increase in CT during hemodialysis significantly improves the constriction of the peripheral resistance and capacitance vessels, although vascular reactivity even appeared to be somewhar more pronounced with a further lowering of CT. Prevention of the increase in CT by adjusting the dialysate temperature during UF +HD appears to be mandatory for the optimization of hemodynamic stability during dialysis. This might even be of more clinical importance in the treatment of hypotensive prone cardiaccompromised patients. 


\section{References}

1. Laupacis A, Muirhead N, Keown P, Wong C. A disease-specific questionnaire for assessing quality of life in patients on haemodialysis. Nephron 1992:60:302-6.

2. Wehle B, Asaba H, Castenfors J, Furst P, Gunnarsson B, Shaldon S, Bergstrom J. Hemodynamic changes during sequential ultrafiltration and dialysis. Kidney Int 1979; 15:411-8.

3. Flemming SJ, Wilkinson JS, Aldridge C, Greenwood RN, Baker LRI, Cattell WR. Blood volume changes during isolated ultrafiltration and combined ultrafiltrationdialysis. Nephrol Dial Transplant 1988;3:272-6.

4. Kooman JP, Wijnen JAG, Draayer $P$, et al. Compliance and reactivity of the peripheral venous sytem in patients treated with chronic intermittent hemodialysis. Kidney Int 1992;41:1041-8.

5. Knoman JP, Daemen MJ, Wijnen R, Verluyten-Goessens MJ, van Hooff JP, Leunissen KM. Morphological changes of the venous system in uremic patients. Nephron 1995;69:454-8.

6. Greenway CV, Wayne Lautt W. Blood volume, the venous system, preload, and cardiac output. Canadian J Phys Phar 1986;64:383-7.

7. Daugirdas JT. Dialysis hypotension; a hemodynamic analysis. Kidney Int 1991;39:233-46.

8. Kooman JP, Gladziwa U, Böcker G, van Bortel LMAB, van Hooff JP, Leunissen KML. Role of the venous system in hemodynamics during ultrafiltration and bicarbonate dialysis. Kidney Int 1992;42:718-26.

9. Henderson LW, Koch KM, Dinarello CA, Shaldon S. Hemodialysis hypotension: the interleukin-1 hypothesis. Blood Pur 1993;1:3-8.

10. Dinarello CA. Interleukin- 1 and tumor necrosis factor and their naturally occurring antagonists during hemodialysis. Kidney Int 1992;42(38):S68-S72.

11. Yokokawa K, Mankus R, Saklayen MG, et al. Increased nitric oxide production in patients with hypotension during hemodialysis. An Int Med 1995;123:35-7.

12. Bergamo Collaborative Dialysis Study Group. Acute intradialytic well-being; results of a clinical trial comparing polysulfone with cuprophane. Kidney Int 1991;40:714-9.

13. Collins DM, Lambert MB, Tannenbaum JS, Oliverio M, Schwab SJ. Tolerance of hemodialysis: a randomized prospective trial of high-flux versus conventional highefficiency hemodialysis. J Am Soc Nephrol 1993;4:148-54.

14. Skroeder NR, Jacobson SH, Lins LE, Kjellstrand CM. Acute symptoms during and between hemodialysis: the relative role of speed, duration, and biocompatibility of dialysis. Artif Org 1994; 18:880-7.

15. Aakhus S, Bjoernstad K, Jorstad S. Systemic cardiovascular response in hemodialysis without and with ultrafiltration with membranes of high and low biocompatibility. Blood Purif 1995:13:229-40.

16. van Kuijk WHM, Buurınan WA, Gerlag PG, Leunissen KML. Vascular reactivity during combined ultrafiltration-hemodialysis: influence of dialysis derived contaminants. J Am Soc Nephrol 1996:7:2664-9. 
17. Provenzano R, Sawaya B, Frinak $S$, et al. The effect of cooled dialysate on thermal energy balance in hemodialysis patients. Trans Am Soc Artif Intern Organs 1988; 17:515-8.

18. Krämer $\mathrm{M}$, Polaschegg $\mathrm{HD}$. Control of blood temperature and thermal energy balance during hemodialysis. Proc Annu Int Conf IEEE-EMBS 1992;14:2299-300.

19. Maggiore Q, Dattolo P, Piacenti M, et al. Thermal balance and hypotension Int J Artif Organs 1995;18:518-25.

20. van der Sande FM, Kooman JP, Burema JHGA, et al. Effect of dialysate temperature on energy balance during haemodialysis; quantification of energy transfer from the extracorporeal circuit to the patient. Am $J$ Kidney Dis 1999;33:1115-21.

21. Gotch FA, Keen ML, Yarian SR. An analysis of thermal regulation in haemodialysis with one and three compartment models. Trans Am Soc Artif Intern Organs 1989;35:622-4.

22. van Kuijk WHM, Luik AJ, de Leeuw PW, et al. Vascular reactivity during hemodialysis and isolated ultrafiltration: thermal influences. Nephrol Dial Transplant 1995;16:1852-8.

23. van Kuijk WHM, Hillion D, Savoiu C, Leunissen KML. Critical role of the extracorporeal blood temperature in the haemodynamic response during haemofiltration. J Am Soc Nephrol 1997;8:949-55.

24. Keijman JMG, van der Sande FM, Kooman JP, Leunissen KML. Thermal energy balance and body temperature: comparison between isolated ultrafiltration and haemodialysis at different dialysate temperatures. Neprol Dial Transplant 1999; 14:2196-2000.

25. Krämer M, Steil H, Polaschegg HD. Optimization of a sensor head for blood temperature measurement during haemodialysis. Proc Ann Int Conf [EEE-EMBS 1992;14:1610-1.

26. The Criteria Committee of the New York Heart Association. Diseases of the Heart and Blood Vessels; Nomenclature and Criteria for Diagnosis. 1964 6th Ed. Little, Brown, Boston.

27. Lindholm T, Thysell H, Yamamoto $\mathrm{Y}$, Forsberg B, Gullberg CA. Temperature and vascular stability in hemodialysis. Nephron 1985;39:130-3.

28. Marcen R, Quereda C, Orofino L, et al. Hemodialysis with low-temperature dialysate: a long-term experience. Nephron 1988;49:29-32.

29. Coli U, Landini S, Lucatello S, et al. Cold as cardiovascular stabilizing factor in hemodialysis: a hemodynamic evaluation. Trans Am Sos Artif Intern Organs $1983 ; 29: 71-5$.

30. Jost CMT, Agarwal R, Khair-El-Din T, Grayburn PA, Victor RG, Henrich WL. Effects of cooler temperature dialysate on hemodynamic stability in 'problem' dialysis patients. Kidney Int 1993;44:606-12.

31. Levy FL, Glaburn PA, Foulks CJ, Brickner ME, Henrich WL. Improved left ventricular contractility with cool temperature hemodialysis. Kidney Int 1992;41:961-5. 
32. Orofino L, Marcen C, Quereda C, et al. Epidemiology of symptomatic hypotension in hemodialysis patients: is cool dialysate beneficial for all patients? Am $\mathbf{J}$ Nephrol 1990; 10: 177-80.

33. Mahida BH, Dumler F, Zasuwa G, Fleig G, Levin NW. Effect of cooling dialysate on serum catecholamines and blood pressure stability. Trans Am Soc Artif Intern Organs 1983;29:384-9.

34. Schneditz D, Martin K, Kramer M, Kenner T, Skrabal F. Effect of controlled extracorporeal blood cooling on ultrafiltration-induced blood volume changes during hemodialysis. J Am Soc Nephrol 1997:8:956-64.

35. Penaz J. Photoelectric measurement of blood pressure, volume and flow in the finger. Digest 10th Int Conf Med Biol Engng 104, Dresden 1973.

36. Whitney RJ. The measurements of volume changes in human limbs. J Physiol 1953;121:1-27.

37. Maeda $\mathrm{K}$, Morita $\mathrm{H}$, Shizato $\mathrm{T}$, et al. Role of hypovolemia in dialysis-induced hypotension. Artif Organs 1988:12:116-21.

38. Steuer RR, Harris DH, Conis JM. A new technique for monitoring hematocrit and circulating blood volume: Its application in renal dialysis. Dialysis and Transplantation 1993;22:260-5.

39. L.eypoldt JK, Cheung AK, Steuer RR, Haris DH, Conis JM. Determination of circulating blood volume by continuously monitoring hematocrit during hemodialysis J Am Soc Nephrol 1995;6:214-9.

40. Stevens J. Applied multivariate statistics for the social sciences. Hillsdale, New Yersey, Lawrence Erlbaum Associates, Publishers, 1992.

41. Maggiore Q, Pizzarelli F, Sisca S, et al. Blood temperature and vascular stability during hemodialysis and hemofiltration. Trans Am Soc Artif Intern Organs 1982;28:523-7.

42. Fine A, Penner B. The protective effect of cool dialysate is dependent on patients' predialysis temperature. Am J Kidney Dis 1996;28:262-5.

43. Davenport A, Davison A, Will E. Membrane biocompatibility: effects on cardiovascular stability in patients on hemofiltration. Kidney Int 1993;43:s230-s4.

44. Kluger $M$, Turnbull A, Cranston W. Wing A, Gross M, Rothenburg B. Endogenous cryogen excreted by the kidneys. Am J Physiol 1981;241:R271-R6.

45. Tripathi A, Shi X, Wenger CB, Nadel ER. Effect of temperature and baroreceptor stimulation on reflex venomotor responses. J Appl Physiol 1984;57:1384-92.

46. Johnson JM. Nonthermoregulatory control of human skin blood flow. J Apll Physiol 1986:61:1613-22.

47. Wood JE, Eckstein JW. A tandem forearm plethysmograph for study of acute responses of the peripheral veins of man: the effect of environmental and local temperature change, and the effect of pooling blood in the extremities. J Clin Invest 1958:37:41-50.

48. Rothe CF. Reflex control of veins and vascular capacitance. Phys Rev 1983;63:1281-342. 


\section{Chapter 9}

\section{General Discussion}

FM van der Sande, JP Kooman, KML Leunissen

Strategies for improving hemodynamic stability in cardiaccompromised dialysis patients. Am J Kidney Dis (in press) 


\section{Introduction}

Despite the fact that the quality of life of patients undergoing hemodialysis and the growing understanding of the pathophysiological mechanisms that contribute to hemodynamic instability during hemodialysis has improved during the last 20 years, hemodialysis associated hypotension still remains a significant cause of patient morbidity ${ }^{1}$. The incidence of intradialytic hypotension is estimated at $25 \%$ and is even expected to increase due to an increasing number of elderly dialysis patients and to an increasing number of cardiovascular compromised dialysis patients ${ }^{2}$. In these hemodialysis patients, structural cardiovascular abnormalities as a decreased left ventricular compliance and a decreased venous compliance are common $^{3-6}$. These structural cardiovascular changes have important clinical implications, making dialysis patients more susceptible to the development of intradialytic hypotension ${ }^{7.8}$.

Symptomatic hypotension may occur as a result of a fall in blood volume and reduced vascular reactivity during dialysis in combination with structural abnormalities of the cardiovascular system. Therefore, in this aspect, strategies for improving hemodynamic stability should address each of this factors separately. In this chapter the optimal treatment for improving hemodynamic stability in cardiaccompromised dialysis patients will be discussed.

\section{Plasma volume preservation}

\section{Fluid status of the patient}

The immediate cause of a decrease in blood pressure during hemodialysis is intravascular hypovolemia. The fluid status of the patient has a major influence on changes in blood volume during dialysis. Adequate assessment of the fluid state, especially in cardiac-compromised patients, is mandatory to prevent intradialytic, intravascular hypovolemia and in consequence, intradialytic hypotension.

Structural cardiovascular changes such as a decreased left ventricular compliance (i.e. diastolic dysfunction) or a reduced myocardial contractility (i.e. systolic dysfunction) may predispose to symptomatic hypotension ${ }^{x-13}$. These patients have a very small margin between clinical overhydration and underhydration and are prone both to symptomatic hypotension and congestive heart failure ${ }^{8.12}$. Especially in these patients an optimal estimation of the dry-weight is of great importance to prevent intradialytic hypotension and interdialytic fluid gain. Echography of the inferior caval vein diameter correlates well with blood volume and right atrial pressure in dialysis patients and was found to be of clinical value in the assessment of dry weight in these patients. Ideally, the inferior caval vein diameter should be 
measured 1-2 hrs after dialysis because of ongoing refill from the interstitial ${ }^{14}$. Although the inferior caval vein diameter is a derivative of right atrial pressure, one should be careful with its interpretation as a marker of dry-weight in patients with severe left ventricular and/or valvular dysfunction ${ }^{15}$. In these patients the myocardial function should be taken into account, and based on the existence of either systolic or diastolic dysfunction optimal dry-weight should be determined.

\section{Ultrafiltration rate}

A main determinant of plasma volume preservation is the ultrafiltration rate. Despite a rapid decrease in vascular hydrostatic pressure, the fluid that is removed from the intravascular compartment cannot be compensated completely by refill from the interstitial at high ultrafiltration rates ${ }^{16-19}$. In chapter 2 it has been shown that the decrease in systolic blood pressure in cardiac-compromised patients when compared to patients without cardiac failure was much more distinct during ultrafiltration combined with hemodialysis (UF+HD) at a higher ultrafiltration rate, whereas there was a comparable decrease in blood volume between the 2 groups $^{20}$. Problems may be avoided by using an empirically determined maximal ultrafiltration rate in cardiac-compromised patients, which may differ for isolated ultrafiltration (i-UF) and UF+HD, and is also depending on the existence of either diastolic or systolic dysfunction of the myocardium. To obtain this goal, the duration of treatment may have to be extended ${ }^{21}$.

\section{Sodium profiling}

Another important factor is the dialysate sodium concentration. It has been shown that preventing the reduction in plasma osmolality during hemodialysis could improve hemodynamic instability ${ }^{22}$. The mechanism by which a high dialysate sodium concentration leads to hemodynamic stability seems to be mainly related to an improvement in plasma volume preservation ${ }^{23}$. Although sodium appears to be an important factor in hemodynamic stability during hemodialysis in cardiac stable patients, less is known about the effect of high sodium dialysis on plasma volume preservation in cardiac-compromised dialysis patients. A higher dialysate sodium may result in an increase of the exchangeable sodium pool, at the cost of thirst, in an increase in interdialytic weight gain and hypertension ${ }^{24}$. Since cardiaccompromised patients are very vulnerable to the above mentioned side-effects of the increased exchangeable sodium pool and in consequence to both symptomatic hypotension during dialysis and pulmonary congestion in between the dialysis, a balance has to be found between the beneficial effects of high sodium dialysate on plasma volume preservation without its deleterious effects. Sodium profiling allows to modify the quantity of sodium required for avoiding patient overload, and may reduce the incidence of intradialytic hypotension ${ }^{14.25-28}$. New devices are on their 
way, which enable us to adjust and control the dialysate sodium concentration automatically in order to target at the end of the dialysis session a value for the patient's plasma water conductivity ${ }^{29}$. However, the optimal approach for individualization of dialysate sodium concentration in cardiac-compromised patients has not been studied yet. Until that time in these patients the dialysate sodium concentration should be empirically individualired, whereas higher dialysate sodium concentrations should be used with great caution because of the previously mentioned side-effects ${ }^{26.30}$.

\section{Intravenous fluids}

The management of intradialytic hypotension is volume expansion, irrespective of the underlying mechanism. This has been done by injecting isotonic or hypertonic fluids, for instance isotonic or hypertonic saline ${ }^{31}$. A clinically frequent performed practice that frustrates attempts to attain dry-weight by increasing the fluid burden, thus necessitating greater ultrafiltration and further hypotension. Moreover, because of the side-effects of hypertonic saline, such as thirst, interdialytic weight gain and hypertension could especially be of great clinical importance in cardiaccompromised patients, and therefore this fluid is not without drawbacks. Volume expansion can also be performed by hyperoncotic infusions, such as dextran and mannitol ${ }^{31}$. However, because of their side-effects these fluids are of limited clinical importance.s. An intravenous infusion of albumin, an expensive and widely used fluid, or other hyperoncotic fluids could further enhance vascular refilling and improve hemodynamic stability ${ }^{38}$. Recent data have questioned the safety of albumin infusions, since it was reported that there was an increased risk of death in patients treated wit albumin because of hypovolemia ${ }^{39}$.

So, the ideal fluid should be inexpensive, rapid in onset, prolonged in duration, and associated with no side-effects. In intensive care wards hydroxyethylstarch, a relatively inexpensive synthetic colloid is used in the management of hypovolemic disturbances ${ }^{38,40}$. Because of its physicochemical qualities, hydroxyethylstarch has a long-standing volume effect up to $4 \mathrm{hrs}^{41}$. In chapter 3 the efficacy of isotonic saline $(0.9 \%)$, albumin $(20 \%)$ and hydroxyethylstarch $(10 \%)$ on blood volume during UF $+H D$ in stable dialysis patients was compared ${ }^{42}$. The fluids were infused when the decrease in blood volume was more than $10 \%$, whereas the ultrafiltration was continued. After infusion of hydroxyethylstarch and albumin, uhere was an immediate and sustained effect on blood volume, whereas blood volume continued to decrease with saline. Systolic blood pressure tended to decrease more with saline as compared to albumin and hydroxyethylstarch.

Data on the effect of both hypertonic saline and albumin on systolic blood pressure course in cardiac-compromised dialysis patients with frequent hypotensive periods are even scarce. In chapter 4 in cardiac-compromised patients with frequent symptomatic hypotensive episodes the efficacy of hypertonic saline $(3 \%)$, albumin 
$(20 \%)$ and hydroxyethylstarch $(10 \%)$ was assessed ${ }^{43}$. An intravenous infusion of $33 \mathrm{~mL}$ of saline, or $100 \mathrm{~mL}$ of albumin or hydroxyethylstarch was given when systolic blood pressure was less than $100 \mathrm{mmHg}$ or when the decrease in systolic blood pressure was greater than $25 \mathrm{mmHg}$ versus the start of the treatment. Also in this study the ultrafiltration was continued at the same rate. The results of this study showed that the decrease in systolic blood pressure after the intravenous infusion of the fluids was significantly greater when using saline compared with hydroxyethylstarch and tended to decrease more when using saline compared with albumin. Between albumin and hydroxyethylstarch there were no significant differences. From these 2 studies it can be concluded that the infusion of $100 \mathrm{~mL}$ of hydroxyethylstarch (10\%) is an effective maneuver in maintaining systolic blood pressure and preserving blood volume in hypotensive prone dialysis patients.

\section{Cardiovascular reactivity}

\section{Dialysate calcium concentration}

Calcium ions can have a pivotal role in the contractile process of both vascular smooth muscle cells and cardiac myocytes. However, because of the increased incidence of hypercalcemia, it is advised to use lower dialysate calcium concentrations to prevent or to treat hypercalcemia ${ }^{44-49}$. Several studies in dialysis patients have shown that changes in ionized calcium levels have significant hemodynamic effects ${ }^{51,51}$. This effect of dialysate calcium concentration on blood pressure seems to be mediated predominantly through changes in myocardial contractility, although several investigators also found a change in vascular reactivity ${ }^{50-34}$. A recent study by our group found that there was a significantly higher decrease in blood pressure during dialysis with low calcium dialysate compared with high calcium dialysate in patients with normal cardiac function, and this difference was mainly related to a decreased left ventricular contractility during the use of low calcium dialysates.

In chapter $\mathbf{5}$ in cardiac-compromised patients the effects of low calcium and high calcium dialysate on systolic blood pressure course were compared ${ }^{56}$. In this study systolic blood pressure decreased statistically and clinically significantly during UF + HD with the use of low calcium dialysate. On the other hand, during high calcium dialysate in the same patients systolic blood pressure decreased significantly, whereas mean arterial pressure remained unchanged. Moreover, during low calcium dialysate, blood pressure continued to decrease, whereas during high calcium dialysate blood pressure stabilized after $60 \mathrm{~min}$ and increased thereafter. This effect was mediated by direct changes in myocardial contractility, whereas systemic vascular resistance remained unchanged. Therefore, increase in 
dialysate calcium concentration has a clinically important positive effect on the blood pressure response during UF $+\mathrm{HD}$ in cardiac-compromised patients. The use of a $1.75 \mathrm{mmol} / \mathrm{L}$ calcium dialysate is indicated as a strategy for improving hemodynamic stability during during UF $+\mathrm{HD}$ in cardiac-compromised patients.

\section{Decrease in dialysate temperature}

In addition to a decline in blood volume during hemodialysis, an impaired vascular response is implicated in the pathogenesis of intradialytic hypotension. Isolated ultrafiltration has been shown to improve hemodynamic stability, which is due to a larger increase in vascular resistance, as compared to UF $+H D$. This difference might, among other factors, be caused by differences in core temperature and energy transfer over the extracorporeal circuit ${ }^{57.58}$. However, until recently, very little information was available regarding the influence of hemodialysis and $\mathrm{i}$-UF on these parameters. New devices enable us to study and to model the extracorporeal energy transfer continuously during a dialysis treatment.

In chapter 6 we studied changes in core temperature and energy transfer during $\mathrm{UF}+\mathrm{HD}$ with a dialysate temperature of respectively $37.5^{\circ} \mathrm{C}$ and $35.5^{\circ} \mathrm{C}$. We found that core temperature increased significantly during UF $+\mathrm{HD}$ at a dialysate temperature of $37.5^{\circ} \mathrm{C}$, whereas it remained stable during UF $+\mathrm{HD}$ at a dialysate temperature of $35.5^{\circ} \mathrm{C}^{59}$. In addition, as discussed in chapter 7 , we observed that core temperature decreased during i-UF. To achieve the same thermal energy transfer during UF $+\mathrm{HD}$ as during $\mathrm{i}-\mathrm{UF}$, a mean dialysate temperature of $34.8^{\circ} \mathrm{C}$ was needed ${ }^{60}$.

An increase in core temperature, as observed during UF +HD $37.5^{\circ} \mathrm{C}$, causes vasodilatation in the peripheral vasculature and might thus interfere with the normal vascular response to a decrease in blood volume ${ }^{61,62}$. Indeed, only a small increase in peripheral vascular resistance was observed during UF $+\mathrm{HD} 37.5^{\circ} \mathrm{C}$ despite a decline in blood volume. In contrast, peripheral vascular resistance increases to a significantly higher degree during i-UF and cool temperature dialysis $\left(35^{\circ} \mathrm{C}\right.$ to $36^{\circ} \mathrm{C}$ ) and leads to an improvement in hemodynamic stability $y^{63-67}$. Moreover, cardiac contractility appears to be increased during cool temperature dialysis ${ }^{66}$. These effects might be associated with an increase in sympathetic nerve activity ${ }^{64}$. Cool dialysis was found to be especially efficient in patients with a low predialysis core temperature, as is commonly observed in dialysis patients. This could be explained by the fact that in these patients, the rise in core temperature during dialysis is higher compared with patients with normal predialytic core temperatures, as shown in chapter $6^{59}$.

In addition, also the reactivity of the capacitance vessels is highly dependent on changes in core temperature. During dialysis with a dialysate temperature of $37.5^{\circ} \mathrm{C}$, even a dilatation of peripheral veins was observed despite a decline in blood volume. This is in contrast to the marked increase in venous tone which was 
observed during i-UF and cool dialysis. Since centralization of blood during a decline in blood volume is highly dependent on changes in venous reactivity ${ }^{7}$, it appears therefore of great clinical importance to prevent the increase in core temperature, especially in cardiac-compromised patients who are depending on an adequate return of blood to the heart to maintain cardiac output.

\section{Optimisation of extracorporeal energy transfer}

Thus, the extracorporeal blood temperature appears to be of great importance for the vascular response during hemodialyis. However, it was not known whether differences in extracorporeal energy transfer and core temperature were solely responsible factor for the divergent vascular response between i-UF and hemodialysis. To elucidate the relative importance of these parameters on vascular reactivity, in chapter 8 the effect of $\mathrm{i}-\mathrm{UF}, \mathrm{UF}+\mathrm{HD} 37.5^{\circ} \mathrm{C}, \mathrm{UF}+\mathrm{HD} 35.5^{\circ} \mathrm{C}$ and $\mathrm{UF}+\mathrm{HD}$ with a similar amount of energy transfer over the extracorporeal system was compared ${ }^{68}$. In this study we showed for the first time that differences in vascular reactivity between i-UF and hemodialysis completely disappear when both treatment modalities are matched for extracorporeal energy transfer, suggesting that this is the only most important factor for differences in vascular response between i-UF and standard hemodialysis (UF+HD $37.5^{\circ} \mathrm{C}$ ). Prevention of an increase in core temperature, as shown during $\mathrm{UF}+\mathrm{HD} 35.5^{\circ} \mathrm{C}$, also led to a significantly higher increase in forearm vascular resistance and venous tone compared with $\mathrm{UF}+\mathrm{HD} 37.5^{\circ} \mathrm{C}$, although vascular reactivity even appeared to be somewhat more pronounced when core temperature was lowered further by a more negative energy transfer. Therefore, it is advised to start with hypotensive prone cardiaccompromised patients with a dialysate temperature of $35.5^{\circ} \mathrm{C}$. A further reduction in dialysate temperature might have some additional beneficial effect, although it appears to be rather minor.

\section{The future: closed-loop biofeedback system}

Recent developments have made it possible to monitor relative changes in blood volume continuously during dialysis ${ }^{69}$. The basis of these techniques is the continuous monitoring of hematocrit, total protein, or hemoglobin from lysed erythrocytes from which the fall in blood volume can be estimated ${ }^{70.72}$. In some newer dialysis machines, options for continuous blood volume monitoring have become standard. With continuous blood volume monitoring, it may become possible to detect a fall in blood volume before this leads to symptomatic hypotension. If a steep fall in blood volume occurs, one may prevent a further decline, e.g. by slowing the ultrafiltration rate. It has been suggested that 
hypotensive periods occur at a patient-specific hematocrit ${ }^{73}$. The use of blood volume monitoring may enable the clinician to individualize ultrafiltration and may prevent hemodialysis hypotension in individual patients. However, the critical threshold within a safe margin has to be determined empirically for each patient.

Also the development of a sodium modeling device might enable us to automatically adjust and control the dialysate sodium concentration in order to improve plasma volume preservation and in consequence blood pressure, without the deleterious side-effects of too great a salt load to the patient ${ }^{26,311}$.

When blood volume decreases to a certain extent the first step should he a reduction in ultrafiltration rate, and at the same time the dialysate sodium might be increased. When blood pressure still declines despite these strategies, infusion of $100 \mathrm{~mL}$ of hydroxyethylstarch in 5 to $10 \mathrm{~min}$ might be considered because of an instantaneous effect on blood volume preservation and consequently, on blood pressure.

Although the fact that decreasing the dialysate temperature improves hemodynamic stability during dialysis, the influence of this parameter seems to be widely underestimated. Especially since there are new devices, such as a blood temperature monitor, which enable us to measure and model core temperature, venous and arterial blood temperature and extracorporeal energy transfer in a noninvasive way ${ }^{74-76}$. In the future, it may become possible to individualize dialysate temperature in order to prevent the increase in core temperature during UF $+\mathrm{HD}$.

\section{Conclusion}

With an increasing number of cardiovascular-compromised dialysis patients special attention should be given to this group of patients. As the age of patients on hemodialysis increases steadily, it is a challenge to provide a comfortable treatment in these patients by reducing the incidence of symptomatic hypotensive periods. This can often be accomplished by the use of following relatively simple clinical maneuvers.

Great care should be taken about the myocardial function of the dialysis patient, since the existence of diastolic or systolic dysfunction have great negative influences on the hemodynamic stability during dialysis. The decline in blood volume can be reduced by adequate estimation of the optimal dry-weight by objective methods. The ultrafiltration rate should be moderate, and limited to a certain extent, and individualized for each patient. Until now the optimal dialysate sodium concentration on levels of plasma volume preservation in cardiaccompromised patients remains to be elucidated. As high dialysate sodium concentrations could have deleterious effects in these vulnerable patients, the dialysate sodium concentration should, if possible, be adjusted to a "physiological" 
dialysate sodium concentration. When blood pressure still decreases because of a decrease in blood volume the infusion of $100 \mathrm{~mL}$. of hydroxyethylstarch may improve hemodynamic stability. To improve cardiovascular reactivity it is mandatory to use a dialysate calcium concentration of $1.75 \mathrm{mmol} / \mathrm{L}$ in combination with a dialysate temperature of $35.5^{\circ} \mathrm{C}$. When it is still necessary to improve vascular reactivity, decreasing the core temperature by adjusting the energy transfer over the extracorporeal system might have an additional beneficial effect.

In the future, it may become possible to integrate blood volume monitoring, blood temperature monitoring, and plasma conductivity monitoring within a closed-loop biofeedback system, which automatically adjusts the ultrafiltration rate. the plasma sodium concentration of the dialysate and the dialysate temperature according to the individually chosen profile of the patient. Such an approach may be of great clinical importance in preventing hemodialysis associated hypotension in the cardiac-compromised patient. 


\section{References}

1. Laupacis A, Muirhead N, Keown P, Wong C. A disease-specific questionnaire for assessing quality of life in patients on haemodialysis. Nephron 1992;60:302-6.

2. Zucchelli P, Santoro A. Dialysis-induced hypotension: a fresh look at pathophysiology. Blood Purif 1993;11:85-98.

3. Kooman JP, Wijnen JAG, Draaijer P, van Bortel L, Gladziwa U, Struyker Boudier HAJ, Peltenburg HG, van Hooff JP, Leunissen KML. Compliance and reactivity of the peripheral venous system in patients treated with chronic intermittent haemodialysis. Kidney Int 1992:41:1041-8.

4. London GM, Marchais SJ, Safar ME, Genest AF, Guerin AP, Metivier F, Chedid $\mathrm{K}$, London $\mathrm{AM}$. Aortic and large artery compliance in end-stage renal failure. Kidney Int 1990;37:137-42.

5. Parfrey PS, Harnett JD, Foley RN. Left ventricular hypertrophy in dialysis patients. Semin Dial 1992;5:34-41.

6. Rostand SG, Kirk KA, Rutskey EA. The epidemiology of coronary artery disease in patients on maintenance haemodialysis: implications for management. Contrib Nephrol 1986;52:34-41.

7. Kooman JP, Gladziwa U, Bocker G, van Bortel LMAB, van Hooff JP, Leunissen KML. Role of the venous system in hemodynamics during ultrafiltration and bicarbonate dialysis. Kidney Int 1992;42:718-26.

8. Ritz E, Rambausek M, Mall G, Ruffman K, Mandelbaum A. Cardiac changes to uremia and their possible relation to cardiovascular instability on dialysis. Contrib Nephrol 1990;78:221-9.

9. Bondia A, Tabernero JM, Macias JF, Martin-Luengo C. Autonomic nervous system in hemodialysis. Nephrol Dial Transplant 1988:2:174-80.

10. Parfrey PS, Foley RN, Harnett JD. Left ventricular hypertrophy in dialysis patients. Sem Dial 1992;5:34-41.

11. Kooman JP, Leunissen KML. Cardiovascular aspects in renal disease. Curr Op Nephrol Hypert 1993:2:791-7.

12. Cohen-Solal A. Left ventricular diastolic dysfunction: pathophysiology, diagnosis and treatment. Nephrol Dial Transplant 1998;13:S3-S5.

13. Wizemann V, Blank S, Kramer W. Diastolic dysfunction of the left ventricle in dialysis patients. Contrib Nephrol 1994;106:106-9.

14. Katzarski KS, Nisell J, Randmaa I, Danielsson A, Freyschuss U, Bergström J. A critical evaluation of ultrasound measurement of inferior vena cava diameter in assessing dry weight in normotensive and hypertensive dialysis patients. Am J Kidney Dis 1997;30:459-65.

15. Mandelbaum A, Ritz E. Vena cava diameter measurement for estimation of dry weight in hemodialysis patients. Nephrol Dial Transplant 1996;11;S24-S7.

16. Henderson LW. Symptomatic hypotension during dialysis. Kidney Int 1980;17:51-6.

17. Ronco Co Fabris A, Chiaramonte $S$, De Dominicis E, Feriani M, Brendolan A, Bragantini L, Milan M, Dell'Aquila R, La Greca G. Comparison of four different short dialysis techniques. Int J Art Org 1988;11:169-74. 
18. Keshaviah P, Shapiro FL. A critical examination of dialysis-induced hypotension. Am J Kidney Dis 1982;2:290-301.

19. Van Stone IC, Bauer JH, Carey J. The effect of dialysate sodium concentration on body fluid distribution during hemodialysis. Trans Am Soc Artif Organs 1980;26:383-6.

20. van der Sande FM, Mulder AW, Hoorntje SJ, Peels KH, van Kuijk WHM, Kooman JP, Leunissen KML. The hemodynamic effect of different ultrafiltration rates in patients with cardiac failure and patients without cardiac failure: comparison between isolated ultrafiltration and ultrafiltration + hemodialysis. Clin Nephrol 1998;50:301-8.

21. Brunet $P$, Saingra $Y$, Leonetti F, Vacher-Coponat H, Ramananarivo P, Berland Y. Tolerance of haemodialysis: a randomized cross-over trial of 5-h versus 4-h treatment time. Nephrol Dial Transplant 1996;11:S46-S51.

22. Rodrigo F, Shideman J, McHugh R, Buselmeier T, Kjellstrand C. Osmolality changes during haemodialysis: natural history, clinical correlations, and influence of dialysate glucose and intravenous mannitol. Ann Int Med 1977:86:554-61.

23. van Kuijk WHM, Wirtz JJM, Grave W, de Heer F, Menheere PPCA, van Hooff JP, Leunissen KML. Vascular reactivity during combined ultrafiltrationhaemodialysis: influence of dialysate sodium. Nephrol Dial Transplant 1996:11:323-8.

24. Robson M, Oren A, Ravid M. Dialysate sodium concentration, hypertension, and pulmonary edema in haemodialysis patients. Dial Transplant 1978;7:678-9.

25. Port FK, Johnson WJ, Klass DW. Prevention of dialysis disequilibrium syndrome by the use of high sodium concentration in the dialysate. Kidney Int 1973;3:327-33.

26. Henrich WL, Woodard TD, McPhaul JJ. The chronic efficacy and safety of high sodium dialysate: double-blind, crossover study. Am J Kidney Dis 1982;2:349-53.

77. Cybulsky AVE, Matni A. Hollomby DJ. Effects of high sodium dialysate during maintenance haemodialysis. Nephron 1985:41:57-61.

28. Locatelli F, Ponti R, Pedrini L, di Filippo S. Sodium and dialysis: a deeper insight. Int J Artif Org 1989;12:71-4.

29. Petitcierc $T$, Hamani A, Jacobs C. Optimization of sodium balance during haemodialysis by routine implementation of kinetic modelling: technical aspects and preliminary clinical study. Blood Purif 1992:10:309-16.

30. Wilkinson R, Barber SG, Robson V. Cramps, thirst and hypertension in haemodialysis patients - the influence of dialysate sodium concentration. Clin Nephrol 1977;7:101-5.

31. Mujais SK, Ing $T$, Kjellstrand $C$. Acute complications of hemodialysis and their prevention and treatment. In: Replacement of Renal Function by Dialysis, $4^{\text {th }}$ ed., edited by Winchester JF. Washington, Kluwer Academic Publishers 1995;698-724.

32. Bergonzi G, Paties C, Vassallo G, Zangrandi A, Poisetti PG, Ballochi S, Fontana F. Scarpioni L. Dextran deposits in tissues of patients undergoing haemodialysis. Nephrol Dial Transplant 1990;5:54-8.

33. Richter AW, Hedin H. Dextran hypersensitivity. Immunology Today 1982;3:132-8. 
34. Better OS, Rubinsteih I, Winaver JM, Knochel P. Mannitol therapy revisited (19401997) Kidney ]nt 1997:51:886-94.

35. Aviram A, Pfau A, Czackes JW, Ullman TD. Hyperosmolality with hyponatremia caused by inappropriate administration of mannitol. Am J Med 1967;42:648-50.

36. Dorman HR, Sondheimer JH, Cadnapaphornchai P. Mannitol-induced acute renal failure. Medicine (Baltimore) 1990;69:153-9.

37. Conte G, Dal Canton A, Imperatore P, De Nicola L, Gigliotti G, Pisanti A, Memoli B, Fuiano G, Esposito C, Andreucci VE. Acute increase in plasma osmolality as a cause of hyperkalemia in patients with renal failure. Kidney Int 1990;38:301-7.

38. Boldt J, Heesen M, Muller M, Pabsdorf M, Hempelmann G. The effects of albumin versus hydroxyethylstarch on cardiorespiratory and circulatory variables in critically ill patients. Anest Analg 1996;83:254-61.

39. Cochrane Injuries Group Albumin Reviewers. Human albumin administration in critically ill patients: systemic review of randomized controlled trials. BMJ 1998;317:235-40.

40. Hankeln K, Radel C, Beez M, Laniewsky P, Bohmert F. Comparison of hydroxyethylstarch and lactated Ringer's solution on hemodynamics and oxygen transport of critically ill patients in prospective crossover studies. Crit Care Med 1989;17:133-5.

41. Weidler B, von Bormann B, Sommermeyer K, Lohmann E, Peil J, Hempelmann G. Pharmakokinetische Merkmal als Kriterien für den klinische Einsatz von Hydroxyethylstarke. Arnzheim.-Forsch Drug Res 1991;41:494-8.

42. van der Sande FM, Kooman JP, Barendregt JNM, Nieman FHM, Leunissen KML. Effect of Intravenous Saline, Albumin or Hydroxyethylstarch on Blood Volume during combined Ultrafiltration and Hemodialysis. J Am Soc Nephrol 1999; 10:1303-8.

43. van der Sande FM, Luik AJ, Kooman JP, Verstappen V, Leunissen KML. Effect of Intravenous Fluids on Blood Pressure Course during Hemodialysis in Hypotensive Prone Patients. J Am Soc Nephrol (in press).

44. Argiles A, Kerr PG, Canaud B, Flavier JC, Mion C. Calcium kinetics and the longterm effects of lowering dialysate calcium concentration. Kidney Int 1993;43:630-40.

45. Johnson WJ. Optimum dialysate calcium concentration during maintenance haemodialysis. Nephron 1976;17:241-58.

46. Slatopolsky E, Weerts C, Lopez-Hilken S, Norwood K, Zink M, Windus D, Delmez J. Calcium carbonate as a phosphate binder in patients with chronic renal failure undergoing dialysis. N Engl J Med 1986;315:157-61.

47. Mactier RA, VanStone J, Cox A, VanStone M, Twardowski Z. Calciumcarbonate is an effective phosphate binder when dialysate calcium concentration is adjusted to control hypercalcemia. Clin Nephrol 1987;28:222-6.

48. Sherman RA. On lowering dialysate calcium. Semin Dial 1988;1:78-9. 
49. Sawyer N, Noonan K, Altmann P, Marsh F, Cunningham J. High-dose calcium carbonate with stepwise reduction in dialysate calcium concentration: Effective phosphate control and aluminium avoidance in haemodialysis patients. Nephrol Dial Transplant 1989;4:105-9.

50. Maynard JC, Cruz C, Kleerekoper M, Levin NW. Blood pressure response to changes in serum ionized calcium during haemodialysis. Ann Intern Med 1986; 104:358-61.

51. Fellner SK, Lang RM, Neumann A, Spencer KT, Bushinsky DA, Borow KM. Physiological mechanism for calcium-induced changes in systemic arterial pressure in stable dialysis patients. Hypert 1989;13:213-8.

52. Leunissen KML, van den Berg BW, van Hooff JP. Ionized calcium plays a pivotal role in controlling blood pressure during haemodialysis. Blood Purif 1989;7:233-9.

53. Henrich WL, Hunt JM, Nixon JV. Increased ionized calcium and left ventricular contractility during haemodialysis. N Eng J Med 1984;310:19-23.

54. Lang RM, Fellner SK, Neumann A, Budshinsky DA, Borow KM. Left ventricular contractility varies directly with blood ionized calcium. Ann Intern Med 1988; 108:524-9.

55. van Kuijk WHM, Mulder AW, Peels CH, Harff GH, Leunissen KML. Influence of changes in ionized calcium on cardiovascular reactivity during haemodialysis. Clin Nephrol 1997;47:190-6.

56. van der Sande FM, Cheriex EC, van Kuijk WHM, Leunissen KML. Effect of dialysate calcium concentrations on intradialytic blood pressure course in cardiaccompromised patients. Am J Kidney Dis 1998;32:125-31.

57. Maggiore Q, Pizzarelli F. Sisca S, Zocalli C, Parlongo S, Nicolo F, Creazzo G. Blood temperature and vascular stability during haemodialysis and hemofiltration. Trans Am Soc Artif Intern Organs 1982;28:523-7.

58. van Kuijk WHM, Luik AJ, de Leeuw PW, van Hooff JP, Niemann FHM, Habets HML, Leunissen KML. Vascular reactivity during haemodialysis and isolated ultrafiltration: thermal influences. Nephrol Dial Transplant 1995;10:1852-8.

59. van der Sande FM, Kooman JP, Burema JHGA, Hameleers P, Kerkhofs AMM, Barendregt JM. Leunissen KML. Effect of dialysate temperature on energy balance during haemodialysis; quantification of energy transfer from the extracorporeal circuit to the patient. Am J Kidney Dis 1999;33:1115-21.

60. Keijman JMG, van der Sande FM, Kooman JP, Leunissen KML. Thermal Energy Balance and Body Temperature: comparison between Isolated Ultrafiltration and Haemodialysis at different Dialysate Temperatures. Neprol Dial Transplant 1999; 14:2196-2000.

61. Schneditz D, Martin K, Krämer M, Kenner T, Skrabal F. Effect of controlled extracorporeal blood cooling on ultrafiltration-induced blood volume changes during haemodialysis. J Am Soc Nephrology 1997;8:956-4.

62. Daugirdas JT. Dialysis hypotension: a Haemodynamic analysis. Kidney Int 1991; 39:233-46. 
63. Coli U, Landini S, Locatello S, Fracasso A, Morachiello P, Righetto F, Scanferla F, Onesti G, Bazzato G. Cold as cardiovasular stabilizing factor in haemodialysis: Haemodynamic evaluation. Trans Am Soc Artif Intern Organs 1983;29:71-5.

64. Mahida BH, Dumler F, Zasuwa G, Flieg G, Levin NW. Effect of cooled dialysate on serum catecholamines and blood pressure stability. Trans Am Soc Artif Intern Organs 1983:29:384-9.

65. Sherman RA, Faustino EF, Bernholc AS, Eisinger RP. Effect of variations in dialysate temperature on blood pressure during haemodialysis. Am J Kidney Dis 1984;4:66-8.

66. Levy FL, Grayburn PA, Foulks CJ, Brickner ME, Henrich WL. Improved left ventricular contractility with cool temperature haemodialysis. Kidney Int $1992 ; 41: 961-5$.

67. Fine A, Penner B. The protective effect of cool temperature dialysate is dependent on patients' predialysis temperature. Am J Kidney Dis 1996;28:262-5.

68. van der Sande FM, Gladziwa U, Kooman JP, Bocker G, Leunissen KML. Energy transfer is the single most important factor for the difference in vascular response between isolated ultrafiltration and hemodialysis. Submitted.

69. Ishihara T, Igarashi J, Kitano T, Shinzato T, Maeda K. Continuous hematocrit monitoring method in an extracorporeal circulation system and its application for automatic control of blood volume during artificial kidney treatment. Artil ()rg 1993; 17:708-16.

70. Flemming SJ, Wilkinson JS, Aldridge C, Greenwood RN, Baker LRI, Cattell WR. Blood volume changes during isolated ultrafiltration and combined ultrafiltrationdialysis. Nephrol Dial Transplant 1988;3:272-6.

71. Steuer R, Leypoldt JK, Cheung A, Senekjian H, Connis J. Reducing symptoms during dialysis by continuously monitoring the hematocrit. Am J Kidney Dis $1996 ; 27: 525-32$.

72. Schallenberg U, Stiller S, Mann H. A new method of continous hemoglobinometric measurements of blood volume during dialysis. Life Support Systems; 1987;5:293-305.

73. Steuer R, Leypoldt JK, Cheung A, Harris D, Conis J. Hematocrit as an indicator of blood volume and a predictor of intradialytic morbid events. Trans Am Soc Artif Int Org 1983;24:383-9.

74. Krämer M, Steil H, Polaschegg HD. Optimization of a sensor head for blood temperature measurement during haemodialysis. Proc Ann Int Conf IEEE-İMBS $1992 ; 14: 1610-1$.

75. Krämer $\mathrm{M}$, Polaschegg HD. Control of blood temperature and thermal entergy balance during haemodialysis. Proc Ann Int Conf IEEE-FiMBS 1992;14:2299-300.

76. Provenzano R, Sawaya B, Frinak S, Polashegg HD, Roy T, Zasuwa G, Dumler F, Levin NW. The effect of cooled dialysate on thermal energy balance in haemodialysis patients. Trans Am Soc Artif Organs 1988;34:515-8. 


\section{Chapter 10}

Summary and concluding remarks 


\section{Summary and concluding remarks}

In patients with end-stage renal failure, uremic toxins are not eliminated and the electrolyte- and acid-base status of the body will be disturbed. Furthermore, body fluid will increase because of a decline or complete disappearance in urinary production. During chronic hemodialysis, which is usually performed intermittently in a relatively short period of time, i.e. 2 to 3 times weckly during 3 to $5 \mathrm{hrs}$, these disturbances in electrolyte, acid-base status. and the excess of fluid are corrected with the help of an artificial kidney. Ultrafiltration can be performed with (hemodialyis combined with ultrafiltration) or without (isolated ultrafiltration) the presence of dialysis fluid.

The number of patients with end-stage renal failure and treated with chronic intermittent hemodialysis is still growing. This number will continue to rise because of a wider acceptance of elderly people, because of further improvement in the dialysis technique, and because of an increasing number of patients with endstage renal failure caused by diabetes mellitus or cardiovascular diseases.

While there are dialysis patients who hardly suffer from hemodialysis, in some patients serious complications such as hypotensive episodes may occur. Hypotension during dialysis may induce minor but troublesome side-effects to the patient, such as nausea. vomiting, and dizziness, but may also lead to myocardial infarction and cerebrovascular accidents. With regard to intradialytic hypotension two factors play a major role, the decrease in blood volume because of ultrafiltration (excess of fluid removal) and the impaired reactivity (constriction) of the resistance vessels (small arteries and arterioles) and capacitance vessels (venules and veins). In healthy subjects, a decrease in blood volume is generally well tolerated. When blood volume is diminishing, peripheral vascular resistance and heart rate are increasing, whereas the veins are constricting. Constriction of these veins are of great importance since $60 \%$ to $80 \%$ of the blood is located in the venous system. The latter results in a centralisation of blood volume, thus maintaining adequate cardiac filling pressure and cardiac output. In contrast to isolated ultrafiltration, hemodialysis itself might interfere with the reactivity of heart and arterial and venous system, although the explanation for this phenomenon is not known yet to this day.

With respect to a decrease in blood volume during hemodialyis, several factors may be of importance, such as the optimal dry-weight of the patient, the dialysate sodium concentration, and the ultrafiltration rate. From a clinical point of view it is known that the existence of an impaired myocardial function may contribute to hypotensive episodes during hemodialysis. Most studies on hemodynamic stability during hemodialysis are done on patients with a normal cardiac function. However, with an increasing number of cardiovascular compromised dialysis patients, special attention should be given to this group of patients. It is therefore of great 
importance to study what the optimal strategy is for reducing the incidence of symptomatic hypotensive periods in this group of patients.

The aims of this thesis were to identify factors of clinical judgement that could be of influence in optimising blood volume preservation and hemodynamic stability during hemodialysis. especially in patients with an impaired myocardial function. Furthermore the mechanism behind the impaired reactivity of venous and arterial system during hemodialysis was aim of our study.

In chapter 1 the literature is reviewed on the (patho)physiological factors influencing maintenance of blood pressure stability during dialysis therapy with regard to changes in blood volume, reactivity of arterial and venous system, myocardial contractility and the responses of the heart to changes in ventricular volume and ventricular pressure. In this chapter, special attention was given to these factors in relation to the myocardial function of the dialysis patient.

In chapter 2 the effects of different strategies of dialysis at different ultrafiltration rates on changes in blood volume and blood pressure in patients with and without an impaired myocardial function were studied. Changes in blood volume and blood pressure were measured with an ultrafiltration rate of $500 \mathrm{ml} / \mathrm{hr}$ and $1000 \mathrm{ml} / \mathrm{hr}$ during isolated ultrafiltration and hemodialysis combined with ultrafiltration.

The decrease in blood volume was only dependent on the ultrafiltration rate. Although there were no differences in changes in blood volume between isolated ultrafiltration and hemodialysis combined with ultrafiltration, in patients with an impaired myocardial function systolic blood pressure decreased in all cases. In patients without an impaired myocardial function systolic blood pressure decreased only during hemodialysis combined with ultrafiltration at the higher ultrafiltration rate. However, the decrease in systolic blood pressure was more distinct in patients with an impaired myocardial function at the higher ultrafiltration rate.

From this study we conclude that differences in hemodynamic stability between isolated ultrafiltration and hemodialysis combined with ultrafiltration and between patients with and without an impaired myocardial functions were not related to differences in blood volume preservation. Other factors like different changes in vascular reactivity might be responsible for the observed differences. Moreover, for the first time it was shown that in patients with an impaired myocardial function compared to patients without an impaired myocardial function the decrease in blood pressure was more distinct.

The immediate cause of a decrease in blood pressure during hemodialysis is intravascular hypovolemia. The acute management of intradialytic hypotension during hemodialysis is dependent on intravenous volume expansion of several fluids. However, there are no studies comparing the effect of different fluids on 
changes in blood volume during hemodialysis. In chapter 3 the effectiveness of 3 fluids, isotonic saline $(0.9 \%)$, albumin $(20 \%)$ and HES $(10 \%)$ on changes in relative blood volume, during 3 treatment sessions with hemodialyis combined with ultrafiltration in patients without an impaired myocardial function was assessed. An intravenous infusion of $100 \mathrm{ml}$ of fluid was given when the decrease in BV versus baseline was more than $10 \%$ versus the "tart of the dialysis session. The ultrafiltration was continued. When we compared blood volume at the end of the dialysis session with those at the time of infusion, blood volume continued to decrease significantly with saline and albumin, but not with hydroxyethylstarch. Between albumin and hydroxyethylstarch there were no significant differences in changes in blood volume, while between hydroxyethylstarch and saline and between albumin and saline the differences in changes in blood volume were significant.

From this study we conclude that hydroxyethylstarch is a promising fluid in preserving blood volume, comparable to albumin, but superior to saline.

The effectiveness of intravenous fluids on changes on blood pressure course in patients with an impaired myocardial function has never been studied before. Therefore, in chapter 4 the effectiveness of hypertonic saline, albumin, and hydroxyethylstarch on changes in blood pressure in patients with an impaired myocardial function who frequently complained of hypotensive episodes was compared.

The fluids were given when systolic blood pressure was less than $100 \mathrm{mmHg}$ or when the decrease in systolic blood pressure was greater than $25 \mathrm{mmHg}$ versus the start of the treatment. The ultrafiltration was continued at the same rate. When comparing systolic blood pressure at the end of the dialysis session with that at the time of infusion, systolic blood pressure continued to decrease with saline, increased with albumin, and increased significantly with hydroxyethylstarch.

The conclusion from this study was that hydroxyethylstarch was an effective fluid in maintaining systolic blood pressure in hypotensive prone patients with an impaired myocardial function, comparable to albumin. but superior to hypertonic saline.

Calcium ions can play a pivotal role in the contractile process of both vascular smooth muscle cells and cardiac myocytes. In chapter 5 the effect of different dialysate calcium concentrations on changes in blood pressure during hemodialysis in patients with an impaired myocardial function was studied. During 2 standardised dialysis sessions which only differed in the dialysate calcium concentration (low-calcium dialysate: $1.25 \mathrm{mmol} / \mathrm{l}$, and high-calcium dialysate: $1.75 \mathrm{mmol} / \mathrm{l}$ ) changes in blood pressure, and by means of an echocardiography, changes in myocardial contractility were measured. The decrease in blood pressure 
was more distinct during hemodialysis with low-calcium dialysate compared to high-calcium dialysate. Cardiac output and stroke volume remained unchanged during hemodialysis with high-calcium dialysate and decreased during hemodialysis with low-calcium dialysate.

From this study we concluded that, in patients with an impaired myocardial function, increasing the dialysate calcium concentration had a positive effect on blood pressure course during hemodialysis and that this response was mediated by changes in myocardial contractility.

With regard to intradialytic hypotension during hemodialysis not only a decrease in blood volume, but also an impaired reactivity of the arterial and venous system to a decrease in blood volume is implicated in the pathogenesis of intradialytic hypotension. Several studies have shown that changes in dialysate temperature might be of influence on vascular reactivity, although the exact mechanism behind this phenomenon has not been clarified yet. To gather more insight in this phenomenon in chapter 6 the effect of different dialysate temperatures on blood pressure and energy balance between patient and extracorporeal system was studied. During 2 different dialysis sessions which differed only in the dialysate temperature, cool-temperature dialysis $\left(35.5^{\circ} \mathrm{C}\right)$ and standard-temperature dialysis $\left(37.5^{\circ} \mathrm{C}\right)$, by continuous measurement of temperature in the arterial and venous side of the extracorporeal system, the amount of energy transfer was calculated. Also the core temperature and blood pressure were measured before, during, and at the end of the dialysis session. Core temperature increased during standard temperature dialysis despite a small negative energy balance from the patient to the extracorporeal circuit. During cool-temperature dialysis, core temperature remained unchanged despite significant energy loss from the patient to the extracorporeal system, and even increased in some patients with a low pre-dialytic core temperature. Systolic blood pressure decreased to a larger degree during standardtemperature dialysis compared with cool-temperature dialysis.

From this study we conclude that hemodialysis itself affects core temperature regulation. The removal of heat by the extracorporeal circuit and/or the activation of autoregulatory mechanisms attempting to preserve core temperature might be responsible for the beneficial hemodynamic effects of cool-temperature dialysis.

Hemodynamic stability is better maintained during isolated ultrafiltration compared to hemodialyis combined with ultrafiltration, which difference might be explained by differences in thermal energy balances. In chapter 7 we compared the effect of isolated ultrafiltration and hemodialysis combined with ultrafiltration at different dialysate temperatures on thermal energy balance. Furthermore the dialysate temperature at which the thermal energy balance during hemodialysis combined with ultrafiltration was similar to the thermal energy balance during isolated 
ultrafiltration, was determined. During 3 different treatment sessions, each consisting of one $\mathrm{hr}$ of isolated ultrafiltration, cold-temperature dialysis $\left(35.5^{\circ} \mathrm{C}\right)$ and standard-temperature dialysis $\left(37.5^{\circ} \mathrm{C}\right)$ the amount of energy balance was calculated. During isolated ultrafiltration, energy loss over the extracorporeal system was more distinct than during cold- temperature dialysis $\left(35.5^{\circ} \mathrm{C}\right)$. To obtain the same thermal energy balance during hemodialysis combined with ultrafiltration as during isolated ultrafiltration, a mean dialysate temperature of $34.75^{\circ} \mathrm{C}$ was needed.

From this study we concluded that the patient loses more energy during isolated ultrafiltration than during cold-temperature dialysis. To obtain the same thermal energy balance during hemodialysis combined with ultrafiltration as during isolated ultrafiltration, further lowering of the dialysate temperature was necessary. The results of this study were of relevance in relation to future clinical investigations on the influence of thermal energy balance on changes in vascular reactivity between isolated ultrafiltration and hemodialysis combined with ultrafiltration.

In chapter $\mathbf{8}$ we studied the hypothesis whether differences in vascular reactivity between isolated ultrafiltration and hemodialysis combined with ultrafiltration were only related to changes in energy balance between the different treatment modalities. During 4 different dialysis treatments, 4 measurements were performed which consisted of $1 \mathrm{hr}$ of isolated ultrafiltration, standard-temperalure hemodialysis $\left(37.5^{\circ} \mathrm{C}\right)$, cold-temperature hemodialysis $\left(35.5^{\circ} \mathrm{C}\right)$. and helludialysis combined with ultrafiltration with a similar energy transfer found for that particular patient during isolated ultrafiltration (energy-mediated hemodialysis). Vitscular reactivity was assessed by strain-gauge plethysmography. The increase in vascular reactivity was more distinct during cold- temperature hemodialysis than during standard-temperature hemodialysis, but increased even more during isolated ultrafiltration and during energy-mediated hemodialysis. During the latter two treatment modalities there were no differences in vascular reactivity at all.

From this study we concluded that when isolated ultrafiltration and hemodialysis were matched for the energy transfer, all differences in vascular response between the two treatment modalities disappeared. Moreover, the increase in core temperature seemed to be the most important factor for the impaired vascular reactivity during hemodialysis. Preventing the increase in core temperature during hemodialysis combined with ultrafiltration appeared to be mandatory for optimisation of hemodynamic stability during dialysis.

In chapter 9 the ideal treatment in patients with an impaired myocardial function, based on the results of this thesis, was discussed. With regard to intradialytic hypotension there are three important factors: changes in blood volume, impaired vascular reactivity and the impaired myocardial function. Special attention should 
be given to the optimal dry-weight of the patient with an impaired myocardial function, since these patients have a very small margin between clinical overhydration and underhydration and are prone to both symptomatic hypotension and congestive heart failure. The ultrafiltration rate should be moderate, and limited to a certain extent, and individualized for each patient to prevent a too rapid decline in blood volume and in consequence a decrease in blood pressure. The dialysate sodium concentration should, if possible, be adjusted to a "physiological" dialysate sodium concentration, in order to prevent a too high sodium load, which may lead to thirst, interdialytic weight gain and fluid-overload. When blood pressure still decreases because of a decrease in blood volume the infusion of hydroxyethylstarch may improve hemodynamic stability. To improve cardiovascular reactivity it is mandatory to use a higher dialysate calcium concentration $(1.75 \mathrm{mmol} / \mathrm{l})$. To improve vascular reactivity the dialysate temperature should be lowered to at least $35.5^{\circ} \mathrm{C}$

The optimal treatment might be the integration of a blood volume monitoring, blood temperature monitoring, and plasma conductivity monitoring within a closedloop biofeedback system, which automatically adjusts the ultrafiltration rate, the plasma sodium concentration of the dialysate and the dialysate temperature according to the individually chosen profile of the patient. Such an approach may be of great clinical importance in preventing hemodialysis associated hypotension in the patient with an impaired myocardial function. 


\section{Chapter 11}

\section{Samenvatting}




\section{Samenvatting}

Bij patiënten met nierfalen ontstaat tengevolge van het niet of onvoldoende functioneren van de nieren een opeenstapeling van afvalstoffen. Door een verminderde of afwezige urineproductie zal ook het lichaamsvocht toenemen. $\mathrm{Om}$ deze stoomissen te corrigeren kan nierfunctievervangende therapie, zoals dialyse (zuivering van bloed) noodzakelijk zijn. Bij hemodialyse wordt enkele malen (meestal 2-3 maal per week) het bloed gedurende enkele uren gezuiverd en wordt ook het teveel aan lichaamsvocht onttrokken (ultrafiltratie). Het aantal patiënten dat nierfunctievervangende therapie behoeft, neemt verder toe. Dit wordt veroorzaakt door met name een toenemend aantal oudere patiënten, die nu ook, door verbetering van de dialysetechniek, voor eventuele nierfunctievervangende therapie in aanmerking komen, en op een toename van het aantal patiënten dat ten gevolge van andere ziekten, zoals suikerziekte en hart- en vaatziekten, nierinsufficiënt wordt.

Alhoewel een dialysebehandeling in het algemeen goed verdragen wordt, kunnen er tijdens de behandeling zelf toch vervelende complicaties ontstaan, zoals een forse daling van de bloeddruk. Deze bloeddrukdaling kan leiden tot misselijkheid, braken en duizeligheid. In ernstiger gevallen kan lage bloeddruk zelfs leiden tot zuurstofgebrek van hart en hersenen. Bij het ontstaan van bloeddrukdalingen tijdens dialyse spelen twee factoren een belangrijke rol, namelijk de daling in het bloedvolume (vocht in de bloedvaten) door het onttrekken van vocht, en een verminderde reactiviteit (samentrekking) van aders en slagaders. Bij gezonde personen ontstaat er geen bloeddrukdaling als het bloedvolume tot een bepaald niveau afneemt. Als reactie op de volume daling treedt er namelijk een reactie van hart en bloedvaten op: de weerstand in de bloedvaten stijgt, de hartfrequentie neemt toe en er ontstaat een constrictie (samentrekking) van het veneuze (aderlijke) systeem. De samentrekking van het aderlijke systeen is zeer belangrijk, aangezien dit meer dan $60 \%$ tot $80 \%$ van het bloed bevat. Door samentrekking van de aders blijft de veneuze terugstroom van bloed naar het hart en dus ook de "cardiac output" (de hoeveelheid bloed die per minuut door het hart wordt uitgepompt) op peil. Tijdens hemodialyse (bloedzuivering) blijkt de reactiviteit van hart en bloedvaten niet optimaal te zijn. De verklaring van de verminderde reactiviteit van aders en slagaders is echter nog niet volledig duidelijk. Wel is aangetoond dat tijdens geïsoleerde ultrafiltratie (waarbij alleen vochi wordt onttrokken) de reactiviteit normaal is vergeleken met de verminderde reactiviteit tijdens hemodialyse (bloedzuivering) gecombineerd met ultrafiltratie.

Bij de daling van het bloedvolume tijdens dialyse spelen de bepaling van het streefgewicht (gewicht na dialyse, waarbij de patiënt een normale hoeveelheid lichaamsvocht heeft), de zoutconcentratie van de dialysaat vloeistof en de snelheid van ultrafiltratie, een belangrijke rol. Het is zeer wel mogelijk dat een verminderde 
pompfunctie van het hart ook zou kunnen bijdragen tot lage bloeddruk perioden tijdens dialyse, alhoewel dit nooit goed is onderzocht. Uit de klinische praktijk is wel bekend, dat lage bloeddruk met name bij patiënten met een verminderde pompfunctie van het hart emstige gevolgen kan hebben. Het is dan ook van groot belang met name bij deze groep patiënten te bestuderen wat de optimale behandelingsstrategie is, om te sterke dalingen in het bloedvolume en bloeddruk te voorkomen.

Het docl van dit proefschrift was het onderzoeken van die klinische factoren die van belang zijn voor het optimaliseren van bloedvolume en bloeddruk tijdens hemodialyse, met name bij patiënten met een gestoorde functie van de hartspier. livens werd het mechanisme achter de gestoorde reactiviteit van aderen en slagaderen tijdens een dialysebehandeling nader onderzocht.

In hoofdstuk 1 is een overzicht gegeven van de (patho)fysiologische (verklarende) factoren welke van invloed zijn op de handhaving van de bloeddruk tijdens dialyse: met name de daling van het bloedvolume, de reactiviteit van het arteriële (slagaderlijke) en veneuze systeem, de contractie (samentrekking) van het hart en de wijze waarop het hart reageert op veranderingen in volume en druk (diastolische functie). In dit hoofdstuk is met name aan deze factoren speciale aandacht geschonken in relatie tot de hartfunctie van de dialyse patiënt.

In hoofdstuk 2 onderzochten wij de effecten van verschillende dialysestrategieën en ultrafiltratie snelheden op veranderingen in bloedvolume en bloeddruk bij patiënten met en zonder een gestoorde functie van de hartspier. De veranderingen in bloedvolume en bloeddruk werden bij een ultrafiltratie snelheid van $500 \mathrm{ml} /$ uur en $1000 \mathrm{ml} / \mathrm{uur}$ gemeten tijdens geïsoleerde ultrafiltratie en tijdens hemodialyse gecombineerd met ultrafiltratie.

De daling in bloedvolume bleek afhankelijk te zijn van de ultrafiltratie snelheid. Alhoewel er zowel bij dialyse patiënten met en zonder een gestoorde hartfunctie geen verschil in de daling in het bloedvolume was tussen geïsoleerde ultrafiltratie en hemodialyse gecombineerd met ultrafiltratie, daalde bij dialyse patiënten met een gestoorde functie van de hartspier in alle gevallen de systolische bloeddruk (bovendruk). Bij patiënten met een normale functie van de hartspier was er alleen een daling van de systolische bloeddruk tijdens hemodialyse gecombineerd met een hogere ultrafiltratie snelheid. De daling van de bloeddruk was het meest uitgesproken bij patiënten met een gestoorde functie van de hartspier tijdens de hoogste ultrafiltratie snelheid.

Uit deze studie concluderen wij dat verschillen in hemodynamische (bloeddruk) stabiliteit tussen geïsoleerde ultrafiltratie en hemodialyse gecombineerd met ultrafiltratie, zowel bij dialysepatiënten met als zonder een gestoorde pompfunctie van de hartspier niet alleen veroorzaakt wordt door verschillen in handhaving van 
het bloedvolume, maar dat ook andere factoren zoals een gestoorde reactiviteit van de aders en slagaders verantwoordelijk zijn voor dit verschil. Tevens werd voor de eerste maal aangetoond dat bij patiënten met een gestoorde pompfunctie van het hart de bloeddrukdaling tijdens dialyse meer uitgesproken is in vergelijking met patiënten zonder een gestoorde hartfunctie.

De initiërende factor voor een daling in de bloeddruk is een daling in het bloedvolume. De acute behandeling van bloeddrukdalingen tijdens dialyse bestaat derhalve uit intraveneuze (in de ader) toediening van infusievloeistoffen. Er zijn echter geen gecontroleerde studies naar de effecten van verschillende infusievloeistoffen op veranderingen in het bloedvolume. In hoofdstuk $\mathbf{3}$ onderzochten wij het effect van 3 verschillende vloeistoffen, te weten fysiologisch zout, een eiwitoplossing (albumine), en een zetmeeloplossing (hydroxyethylzetmeel) op veranderingen in bloedvolume tijdens hemodialyse gecombineerd met ultrafiltratie bij een groep patiënten zonder een gestoorde functie van de hartspier. De vloeistof werd toegediend wanneer de daling in het bloedvolume meer dan $10 \%$ was ten opzichte van het begin van de hemodialyse. De ultrafiltratie werd gecontinueerd. $\mathrm{Na}$ de intraveneuze toediening daalde het bloedvolume verder na toediening van fysiologisch zout en de eiwitoplossing en steeg na toediening van de zetmeeloplossing. De verandering in bloedvolume was niet uitgesproken verschillend tussen de eiwit- en zetmeeloplossing, maar wel tussen fysiologisch zout en de eiwitoplossing en tussen het fysiologisch zout en de zetmeeloplossing.

Uit deze studie concluderen wij dat de zetmeeloplossing een veelbelovende vloeistof is bij het handhaven van het bloedvolume, zeker vergelijkbaar met de (duurdere) eiwitoplossing maar superieur ten opzichte van fysiologisch zout.

Aangezien de effectiviteit van verschillende infusie vloeistoffen bij een bloeddrukdaling nog nooit eerder bij patiënten met een gestoorde functie van de hartspier werd bestudeerd, onderzochten wij in hoofdstuk 4 het effect van hypertoon (geconcentreerd) zout, albumine, en hydroxyethylzetmeel op veranderingen in bloeddruk bij patiënten met een gestoorde functie van de hartspier, bij wie tevens zeer frequent een bloeddrukdaling tijdens dialyse optrad. De vloeistof werd toegediend wanneer de systolische bloeddruk lager was dan $100 \mathrm{mmHg}$ of meer dan $25 \mathrm{mmHg}$ gedaald was ten opzichte van de waarde voor aanvang van de dialyse. $\mathrm{Na}$ de intraveneuze toediening daalde de bloeddruk verder na infusie van hypertoon zout, steeg na toediening van albumine en steeg meer uitgesproken na hydroxyethylzetmeel.

Uit deze studie concluderen wij dat ook bij patiënten met een gestoorde functie van de hartspier bij wie zeer frequent een daling in de bloeddruk tijdens dialyse optreedt, hydroxyethylzetmeel een effectieve vloeistof is bij het handhaven van de bloeddruk, zeker vergelijkbaar met albumine maar duidelijk effectiever dan 
hypertoon zout.

Bekend is dat calcium de contractie kracht van de hartspier kan verbeteren. In hoofdstuk 5 onderzochten wij de effecten van verschillende calcium concentraties tijdens dialyse op veranderingen in de bloeddruk bij patiënten met een gestoorde functie van de hartspier. Tijdens 2 verschillende hemodialyse behandelingen welke alleen verschilden in de samenstelling van het dialysaat calcium (hoog: $1.75 \mathrm{mmol} / \mathrm{l}$, en laag: $1.25 \mathrm{mmol} / \mathrm{l}$ ), werden veranderingen in bloeddruk en, door middel van echografie van de hartspier, veranderingen in de contractiliteit van de hartspier gemeten. De bloeddrukdaling was veel meer uitgesproken tijdens hemodialyse met laag calcium dialysaat vergeleken met hoog calcium dialysaat. Cardiac output en slagvolume (de hoeveelheid bloed die per hartslag wordt uitgepompt) bleven onveranderd tijdens hemodialyse met hoog calcium dialysaat en daalden tijdens hemodialyse met laag calcium dialysaat.

Uit deze studie concluderen wij dat een verhoging van de dialysaat calcium concentratie een positief effect heeft op het bloeddruk beloop tijdens hemodialyse bij patiënten met een gestoorde functie van de hartspier, en dat dit effect beïnvloed wordt door veranderingen in de contractiliteit van de hartspier.

Zoals reeds eerder vermeld, speelt bij het ontstaan van bloeddrukdalingen tijdens hemodialyse niet alleen een afname in het bloedvolume een rol van betekenis, maar ook een verminderde reactiviteit van de bloedvaten op deze daling in het bloedvolume. Alhoewel het precieze mechanisme achter dit fenomeen nog niet is opgehelderd, hebben eerdere onderzoeken aangetoond dat veranderingen in de temperatuur van het dialysaat van invloed zouden kunnen zijn op de reactiviteit van de bloedvaten. Om meer inzicht te krijgen in dit fenomeen onderzochten wij in hoofdstuk 6 de effecten van verschillende dialysaat temperaturen op de bloeddruk en op de energiebalans tussen patiënt en extracorporele systeem (dialyseapparaat en bloedlijnen). Tijdens 2 verschillende hemodialyse behandelingen welke alleen verschilden in de temperatuur van het dialysaat, koude temperatuur dialyse $\left(35.5^{\circ} \mathrm{C}\right)$ en standaard temperatuur dialyse $\left(37.5^{\circ} \mathrm{C}\right)$, werd door continue meting van de temperatuur aan de arteriële en veneuze zijde van de shunt (toegang voor dialyse) de uitwisseling van energie berekend. Ook werden de kerntemperatuur en bloeddruk van de patiënt gemeten voor, tijdens, en direct na het onderzoek. Wij zagen dat de kerntemperatuur steeg tijdens de standaard temperatuur dialyse ondanks een klein verlies van energie naar het extracorporele systeem in alle patiënten. Tijdens de koude temperatuur dialyse bleef de kemtemperatuur onveranderd en steeg zelfs bij enkele patiënten, ondanks fors energieverlies naar het extracorporele systeem. De bloeddrukdaling was minder uitgesproken tijdens de koude temperatuur dialyse dan tijdens de dialyse met de standaard temperatuur. Uit deze studie concluderen wij dat de hemodialysebehandeling zelf de regulatie 
van de kerntemperatuur beïnvloedt. Dit kan van klinisch belang zijn voor de vasculaire (arteriën en venen) reactiviteit tijdens een daling in het bloedvolume. Koude temperatuur dialyse zou zijn positief effect op hemodynamische stabiliteit kunnen hebben door het verwijderen van energie (afkoelen van de patiënt) door het extracorporele systeem en/of door het activeren van mechanismen verantwoordelijk voor het handhaven van de kerntemperatuur.

Tijdens geïsoleerde ultrafiltratie is de hemodynamische stabiliteit beter dan tijdens hemodialyse gecombineerd met ultrafiltratie. Dit verschil zou mogelijk verklaard kunnen worden door verschillen in de energiebalans tussen de verschillende vormen van behandeling. Om meer inzicht te krijgen in deze verschillen vergeleken wij in hoofdstuk 7 de effecten van geïsoleerde ultrafiltratie en hemodialyse bij verschillende dialysaat temperaturen op de energiebalans. Tevens onderzochten wij wat de dialysaat temperatuur moet zijn om dezelfde thermische (temperatuur) effecten te bereiken als tijdens geïsoleerde ultrafiltratie. Tijdens 3 behandelingen bestaande uit 1 uur geïsoleerde ultrafiltratie, koude temperatuur dialyse $\left(35.5^{\circ} \mathrm{C}\right)$ en standaard temperatuur dialyse $\left(37.5^{\circ} \mathrm{C}\right)$, werd met de bovengenoemde methode de uitwisseling van energie berekend. De patiënt verloor meer energie tijdens geïsoleerde ultrafiltratie dan tijdens koude temperatuur dialyse. Om dezelfde energiebalans te verkrijgen tijdens hemodialyse ten opzichte van geïsoleerde ultrafiltratie was een gemiddelde dialysaat temperatuur van $34.75^{\circ} \mathrm{C}$ noodzakelijk.

Uit deze studie concluderen wij dat de patiënt meer energie verliest tijdens geïsoleerde ultrafiltratie in verhouding tot koude temperatuur dialyse. Om een zelfde energiebalans te bereiken tijdens hemodialyse als tijdens geïsoleerde ultrafiltratie is derhalve een nog koelere dialysaat temperatuur noodzakelijk. De resultaten van dit onderzoek zijn van belang voor verder onderzoek naar de invloed van de energiebalans op de verschillen in vaatreactiviteit tussen geïsoleerde ultrafiltratie en hemodialyse.

In hoofdstuk 8 onderzochten wij de hypothese of verschillen in vaatreactiviteit (in de slagaders en aders) tussen geïsoleerde ultrafiltratie en hemodialyse berusten op verschillen in energiebalans tussen de verschillende behandelingsvormen. Tijdens 4 behandelingen, bestaande uit geïsoleerde ultrafiltratie, koude temperatuur dialyse $\left(35.5^{\circ} \mathrm{C}\right)$, standaard temperatuur dialyse $\left(37.5^{\circ} \mathrm{C}\right)$, en hemodialyse gecombineerd met ultrafiltratie waarbij de energiebalans gelijk is aan de waarde gemeten tijdens geïsoleerde ultrafiltratie (energie-gestuurde dialyse) werd de vaatreactiviteit berekend. De vaatreactiviteit werd direct gemeten in de onderarm met behulp van een plethysmograaf door middel van een kwikdraad en een in de ader ingebrachte infuusnaald. De stijging van de vaatreactiviteit was meer uitgesproken tijdens koude temperatuur dialyse in verhouding tot standaard temperatuur dialyse, maar was nog meer uitgesproken tijdens geïsoleerde ultrafiltratie en energic-gestuurde 
hemodialyse. Tijdens de twee laatste behandelingsvormen viel geen enkel verschil in vaatreactiviteit tussen beide behandelingen meer te constateren.

Uit de resultaten van dit onderzoek concluderen wij dat bij een vergelijkbare energiebalans, alle verschillen in vaatreactiviteit tussen beide behandelingsvormen verdwijnen. Dit onderzoek toont ook aan dat de stijging in de kemtemperatuur de belangrijkste factor lijkt te zijn voor de verminderde vaatreactiviteit tijdens dialyse. Het voorkomen van een stijging in de kerntemperatuur tijdens hemodialyse gecombineerd met ultrafiltratie is daarom van cruciaal belang in het optimaliseren van de hemodynamische stabiliteit tijdens de dialyse.

In hoofdstuk 9 is besproken hoe, op grond van de resultaten beschreven in dit proefschrift en eerdere onderzoekingen, de ideale behandeling van een patiënt met een gestoorde functie van de hartspier er uit zou moeten zien. Van groot belang bij bloeddrukdalingen zijn de volgende factoren: daling van bloedvolume, verminderde vaatreactiviteit en stoornissen in de pompfunctie van het hart. Gelet op de hartfunctie van de patiënt moet allereerst het juiste streefgewicht bepaald worden, aangezien een verkeerde inschatting van het streefgewicht enerzijds kan lijden tot ondervulling en bloeddrukdaling en anderzijds kan lijden tot overvulling (een teveel aan vocht). Aangezien een te snelle ultrafiltratie leidt tot een te snelle daling in het bloedvolume en daardoor ook van de bloeddruk, moet de ultrafiltratie snelheid geïndividualiseerd worden. Ook moet de zoutconcentratie van het dialysaat geïndividualiseerd worden waarbij voorkomen dient te worden dat patiënt teveel zout krijgt, waardoor er door dorst en teveel vochtinname kans op overvulling ontstaat. Wanneer de bloeddruk nog steeds laag is door de daling in bloedvolume, kan een intraveneuze toediening van een zetmeeloplossing de bloeddruk stabiliseren. Om de contractiekracht van het hart te verbeteren moet de calcium concentratie in het dialysaat verhoogd worden. Om de vaatreactiviteit te verbeteren moet de dialysaat temperatuur in ieder geval verlaagd worden tot $35.5^{\circ} \mathrm{C}$.

De optimale behandeling bestaat warschijnlijk uit een intergratie van bloedvolume meting, bloedtemperatuur meting en zout geleidbaarheid meting binnen een closedloop (gesloten terugkoppeling) systeem. Dit systeem zou, gericht op een individueel ingesteld dialyse profiel, aangepast aan veranderingen in bloedvolume en bloeddruk, automatisch de ultrafiltratie snelheid, de zout concentratie van het dialysaat, en de dialysaat temperatuur kunnen instellen waardoor de hemodynamische instabiliteit bij de dialysepatiënt met een gestoorde functie van het hart sterk verminderd wordt. 


\section{Dankwoord}




\section{Dankwoord}

Geen enkel onderzoek is mogelijk zonder de hulp en inspanning van velen. De afgelopen jaren heb ik dat meerdere malen mogen ervaren. Een ieder heeft dan ook zijn of haar bijdrage geleverd aan de totstandkoming van dit proefschrift.

$\mathrm{Bij}$ het verrichten van klinisch onderzoek is de medewerking van patiënten onontbeerlijk. Ik heb nooit vergeefs een beroep hoeven doen op hun medewerking. Altijd waren zij bereid om een bijdrage te leveren en werd zelfs, indien noodzakelijk, hun dialyseschema aangepast. Ik wil hen dan ook in het bijzonder bedanken voor het vertrouwen en de bereidwilligheid om aan het onderzoek mee te doen. Ik hoop dat de resultaten van dit onderzoek een bijdrage kunnen leveren aan de kwaliteit van de dialysebehandeling, niet alleen voor henzelf, maar ook voor alle medepatiënten nu en in de toekomst.

Het onderzoek werd verricht op verschillende dialyseafdelingen. I $k$ wil daarom de verpleegkundigen, technici en secretaresses van het academisch ziekenhuis Maastricht, het Catharina ziekenhuis in Eindhoven, het Sint Maartensgasthuis in Venlo, en het Kuratorium für Dialyse und Nierentransplantation in Würselen bedanken. Altijd waren zij bereid mij te helpen en waren zij uitermate geỉnteresseerd in de klinische resultaten van het onderzoek.

Dr. AW Mulder en Dr. SJ Hoorntje (Catharina ziekenhuis, Eindhoven) wil ik bedanken. Beste Fred en Steven jullie vormden destijds het nefrologisch team dat mij de richting voor onderzoek heeft gewezen en de mogelijkheid heeft geboden het onderzoek op de dialyseafdeling van het Catharina ziekenhuis te starten; ik ben jullie hier nog steeds dankbaar voor. Dr. AJ Luik en Dr. V Verstappen (Sint Maartensgasthuis, Venlo) waren bereid om hun afdeling open te stellen voor het onderzoek. Ik hoop dat ons huidige gezamenlijke onderzoek op jullie dialyseafdeling dezelfde vruchten mogen afwerpen als het voor dit proefschrift verrichte onderzoek. In Maastricht werd het echocardiografisch onderzoek verricht door medewerkers van de hartfunctieafdeling onder leiding van Dr. EC Cheriex, en in Eindhoven onder leiding van Dr. CH Peels. Ik dank hen voor de wijze waarop zij in staat zijn geweest in deze moeilijke groep van patiënten de echocardiografische resultaten te interpreteren. Jeroen Keijman, destijds student Geneeskunde, wil ik bedanken voor zijn zeer nauwgezette hulp bij het verrichten van een van de onderzoeken. Dr. U Gladziwa und Dr. G Böcker von dem Kuratorium für Dialyse und Nierentransplantation in Würselen will ich danken für die Zusammenarbeit und die Gastfreiheit die es möglich gemacht haben mein letzte Studien in ihren Zentrum zu vollbringen.

Tiny Wouters wil ik bedanken voor de wijze waarop zij de lay-out en het drukklaar maken van het proefschrift heeft verzorgd. Fred Nieman wil ik bedanken voor zijn hulp bij de statistische bewerking van de onderzoeksgegevens. Harry Kranen, kunstenaar en dialysepatiënt, wil ik bedanken voor het ontwerpen van de cover. Mijn schoonvader wil ik bedanken voor de grammaticale correcties.

De leden van de werkgroep Nefrologie, Maarten Christiaans, Jos Barendregt, Elly van Duijnhoven, en Stijn Konings, wil ik bedanken voor hun bijdrage aan het proefschrift.

De leden van de beoordelingscommissie, Prof. dr. RAMG Donckerwolcke (voorzitter), Prof. dr. HAJ Struijker Boudier en Dr. JHM Tordoir wil ik bedanken voor de kritische 


\section{beschouwing van dit proefschrift.}

I also would like to thank Prof. dr. NW Levin and Prof. dr. F Locatelli for thei: willingness to critically review my manuscript. It is a great privilige for me to have such experts in the world in the field of dialysis on the board of my thesis.

Mijn opleider in het aandachtsgebied Nefrologie Prof. dr. JP van Hooff wil ik bedanken. Beste Hans, de bijna 5 jaar die ik op de afdeling Nefrologie van het azM werk heb ik steeds als zeer prettig ervaren. Voor alle problemen op de werkvloer had je een praktische oplossing. De ruimte die mij daardoor geboden is heb ik kunnen gebruiken om de onderzoeken in dit proefschrift beschreven te kunnen voltooien. Ik dank je bijzonder hiervoor. Mijn opleider algemeen interne geneeskunde in het Catharina ziekenhuis in Eindhoven en later in het academisch ziekenhuis Maastricht Prof. dr. HFP Hillen wil ik eveneens bedanken.

Mijn copromotor Dr. JP Kooman wil ik bedanken. Beste Jeroen, niemand is in staat sneller onderzoeksprotocollen te schrijven dan jij. Ik ben diep onder de indruk van de wijze waarop jij in staat bent onderzoeken en resultaten hiervan in korte tijd te doorzien en deze in gedachten al in artikel vorm te produceren. Mede dankzij jouw onvermoeibare steun is de totstandkoming van dit proefschrift in een stroomversnelling geraakt. De "rode pen" is voor mij een begrip geworden.

Een bijzonder woord van dank gaat uit naar mijn promotor, Prof. dr. KML Leunissen. Beste Karel, de afgelopen jaren heb ik je alleen maar meer taken op je zien nemen, desondanks heb ik nooit vergeefs een beroep op je gedaan. Altijd stond je klaar met een constructief antwoord op vragen mijnerzijds betreffende het onderzoek. Een belangrijk opmerking in alle discussies die we gevoerd hebben, en niet alleen over de inhoud van het proefschrift, was dat alles een "win - win" situatie is. Ik hoop dat dit proefschrift zal resulteren in een "win - win" situatie voor al onze patiënten. Het proefschrift is er één. in een door jou geïnitieerde lijn van onderzoeken, de afgelopen jaren leidende tot vele proefschriften, waarbij je copromotor bent geweest. Het is voor mij een bijzondere eer je eerste promovendus te zijn.

Een speciaal woord van dank gaat uit naar mijn ouders. Dankzij jullie ben ik in staat geweest geneeskunde te studeren. Een jongensdroom werd daarmee vervuld.

Lieve Edith, het laatste dankwoord is voor jou. Bij al mijn onderzoeken was jij mijn steun en toeverlaat. Altijd heb ik op je kunnen rekenen, bij nacht en ontij. Je bent mijn stimulans geweest in perioden van twijfel. De afgelopen jaren heb ik jouw doorzettingsvermogen en moed bewonderd. Ik dank je voor alles wat je voor ons hebt gedaan. 


\section{Curriculum Vitae}




\section{Curriculum Vitae}

Frank van der Sande werd geboren op 5 november 1957 te Amsterdam. Het diploma HAVO werd behaald in juni 1975 en het diploma Atheneum B in juni 1977 aan het Fioretticollege te Lisse. Van september 1977 tot september 1978 werd de militaire dienstplicht vervuld. In hetzelfde jaar ving hij aan met de studie Andragologie aan de Universiteit van Amsterdam te Amsterdam. In 1980 ving hij na driemaal daarvoor te zijn uitgeloot aan met de studie Geneeskunde aan de Vrije Universiteit te Amsterdam. In april 1982 haalde hij het kandidaatsexamen Andragologie. Tijdens zijn studie Géneeskunde werd onderzoek verricht onder leiding van Dr. $\mathrm{K}$ Bakker in het Diaconessenziekenhuis (Heemstede) naar de voetproblemen bij patiënten met suikerziekte. Voor dit onderzoek kreeg hij in 1988 de nationale prijs van de Nederlandse Vereniging voor Diabetes Onderzoek. Het artsexamen werd behaald in september 1988, waarna hij van januari 1989 tot juni 1989 als arts-onderzoeker werkzaam was aan de Vrije Universiteit te Amsterdam onder leiding van Dr. R Heine waar onderzoek verricht werd naar een gewichtsreductieprogramma bij patiënten met suikerziekte. In juni 1989 begon hij eerst als AGNIO interne geneeskunde en in april 1990 als assistent-in-opleiding op de afdeling Inwendige Geneeskunde van het Catharina Ziekenhuis te Eindhoven (opleider Dr. HFP Hillen). De opleiding werd vanaf april 1994 tot de voltooiing in december 1995 voortgezet op de afdeling Inwendige Geneeskunde van het academisch ziekenhuis Maastricht (opleider Prof. dr. HFP Hillen). Tijdens de opleiding Inwendige Geneeskunde werd gestart met onderzoek op de afdeling nierziekten van het Catharina Ziekenhuis te Eindhoven onder leiding van Dr. AW Mulder en Dr. SJ Hoorntje en onder leiding van Dr. KML Leunissen (Maastricht). Vanaf 1996 werd dit klinisch onderzoek voortgezet en de opleiding tot nefroloog gevolgd op de afdeling nierziekten van het academisch ziekenhuis Maastricht (opleider Prof. dr. JP van Hooff). Voor het onderzoek beschreven in hoofdstuk 5 van dit proefschrift won hij in 1996 de 'International Society of Blood Purification award'. Voor het onderzoek beschreven in hoofdstuk 8 van dit proefschrift won hij in 1999 de 'International Society of Blood Purification award'. Sinds januari 1996 is hij als internist en sinds mei 1997 als internist-nefroloog werkzaam in het academisch ziekenhuis Maastricht.

Hij is getrouwd met Edith Koks en vader van Gerben. 
